OUTCOMES AND INCOMES: IMPLEMENTING A MENTAL HEALTH

RECOVERY MEASURE IN A MEDICAL MODEL WORLD

\author{
by \\ JANET M. HOY \\ Submitted in partial fulfillment of the requirements \\ For the degree of Doctor of Philosophy
}

Dissertation Advisor: Dr. Jerry Floersch

Mandel School of Applied Social Sciences

CASE WESTERN RESERVE UNIVERSITY

May, 2008 


\section{CASE WESTERN RESERVE UNIVERSITY \\ SCHOOL OF GRADUATE STUDIES}

We hereby approve the thesis/dissertation of

Janet M. Hoy

candidate for the Doctor of Philosophy degree *.

(signed)_Jerry Floersch, Ph.D.

(chair of the committee)

Sharon Milligan, Ph.D.

Kathleen Wells, Ph.D.

Kurt Stange, Ph.D., M.D.

(date) March 21, 2008

*We also certify that written approval has been obtained for any proprietary material contained therein. 
Copyright ( 2008 by Janet M. Hoy All rights reserved 


\section{TABLE OF CONTENTS}

LIST OF TABLES..................................................... 2

LIST OF FIGURES................................................. 3

ACKNOWLEDGEMENTS..................................... 4

ABSTRACT...................................................... 5

Chapter

1. INTRODUCTION \& AIMS......................... 7

2. BACKGROUND \& SIGNIFICANCE............... 22

3. RESEARCH DESIGN AND METHODS........... 66

4. AGENCY CONTEXTS.......................... 99

5. THE CPST PERSPECTIVE........................ 136

6. THE CONSUMER PERSPECTIVE.................. 182

7. EXPLICIT IMPLEMENTATION PROCESSES... 206

8. EMBEDDED SYSTEM PROCESSES................ 229

9. DISCUSSION, IMPLICATIONS \& CONCLUDING THOUGHTS....................................... 252

APPENDIX................................................. 283

REFERENCES........................................................ 315 


\section{LIST OF TABLES}

Table

1. Identified facilitators of implementations........... 25

2. Ethnographies of implementations................. 61

3. CPST demographics.............................. 138

4. Consumer demographics............................ 185 


\section{LIST OF FIGURES}

Figure

1. Four dimensions of implementation................. 56

2. Intersecting stakeholder standpoints and the four implementation dimensions........................ 58

3. Organization of Ohio public mental health services 70

4. Cube metaphor for institutional ethnography..... 85

5. Flow of snowball sampling....................... 209

6. Inter-textual circle - medical model................. 245

7. Inter-textual circle -mental health recovery ........ 247

8. Lived experience of paradigm juncture via textually-mediated processes....................... 250 


\section{ACKNOWLEDGEMENTS}

I am very grateful for the unwavering love, support, and encouragement of my parents, Tom and Joan, and my siblings Vince and Linda. They helped in so many ways, large and small, to make this dissertation a reality. Mom and Dad, I could not have gotten this done without you!

I would like to thank the Ohio Department of Mental Health for their generous financial support of this dissertation, along with my committee members: Jerry Floersch (chair); Sharon Milligan, Kathleen Wells, and Kurt Stange - for their guidance, encouragement and wisdom. Jerry has been an amazing mentor throughout my time in the doctoral program; a special thanks to you, Jerry, I can't put into word what my time learning from you has meant to me.

I wish to thank my friends, my cohort 2002 classmates, Victor, Arol, Betsy, Helen, and all those who have made the load on this journey a little lighter!

I am grateful for the love and encouragement of my partner Leslie Eppler, which have helped to sustain me during this endeavor. And, I am profoundly thankful for the patience and generosity of all the participants in this study, who took the time to painstakingly share their experiences with me. 


\title{
Outcomes and Incomes: Implementing a Mental Health Recovery Measure in a Medical Model World
}

\author{
Abstract \\ by
}

\section{JANET M. HOY}

Because social work practice and policy changes are often not easily implemented under everyday conditions, increasing attention is being focused on implementation (NIMH, 2002, 2005). The aims of this qualitative case study are twofold: (1) to describe how frontline clinicians and clients implement a state-mandated mental health policy; and, (2) to articulate the system processes connected to and embedded in frontline implementation experiences.

Ethnographic methodology was employed to explicate the processes through which frontline clinicians implemented a state mental health policy mandating completion and clinical utilization of a 67 -question outcomes survey with adults living with severe mental illness (mental health consumers). Data was collected through participant-observation of 17 consumer-clinician dyads ( $\mathrm{n}=17$ consumers and 9 clinicians recruited from 4 mental health centers) completing and/or discussing the survey. To trace processes embedded in clinical experiences, a bottom-up, snowball 
sampling interview strategy was used to collect data from other stakeholders $(\mathrm{n}=22)$.

Atlas.ti was used to manage and analyze data. Thematic analysis provided descriptive information about the processes through which unplanned confluences of systemlevel/institutionalized processes manifested in frontline experiences and served to hinder implementation efforts. Consumers and clinicians identified several overlapping work processes related to what both groups of participants referred to as "doing the outcomes". Embedded within and across these processes were two overarching, institutionalized processes: a paradigm conflict between the medical model and mental health recovery (manifesting at the frontlines as difficulty in integrating a symptom-focused treatment plan with an outcomes measure of broader mental health recovery constructs such as empowerment); and compliance-driven organization of time with regards to clinical documentation. These institutionalized processes served to undermine consumer and clinician attempts to meaningfully use the outcomes measure.

Grounded in frontline experiences, this study offers a detailed description of an implementation in which interrelated system processes converge, manifest and are negotiated at the frontlines. Through taking up perspectives of frontline workers in naturalistic settings, problematic confluences of system processes where the 'rubber meets the road' can be explicated and intervened upon, rather than remaining unarticulated barriers to implementation. 


\section{CHAPTER ONE - INTRODUCTION \& AIMS}

\section{Introduction}

Understanding how implementations of changes in policies, programs and practices occur is arguably as important as understanding why the change should occur. A commonplace definition of change is: "to make or become different; exchange for another; move from one to (another); and/or move from one system or situation to another" (Oxford Dictionary, n.d.). Examples of driving forces to change from existing practices and policies in social work and related fields include but are not limited to:

- The desire to facilitate specified outcomes via using 'best practices' based upon evolving empirical evidence (Drake et al, 2001; Gambrill, 1997).

- A commitment to facilitating ongoing transformative social changes based upon ideals of social justice (Lundy, 2004; Hooks, 2003).

- The increasing need to provide cost-effective services with clearly demonstrable social impacts due to funding scarcities (Gray, 2001).

- Changing political and societal value climates (Baer, 2004).

- The advent of outcome-oriented managed care (Mechanic, 1999). In actuality, practice and policy changes are often due to varying combinations of these and/or other interrelated impetuses. As Mullen el al (2006, p.4) put it: "Gone are the times when social work could assume that it had a manageable and relatively stable knowledge base." In addition to varying driving forces for implementing changes, the knowledge bases through which new micro-, meso-, and macro-focused practices are created often vary. For ease of reference, when I refer to 'practice', I will henceforth be encompassing micro-system, meso-system and/or macro-system interventions, and 
explicitly stating when I mean to refer to only one type of client system practice, e.g., micro-focused practice.

The definitions of micro-system, meso-system and macro-system differ somewhat across social science theoreticians. Because the social work profession has historically been heavily influenced by systems theory, I will draw upon Gordon's (1970; cited in Parsons, Hernandez \& Jorgensen, 1995) classic definitions for these three constructs. Briefly put, Gordon (1970; cited in Parsons, Hernandez \& Jorgensen, 1995) frames social work practice as systems boundary work, in which interventions can be focused on: society and communities (macro-systems); organizations and groups (meso-systems); and individuals and families (micro-systems). Peace (2003) delineates numerous shortcomings to these constructs as so defined; emphasized among these are false dichotomizing, and lack of attention to the dialectic between individual agency and social structure. However, the systems theory constructs (e.g, micro, meso, macro) nonetheless offer conceptual utility, and continue to be utilized heavily in social work and other discourses. I will thus utilize these constructs as defined above, while acknowledging the limitations and short-comings of such constructs in addressing the development and implementation of new practices and practice changes in complex service systems.

The development of new practices and practice changes is not drawn from a homogenous knowledge base. Some new practices are derived from unarticulated knowledge gained by direct service practitioners through and within the concrete and specific tasks of doing everyday practice work (a.k.a.-Polanyi's (1966) 'tacit knowledge'). Other new practices are developed in an explicitly defined fashion (a.k.a. Polyani's (1966) 'explicit knowledge'), such as through knowledge gained and applied 
through conducting empirical studies in academic and other scientific settings. While empirical studies are considered by many to be the domain of scientists, empirical methods for generating practice change knowledge can be integrated into practice settings; examples of this include the development of practitioner-based research networks in primary care (Nutting, Beasley, \& Werner, 1999), and the creation and institutionalization of research programs utilizing both researchers and clinicians within clinical settings (Wells, Feldman and Kelman, 1988). However, organizational issues (Wells et al, 1988) and broader service system contexts (Shaw, 2006) can pose numerous challenges to creating and sustaining such practice-based research endeavors. Wells et al (1988) also notes there can be difficulties in negotiating differences in researcher and practitioner training and perspectives in practice-based research endeavors.

Boland \& Tenkasi (1995) refer to such differing and at times fragmented perspectives on generating different kinds of knowledge and practices as "communities of knowing" (p.350). Such varied perspectives on practice creation and implementation were identified by social work scholars as early as 1931, when Karpf asserted that there could be social scientists developing knowledge, social technologists who adapt the knowledge for application, and the real-world practitioners who actually do the applications (Kirk \& Reid, 2002). Karpf’s (1931, cited in Kirk \& Reid, 2002) lamentations regarding the barrier-laden complexities of implementing and integrating practice changes created through combinations of such perspectives "...continue to bedevil social work education half a century later" (p. 170).

While the problems entailed in implementing a change in practice are not new, increasing attention is being paid to the notion of 'implementation', within and across 
"communities of knowing". The National Institute of Health (NIH) developed a plan that delineates numerous initiatives tied to implementation workgroups (e.g., Building Blocks, Pathways and Networks Implementation Group, Molecular Libraries and Imaging Implementation Group, Structural Biology Implementation Group, and Interdisciplinary Research Implementation Group; for a full listing, see http://nihroadmap.nih.gov/initiatives.asp), which will guide its funding for the foreseeable future. And, a group of researchers from across the nation who were studying the implementation of the federal welfare reform policy began meeting and consolidated what they'd learned about implementation, resulting in two comprehensive companion volumes: A Guide to Implementation Research (Werner, 2004), and Policy into Action (Lennon and Corbett, 2003).

Such increased attention to the phenomenon of implementation underscores a central question-'how do intentional practice changes occur?' However, there is no central way in which implementation is defined. The verb implement is derived from the Latin word implere which means ‘to fill up' or 'employ’ (Oxford Dictionary, n.d.). Implementation is defined in a variety of ways:

- $\quad$ To put into effect (Oxford Dictionary, n.d.).

- All that must be done by an organization to harness a particular technology (Sarker, 2000).

- A specified set of activities designed to put into place an activity or program of known dimensions (Fixsen et al, 2005).

- A planned process of introduction of innovations or changes of proven value, in order to secure a structural position in professional action, the 
functioning of an organization, or the structure of the healthcare system (Meiland et al, 2004).

Irrespective of differing definitions of implementation, individuals from across the applied professions-such as medicine (Haynes \& Haines, 2002), education (Sindelar \& Brownell, 2001); occupational therapy (Atwal, 2002), social work (Barratt, 2003), and public health (Kelly et al, 2000)-concur that there is a growing and urgent need to address the 'gap' between research-derived practice changes, and the beneficial implementation (however it is defined) of such practices in real world practice systems. Social policy researchers identify a similar disconnect between the policy to be implemented, and what actually happens in the implementation endeavor. Brodkin (2003) refers to the need for "... separating policy fact from policy fiction..." in a policy implementation endeavor, defining policy fiction as “... the rhetorical or ascribed intent of policy... \{and $\}$...the administrative constructs used as proxies for program activities..." (p. 151).

The idea of 'implementation science' as an area of inquiry in its own right has been put forth (Fixsen et al, 2005; Bammer, 2005). Fixsen and colleagues recently founded a peer-reviewed journal and network for scholars specializing in 'implementation science’ (http://www.implementationscience.com/); the basic aim of this society is rooted heavily in the evidence-based practice (EBP) movement (see Chapter 2 of this dissertation for further discussion of EBP), and is as follows: to promote the uptake of research findings into routine healthcare in both clinical and policy contexts. Implementation research is defined as "the scientific study of methods to promote the systematic uptake of clinical research findings and other evidence-based practices into 
routine practice, and hence to improve the quality and effectiveness of health care" (Implementation Science, 2006, About implementation science, para. 2).

Translation science, while similarly rooted in the EBP movement, is part of the NIH Roadmap Initiative and more broadly defined to encompass both basic research and applied research, with the notion of 'implementation science' falling into the later category. According to NIH:

Translational research includes two areas of translation. One is the process of applying discoveries generated during research in the laboratory, and in preclinical studies, to the development of trials and studies in humans. The second area of translation concerns research aimed at enhancing the adoption of best practices in the community. The term 'science' describes the discovery of new knowledge about health and disease prevention, pre-emption, and treatment, as well as methodological research to develop or improve research tools. (http://grants.nih.gov/grants/guide/rfa-files/RFA-RM-07-002.html)

Brekke et al (2007) specifically outline an agenda for the social work profession in influencing the translational research agenda, indicating that training individuals to be proficient at translational research is a "critical public health need" (p.123). .

While Bammer (2005) and colleagues also assert that implementation is emerging as a important and distinct area of inquiry, they approach implementation from a broader conceptual lens, encompassing a range of relevant epistemologies, conceptualizations and methodologies. Specifically, Bammer (2005) proposes a unifying meta-framework for implementation and integration scientific endeavors, in which the pillars are: 
1. Systems thinking and complexity science-orients us to looking at the whole and its relationship to the issue

2. Participatory methods-emphasizes that all the stakeholders have a contribution to make

3. Knowledge management, exchange and implementation-involves appreciating and working with diverse epistemologies, to enhance methods for accessing and integrating current implementation knowledge from diverse sources, and to develop a fuller understanding of how implementation actions occur (p.2).

To explore and share information and resources pertaining to these areas, Bammer (2005) and colleagues founded an international network, entitled Implementation \& Integration Science (http://www.anu.edu.au/iisn/).

Many tenets of Bammer's (2005) approach are derived from the field of organizational behavior (OB). OB scholars Aram and Salipante (2003) approach implementation research as "bridging scholarship", which entails bridging diverse epistemologies, among other aspects of knowledge utilization. Organizational behavior scholars Bradbury and Reason (2003) likewise emphasize the need to connect research and practice communities by coordinating efforts across diverse sources:

Most efforts to describe the gap, perhaps ironically, continually re-establish it, by underscoring the disconnect between research and application. Research has traditionally been assumed to occur in a different domain from application and is practiced by 'practitioners', who, by definition, are not researchers. Strategies for enhancing appropriate use of research stress the importance of new institutional 
emphasis on forging closer bonds between the fragmented spheres of knowledge generation and knowledge application (p.5).

Toward such an end, the National Institute of Health (NIH) issued a three-year request for research proposals that would "build knowledge on methods, structures and processes" for implementing new practices and clinical procedure changes in actual practice settings (National Institute of Mental Health, 2002); this initiative was renewed for an additional three years in November of 2005 (National Institute of Mental Health, 2005). The need for more research to understand the inter-relatedness of social processes and how multiple layers of activities occur during implementations is similarly called for from what many consider as one of the most comprehensive literature review on micro practice-focused EBP literature (Fixsen et al, 2005), and within an edited volume summing up a vast amount of social policy implementation research done on welfare reform (Lennon \& Corbett, 2003). Glisson (2007), expounding on the sociotechnical model of organizational effectiveness, likewise suggests: “...the implementation of effective mental health and social services is as much a social process as a technical process, and a service organization's social context is as important to implementation effectiveness as core technology (e.g., treatment models, assessment tools, etc.)...” (p.738).

It seems that understanding the nature of social processes is an important key to better understanding the implementation of practice changes. However, in seeking to better understand implementation, the nebulous notion of 'social processes' muddies up 
the waters no small amount. Bain (1932) decried using the term 'social processes' in any sort of knowledge pursuit (p.1):

...social process is used with many shades of meaning and is often treated as if were a natural science concept... when used singularly, it denotes the existence of societal activities that are continuously changing... other terms, such as social interaction, social change, social dynamics, etc.... convey much the same meaning. Social process is too ambiguous, too indefinite, too inclusive, to be useful as a natural science concept... (p.1)

Nearly 30 years later, the vagaries of 'social processes' remains essentially the same. Puddifoot (2000) similarly laments:

...more than three decades after the publication of Human Behavior and Social Processes, there remains considerable ambiguities in the term 'social process'-the term being employed in what might be called a 'quasi-descriptive manner'... with little if any actual detailed explanation... (p. 80)

In comparing and contrasting definitions of social processes, I came across Canadian sociologist Dorothy Smith's (2005) construct of 'social relations', which seemed to offer potential explanatory value, with regards to social processes within implementation efforts. Smith (2005) explains social relations as follows:

...the term does not refer to relationships such as those between instructor and student, boyfriend and girlfriend, or parent and child. Rather, it orients to people's doings in particular local settings, as articulated to sequences of action that hook them up with what others are or have been doing elsewhere and 
elsewhen. It is useful analytically to think of social relations as temporal sequences in which the foregoing intends the subsequent, and in which the subsequent 'realizes' or accomplishes the social character of the preceding... the object of (social) focus is embedded in series of coordinated actions (between people). (p. 228)

Smith (2005) situates social relations within a theory of socially organized knowledge, in which social relations can reproduce, in and through individual lived experiences, aspects of a larger system in which the individual is embedded. For example, an individual showing an all-day bus pass upon entering a bus would be having a lived experience that is repeated by numerous individuals across a given city. While "showing a bus pass" might appear to be an individual act, it is constituted in part by embedded social processes occurring at other times and places, which serve to in part create the circumstances that make "showing a bus pass" meaningful, relevant, and replicable. Examples of these other social processes embedded within "showing a bus pass" would be: enactments of city transportation department policies related to buses; the cost of gasoline to operate a bus; and planning the frequency and locations of bus stops and routes.

Extrapolating the work of Smith (2005) to the implementation of a practice change, social relations would in part pertain to producing or creating temporal sequences of particular activities (comprising what is to be implemented) of particular individuals in particular local settings. For the purposes of conceptual specificity and relevancy to implementation, I am defining the term 'social processes' via Smith's (2005) definition of 'social relations', within this dissertation. 
A large-scale implementation effort, entailing a policy and related practice changes, and involving a myriad of social processes, is currently occurring in the Ohio public mental health system. This effort is a result of a state mandate via the Ohio Administrative Code, referred to as the Ohio Consumer Outcomes Initiative. The Ohio Consumer Outcomes Initiative rule became effective in 2003, and requires most mental health service providers receiving public funding to complete and use in treatment planning mental health recovery-oriented outcomes survey instruments with all consumers who use specified services; however, a threshold of submitting at least one completed outcomes survey for $80 \%$ of consumers was set for implementation. (Appendix A). This initiative encompassed the completion of adult outcomes instruments and/or youth outcomes instruments, depending upon what consumer population(s) were being served by a given agency. These population-specific survey instruments are collectively referred to as the Consumer Outcomes Surveys. The Consumer Outcomes Surveys were developed through years of collaborative research between mental health consumers (adult diagnosed with a DSM-IV mental illness who use publicly-funded case management/community support services), researchers, clinicians (mental health case managers/community support staff), family members, administrators, and other mental health system stakeholders $\left(\mathrm{ODMH}^{2}, 2002\right)$. Evidence of quality assurance activities related to the Consumer Outcomes Surveys are also mandated. Compliance with the completion threshold is required to renew or obtain certification as a public mental health service provider in Ohio.

The implementation of the Ohio Consumer Outcomes Initiative has been underway for several years, and agencies are in various stages of implementation and 
compliance. This implementation endeavor can be construed as both a policy implementation, and the implementation of a change in clinical practice, in that it requires the implementation of new practice-related behaviors, e.g. the completion and use in treatment planning of a standardized, recovery-focused outcomes tool. The realization of this policy essentially occurs (or does not occur) at the frontlines, where the 'rubber meets the road', and where the survey is (or is not) completed and clinically utilized with consumers.

Identifying and delineating the social processes connected to and embedded in frontline efforts to complete and clinically use the Consumer Outcomes Surveys in everyday practice could:

1) Produce specific knowledge that may help stakeholders in the Ohio public mental health system in their specific implementation efforts.

2) Contribute to implementation science through describing the interrelated social processes related to the implementation of this policy and practice change.

From an intensive, descriptive case study of such social processes, hypotheses could also be developed and tested. To limit the scope and focus, one particular Consumer Outcomes Survey instrument was focused on: the Adult Consumer Form.

Because I myself am a stakeholder in the Ohio public mental health system, having worked in multiple capacities including as a clinician who has administered the Adult Consumer Form, I had some thoughts as to what I might find in such a study. In my analysis, I was careful to bracket and put aside my a priori ideas to the best of my abilities. My experiences with the Adult Consumer Form differed substantially from that of frontline staff participants in this study in that I administered the form at the point of 
intake, with people who then were assigned to someone else for ongoing services; the frontline staff participants in this study administered the form with consumers who were on their caseloads and who they worked with on an ongoing basis.

Given this difference, I expected that the frontline staff participants might not learn as much new information about a consumer via administering the form. While this was understandably true to some extent, during oral administrations only, through initially verbally responding to the abstract form questions with emergent and specific life situations, consumers did share significant and new information with their staff. And, perhaps most exciting to me in my findings was the extent to which consumers indicated that they found the process of "doing the outcomes", particularly via oral administration, to generate introspection, self-awareness and an expectation of change/improvement to varying degrees.

In my findings, perhaps most concerning to me was the extent to which tracking and complying with due dates for various required documents, including the Adult Consumer Forms, dominated frontline staffs' and consumers' understandings and experiences of clinical documentation. Frontline participants, both clinicians and consumers, overwhelming referred to clinical documents as things that were "done because they are due", rather than as tools that were useful. While I was aware that compliance had a role in most paperwork, the extent to which compliance was focused upon not only by frontline participants, but across agencies, was startling to me.

It has been some years since I had a caseload for which I was responsible for chart upkeep and other ongoing required documentation, and while I remember feeling stress and pressure to keep my paperwork current and in compliance with particular 
requirements, I didn't recall feeling overwhelmed with "chart management" and "keeping up with paperwork" to the extent that was articulated to me by frontline clinician participants. I realized that there have been substantive changes in funding and reimbursement infrastructure for public mental health since that time which I did not initially consider as I embarked upon my research. In tracing and elucidating the system processes embedded in the experiences of my frontline participants as they participated in this implementation effort, I became aware of how changes pertaining to fee-for-service billing and medical necessity impacted my participants' experiences of the Adult Consumer Form, as well as clinical documentation in general.

\section{Aims \& Research Questions}

The aims of my study were two-fold:

1. To generate specific information about the social processes involved in implementing the Consumer Outcomes Initiative that may be useful to stakeholders in Ohio's public mental health system.

2. To contribute to implementation science, through offering an intensive, detailed, descriptive case study of the social processes embedded in and connected to frontline experiences implementing a practice change (completing and clinically utilizing a standardized outcomes tool) in a naturalistic, complex service system (the Ohio public mental health system). 
I addressed these aims through answering the following two research questions:

1. How do frontline clinicians ("CPST staff") and mental health consumers understand, experience and use the Adult Consumer Form?

2. What mental health system-related processes are embedded in and connected to these frontline understandings, experiences and uses? 


\section{CHAPTER TWO - BACKGROUND \& SIGNIFICANCE}

\section{Introduction}

In this chapter, I first take a broad, exploratory approach to understanding the phenomenon of implementation, through considering themes across multi-disciplinary literature on implementation. In exploring the multi-disciplinary literature, I discovered five facilitators anecdotally referenced as key to implementation success, with the most referenced factor being 'collaborating between representatives of stakeholder groups'. Keeping in mind the importance of stakeholder groups, I then examine how implementation is conceptualized and studied in three bodies of literature (social policy; organizational behavior; and evidence-based practice), which roughly correspond to macro, meso and micro domains of social work practice. Within each of these bodies of literature, and across differing conceptualizations of implementation, a need for more information on the interrelated social processes spanning micro, meso and macro contexts in implementation efforts is clearly evident. I then offer a synthetic view of the literature via an integrative framework for differing dimensions of implementation that are negotiated through social processes between stakeholders. And, because ethnography is referenced as a process-oriented method, I also review recent empirical studies that employ ethnographic methodology to study social processes in implementation efforts.

\section{An Exploratory Review of Multi-Disciplinary Literature on Implementation}

In order to broadly glean the current state of knowledge on the phenomenon of implementation, I reviewed over 100 implementation-related articles from an array of international academic publications in wide variety of applied, social science-related 
disciplines. My purposes in this initial step were to familiarize myself with the literature, and to search for any overarching understandings about the nature of implementations. Due to the discrepancy of term definitions used related to implementations, rather than limiting my search to 'implementation', I also used the following variations of the following search terms: research and development; technology transfer; diffusion; dissemination; and knowledge utilization. I searched multiple databases containing peerreviewed articles, including health, science, information technology, and social science databases. Among the databases searched were: CINHAL; JSTOR; MEDLINE; PAIS International; Proquest Nursing and Allied Health Source; PsycINFO (1967-), Psychology Behavioral Science Collection; Social Work Abstracts; and SIRS Researcher. This literature review did not originate purposefully as such, but rather, evolved from initial curious forays into the vast literature on implementation. I thus cannot produce an explicit record of my search trajectory, nor am I able to exhaustively identify specific databases, and am making no claims with regards to this review being an exhaustive one. Rather, it is a broad first pass (conducted over the first year of my doctoral program) through a vast body of implementation literature, in which I selectively focused on articles that focused on and explicitly addressed the phenomenon of implementation of a practice change in some detail. Although numerous studies and articles have been written since (and will be discussed in the following sections of this chapter), the each of themes I discovered in my initial pass through the implementation literature continue to reoccur.

The kinds of practice changes discussed in the articles I initially reviewed included the following: clinical procedures; practice models (social service, behavioral 
health, education, health care); assessment and outcomes tools; policies; computer technologies; and organizational procedures. In reading the articles, I began to notice recurrent ideas and themes, and started noting and tabulating them in a simple thematic analysis fashion. From this analysis emerged facilitators to implementations of practice changes that were referenced by multiple authors. Specifically, I discovered that many authors, irrespective of any conflicting theoretical approach, repeatedly, and often anecdotally, identified five factors - some related and some seemingly contradictory — as facilitators in the implementation of practice changes (Table 1).

Collaborating between stakeholder representatives from different groups impacted by the implementation was the most cross-referenced implementation facilitator. Interestingly, two other facilitating factors appeared to be contradictory to each other: maintaining high fidelity to an innovation and adapting and reinventing an innovation. High fidelity related to maintaining the innovation in its originally created form so as to maximize anticipated positive outcomes; adaptation and reinvention pertained to modifying an innovation to fit in a relevant, meaningful way into a specific context (agency, community, etc.). I also identified one particularly cross-referenced barrier implementation efforts; this barrier pertained to the struggle to develop system policies and infrastructures that were integrated with and supported practitioners' everyday attempts to implement a given innovation (Haynes and Haines, 2002; Fadden, 1997; Farhall, 2002; Bower, 2002). 


\section{Table 1}

\section{Identified facilitators of implementations}

Facilitator
References
Collaborating among representatives from all stakeholder groups being impacted by the innovation, regarding aspects of creating, planning for and/or implementing the innovation

Adapting and/or reinventing of the innovation to fit the needs of the local communities

Maintaining high fidelity to the original innovation

Perceiving benefits and/or usefulness of the innovation

Having local ownership of the innovation
Allen, 1994; Barker, 1994; Bartels, 2002; Bedregal, 2001; Bellman, 1996; Bond, 2001; Bradbury, 2003; Cowley, 1999; Depoy, 1999; Fisher, 1999; Fitzsimons, 2002; Gilliam, 2002; Dixon, 2001; Herie, 2002; Gibbon, 2002; Gerrish, 1999; Lee, 2003; Ho, 2002; Hugentobler, 1992; Innes, 1999; Jones, 2000; Kerr, 1996; Lauri, 1982; Mander, 2002; Marshall, 2001; McDevitt, 1998; McKenna, 1995; Moody, 2001; Reason, 2001; NAMI, 2003; Nastasi, 2000; Ochocka, 2002; Ohio Department of Mental Health, 2002; Oliver, 2002; Pearcey, 1996; Pfeil, 2001; Pilgrim, 1998; Ring, 2001; Scott, 1959; Slade, 2000; Small, 1995; Rappaport, 1990; Smith, 2000; Somekh, 1995; Thorslund, 1988; Tobin, 1997; Waterman, 1995; Webster, 1999; Wood, 1998;

Broner, 2001; Caburnay, 2001; Caplan, 1976; Cowley, 1999; Deci, 1995; Dixon, 2001; Fadden, 1997; Fitzsimons, 2002; Gerrish, 1999; Grimshaw, 2002; Haines, 2002; Harris, 2001; Harvey, 2002; Henggler, 1994; Herie, 2002; Ho, 2002; Innes, 1999; Lauri, 1982; Lee, 2003; Mander, 2002; Marshall, 2002; Mayer, 2000; McCormack, 2001; McKenna, 1995; Mittman,1992; Moody, 2001; Muser, 2002; Natasi, 2000; National Center for Disability Research, 1996; Ochcocka, 2002; Peacey, 1996; Pfeil, 2001; Pilgrim, 1998; Ring, 2001; Slade, 2002; Smith, 2000; Somekh, 1995; Tannebaum, 1994; Wood, 1998

Bartels, 2002; Bedregal, 2001; Blum, 1995; Bond, 2001; Cameron, 1999; Chilvers, 2002; Deci, 1995; Dixon, 2001; Drake, 2001; Essock, 1995; Fadden, 1997; Farhall, 2002; Frese, 2001; Gerrish, 1999; Harvey, 2002; Haynes, 2002; Henggeler, 1994; Hugentobler, 1992; Mander, 2002; Marshall, 2001; McCormack, 2001; McCormack, 2002; McKenna, 1995; Mueser, 2002; NAMI, 2003; Saunders, 1988; Schoenwald, 2001; Sheldon, 2002; Sloboda, 2002; Tanenbaum, 1999; Torrey, 2001; Webster, 1999

Bartels, 2002; Bedregal, 2001; Blum, 1995; Bond, 2001; Cameron, 1999; Chilvers, 2002; Deci, 1995; Dixon, 2001; Drake, 2001; Drake, 2001; Essock, 1995; Sloboda, 2002; Frese, 2001; Fadden, 1997; Farhall, 2002; Gerrish, 1999; Harvey, 2002;

Haynes, 2002; Henggeler, 1994; Hugentobler, 1992; Mander, 2002; Marshall, 2001; McCormack, 2002; McCormack, 2001; McKenna, 1995; Mueser, 2002; Saunders, 1988; Schoenwald, 2001; Sheldon, 2002; Tanenbaum, 1999; Torrey, 2001; Webster, 1999;

Bradbury, in press; Broner, 2001; Fitzsimons, 2002; Gerrish, 1999; Harris, 2001; Ho, 2002; Innes, 1999; Laurie, 1982; Lee, 2003; Lee, 2002; Leighton, 2000; Mander, 2002; McDevitt, 1998; McKenna, 1985; Mittman, 1992; Moody, 2001; Mueser, 2002; Natasi, 2000; Ochocka, 2002; Peacey, 1996; Pfeil, 2001; Pilgrim, 1998; Ring, 2001; Somekh, 1995; Webster, 1999; Wood, 1998

Broner, 2001; Cowley, 1999; Deci, 1995; Fadden, 1997; Foxon, 1997; Gerrish, 1999; Grimshaw, 2002,; Haines, 2002; Harris, 2001, Herie, 2002; Lee, 2002; McKenna, 1995; Nuttnab, 1992; Natasi, 2000; Oxman, 1995; Ring, 2001; Rogers, 2001; Rosenheck, 2001; Schoenwald, 2001; Simpson, 2001; Torrey, 2001 
I speculate that a lack of collaboration between stakeholders could create numerous impediments to developing infrastructures and policies to support the use of a given innovation, for what may be abundantly obvious (with regards to what is needed in a given implementation effort) to a representative of one stakeholder group (such as frontline practitioners or service users) may be less so to representatives from another stakeholder groups (such as administrators and policy-makers). Lyons et al (2005) in an inductive study discovered that barriers and facilitators to an implementation effort were viewed differently according to stakeholder group; administrators, physicians and nurses each identified differing facilitators and barriers. Allen (1994) similarly considered the diversity of perspectives in a mental health system evaluation.

In considering more recent literature, stakeholder perspectives on implementation endeavors continue to be examined. Proctor et al (2007) explored the perspectives of agency directors in community mental health centers attempting to implement evidencebased practices; Aarons and Palinkas (2007) studied the perspectives of service providers in the implementation of an evidence-based child welfare practice. With regards to stakeholder perspective, Aaron and Palinkas (2007) asserted: "To some extent, the nature of the process, problems and solutions may be dependent on the perspectives and experiences of a given stakeholder group" (p.411).

Through such a statement, Aaron and Palinkas (2007) seemed to point to standpoint theory, and the related idea of "partial perspective" (Collins, 1990; Haraway, 1988; Harding, 1991; Harstock, 1983), as a way to begin to understand the complexities of inter-related and differing stakeholder perspectives in a given implementation effort. 
Oversimplified, standpoint theory asserts that those in positions of less power can access knowledge not available to those in positions of more power, especially regarding nuances of social relationships and how things work under specific, material conditions. For example, service users and clinicians at the frontlines implementing an agency-wide clinical practice change would likely have first-hand understandings (some shared, some differing), that an administrator would not likely have access to in the same way; however, the decision-making power regarding what is being implemented agency-wide is typically the responsibility of (and power held by) the administrator. I would further extend this idea to suggest that frontline clinicians conversely may likely not have a clear understanding of policy issues related to what they are attempting to implement. To better understand how implementations are understood by those with such different vantages, I next turned to literature written from micro, meso and macro-focused practice perspectives.

\section{Examining Macro, Meso and Micro-focused Conceptualizations of Implementation Macro-focused Conceptualizations: Social Policy and Implementation} Upon reviewing this area of scholarship, it seems that those attempting to implement social policies often struggle at least in part with what Small (1995) referred to as "ill-structured" social problems, "...the ones that do not have well-defined or reliable methods of determining a problem or its solution; the problem definition varies as a function of the particular situational circumstances and the stakeholders' perspectives..." (p. 948). Holcomb and Nightingale (2003) explained social policy implementation as a multi-stage phenomenon that occurs over time: 
...from the early stages when legislation is formed and regulations developed, to the actual delivery of services at the grass roots level, and all administrative, political and operational stages in between...implementation analysis is a category of research within the broader domain of policy analysis...(p.39)

Charlesworth and Born (2003) similarly defined implementation in the social policy context as the process of carrying out a policy decision and/or the interactions that occur between settings and taking actions to achieve policy goals. Lennon and Corbett (2003) categorized policy implementation research as falling under the broad umbrella of program evaluation:

Program evaluations have two distinct conceptual components: implementation analysis and impact analysis. Implementation analysis seeks to understand the program in its own right...how systems function... goals of the policy... whether those goals are internally consistent and shared among multiple stakeholders... what administrative and management procedures are engaged... whether they reflect the intent of the program designers... how policy is changed by frontline staff... whether the clients are reacting to the program... Impact analysis encompasses the research questions most commonly associated with program evaluations - whether the program or policy has the desired effect on critical outcomes... (p. 2-3).

Lennon, Corbett and many other researchers and administrators greatly furthered understandings of implementing policy via combining their efforts through a series of meetings (Werner, 2004). The conclusions drawn through these series of meetings are summarized in the following two companion volumes: A Guide to Implementation 
Research (Werner, 2004), and Policy into Action (Lennon and Corbett, 2003). In summarizing approaches to implementation, Werner (2004) differentiated the conceptual frameworks used in policy implementation research as those that:

...may be internal to the program and rest on the provisional theory or theories motivating the program design... alternately, the causal framework may be external to the program, and rest on grander theories about how forces in society at large, or within the bureaucracy itself, interact to shape program experiences and outcomes... finally, the causal framework may rest on an intimate understanding of how the program fits into the stakeholders' lives and activities... (p. 145)

In terms of how implementing policies is studied, Werner $(2004, \mathrm{p} .7)$ broadly divided existing approaches to policy implementation research into three categories: documenting implementation ('what is happening'); assessing implementation ('is it what we want or expect to happen?); and explaining implementation ('why is it happening as it is?). Holcomb and Nightingale (2003) further delineated implementation research as attempting to reach the following analytic objectives:

- To develop program typologies or models based on studies in selected sites or programs.

- To generalize conditions or experiences in selected sites to a broader universe of sites.

- To suggest "best practices" or potentially promising approaches, in particular types of jurisdictions or for particular types of individuals, based on analysis and observation in selected sites (p.44). 
This collaborating group of researchers and administrators focused not only on emerging knowledge about implementing social policy, but also on retrospective understandings. Brodkin (2003, p.147-150) explicated the evolving understandings of implementation from one generation to the next as first, second and third wave knowledge: first seeking to identify what interfered with the linear process of policy implementation (the first wave); next embracing and studying the ambiguities of policy implementation within complex organizations (the second wave); and also understanding policy implementation as an extension of policy politics (the third wave). In considering the 'three generations of implementation research', Lennon and Corbett (2003) concluded that in order to move the state of policy implementation knowledge forward, there is currently a need to "...study process issues at every level of implementation, each in its own right, and to value systematic descriptions rather than demand overall predictive capacity" (p. 20). Hasenfeld \& Brock (1991) similarly pointed to the need to understand policy implementation as a domain that encompasses linkages between policy, actors, driving forces and service structures, and propose a political economy framework in order to do this.

Palley (2004), in her study on the implementation of disciplinary procedures in the Individuals with Disabilities Act, noted that some policy researchers are integrating bottom-up and top-down models of implementation; this may be a way to get at such complexities in policy implementation. Wedel et al (2005) suggested an 'anthropology of public policy' as a way to build such process knowledge, through using ethnographic approaches that could: “...uncover the constellations of actors, activities, and influences that shape policy decisions, their implementation, and their results..." (p.30). Shore and 
Wright (1997) similarly suggested that an ethnographic approach in studying policy implementation is ideal in furthering understanding of “...the workings of multiple, intersecting and conflicting power structures that are local but tied to non-local systems..."(p.13).

The re-conceptualizing of the 'ethnographic field' from one that is geographically/locality bound, to one that is determined by extended social relations and power between individuals at multiple locations, is crucial in such an ethnographic approach (Smith, 2005, 1987; Wedel et al, 2005; Shore \& Wright, 1997, Reinhold, 1994). Wedel et al (2005) underscored the need for such ethnographic studies and social network analyses that explicate social processes and power relations between individuals involved in a given policy implementation effort, stating:

...the long-established frameworks of 'state' and 'private'; 'local' or 'national' and 'global'; 'macro' and 'micro'; 'top down' and 'bottom up'; and 'centralized' and 'decentralized' not only fail to capture current dynamics in the world but actually obfuscate the understanding of many policy processes ... [social networks are]... a useful way to conceptualize the mixes of 'state' and 'private', of 'macro' and 'micro', of 'local' or 'national' and 'global', of 'top down' versus 'bottom up', and of 'centralized' versus 'decentralized' (p.30). 


\section{Meso-focused Conceptualizations: Organizational Behavior \& Implementation}

While the organization is one of the relevant units of inquiry both social policy (reviewed in the previous section) implementation literature and multi-level and microfocused EBP implementation literature (reviewed in the following section), the field of organizational behavior $(\mathrm{OB})$ gives primacy to the organization as the unit of inquiry for any given topic, including implementation. According to Holland (1995, p.1788), an organization can be defined as “...formalized groups of people who make coordinated uses of resources and skills to accomplish given goals or purposes...." Human service organizations are explicated by Hasenfeld (1985) to have five main components: client system attributes; interventions; interaction patterns (between staff and client systems); control procedures; and general operations. Hasenfeld (1985) defined the operations component as that which "specifies the organization and sequencing of staff activities in the service delivery process" (p.663).

Such organizational components are clearly related and overlapping. Sosin (2001) connected organizational attributes, such as those pertaining to general operations, to the intensity of the delivery of specific micro-focused interventions, and calls for intervention leaders to "... become aware of and capable of manipulating the organizational context of treatment" (p.371). Given the interdependence between such components, and in keeping with OB tenets, I in this section focused primarily on the implementation of changes in operations (including the implementation of operations changes so as to better encompass a micro-focused practice change within the organization). I am choosing to focus on operations to frame the inter-functioning of 
organizational attributes as a distinct unit of analysis, toward which meso-focused practices are aimed.

The implementation of changes in meso-focused practice is often not explicitly framed as such, but rather, characterized in OB literature as a phenomenon embedded in cycles of creating and sharing knowledge through which changes in organizational practices are developed and sustained; e.g., knowledge development and utilization (Aram \& Salipante, 2003; Bradbury \& Reason, 2003; Huff, 2000; Boland \& Tenkasi, 1995; Gibbons et al, 1994). OB scholars Boland and Tenaski (1995) framed implementing practice changes as something that occurs through 'communities of knowing' interfacing dynamically. Senge and Scharmer (2001), much like Karf (1931, cited in Kirk \& Reid, 2002), conceptualized such interfaces as iterations of communications between those in research, management and end-user roles; e.g., researchers create the new practice, management makes the decision (unilaterally, consensus building, or other ways) to implement the new practice, and end-users then actually utilize the new practice and give feedback to prompt the development of further practice changes. Aram and Salipante (2003) articulated a need to develop a 'bridging scholarship' as one way to mediate the epistemological and practical differences between such ways of knowing and operating within and beyond organizations; differentiating between practice knowledge that is relevant (highly specific, contextual and subjective) and rigorous (portable, predictable, generalizable).

Other OB scholars have developed similar conceptual frameworks for knowledge development and utilization. Gibbons et al (1994) differentiated between Mode One and Mode Two knowledge development and use. Mode One is conceptualized as traditional 
discipline-oriented research that is conducted by individuals in scientific settings according to the norms of academic research, and disseminated to practicing managers and administrators through professional journals and conferences (Gibbons et al, 1994). Gray (2001) referred to an organization that operates predominantly on Mode One knowledge as an "evidence-based organization". Mode Two is conceptualized as knowledge that is developed and implemented informally through efforts of (management) practitioners to solve an immediate and local problem (Gibbons et al, 1994). Huff (2000) extended the work of Gibbons et al, through the development of a Mode 1.5 knowledge production, in which the conventions of academic sciences are used to conduct research, but the organizational practice issues being learned about or created, and changed (implemented) are those identified as relevant by (management) practitioners.

Bradbury and Reason (2003) similarly emphasized the need for representatives from various communities of learners to interface in order to create and implement new practices, but in addition suggest a specific meso-focused practice to create such an interface, through their suggest of action research as a way to both create and implement practice changes. Briefly, action research as a methodology involves iterations of collaborative meetings in which a specific problem is identified (by representatives of all stakeholder groups involved in the problem); solutions are created, and then implemented and modified until a desirable solution is reached. The creation of a new practice change and the implementation that practice are thus not construed as discreet activities, but rather, embedded in cycles of action research. 
Rather than looking at practice change cyclically, Bottrup (2005) took a different conceptual lens to understanding organizational change, through focusing on the role of inter-organizational interactions in knowledge creation and utilization. Bottrup (2005) explained organizational networks as formal or informal entities which are compromised of a number of independent organizations and fall under one of two types:

- $\quad$ Business networks-those concerned with optimization of production and reduction of cost changes; often comprised of organizations from different levels in the supply/production chain which are typically referred to as a vertical network.

- Development networks-those that convene to support organizational development and learning, enhance implementing existing knowledge, and create new knowledge; characterized by organizations being on the same level in the production process, and/or contributing with complementary knowledge (a.k.a.-horizontal networks) (p.509-10).

Practice-based research networks in primary care settings would be an example of a development network (Bottrup, 2005). In contrast, business networks tend to involve different types of organizations with interdependent, often contracted obligations to each other, which when optimized through a particular business network can result in mutual financial gain (Bottrup, 2005).

Actual practice changes, while they may be generated through networks, and/or through interfaces between individuals from different communities of knowing, must still occur in specific, multi-faceted organizational contexts. Glisson (2007) explicated the 
sociotechnical model of organizational effectiveness (Porras \& Robertson, 1992;

Rousseau, 1977) as a way to understand the relevance of such contexts:

The expectations, norms and perceptions that form the organization's social context can inhibit, truncate, reinvent, or adapt core technologies in ways that render the technologies ineffective. On the other hand, the organization's social context can also support effective services with norms, values, expectations, and attitudes that complement and enhance its core technology. (p. 738).

Glisson (2007) called for the development of organizational context assessment methods, identification of organizational contexts that inhibit or contribute to the implementation of effective services, and the creation of evidence-based organizational interventions “...that can create organizational social contexts to support the implementation of effective services" (p. 737). Further, Glisson (2007) identified an implementation model he is in process of developing, which entails three service system domains involved in implementations:

They are the consumer domain, the technical domain, and the organizational domain... the consumer domain includes the characteristics, behaviors and attitudes of the service consumers... the technical domain includes the treatment and practice models, assessment tools, and technical training used by the service providers who work in the organization. Finally, the organizational domain includes the organization's culture, climate, work attitudes, and related factors that form the organizational social context in which services are provided. (p. 737). 
In considering such domains, the question remains, how do these interface within a given implementation endeavor in a specific organizational context? Wheatley (1994) offered a way to conceptualize complex changes within specific organizational contexts, through explicitly considering the interplay and complexities of specific processes and activities entailed in an organizational change from a chaos theory perspective. Wheatley (1994) suggested that nonlinear complexity models (which can be mathematically calculated) offer explanatory value for understanding how organizations change. Litaker et al (2006), applying Wheatley's (1994) idea, explained and related complexity theory to primary care organizations as follows:

Health care delivery consists of numerous simple and complex "systems" or processes, ranging from those that are deterministic to those with features of randomness. A deterministic system is one that has predictable outcomes. Given the same starting conditions and the same equation, the same results are expected (e.g., the inoculation of a virus into tissue culture medium regularly results in cell disruption and viral replication). Complex nonlinear systems, in contrast, are difficult to fully characterize because of the potential for multiple interactions and feedback loops within and outside of the system. Furthermore, many of these systems exhibit actions that follow nonlinear, unpredictable trajectories, but possess underlying patterns that are detectable and based in probabilities related to constraints placed on each system... Similarly, patient care consists of numerous processes in which multiple factors or agents exert influence on their availability, application, and sequence in highly variable ways, which results in outcomes that are less than predictable" (p. S31). 
Litaker et al (2006) thus framed changes in primary care practices (in the delivery of preventative health counseling) as nonlinear, complex interplays between numerous processes occurring within a given primary care setting.

Complex, nonlinear systems (and deterministic systems) as articulated in complexity theory, and the notion of "communities of knowing" can be potentially integrated through Small's (1995) conceptualizations of "ill-structured" and "wellstructured" problems (p. 948). According to Small (1995):

Whereas conventional academic social sciences have tended to study 'wellstructured' problems (the ones that 'tend to be solvable if the right sequence of steps is used in applying set principles, in which the problem is 'viewed as the same from all perspectives and once solved, the solution is applicable to the problem whenever it is encountered'), action-oriented approaches tend to focus on 'ill-structured' problems (the ones that do not have well-defined or reliable methods of determining a problem or its solution; the problem definition varies as a function of the particular situational circumstances and the stakeholders' perspectives). (p.948)

In considering this quote from Small, a community of knowing (conventional academic researchers) is seen to be noted, and, extrapolating from complexity theory, wellstructured problems could be construed as occurring in deterministic systems, and illstructured problems could be construed occurring in complex non-linear systems.

Those attempting to facilitate intentional practice change within specific organizations, irrespective of which communities of knowing they may be a part of, seem to be facing issues that are thus "ill-structured" and often difficult to define and address. 
Abbott (1995) suggested that, to begin understand the nonlinear complexities through which the implementation of organizational change occurs, researchers should first attend to the key properties of order and sequence of events across implementation efforts through creating narratives of processes between individuals within an organization. Pettigrew $(1995,1997)$ similarly argued that the explicating the interconnections between context and processes is crucial in furthering an understanding of the how organizational practice changes are implemented.

\section{Micro and Multi-level Conceptualizations: Evidence-based Practice Philosophy and Implementation}

Policy implementers, organization leaders and others attempting to implement practice changes all typically do so in vastly complex environments that may span macro, meso and micro contexts. Within micro-focused practice literature, I found proponents of evidence-based practices made the bulk of contributions with regards to the field of implementation science. To limit scope and focus of this section, I focused on these contributions.

Proponents of evidence-based practices typically focus their implementation efforts specifically on practices that have already been created and extensively evaluated, and for which efficacy and effectiveness have already been established through randomized, controlled research trials. Drake et al (2001) defined evidence-based practices (EBPs) as:

...interventions for which there is consistent scientific evidence showing that they improve client outcomes. For example, research shows that using antipsychotic 
medications within specific dosage ranges and providing education and skill training for family caregivers over several months prevents or delays relapses of schizophrenia. The requirements for scientific evidence used by different groups sometimes vary, but in general the highest standard is several randomized clinical trials comparing the practice to alternative practices or to no intervention. When the separate trials are considered together, such as through a meta-analysis, the evidence supports the superiority of the evidence-based practice over the alternatives, including no intervention... (p. 180)

Gambrill (2006) defined EBP more broadly, stating: “...EBP is an evolving process. It describes a philosophy and process designed to forward the effective us of professional judgment in integrating information regarding each client's unique characteristics, circumstances, preferences, and actions and external research findings" (p.339).

In the United States, EBP typically refers to practice focused on clinical issues as suggested by the definitions above, perhaps because the shift toward EBP began in medicine and health care arenas (Mullen \& Steiner, 2004). However, as stated by Mullen \& Steiner (2004): “... [EBP] encompasses policy, management, and direct or clinical practice. The field needs evidence-based policies, evidence-based management, and evidence-based direct services..." (p. 112). Regardless of whether a given EBP is created to intervene with micro, meso or macro client systems, its implementation would likely span all three contexts to varying degrees. The implementation of an EBP is thus best construed as a multi-level (individual, organizational and system-level) phenomenon (Panzano et al, 2002-2003; Proctor, 2004; Fixsen et al, 2003, 2005), irrespective of the client system it was created for. (Readers are directed to: Science and Social Work, 
published by Kirk and Reid in 2002, for a detailed explication of how science and the EBP movement have emerged in the social work profession; and to Gambrill's (2006) Evidence-based Practice and Policy: Choices Ahead for an in-depth analysis of the various views on EBP. ) For the purposes of explicating micro-focused understandings of implementation, and because the literature on the implementation of micro-focused EBPs in human service settings is arguably the most developed to date, this section will focus specifically upon the implementation of primarily micro-focused EBPs.

In what is perhaps the current definitive literature review on implementing EBPs, Fixsen et al (2005) explained implementation as follows:

Implementation is defined as a specified set of activities designed to put into place an activity or program of known dimensions. According to this definition, implementation processes are purposeful and are described in specific detail that independent observers can detect the presence and strength of the 'specific set of activities' related to implementation. In addition, the activity or program being implemented is described in sufficient detail so that independent observers can detect its presence and strength... when thinking about implementation activities, the observer must be aware of two sets of activities (intervention-level activities and implementation-level activities) and two sets of outcomes (intervention outcomes and implementation outcomes). (p.5)

In defining implementation, Fixsen et al (2005) further differentiated between:

- $\quad$ Paper implementation-putting into place new policies and procedures, with the adoption of an EBP as the rationale for the policies and procedures. 
- $\quad$ Process implementation-putting new operating procedures into place to conduct training workshops on the EBP, provide supervision, change information reporting forms, and so forth.

- $\quad$ Performance implementation-putting procedures and processes into place in such a way that the identified functional components of change are used with good effect for consumers (p.6).

Panzano et al (2002-2003), in the context of studying the implementation of specified EBPs in the public mental health system of Ohio, developed a multi-level model of implementation success. Within this model, environmental variables, interorganizational relationship variables, organizational variables, project variables and innovation variables are carefully specified as independent variables (Panzano et al, 2002-2003). Dependent variables in this model are related to measures of implementation success, specifically innovation effectiveness and implementation effectiveness (Panzano et al, 2002-2003). Other scholars (McAdam, 2005; Meiland et. al, 2004; Proctor, 2004) are similarly focused on the development of multi-level implementation models; in each of these models, specific factors at each of these three levels are identified and hypothesized to impact the success of a given effort to implement a micro-focused, evidence-based practice.

Based on their synthetic analysis of the relevant literature, Fixsen et al (2005) presented a conceptual framework for implementation which likewise entails multiple levels but is instead organized according to functions. Fixsen et al (2005) specify their implementation framework as being relevant for well-defined programs and practices; this framework is comprised of five components: 
1. Source-a "best example", often a composite of the original practice or program that was developed and evaluated and the best features of attempted implementations of that practice or program.

2. Destination-the individual practitioners and the organization that adopts, houses, supports and funds the installation and ongoing use of an innovation.

3. Communication link-a group of individuals, a.k.a.-'purveyors', representing a program or practice who actively work to implement the defined practice or program with fidelity and good effect at an implementation site.

4. Feedback mechanism-a regular flow of reliable information about performance of individuals, teams and organizations acted upon by relevant practitioners, managers and purveyors.

5. Sphere of influence-the social, economic, political, historical and psychosocial factors that impinge directly or indirectly upon individuals, organizations and systems. (p. 12)

Fixsen et al (2005) drew the following general conclusions on what is presented as an "overview of the 'best practice' evidence with respect to implementation":

1. The best evidence points to what does not work, with regards to implementation; specifically, neither information dissemination nor training are alone sufficient to ensuring a successful implementation. 
2. There is good evidence that successful implementation efforts designed to achieve beneficial outcomes for consumers require a longer term, multilevel approach.

3. There is little evidence related to organizational and systems influences on implementation, their specific influences, or the mechanisms for their impact (but there is little doubt as to their having an impact). (p.70)

\section{Comparing, Contrasting and Integrating Understandings of Implementation}

In the previous sections I explored the phenomenon of implementation as addressed in communities of knowing focused on targeted client systems (macro, meso and micro), in which I found multiple assertions that implementation typically is a multilevel phenomenon, irrespective of the targeted client system. For example, multiple states have passed legislation (mandated policy/ macro client system) requiring agencies (organizations/ meso client system) to implement empirically tested treatments for youth and families (micro client systems); these are not discrete systems, but rather, are interrelated and intertwined (Glisson \& Schoenald, 2005). Conceptualizations of 'implementation' in previous sections most notably diverge on whether implementation is a phenomenon that is distinct from or embedded within the creation of new practice innovations, and in how variations from a specified practice (particularly evidence-based practices) are construed. In this section, I compare and contrast circular/nonlinear and 
linear conceptualizations of implementation across literatures discussed in the prior section, and suggest four shared dimensions of implementation as a way to integrate and make explicit what at first glance may appear as fragmented and diverging ideas about the notion of implementation.

\section{'Implementation': a Cyclical/Nonlinear Process Intertwined with Creating New}

\section{Practices}

The underlying idea of 'implementation' as embedded in larger collaborative (between researchers, clinicians, consumers and other stakeholders) cyclical processesentailing iterations of generating ideas, developing new practices, testing them in actual settings, evaluating, and revising as needed-is most visible in the social policy and organizational behavior literature. However, this idea of implementation as a cyclical process intertwined with new practice creation is present in all practice domains to varying degrees. Sub-categories encompassing this theme include but are not limited to: 'action research' from the social psychology and organizational behavior literatures (Lewin, 1946; Bradbury \& Reason, 2003); 'collaboratives', 'consensus-building' and 'coalitions' from the social policy literature (Bailey, 2000; Milligan, Coulton, York \& Register, 1996; Mattessich \& Monsey, 1992); and 'feminist research' (Miller, 1991); and 'research and development' from the micro social work practice literature (Blum, Biegel, Tracy \& Cole, 1995).

Conceptualizations across these subcategories are fairly similar. For example, OB scholars Bradbury \& Reason (2003) conceptualized action research cycles as a nonlinear, micro-to-macro method for integrating the creation and context-specific 
application of practice knowledge while also "developing infrastructure to sustain a large-scale change" (p. 20). Iterations of these action research cycles thus allow for stakeholders to co-create, co-implement, co-evaluate and co-modify innovations in specific practice settings (Bradbury \& Reason, 2003). Social policy scholar Claudia Coulton (2004) similarly noted the often iterative and idiosyncratic nature in which macro interventions are implemented:

Community interventions... are often implemented through a participatory action process that is incremental and emergent by design. Numerous individuals and groups may be involved in a diverse and complex set of activities, which are difficult to document and measure in sufficient detail so that they can be replicated. Although these initiatives are typically guided by a set of principles and draw upon practice experience, the tacit knowledge of the members of the community is often an important ingredient in shaping the intervention.

Converting these sources of knowledge to an intervention plan that can be studied has proven daunting. (p.9)

The general principles of using iterations of collaborative problem-solving and non-hierarchical consensus-building to cyclically create new practices and implement changes are not in and of themselves revolutionary; the use of collaborative, nonhierarchical approaches can be traced to indigenous tribal councils (Harris, 2001); and perhaps to other sources as well. According to Small (1995), despite evolving separately, such approaches to implementation "advocate remarkably similar agendas and share a core of epistemological assumptions and methodological strategies... the fact that very 
different traditions have independently evolved and come to similar conclusions regarding principles and practices provides a form of cross-validation” (p.941).

\section{'Implementation': a Linear Process Discrete from Creating New Practices}

In contrast, the view of implementation as a predominantly linear transfer of knowledge to get an existing innovation replicated and into use-with fidelity to the original model-is held by many evidence-based practice (EBP) proponents across micro, meso and macro settings. This is not to say that there may not be many elements of the consensus-building, cyclical processes described in the preceding section present in a linear knowledge transfer; to the contrary, many EBP technical assistance centers help agencies implement EBPs through mobilizing iterative, collaborative stakeholder efforts! The process becomes a linear transfer through a focus on the replication of an existing practice which is being treated as portable and predictable entity (Aram \& Salipante, 2003). The rationale for such an approach is obvious; the pre-existing practice has in some settings demonstrated specified, positive client outcomes, and it is reasonable to believe that the use of such a tested practice could potentially benefit many people with its predictable outcomes.

Much of this approach to implementation is rooted in the work of the following four theorists: the hybrid corn dissemination model proposed by Ryan and Gross (1943); the diffusion of innovations theory (Rogers, 1995); and Wiebe's (1952) social marketing theory. Each of these treated an 'implementation' as essentially a linear process, involving the knowledge transfer of a 'finished product' to its end-users; this is in contrast to those working from a cyclical perspective who generally treat a new practice 
as a collaborative 'work-in-progress'. Drake et al (2001) and Essock et al (1995) made compelling arguments for treating the new practice as a 'finished product'; they both indicate that while circumscribed or modified evidence-based practices are often an improvement over the status quo, too many changes to an evidence-based innovation would potentially sacrifice the innovation's efficacy, likely resulting in poorer outcomes for consumers of the services.

This predominantly linear knowledge transfer approach is exemplified through efforts to facilitate the implementation of an integrated dual diagnosis treatment model (IDDT) created and rigorously studied by Drake (2001) and his colleagues. Activities pertaining to disseminating and facilitating the implementation of the IDDT treatment model typically draw from knowledge transfer principles and strategies. Examples of such activities include, but not limited to: audience segmentation (a social marketing construct) via the use of 'tool kits' created for specific stakeholder subgroups (Drake et al, 2001; standardized practice guidelines and fidelity measures (Drake et al, 2001); consultation and training (Drake et al, 2001); and the facilitation of stakeholder collaboration and consensus building toward maintaining maximal fidelity to the original innovation (Biegel et al, 2003).

‘Tool kits' are essentially implementation manuals with information targeted to specific sub-groups of end-users, such as consumers, clinical supervisors, and mental health administrators (Drake et al, 2001). Tool kits are typically disseminated through educational outreach (a.k.a. 'academic detailing') in the forms of workshops and consultations aimed at promoting the faithful implementation of evidence-based practices 
among knowledge users; fidelity is monitored through a variety of methods including observation and fidelity scales (Drake et al, 2001).

Specific technical assistance programs are being developed to facilitate the widespread implementation of the IDDT model. One such technical assistance program is the Ohio SAMI (substance abuse and mental illness) CCOE (coordinating center of excellence). Biegel el al (2003, p.534) explained services offered by the Ohio SAMI CCOE as : “...assisting programs to implement and maintain high fidelity to the IDDT..." through offering “...training and technical assistance, dissemination, and research to mental health and substance abuse programs...”. In conceptualizing how agencies implement the IDDT, staff at the Ohio SAMI CCOE draw from an adaptation of a stages of change model (Boyle \& Kroon, 2006):

A stage-wise process for EBP implementation suggests a useful application of the stages of change to organizational development in a somewhat prescriptive manner. Stage-wise change has been described for both individuals and organizations in an overlapping yet progressive sequence from precontemplation of the problem to contemplation, followed by determination, action, and maintenance or sustaining behaviors. (p. 75)

With regards to fidelity and organizational variations from the IDDT model that may occur, Biegel et al (2003) stated:

The SAMI CCOE supports fidelity to the IDDT model while appreciating the need for adaptations to the many service systems and situational challenges occurring in Ohio. Ongoing state- and county-level collaborations are essential among currently parallel mental health, substance use, criminal justice, housing, 
and vocational rehabilitation systems for model fidelity to be maximally sustained (p. 535)... The CCOE's experience in Ohio, a state with a wide range of contextual variation, suggests that adaptations to the original IDDT model are likely. It is hoped that careful monitoring of modifications as they occur naturally will encourage the flexibility necessary for evidence-based practice implementation in diverse settings without sacrificing the most salient elements of the model. It is expected that in this way a knowledge base about the parameters of a successful adaptation will be developed... (p. 543)

\section{'Implementation': Entailing both Linear and Cyclical/Nonlinear Processes}

In contrast to more cautious views on adaptations/variations from fidelity held by many working from predominantly linear implementation approaches, approaches to implementation focusing on both linear and cyclical/nonlinear processes typically actively pursue what can be construed as positive variations on existing practices (Litaker et al, 2006). Litaker et al (2006) elaborate on positive variance as follows:

... standardizing care without identifying desirable variation or unique adaptations that take advantage of local opportunities and strengths (sometimes referred to as "positive variation" or "positive deviance") misses an important opportunity to identify and investigate unanticipated circumstances or locally adapted practice configurations associated with better health outcomes. The importance of the context within which a practice is situated is evident when efforts to apply an intervention in one setting yield unexpected results in another. For this reason, others have emphasized the need to understand the interplay 
between context, structure and process as a necessary antecedent to designing and implementing interventions that seek to improve outcomes. (p. S30)

Given interventions and practices are thus approached as needing to be contextually adapted as well as utilized in a way that preserves or increases positive related outcomes.

Ruhe et al (2005) exemplified such an approach through their analysis of a specified meso-focused intervention to facilitate increases in preventative service delivery in primary care. This intervention was tested via a STEP-UP (Study to Enhance Prevention by Understanding Practice) clinical trial, and findings showed sustainable increases in preventative care. Ruhe et al (2005) then conducted a retrospective analysis on how this intervention was tailored to specific practice contexts, and concluded: "Taking the time to individualize interventions to fit evolving conditions and needs of the clinical practice environment is beneficial to the long-term sustainability of change efforts" (p. 733).

Lee and Garvin (2003) and Marshall et al (2001) likewise focus specifically upon specific relational and contextual aspects involved in the application and modification of (micro-focused) evidence-based practice innovations. Marshall et al (2001) asserted that cyclical processes of consensus building "may be used to adapt best practice models to meet unique needs within local communities" (p. 105). This is in contrast to many who utilize linear transfer implementation approaches and tend to view consensus building as a vehicle to maximize fidelity to a given EBP.

Toward meeting local needs in specific communities, Natasi (2000), alongside atrisk teens and other stakeholders in Sri Lanka, facilitated the adaptation and coimplementation of a sexual risk prevention model in Sri Lanka through iterative action 
research processes which she deemed the 'participatory intervention model' (PIM). This PIM (a meso-focused intervention approach) integrated traditional research-based knowledge and principles about sexual risk prevention imported from other cultures, with contextually relevant and locally invented practices, rather than privileging fidelity to any one imported intervention model (Natasi, 2000). Natasi (2000) offered the term "ecological validity" to depict what was being sought after and created through this collaborative endeavor, defining ecological validity as: “...the culture- or context specificity of interventions...", thus, "we go beyond the notion of acceptability as the consumers' perceptions of the intervention as useful, feasible, effective with their worldviews, to include involvement, ownership and empowerment of stakeholders... the goals of acceptability are extended beyond integrity and efficacy to include institutionalization and sustainability of intervention efforts" (p. 209).

Lee and Garvin's (2003) practice adaptation approach is very similar to those described above, and can be summarized as follows:

1) End-users should be active rather than passive recipients of the 'expert' knowledge through the use of two-way communication and information exchanges (between researchers and other stakeholders), rather than information transfers (from researchers to other stakeholders).

2) Evidenced-based innovations should be treated as dynamic and contextdependent.

3) Adaptability of an innovation to local needs should be prioritized over traditional research conventions which privilege fidelity. 
Lee and Garvin (2003) thus made three assertions about what the nature of ideal implementation activities should pertain to: 1 ) the nature of the properties (dynamic and context-dependent) of an applied practice innovation; 2) the nature of the interrelationships and communications (multidirectional communication) between traditional researchers and other stakeholders; and 3) the nature of appropriate implementation (adapting/reinventing) of an innovation.

\section{Four Implementation Dimensions: the Problem, the Innovation, the Communication, and the Appropriate Implementation Activities}

In considering linear and cyclical/nonlinear views on implementation, it appeared to me as though variability falls along these three dimensions pointed to by Lee and Garvin (2003): the nature of the practice innovation; the nature of the communications between stakeholders; and the nature of what is considered to be appropriate implementation. In addition, the nature of the problem being addressed-Small's (1995) ill-structured problems versus Fixsen's (2005) well-defined problems-also seemed to be a recurrent theme around which variability is evident. In revisiting the notions of stakeholder perspective and collaboration-as discussed early on in this chapter-I speculate that a given implementation effort may indeed entail an entangled web of continuums in terms of stakeholder perspectives on the nature of these four things.

The nature of the problem at-hand (ill-structured vs. well-defined) that a given group of individuals is attempting to address by implementing a practice may at first glance seem to be the pivotal dimension in an implementation effort. A clear cut problem that is defined and viewed as more or less the same from all perspectives, and that once 
solved has a solution that is applicable wherever the problem is encountered (Fixsen et al, 2005; Small, 1995), would point to a linear implementation model with the aim of replicating the discovered solution through predominantly linear knowledge transfer. Conversely, an amorphous problem which has a definition that varies as a function of the particular situational circumstances and stakeholder perspective, would suggest a need to create and implement through iterations of knowledge exchange a specific and locally relevant innovation.

The nature of the properties (dynamic and context-dependent vs. fixed and portable) of a given innovation to be implemented would seemingly coincide with the nature of the problem, as would the nature of appropriate implementation activities (adapting/reinventing an innovation vs. replication) and the nature of stakeholder communication (knowledge transfer vs. knowledge exchange). Yet, there are clearly middle grounds in each of these dimensions of implementation, as exemplified by the work of Lee and Garvin (2003) and Marshall (2001). And as previously stated, what is framed as the implementation of a predominantly micro-focused EBP (entailing a welldefined problem, knowledge transfer, and replication implementation) typically also entails implementing related and often context-dependent changes (a.k.a.-ill-structured problems) at organizational and policy levels.

Likewise, what is framed as a policy implementation typically necessitates implementation of related changes at the organizational and direct practice levels. It is thus likely that any given implementation effort entails a dynamic web of stakeholder perspectives (and their related behaviors) pertaining to the nature of the problem, innovation, communication and appropriate implementation activities, all of which may 
be interrelated to varying degrees. As Aaron et al (2007) said: "To some extent, the nature of the process, problems and solutions may be dependent on the perspectives and experiences of a given stakeholder group" (p.411).

In order to encompass and begin to integrate the variation across (and within!) stakeholder perspectives on each of the four proposed dimensions of implementation, which may be occurring in any given implementation effort, I framed each of the four identified dimensions of implementation as continuums (Figure 1). Thus, nature of the problem can be characterized as ranging from highly well-defined to extremely illstructured, as illustrated in Figure 1. Likewise, the nature of innovation can be viewed as ranging from extremely portable with fixed components, to highly dynamic and contextdependent. The nature of stakeholder communications would similarly range from predominantly unidirectional knowledge transfer, to multidirectional knowledge exchange. And, the nature of appropriate implementation activities would range from aiming for strict innovation replication, to striving to create and implement a highly context-dependent and locally relevant innovation.

Based on my review of literature, which pointed to the importance of intersecting of different stakeholder perspectives (i.e.--collaborating between representatives of multiple stakeholder groups) as well as the complexities of processes entailed in implementation efforts, I considered the dimensions of implementation as grounded within particular standpoints. To crudely illustrate the relevance of stakeholder standpoint in understanding an implementation, Figure Two depicts the dimensions of implementation in part as a function of the intersecting of stakeholder standpoints, using researcher and practitioner standpoints as an exemplar. 


\section{Figure 1. Four Dimensions of Implementation}

Nature of the problem to be addressed

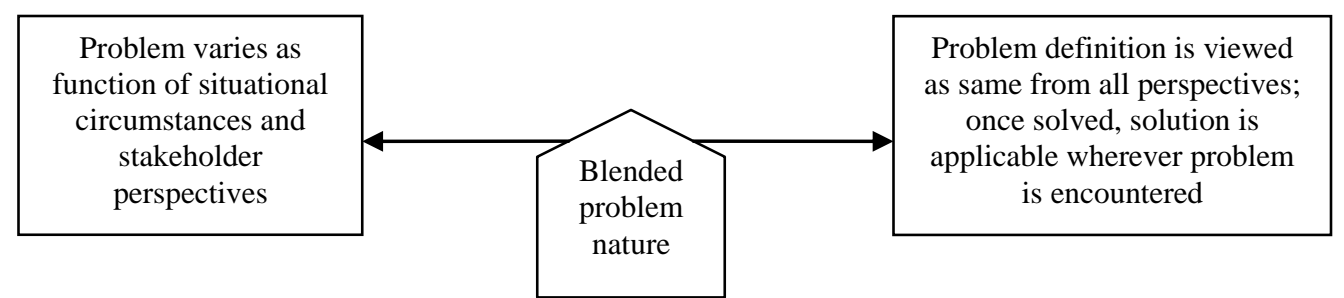

Nature of the properties of the innovation (fixed vs. dynamic) in addressing the problem

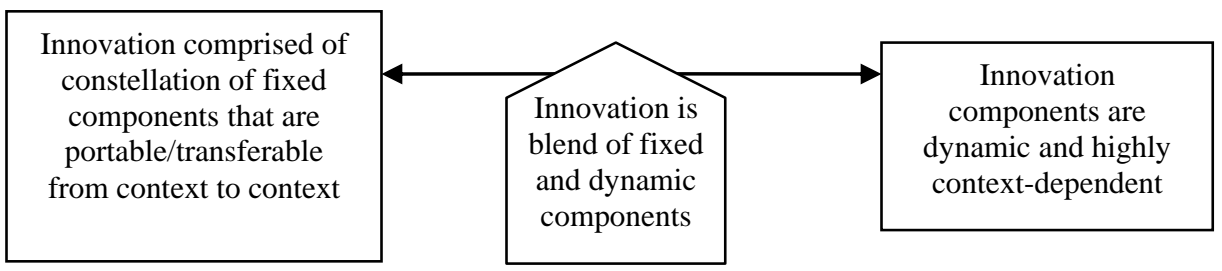

Nature of the communications (multi-directional knowledge exchange vs. linear knowledge transfer) between stakeholders

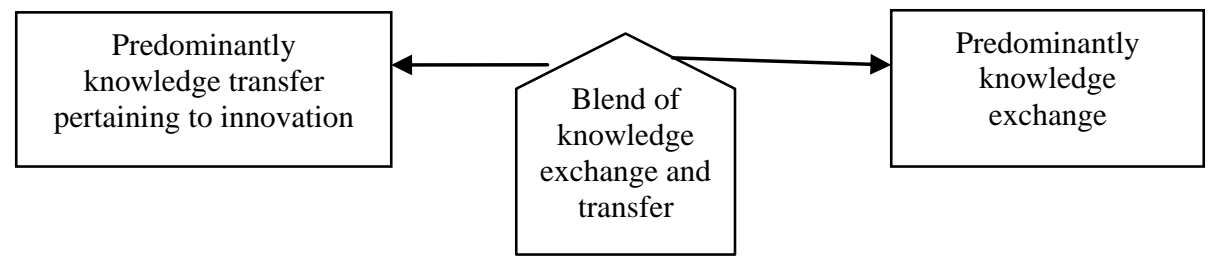

Nature of appropriate implementation activities

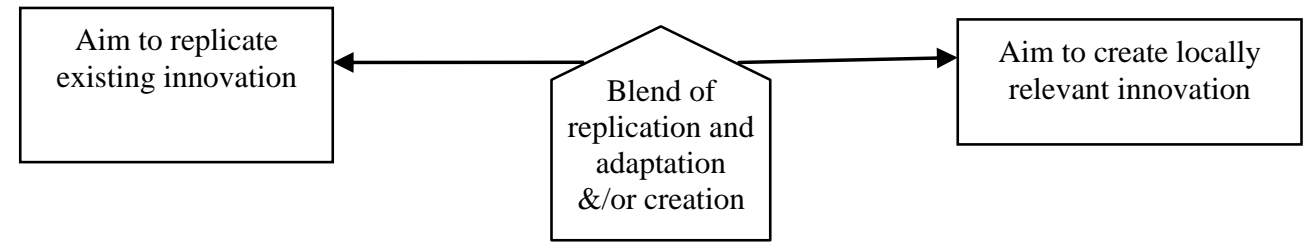


(This is not to suggest that there are not many other variations of stakeholder perspective intersections that could be similarly depicted, such as practitioner and policy maker, policy maker and researcher, etc. Although not explicitly addressed in the literatures reviewed, I adamantly believe that there is variation within as well as between stakeholder groups, and am in no way indicating a belief in homogeneity within stakeholder groups, although the oversimplified illustration I am using may suggest that ...)

The first quadrant in Figure Two illustrates both researchers and practitioners having active roles in the defining the problem, innovation and implementation agenda via multi-directional knowledge transfer. In the second quadrant, practitioners are creating highly contextually specific practices to address local and specific problems, perhaps drawing upon research-derived knowledge learned in trainings or books, but with actual researchers not in an active role. The third quadrant depicts the recipient role of the practitioner and the active role of the researcher in a classic EBP knowledge transfer scenario. And in the fourth quadrant, the vague and unexplicated diffusion and uptake of practices is represented. I use the terms active and passive to reflect the nature of communication between the stakeholders, with passive referring to being a recipient (of a linear knowledge transfer) or absent, and active referring to participating in multidirectional knowledge exchange (co-creation/adaptation-focused). 


\title{
Figure 2. Intersecting stakeholder standpoints and four implementation dimensions
}

\section{$\underline{\text { Practitioners }}$}

\author{
Active \\ Passive
}

\section{$\underline{\text { Researchers: }}$}

Active

Passive

\section{Quadrant One - problem and implementation agenda collaboratively defined:}

Practitioners and academic researchers as cocreators of knowledge (Bradbury \& Reason, 2003); 'Mode 1.5' research (Huff, 2000); often involves use of consensus-building models; coalition-building; action research; participatory research; empowerment research; feminist methods; practitioner-researcher model.

Innovation/implementation approach $=$ dynamic/adaptive or blend of dynamic/adaptive \& fixed/fidelity-focused

\section{Quadrant Three - problem and implementation agenda predominantly defined by traditional researcher or other related proponent:}

Practitioners as end-users of knowledge (Rogers, 1995); 'Mode 1' research (Gibbons et al, 1994); agricultural extension models - other stakeholders as 'knowledge recipients' (Fliegel, 1993); social marketing models - other stakeholders as 'target population' (Wiebe, 1952).

Innovation/implementation approach $=$ fixed/fidelity-focused

Quadrant Two - problem implementation agenda predominantly defined by practitioners:

Practitioners, clients, etc. in dual roles of knowledge creator and knowledge users; 'Mode 2 ' research (Gibbons et al, 1994); may involve use of program and practice evaluation methods, applications of action research, grassroots activism, making tacit knowledge explicit.

Innovation/implementation approach =dynamic/adaptive

\section{Quadrant Four - no clear definer} of problem and implementation agenda:

'Spontaneous, unplanned spread of new ideas' (Rogers, 1995, p. 7); natural diffusion of technologies/ free market forces.

Innovation/implementation approach $=$ unknown, dynamic/adaptive and/or linear/fidelity-focused?

Each quadrant offers a crude representation of a perspective intersection in a

given type of implementation endeavor. However, the dynamic processes occurring between the multiplicity of perspectives people have on (and subsequent choices and 
behaviors pertaining to) a given implementation effort are far more complicated that can be pictorially depicted.

\section{Ethnography: a Way to Get Up-Close Implementation Process Information}

The need for more process research to better understand the phenomenon of an "implementation" is well-articulated across the social policy literature (Lennon \& Corbett, 2003), OB literature (Pettigrew, 1995, 1997) and EBP discourse (National Institute of Mental Health, 2002, 2005). Because ethnography is identified a the method of choice for answering ' $h o w$ ' questions pertaining to implementation (Mosse, 2003; Schultze \& Boland, 2000; David, 2003; Werner, 2004; Pettigrew, 1997), I again turned to the literature, this time seeking out recent ethnographies on implementation efforts in complex service settings (involving interactions between multiple individuals and locations). My search was not meant to be exhaustive, but rather, to generally assess current and emergent understandings (of social processes within implementation efforts) derived from recent ethnographic efforts.

\section{Search Methods}

The Electronic Journal Center (EJC)-an online database of peer-reviewed journals created through a consortium of university and college libraries across state of Ohio-contains a vast collection of peer-reviewed journals from a multitude of academic disciplines. Specifically, the EJC contains more than 6,400 journals, 354,000 issues and 6.39 million articles from over 80 academic publishers. The contents of the EJC are divided into the following eleven academic subject categories: 
1. Arts and Humanities

2. Business, Economics, and Management

3. Chemistry and Chemical Engineering

4. Computers and Computer Science

5. Earth Sciences

6. Engineering

7. Health Sciences and Medicine

8. Life Sciences

9. Mathematics

10. Physics and Astronomy

11. Social Sciences

The following Boolean logic search expression criteria were used to retrieve ethnography articles from the EJC:

- $\quad$ Published in English no earlier than 2000

- The title, abstract, and/or author-identified key words contain "ethnography" and "implement*" (all derivatives of implement, such as implementation, implementing, implemented, etc.)

- $\quad 73$ articles retrieved

\section{Findings}

I did a preliminary review of all articles retrieved, and excluded articles that did not report on findings of specific empirical studies (empirical findings reports of specific 
ethnographies) on implementation efforts in complex service settings (involving

interactions between multiple individuals and locations). A total of ten articles remained,

and are summarized in Table 2.

Table 2

Ethnographies of Implementations (continued next page)

\begin{tabular}{|c|c|c|c|c|}
\hline Author(s) \& year & $\begin{array}{l}\text { What was } \\
\text { implemented }\end{array}$ & $\begin{array}{l}\text { Ethnographic field } \\
\text { (geographic and/ or } \\
\text { processes) }\end{array}$ & $\begin{array}{l}\text { Stated focus of } \\
\text { ethnography }\end{array}$ & Findings \\
\hline $\begin{array}{l}\text { Angus, Hodnett \& } \\
\text { O'Brien-Pallas, } \\
2003\end{array}$ & $\begin{array}{l}\text { Evidence-based } \\
\text { post-partum } \\
\text { nursing practices }\end{array}$ & $\begin{array}{l}\text { Geographic -two } \\
\text { hospitals }\end{array}$ & $\begin{array}{l}\text { To determine if/how } \\
\text { a marketing strategy } \\
\text { stimulated desired } \\
\text { behavior changes; } \\
\text { to describe key } \\
\text { aspects of each } \\
\text { setting which } \\
\text { constrained or } \\
\text { supported } \\
\text { innovation adoption }\end{array}$ & $\begin{array}{l}\text { Influence of social context } \\
\text { is significant on } \\
\text { interventions designed to } \\
\text { implement EBPs; nursing } \\
\text { activities within discrete } \\
\text { settings seem to be } \\
\text { affected by influences } \\
\text { originating beyond those } \\
\text { settings }\end{array}$ \\
\hline $\begin{array}{l}\text { Chieh Lee \& } \\
\text { Myers, } 2004\end{array}$ & $\begin{array}{l}\text { ERP - software } \\
\text { that integrates all } \\
\text { business } \\
\text { functions and } \\
\text { processes }\end{array}$ & $\begin{array}{l}\text { Geographic-one } \\
\text { company and the } \\
\text { large conglomerate } \\
\text { of companies in } \\
\text { which it was a part } \\
\text { of }\end{array}$ & $\begin{array}{l}\text { To understand and } \\
\text { explain how } \\
\text { conflicts over } \\
\text { implementation } \\
\text { strategy (aka - the } \\
\text { 'changing strategic } \\
\text { context') can affect } \\
\text { implementation }\end{array}$ & $\begin{array}{l}\text { As the power-holding } \\
\text { individuals and political } \\
\text { agendas at the corporation } \\
\text { changed, so too did the } \\
\text { company's } \\
\text { implementation strategy }\end{array}$ \\
\hline Coffield, 2002 & $\begin{array}{l}\text { The Indiana } \\
\text { Manpower } \\
\text { Placement and } \\
\text { Comprehensive } \\
\text { Training } \\
\text { Program } \\
\text { (developed in } \\
\text { response to } \\
\text { welfare reform } \\
\text { policies) }\end{array}$ & $\begin{array}{l}\text { Social processes } \\
\text { and geographic-the } \\
\text { complex of social } \\
\text { relations in this } \\
\text { practice change is } \\
\text { entered via the } \\
\text { standpoint of } \\
\text { 'welfare reliant } \\
\text { mothers' in Indiana }\end{array}$ & $\begin{array}{l}\text { Explore how policy } \\
\text { is being } \\
\text { implemented via } \\
\text { tracing processes } \\
\text { and disjunctures } \\
\text { beginning from } \\
\text { welfare reliant } \\
\text { mothers' } \\
\text { experiences of that } \\
\text { policy }\end{array}$ & $\begin{array}{l}\text { Through restrictive } \\
\text { policies, welfare reliant } \\
\text { mothers are forced into } \\
\text { low wage labor market } \\
\text { which actually increased } \\
\text { their poverty }\end{array}$ \\
\hline
\end{tabular}


Table 2

\section{Ethnographies of implementations (continued next page)}

\begin{tabular}{|c|c|c|c|c|}
\hline Author(s) \& year & $\begin{array}{l}\text { What was } \\
\text { implemented }\end{array}$ & $\begin{array}{l}\text { Ethnographic field } \\
\text { (geographic and/or } \\
\text { processes) }\end{array}$ & $\begin{array}{l}\text { Stated focus of } \\
\text { ethnography }\end{array}$ & Findings \\
\hline David, 2003 & $\begin{array}{l}\text { Distance } \\
\text { learning } \\
\text { packages }\end{array}$ & $\begin{array}{l}\text { Geographic and } \\
\text { social processes - } \\
\text { Three distance } \\
\text { learning centers in } \\
\text { three different } \\
\text { countries; } \\
\text { communications } \\
\text { between centers and } \\
\text { package developers }\end{array}$ & $\begin{array}{l}\text { How are } \\
\text { weaknesses } \\
\text { produced by } \\
\text { economic and } \\
\text { geographic isolation } \\
\text { reproduced in } \\
\text { virtual domains? } \\
\text { How can new } \\
\text { distance learning } \\
\text { tech help redress } \\
\text { this? }\end{array}$ & $\begin{array}{l}\text { Technical networks are } \\
\text { social networks, and social } \\
\text { networks are political } \\
\text { networks; resource } \\
\text { allocation was } \\
\text { inadvertently biased } \\
\text { toward those with the least } \\
\text { economic and geographic } \\
\text { isolation; whatever the } \\
\text { potential of the new } \\
\text { packages, it is the social } \\
\text { relations of their } \\
\text { applications that shapes } \\
\text { outcomes }\end{array}$ \\
\hline $\begin{array}{l}\text { Hamman \& Lane, } \\
2004\end{array}$ & $\begin{array}{l}\text { Federal } \\
\text { Comprehensive } \\
\text { School Reform } \\
\text { Demonstration } \\
\text { Program }\end{array}$ & $\begin{array}{l}\text { Geographic and } \\
\text { social processes - } \\
\text { two state education } \\
\text { agencies (in Maine } \\
\text { and Puerto Rico) } \\
\text { and the processes } \\
\text { through which they } \\
\text { interpret federal } \\
\text { policy }\end{array}$ & $\begin{array}{l}\text { To study the } \\
\text { adaptation of } \\
\text { federal education } \\
\text { policy at the state } \\
\text { education agency } \\
\text { (SEA) level }\end{array}$ & $\begin{array}{l}\text { SEA staff members } \\
\text { inevitably adapt federal } \\
\text { initiatives, often through } \\
\text { mediation processes; } \\
\text { adaptations may improve } \\
\text { local intelligibility and } \\
\text { persuasiveness; } \\
\text { adaptations may be a key } \\
\text { component of a policy's } \\
\text { ultimate viability }\end{array}$ \\
\hline Harper, 2005 & $\begin{array}{l}\text { DOTS - an } \\
\text { evidence-based } \\
\text { intervention for } \\
\text { the control of } \\
\text { tuberculosis } \\
\text { (TB) }\end{array}$ & $\begin{array}{l}\text { Geographic - staff } \\
\text { in hospitals, health } \\
\text { posts and TB clinics } \\
\text { in Nepal }\end{array}$ & $\begin{array}{l}\text { To study how } \\
\text { DOTS was taken up } \\
\text { and translated into } \\
\text { practice within } \\
\text { existing health } \\
\text { services in Nepal }\end{array}$ & $\begin{array}{l}\text { Tightening of the } \\
\text { definitional categories (as } \\
\text { per DOTs protocol) had } \\
\text { profound effects in } \\
\text { marginalizing some } \\
\text { people from treatment }\end{array}$ \\
\hline $\begin{array}{l}\text { Koh, } \\
\text { Gunasekaran, } \\
\text { Thomas \& } \\
\text { Arunachalam, } \\
2005\end{array}$ & $\begin{array}{l}\text { Knowledge } \\
\text { management } \\
\text { model }\end{array}$ & $\begin{array}{l}\text { Geographic - call } \\
\text { center for a } \\
\text { company with } \\
\text { multiple locations }\end{array}$ & $\begin{array}{l}\text { To evaluate the } \\
\text { need for knowledge } \\
\text { management in a } \\
\text { call center; to } \\
\text { compare benefits } \\
\text { against efforts of } \\
\text { implementing the } \\
\text { knowledge } \\
\text { management model }\end{array}$ & $\begin{array}{l}\text { Comparison of the } \\
\text { benefits against the efforts } \\
\text { clearly justified } \\
\text { knowledge management } \\
\text { efforts }\end{array}$ \\
\hline $\begin{array}{l}\text { Marci, } \\
\text { Tagliaventi, } \\
\text { Bertolotti, } 2001\end{array}$ & $\begin{array}{l}\text { A new } \\
\text { information } \\
\text { system }\end{array}$ & $\begin{array}{l}\text { Geographic and } \\
\text { social processes - an } \\
\text { Italian firm that } \\
\text { manufactures } \\
\text { staircases, and the } \\
\text { social processes } \\
\text { between those } \\
\text { within the firm }\end{array}$ & $\begin{array}{l}\text { What are the ways } \\
\text { in which the social } \\
\text { network influences } \\
\text { (and is influenced } \\
\text { by) innovation } \\
\text { paths? }\end{array}$ & $\begin{array}{l}\text { When early adopters of an } \\
\text { innovation hold a core } \\
\text { position in the social } \\
\text { network, they tend to } \\
\text { maintain and reinforce } \\
\text { their centrality; early } \\
\text { adopters on the peripheral } \\
\text { of the social network, do } \\
\text { not change/improve }\end{array}$ \\
\hline
\end{tabular}


Table 2

\section{Ethnographies of Implementations (final section)}

\begin{tabular}{|c|c|c|c|c|}
\hline Author(s) \& year & $\begin{array}{l}\text { What was } \\
\text { implemented }\end{array}$ & $\begin{array}{c}\text { Ethnographic field } \\
\text { (geographic and/or } \\
\text { processes) }\end{array}$ & $\begin{array}{l}\text { Stated focus of } \\
\text { ethnography }\end{array}$ & Findings \\
\hline $\begin{array}{l}\text { Penn-Kekana, } \\
\text { Blaauw, \& } \\
\text { Schneider, } 2004\end{array}$ & $\begin{array}{l}\text { Public sector } \\
\text { financial } \\
\text { management } \\
\text { reform }\end{array}$ & $\begin{array}{l}\text { Geographic - two } \\
\text { labor wards (one } \\
\text { rural and one urban) } \\
\text { in district hospitals } \\
\text { in South Africa }\end{array}$ & $\begin{array}{l}\text { What are the factors } \\
\text { that influence } \\
\text { everyday mid-wife } \\
\text { practice during the } \\
\text { implementation of } \\
\text { the financial } \\
\text { reforms? }\end{array}$ & $\begin{array}{l}\text { The financial reform, } \\
\text { which aimed to increase } \\
\text { efficiency and } \\
\text { accountability, had the } \\
\text { unintended consequence } \\
\text { of causing maternal health } \\
\text { services to deteriorate; } \\
\text { more attention needs to be } \\
\text { given to socio-political } \\
\text { context and process issues } \\
\text { in implementation efforts }\end{array}$ \\
\hline Siegel, 2005 & $\begin{array}{l}\text { Research-based } \\
\text { model of } \\
\text { cooperative } \\
\text { learning }\end{array}$ & $\begin{array}{l}\text { Geographic }-5 \\
\text { middle school } \\
\text { teachers within a } \\
\text { given school district }\end{array}$ & $\begin{array}{l}\text { To explore } \\
\text { variations in teacher } \\
\text { implementation of a } \\
\text { research-based } \\
\text { model of } \\
\text { cooperative learning }\end{array}$ & $\begin{array}{l}\text { When attempting to } \\
\text { implement the cooperative } \\
\text { learning lessons, teachers } \\
\text { may benefit from attention } \\
\text { to teacher and student } \\
\text { roles, curricular } \\
\text { requirements, instructional } \\
\text { time, and classroom } \\
\text { management skills }\end{array}$ \\
\hline Woogara, 2005 & $\begin{array}{l}\text { Human Rights } \\
\text { Act, } 1998 \text { ( a } \\
\text { policy passed in } \\
\text { the United } \\
\text { Kingdom, aimed } \\
\text { at increasing } \\
\text { patient privacy in } \\
\text { healthcare) }\end{array}$ & $\begin{array}{l}\text { Geographic - three } \\
\text { acute care wards in } \\
\text { a large hospital }\end{array}$ & $\begin{array}{l}\text { To determine the } \\
\text { extent to which } \\
\text { health professionals } \\
\text { upheld the } \\
\text { philosophy of the } \\
\text { Human Rights Act, } \\
1998\end{array}$ & $\begin{array}{l}\text { Patients had little personal } \\
\text { and information privacy in } \\
\text { the wards; principles of } \\
\text { the Human Rights Act } \\
\text { typically not observed in } \\
\text { everyday practice }\end{array}$ \\
\hline
\end{tabular}

In considering the ethnographies summarized in Table Two, most of the findings generally and/or specifically underscored the importance of social context and social processes in given implementation efforts (Angus et al, 2003; Chieh Lee \& Myers, 2004; Cottfield, 2002; David, 2003; Hamman \& Lane, 2004; Marci et al, 2001; Penn-Kekana et al, 2004; and Siegel, 2005). Not surprisingly, studies in which the field site was implicitly or explicitly expanded to include social processes extending beyond specified geographic boundaries, presented more explicit, richly detailed information the 
interconnections between such processes and contexts in implementation endeavors (Cottifield, 2002; David, 2003; Hamman \& Lane, 2004; and Marci et al, 2001).

Unlike the other studies which addressed social processes extending beyond geographic field site without explicitly defining the field to include both, Coffield's (2002) ethnography of experiences of mothers in the welfare system explicitly defined the ethnographic field site as the institutional field of social processes in which the implementation was occurring rather than a specific geographic region such as an agency or neighborhood, while specifying the welfare policy was being implemented in Indiana. Cottfield's (2002) ethnography was also unique from the others, in that the standpoint of mothers receiving welfare was explicitly identified as the perspective from which the researcher was seeking to understand the implementation phenomenon.

Coffield (2002) identified the particular ethnographic method utilized to be an institutional ethnography (IE). According to Smith (1999), who developed IE, IEs involve an explicit methodological focus on institutionalized relations embedded in and extending beyond specific individual experiences. Of all the ethnographic approaches encompassed in the articles I reviewed, IE seemed particularly suited to generating process-related information in multi-level implementation endeavor, and to linking such processes to a specific stakeholder perspective (which appears to be a potentially salient factor in implementation research).

\section{Conclusion}

Within and across stakeholder perspectives, communities of knowing, academic discourses, and so forth, there are varying and at times contradictory conceptualizations of implementations. Most contemporary conceptualizations of implementation converge 
on implementation as a multi-level (individual, organizational and system) phenomenon, and diverge on whether implementation is a process distinct from (information technology and evidence-based practice discourse) or embedded within (social policy, organizational behavior) the creation of new practices. Conceptualizations pertaining to what is being implemented similarly diverge, regarding whether what is being implemented is a 'finished product' (variance is typically construed negatively), a highly variable, ongoing 'work-in-progress', or some combination of the two (positive variance to a pre-existing practice).

Such varying conceptualizations, along with a cross-literature identified need for more research on the complexities of interconnected social processes (collaborative or otherwise) entailed in implementations, point to a need to conduct more up-close, exploratory studies of actual implementation efforts that take into consideration stakeholder perspectives. Studies on how social processes span micro and macro contexts were also identified as promising in furthering understandings of how an implementation occurs (Linton, 2002; Wedel et al, 2005).

Ethnography and participant observation were identified as methods of choice for answering 'how' questions pertaining to implementation (Mosse, 2003; Schultze \& Boland, 2000; David, 2003; Werner, 2004; Pettigrew, 1997). Ethnographies, in which the field is defined through extended social processes, rather than through strictly geographic boundaries, hold particular promise for explicating the social processes that span micro and macro contexts in implementation efforts (Wedel et al, 2005; Smith, 2005). Such ethnographic studies could contribute to untangling and explicating the webs of activities involved in actual implementation efforts. 


\section{CHAPTER 3: RESEARCH DESIGN AND METHODS}

\section{Introduction and My Standpoint}

Based on what was pointed to in the literature on implementation, I decided to do a process-focused ethnographic study of an implementation endeavor within a complex system. However, I wanted to do something that would also be potentially useful to the Ohio public mental health system, which I have worked in for over a decade. Ohio's public mental health system is currently undergoing a massive transformation effort, toward a mental health recovery-driven service system. Ohio was recognized by the National Alliance on Mental Illness (NAMI) as one of the two best state mental health systems in the country, in a state-by-state analysis of mental health systems conducted by NAMI (2006), based on rankings for recovery supports, services, information access and infrastructure. While there are numerous definitions of mental heath recovery, understanding mental health recovery as a process that may include but is not limited to psychiatric symptom reduction is a common thread among them. Most ideas of mental health recovery encompass aspects such empowerment and quality of life.

While I had pre-existing interests in both implementation and mental health recovery, I wasn't sure how to approach these in a way that could be potentially useful to stakeholders within Ohio's mental health system. I asked people in various roles at various mental health agencies in Northeast Ohio what I could study that might be useful to them, and their responses were essentially a chorus of: "anything you can do to help us figure out what we're doing with the outcomes surveys would be great". 
This outcomes surveys that these particular people were referring were the Consumer Outcomes Surveys; in particular, they referenced the Adult Consumer Form (one of several Consumer Outcomes Survey instruments), which is a 67-question survey focusing on mental health recovery-focused consumer outcomes. Completion and use in treatment planning of the Consumer Outcomes Surveys is being required of community mental health centers (among other public mental health service providers) via a state mandate (Ohio Administrative Code 5122-28-04) known as the Ohio Consumer Outcomes Initiative. This mandate went into effect in September of 2003, and requires agencies to be in compliance with an $80 \%$ survey completion threshold in order to maintain certification as a public mental health service provider in Ohio.

In essence, this implementation effort can be framed as both a policy implementation, and the implementation of a micro-focused practice change via completion and use in treatment planning of a standardized, recovery-focused outcomes instrument. With regards to the micro-practice change, public mental health agencies in Ohio have not been mandated a specific mental health recovery practice model related to the Consumer Outcomes Surveys, nor was a specific way of using the instruments in treatment planning prescribed. Rather, agencies were allowed to create their own methods for how they would use Consumer Outcomes Survey data. Toward both contributing to implementation science, and to generate specific information for stakeholders in the Ohio public mental health system pertaining to implementing the Ohio Consumer Outcomes Initiative, I tutilized the institutional ethnography method (Smith, 1999, 2005) to explore the web of social processes involved in implementing the 
Ohio Consumer Outcomes Initiative, as understood and experienced from a frontline (mental health consumer and direct service provider) perspective.

In doing this institutional ethnography, I myself brought a specific perspective from which I understand the institutional field I was entering into. I came to this study as a person who has a sibling living with a severe mental illness; further, my sibling uses public mental health services in Ohio. And, I have worked in the Ohio public mental health system for nearly fifteen years, seven of which I worked as a case manager/CPST staff. I have multiple friends and acquaintances in various roles (CPST, program manager, agency director, quality assurance staff, etc.) in Ohio's public mental health system. It was in the context of casual conversations in such relationships that this study topic (the implementation of the Ohio Consumer Outcomes Initiative) emerged.

I also have had limited experience administering the Consumer Outcome Survey with new consumers through doing contract diagnostic assessment work, and have worked closely with CPST staff who were using the survey in their everyday work. I thus had preconceived notions of what kinds of experiences I might encounter. To help reduce the likelihood that I would superimpose my own thoughts and experiences upon the lived experiences of my participants, I chose to "bracket" such preconceived notions; that is, I acknowledged them as I became aware of them, noted them, and mentally set them aside so as to more clearly focus upon what my actual participants were showing me and sharing with me. I returned to, reflected upon, and sparingly referenced such bracketed thoughts (not explicitly as such, but rather, by identifying my thoughts as such) throughout the data analysis when I felt such thoughts were relevant to the data analysis. 


\section{Sampling}

\section{An Overview of the Organization of Public Behavioral Health Services in Ohio}

As explicated by Behavioral Health Generations (n.d), the public behavioral health system in Ohio consists of three layers, and two subsystems (mental health services and addiction services) (Figure 3). The first layer is at the state level, which officially includes the Ohio Department of Mental Health (ODMH), and the Ohio Department of Alcohol and Drug Addiction Services (ODADAS); these entities certify, monitor and provide primary funding (the agencies may also provide services that are not monitored, certified, or funded by ODMH and ODADAS) for the agencies providing mental health and addictions services, respectively.

ODADAS is not formally a part of the ODMH-administrated mental health system; however, it is part of the de-facto mental health system in that many ODMH contract agencies are also certified by and contracted with ODADAS; and some county boards combine administration of mental health and addictions. A second layer of administration is found at the county level; county boards serve as a conduit between the state and local provider organizations. Such boards do not provide any direct services to consumers; rather, they contract with various local agencies to provide these services. Community mental health systems are thus funded, reviewed and monitored by ODMH through one of 50 of these county-level mental health boards (board areas consist of one to five counties). Most county boards also have levies which are a significant source of funds for services. The contract (non-profit and for-profit) agencies and state hospitals providing the clinical services comprise the third layer. 
In keeping with the institutional field focus of institutional ethnography, I defined my ethnographic field as the social processes occurring within the institutional field comprised of participating mental health provider agencies, county mental health boards, $\mathrm{ODMH}$, and other entities which may be emergently identified as relevant. I entered this complex of processes through learning about and describing the standpoints of individual frontline clinician and consumers attempting to complete and use the Consumer Outcomes Survey at four community mental health centers (Smith, 1999).

Figure 3. Organization of Ohio public behavioral health services (adapted from Behavioral Health Generations (n.d))

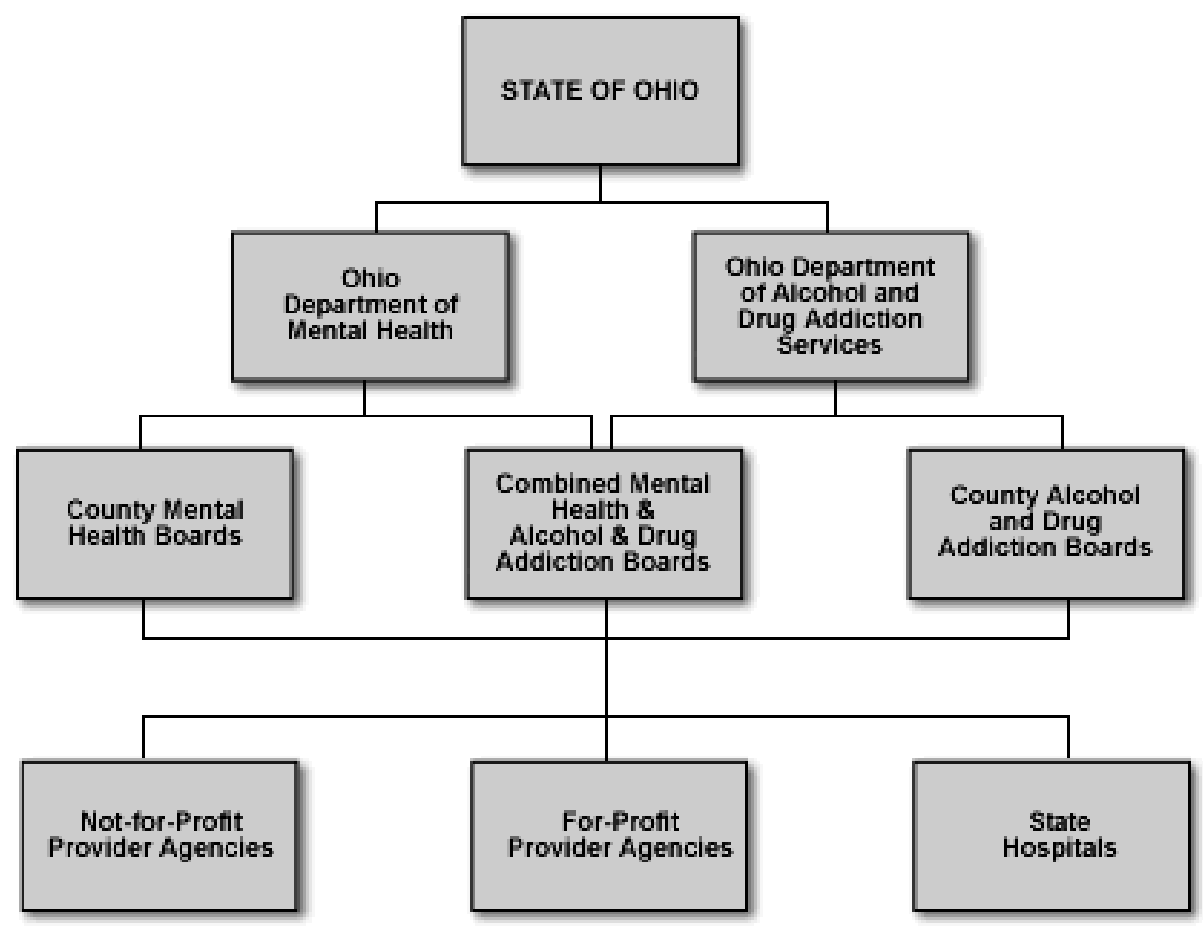




\section{The Provider Agencies and Individual Participants}

The four participating provider agencies (a.k.a.-community mental health centers) in this study are four of the largest providers of public, outpatient mental health services for adults in Ohio. Three of these four agencies are all located within the same large, predominantly urban county, and are governed by the same county mental health board (within this county, addiction services are governed by a separate board). The fourth agency also serves an urban population but is governed by a different board. My selection of these agencies was due to their size, diversity, and most of all due to the expressed interest of their administrators and clinicians early on in the formulation of this study. I approached only these four agencies, due to a prior knowledge of their potential interest in participating. No other agencies were considered or approached, thus no exclusion criteria was used. This was very much a convenience sampling strategy.

To reduce the risk of deductive disclosure, I am not presenting agency-specific demographic information, rather, I am presenting in an aggregated fashion how these agencies are similar and different from each other. The four agencies are similar in the following ways:

- $\quad$ Each has an annual operating budget of between 10 and 20 million dollars.

- $\quad$ Each employs between 60-80 CPST staff.

- $\quad$ Each serves between 3000-5000 mental health consumers.

- $\quad$ Each is headquartered in an urban setting in Ohio.

- Each has multiple "satellite offices" in both urban and suburban settings.

- $\quad$ Each serves predominantly low-income individuals.

- $\quad$ Each relies heavily on Medicaid revenue. 
These agencies differ in terms of ethnicity of the staff and clientele (predominantly Caucasian staff and consumers, predominantly African-American staff and consumers, about 50:50 Caucasian/African-American with regards to both consumers and staff, and 50:50 African-American/Caucasian consumers and predominantly Caucasian staff). The degree of compliance each agency was at in terms of submission of completed Consumer Outcomes Surveys (surveys needed to be submitted to the state for $80 \%$ of enrolled mental health consumers in order for the agency to be in compliance with the Ohio Consumer Outcomes Initiative/code) also varied greatly; only one of the four agencies was in compliance with the $80 \%$ threshold for completed Consumer Outcomes Surveys. And, three of the four agencies were operating at a budget deficit.

While two of the four agencies were multi-service centers, providing numerous services in addition to mental health services, the largest programs at each of these agencies were their outpatient behavioral health programs. All four of these agencies serve predominantly low-income clients in their outpatient behavioral health programs; the vast majority of these clients have either public health insurance (Medicaid or Medicare) or no health coverage. The participating agencies in this study offer community psychiatric supportive treatment services (formerly referred to as case management) and psychiatric services to those living with severe mental illness; these outpatient services serve to help such individuals to live as independently as possible in the community. These programs are part of a continuum of care provided in the community for individuals living with mental illness. State legislation passed in 1988 required each board-managed, local mental health system to establish a 'community support system' which includes residential, crisis, vocational, case management and 
family support services as part of the community mental health system (Behavioral Health Generations, n.d.). Community psychiatric supportive treatment programs are the current incarnation of the case management component of such a 'community support system'. It is in the context of community psychiatric supportive treatment programs that I sought to understand frontline experiences implementing the Ohio Consumer Outcomes Initiative.

To learn about and generate a detailed description of frontline experiences, and to trace the interconnected social processes related to such frontline experiences, I recruited (see the participant recruitment section in this chapter for specific information on recruitment and consent procedures) individuals from the following sub-groups:

- Community Psychiatric Supportive Treatment Staff (CPSTs): CPSTs (formerly known as 'case managers') are individuals who are employed by community mental health centers to provide the following supportive services for mental health consumers (see explanation of 'consumer' below) enrolled in a respective agency's community psychiatric supportive program: ongoing service planning and coordination; linkages to resources and other agencies; assistance in monitoring and management of psychiatric symptoms; crisis intervention; and advocacy to mental health consumers (see explanation of 'consumer' below). CPSTs function essentially in a social work capacity, although credentialing for CPST work varies widely within and between agencies in Ohio. Possible credentials held by those doing CPST work at the three participating agencies include but are not limited to: an associate degree in human service technology; a bachelor's degree in an unrelated field (i.e.- 
education) or related field (sociology, psychology); a bachelor's degree in social work or nursing with appropriate licensure; and a master's degree in social work or counseling with appropriate licensure.

- Administrators/Others: For the purposes of this study, "administrators/others" refers to a heterogeneous group of individuals working in managerial and related capacities in the public mental health system. Administrative roles may include but are not limited to: supervisor; program manager; program director; quality assurance manager; quality assurance director; training coordinator; information technology manager; chief executive officer; policy maker; and elected public official. CPST staff may also be considered an 'other', if they work in a training capacity with new staff. Employment affiliations of the administrators/others may include but are not limited to private non-profits (including but not limited to the three participating agencies) and government (city, county, state and federal) organizations.

- Consumers: "Mental health consumer" is the term used to describe those using mental health services. In this study, the term 'consumer' is used to refer to adults who are using the community support programs (CSP) at each of the participating agencies. CSP programs are targeted toward individuals who are living with a severe and chronic mental illness. Common diagnoses of those using CSP services include: schizophrenia, schizoaffective disorder, bipolar disorder, and major depression. Many people using CSP services also struggle with substance abuse and/or dependency issues. 


\section{Considering Texts as Social Processes in the Implementation Effort}

Written communication is identified as an extremely important and often overlooked kind of social process, which has a potentially much greater reach temporally and geographically than spoken communication (Smith, 2005; Wedel et al, 2005). Pence (2001) explains textual social processes as occurring though processing interchanges, as sequences of occasions in which a given text is enters a locality, is processed in some fashion (which may entail modifying, checking or creating a new related text) by a person, who may then in turn forward the text to its next destination. McCoy (1995) describes individual uses of texts in such processes as textual activation. I thus collected and reviewed written communications that I was referred to by participants, and/or observed them using, as a dimension of the interconnected social processes entailed in implementing the Consumer Outcomes Initiative. Written communications included: clinical records, e-mails, memos, tracking sheets, Ohio Administrative Codes, online manuals, and online web sites of private certification agencies. These texts comprised an additional sampling context through which I explored the interconnected processes entailed in implementing the Ohio Consumer Outcomes Initiative.

\section{What is Being Implemented: the Ohio Consumer Outcomes Initiative and the Consumer Outcomes Survey}

The Ohio Consumer Outcomes Initiative

As previously stated, all publicly-funded mental health agencies in Ohio have been explicitly mandated to implement the Consumer Outcomes Surveys within their 
existing services. Specifically, the Consumer Outcomes Initiative went into effect in September of 2003 through Ohio Administrative Code (OAC) 5122-28-04 (Appendix A), through which community mental health centers (among other provider agencies) in Ohio were mandated to complete and utilize a mental health recovery-oriented survey for at least $80 \%$ of their mental health consumers. Agencies were provided a specific implementation timeline through the mandate (Appendix A) as follows:

- Within six months of the mandate going into effect, or of an agency becoming newly certified, the agencies must be collecting outcomes data.

- Within one year of the mandate going into effect, or of an agency becoming newly certified, the agency must be flowing collected outcomes data to the Ohio Department of Mental Health (ODMH).

- Within two years of the mandate going into effect, or of an agency becoming newly certified, the agency must be able to provide evidence using the outcomes data in treatment planning and quality assurance activites.

$\mathrm{ODMH}^{1}(2002$, p.6) described the purpose of this state-wide Consumer Outcomes Initiative as follows:

1. Assist consumers and clinicians in developing treatment plan goals and measuring progress using the consumer's individual outcome scores.

2. Promote quality improvement at the agency, board and state level using aggregate consumer outcomes scores.

3. Demonstrate accountability of the public mental health system for tax dollars expended. 
Under the mandate, agencies could under some circumstances seek state approval to implement an alternative outcomes measurement system, provided the measures “...reflects the value of consumer recovery" (OAC 5122-28-04, section (C)(2)(c)(i)). Each of the four agencies participating in my study were in process of implementing the Consumer Outcomes Initiative.

\section{The Consumer Outcomes Survey}

The Adult Consumer Form (Appendix B), along with the other Consumer Outcomes Survey instruments, were developed through years of collaborative research, essentially action research, between consumers, researchers, clinicians, family members, administrators, and other mental health system stakeholders (ODMH $\left.{ }^{2}, 2002\right)$.

Conceptual work on the development of what the Consumer Outcomes Surveys measurethe idea of mental health recovery-began a over decade ago, and involved a collaborative and participatory planning process $\left(\mathrm{ODMH}^{5}, 2002\right)$.

Beginning in 1993, ODMH staff met in forums with consumers, family members, providers and other professionals to engage in a dialogue regarding what 'recovery' meant to them $\left(\mathrm{ODMH}^{5}, 2002\right)$. According to $\mathrm{ODMH}$, mental health recovery is defined as "a personal process of overcoming the negative impact of a psychiatric disability despite its continued presence" $\left(\mathrm{ODMH}^{5}, 2002\right.$, p.3). ODMH delineated an individual's movement through the recovery process as non-linear, consumer-directed, and impacted by multiplicity of factors $\left(\mathrm{ODMH}^{5}, 2002\right)$. In 1994, ODMH funded the first round of recovery pilot projects, which resulted in the development of consumer leadership, consumer computer training programs, and consumer operated organizations. The efforts 
led to the conclusion that "given the opportunity, consumers were able to set goals and achieve them" $\left(\mathrm{ODMH}^{5}, 2002\right.$, p.1). In 1995, a framework of recovery was further explored by Ohio's Community Support Council.

In addition to the facilitation of collaborative work toward the development of mental health recovery framework, ODMH, under the leadership of director Michael Hogan, convened the Ohio Mental Health Outcomes Task Force (OTF) in 1996, for the purpose of creating an outcome measurement system for state-wide use in Ohio's public mental health system $\left(\mathrm{ODMH}^{2}, 2002\right)$. The OTF was a diverse group comprised of “...consumers/survivors, family/friends of consumers/survivors, members of racial and ethnic minority groups, providers, researchers, advocates, administrators, local community mental health board member staff, and taxpayers" (Roth, 2005, p. 43).

The OTF met for sixteen months and used participatory decision processes and consensus building to develop tools for an approach to measure outcomes that embraced the values of recovery and resiliency for mental health consumers and their family members $\left(\mathrm{ODMH}^{2}, 2002\right)$. Roth (2005) described some of the specific work done by the OTF as follows:

The Ohio Outcomes Task Force (OTF) developed the Consumer Outcomes System Forms A and B [now referred to as the Adult Consumer Form], as well as the Provider Adult Form A instruments, by incorporating a substantial number of items and scales from established instruments. In addition, OTF developed some new items. The development began with OTF identifying 24 outcomes to be measured. The OTF then reviewed 126 established outcomes instruments looking for entire instruments, subscales or single items designed to measure the 
chosen outcomes. Potential instruments were reviewed based on five criteria:

Direct and Indirect Cost; Psychometric Properties; Consistency with Principles of Consumer Recovery and Empowerment; Cultural Sensitivity; Consistency with OTF Outcomes; and Consistency with Principles for Child and Adolescent Service System Program. (p. 42)

The Adult Consumer Form contains 67 items close-ended questions and Likert scale items, and is comprised of four primary scales as well as subscales and independent items (Roth, 2005). As described by Roth (2005), the four primary scales are:

- Overall Quality of Life (12 items - Cronbach's Alpha .86)

- $\quad$ Symptom Distress Scale (15 items - Cronbach's Alpha .93)

- Overall Empowerment Scale (28 items - Cronbach's Alpha .77)

- Community Activism and Autonomy (6 items - no Cronbach's Alpha listed)

With regards to field testing for specific populations, Roth (2005) indicated:

The Ohio Outcomes Survey is intend for use and has been tested with adults from diverse ethnic/racial backgrounds who have been diagnosed with a serious mental illness or who have a dual diagnosis. During testing, consumers from the following racial/ethic backgrounds were included in the sample. American Indian or Alaska Native, Asian, Black or African American, Native Hawaiian or Other Pacific Islander, White, Hispanic or Latino, and African Somali. (p.44-45) Per ODMH (2005), normative data run showed no statistically significant differences on race.

Currently, community mental health stakeholder systems across the state of Ohio are in various stages of implementing of the Consumer Outcomes Initiative, as well as 
developing meaningful integration of the Consumer Outcomes Surveys within the provision of agency services. According to $\mathrm{ODMH}^{6}$ (2005), fifty of fifty local community mental health boards representing 309 provider agencies are in various stages of implementing the Ohio Consumer Outcomes Initiative, with outcomes information collected on 323,943 unique clients.

\section{Procedures for Recruitment, Consenting and Compensation of Participants}

Through consultation with representatives from each of the four agencies, and in keeping in mind human subjects protection issues, I developed a specific recruitment plan. For three of the four participating mental health agencies, I began recruitment by speaking at a routine CPST staff team meeting. I presented a 10 minute overview of the study questions and procedures, as explicated in the consent forms for CPST staff (Appendix D). This presentation was prefaced by the CPST supervisor introducing me and stating (using a script I provided): "Participation in this study is completely voluntary; it is in no way a condition or expectation of your employment. Janet will now share some information about the study with you. If you decide you are interested in participating, please contact Janet individually for more information." After presenting an overview of the study, I paraphrased from the following script: "Participation in this study is voluntary. Not participating, or withdrawing from the study after you have been participating, will in no way impact your relationship with your employer, Case Western Reserve University, or any cooperating agency. If you are interested in participating, please contact so we can meet individually and I can give you more information. If you decide you want to participate, I will ask you to sign a consent form at that time." 
I then handed out flyers (Appendix C) to all CPST staff at the meeting, and left extra flyers for any staff who were unable to attend. These flyers were placed in the absent staffs' mail boxes for them to review at their leisure. The flyer included my e-mail and phone number.

I began recruitment at the fourth mental health center in a different fashion per the request of administrators at fourth participating mental health center. I sent my CPST recruitment flyer (Appendix C) electronically to the director of programs. The director of programs forwarded my flyer to all CPST staff as an attachment, using the following email script: Hello, Attached is information about an opportunity for you to participate in research that will be occurring at (Agency Name). Your participation in this study would be on a voluntary basis, and in no way an expectation of your employment. If you are interested in participating, please contact Janet Hoy, co-investigator for the study-her contact information is on the flyer. Thanks. When interested CPST staff contacted me via e-mail or phone, I thanked them for their interest and set up a meeting at a location convenient for them; all CPSTs requested that we meet at their offices. I then answered their questions and reviewed the consent form with them. Each CPST signed the consent at that time, and I provided them with a copy of the consent form. A total of 9 CPSTs contacted me for a meeting, and all decided to participate in the study.

Participating CPST staff then sent a mailing (Appendix E) to individuals on their caseload. I relied on the CPSTs' clinical judgment to exclude any consumers, at any point in the study, that they assessed to be: 1) psychiatrically unstable to the extent that participation could pose a detriment/barrier to their ongoing care, and/or 2) that the act of participation would pose some other detriment to the consumer's mental health, due to 
circumstances specific to that individual, and/or 3) unable to provide informed consent due to mental or other impairment. When contacted by mental health consumers interested in participating, the CPSTs then paraphrased from a script I provided them: "Two researchers from Case Western Reserve University-Janet and Jerry-are doing a study on how we're using the consumer outcomes survey. Participation is in no way a requirement for continuing our work together-whether or not you participate is completely up to you. If you want more information about participating, I can set up a time for us to meet with Janet".

I next met with interested consumers with their CPST staff, at the CPSTs' offices (per the consumers' requests). I gave a brief overview of the study as explicated in the consumer consent forms (Appendix F), and answered questions that each consumer had. I met with a total of 17 consumers, and all 17 decided to participate in the study. We reviewed the consent forms (Appendix F) at that time, and I provided the consumers with copies after they signed.

As indicated in the CPST consent form, toward the end of the time I spent with each CPST doing participant observation, each CPST and I did individual interviews in which I asked participating CPST staff to identify people-who have been significant in their uses of the outcomes-that they thought would be relevant for me to interview. I asked each CPST staff if it is okay to identify that CPST staff as the person who suggested I contact the potential interviewee, and all stated I could do so. I then contacted the identified potential interviewee, and used the following script: " $\mathrm{Hi}, \mathrm{I}$ 'm Janet Hoy; I am affiliated with Case Western Reserve University, and I'm doing a study on how the Consumer Outcomes are being implemented. X (name of person who 
suggested I contact the potential interviewee) told me you were important in their work with the Consumer Outcomes, and suggested I interview you". A total of 25 people were identified in this fashion, of which 22 agreed to participate. I continued recruiting in this snowball sampling fashion until I was not being referred to any new people; sampling saturation occurred after I had interviewed 22 people, and was being referred only to the same two ODMH staff. To limit the scope and focus of this study, I considered sampling saturation reached at that time.

As compared to administrative/other participants, participating in this study entailed a substantial greater time commitment for CPSTs and consumers, as CPSTs and consumers were observed over time via participant observation as well as interviewed individually (whereas no participant observation of participating administrators occurred). I thus offered compensation to participants (consumer and CPST) who such an extended time commitment, as explicated in their consents. I provided compensation to the participants as follows: $\$ 30$ in Visa gift cards for each participating mental health consumer, and \$50 in Visa gift cards for each participating CPST. The CPSTs were compensated at a higher amount due to the substantially greater amount of time their participation entailed. The consumers were compensated at a higher rate due to the more personal nature of the information they are providing. Compensation protocol was explained as the consent forms (see Appendices C and F) were reviewed. Seventeen clients were paid a $\$ 15$ Visa gift card at the conclusion of their first observed session, and 16 clients ( 1 client repeatedly no-showed for his scheduled interview with me) were paid second $\$ 15$ Visa gift card after they completed their individual taped interviews (approximately 2 months after their first observed sessions). The 9 CPST clinicians 
were paid $\$ 50$ after they completed their individual taped interviews (approximately 2 months after participant observation began with them and their participating clients).

\section{Methodology and Analytic Strategies}

\section{An Overview of Institutional Ethnography}

Ethnography has been identified as a method of choice in seeking to understand how something occurs (see previous chapter). In studying how micro and macro social issues interface, Wedel et al (2005) and Smith (1987, 2005) specifically advocate an ethnographic approach that expands the ethnographic field (traditionally defined according to geographic boundaries) to encompass extended, interrelated social processes between people who may never meet face-to-face but whose work tasks nonetheless impact each other. According to Wedel et al (2005) “...today, 'the field' often consists of loosely connected actors with varying degrees of institutional leverage located in multiple sites that are not always geographically fixed..." (p.39). To answer the two specified research questions, I employed a specific type of this kind of 'extended field' ethnographic approach, known as "institutional ethnography” (Smith, 2005).

While the name of this research approach-institutional ethnography (IE)-suggests a process and end-result perhaps very similar to those working from traditional (cultural) ethnographic methods (with localized fields defined by geographic boundaries), these are in actuality two related but distinctly different approaches to empirical inquiry. IE will not produce an accounting of a culture described in rich detail through deep immersion into local community life (the usual end-result and processes entailed in traditional ethnographies). Rather, the IE approach to empirical inquiry was developed by 
Canadian sociologist Dorothy Smith (1987) to generate a richly detailed account of the interconnected social processes-often occurring across distance and over time-that structure and organize the everyday experiences of particular individuals. Smith (1987) uses the metaphor of the cube, emerging in perspective when points are connected, to illustrate how IE analyses allows one to 'see' the trans-local, trans-temporal relations (processes) coordinating people's activities in particular local sites:

Figure 4. Cube Metaphor for Institutional Ethnography (IE)
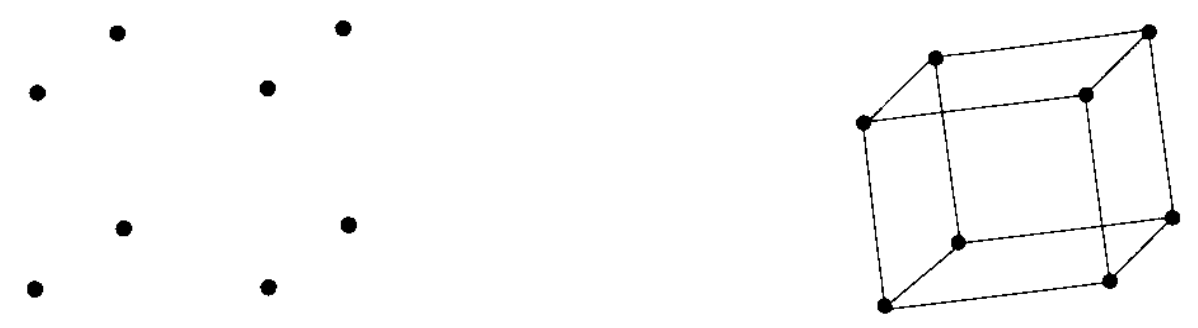

To generate such an account of interconnected social relations (processes) across individual experience, organizational practice and policy areas, the IE approach combines Smith's social organization of knowledge theory, traditional ethnographic method, and textual discourse analysis. Simply put, Smith's (2005), in her social organization of knowledge theory, asserts that:

1. Many aspects of individuals' everyday material life experiences are socially organized through the interplay of institutionalized, extended social relations (processes) that are occurring across time and space. 
2. Tracking and making the explicit and embedded nature of these social relations (processes) apparent can be empowering and useful to actual individuals whose everyday lives are being impacted by such relations.

Social relations (processes) as theorized by Smith-particularly the trans-local, trans-temporal processes-are accomplished in part through what Smith has labeled "textually-mediated social organization". To tap into this dimension of social organization, IE employs fieldwork study of 'texts-in-use', e.g., documents used by participants (Smith, 1999). When I refer to mental health system processes, I am thus henceforth referring to the institutionalized social processes (including textually mediated processes) that are embedded within or connected to consumer and CPST understandings, experiences and uses of the Consumer Outcomes Survey.

As summarized by Townsend (1998), institutional ethnographies involve three data collection methods (participant observation, interviews, and document review); data saturation occurs when "sufficient data are collected to record how everyday practice actually works within an institutional framework" (p.19). Three interrelated phases undergird data collection and analysis in institutional ethnography (Townsend, 1998):

1. The creating of a detailed description of the everyday understandings and experiences of those whose standpoint is being taken in entering a web of social relations (processes).

2. Mapping of the social processes that connect the work being studied with the work of others... the actions, verbal communications, written communications (policies, procedures, classifications, legislation, 
statistics), and other social processes... that routinely organize what can be done in everyday practice.

3. Making explicit the character and impact of the institutionalized processes that coordinate and control the work done by those whose standpoint is initially taken on.

The IE approach explicitly rejects the "unbiased observer" approach used in traditional ethnographies. Instead, the IE approach embraces and insists upon 'going local'; the standpoints of specific individuals (whose everyday work and experiences are being focused upon) is considered to be the valid entry point into a given set of extended social processes (Smith, 1987, 2005). As explained by DeVault (1999), “...the Institutional Ethnographer takes up a point of view in a marginal location; she 'looks' carefully and relatively unobtrusively, like any field worker, but she looks from the margins inward... searching to explicate the contingencies...that shape local contexts..." (p.47). Through tracing the social processes beginning from actual frontline understandings, experiences and uses of the Consumer Outcomes Survey (where 'the rubber meets the road', in terms of whether the implementation of the Ohio Consumer Outcomes Initiative is actually occurring as conceptualized), I was better be able to identify the relevant system processes (those that factor into the actual uses of the outcomes surveys).

\section{Specific Data Collection and Analysis Strategies}

To answer the first question in this research study-How are CPSTs and consumers understanding, experiencing and using the Consumer Outcomes 
Survey?-I used a combination of participant observation, interviews, and review of charts over a period of about ten months. The standpoints of CPST staff and consumers were the point of entry into the extended social processes shaping the uses of the consumer outcomes surveys. I spent about two and a half months at each agency doing participant observation. The three interrelated purposes of my participant observation, as per the guiding tenets of institutional ethnography (Smith, 2005) were to:

1. To learn from my CPST and consumer participants their perceptions of understanding, experiencing and using the Consumer Outcomes Survey and results under everyday practice conditions.

2. Observe and note other uses of the outcomes surveys, such as uses pertaining to planning and documenting services and/or related tasks.

3. Create an integrative account of how such understandings, experiences and uses of the Consumer Outcomes Surveys are occurring within the everyday work of CPSTs and consumers.

Toward the end of my shadowing time, I did individual, semi-structured interviews (see Appendices G \& J) with each CPST and each consumer, and taperecorded each interview. I then had the interviews transcribed and entered them, along with my field notes, into my qualitative software package, ATLAS.ti.

I created four primary documents in ATLAS.ti, so as to be able to easily identify, compare and contrast within-agency and cross-agency themes. I began by assigning each line of data a first-level code, e.g., "printed outcomes report"; I did this to stay as grounded in my participants' own descriptions of their experiences as possible. I next took these first-level codes and compared and looked for similar or interconnecting 
experiences, activities and understandings, and group the similar first-level codes into broader themes within and across agency settings. I continued in this fashion until all data were accounted for, no new themes were being generated, and a detailed description of processes through which CPSTs and consumers understand, experience and use the Consumer Outcomes Survey had emerged.

To check for validity at this point in my analysis, I solicited feedback from CPST and consumer participants, with regards to whether the description generated was consistent with their lived experiences (Kuzel \& Like, 1991). I utilized Kuzel and Like's (1991) technique of thick description in writing my description to increase trustworthiness of my findings, in which they suggest including the researcher's interpretations and observations along with reported data, and methodologically situating such interpretations, observations and data. Specifically, I included my own observations and interpretations, in addition to describing observations and sharing quotations pertaining to the outcomes, and also began each data chapter with a specific accounting of how institutional ethnography (IE) tenets informed my analysis at that given point in my analytical work to help ensure methodological rigor according to IE. I also compared progress notes pertaining to interactions I actually observed through shadowing, with my field notes of those observations, to triangulate and gain additional insights into concrete outcomes uses and related processes.

I addressed my second research question-What mental health system-related social processes are impacting these understandings and uses?-via snowball sampling and interviewing, along with analysis and tracing the trajectories of "texts-in-use" across the service system. Whenever possible, I collected and reviewed documents referred to 
me by participants as relevant to their work with outcomes-a.k.a. 'texts-in-use' (Smith, 2005)-and reviewed them for content and impact on CPST and consumer experiences related to the Consumer Outcomes Survey. I then mapped the sequencing of the identified texts as they were processed throughout the system, along with related social processes (Appendix K). I integrated processes and information shared with me by Administrative/Other participants via interviews regarding their own work, to create a narrative account of interrelated social processes embedded in and connected to frontline experiences of the Consumer Outcomes Survey (Appendix K).

Using what I have learned from participants' self-report, texts and my own observations, I then developed an integrative analysis of how system processes manifest in frontline experiences of the Consumer Outcomes Survey. As per institutional ethnography tenets, to identify and explicate system processes embedded in frontline experiences, I searched for and explicated cross-agency tensions and experiences in the everyday work of CPSTs and consumers as they attempted to implement the Consumer Outcomes Survey, and considered how these tensions and experiences fit with the explicitly mapped processes (Smith, 1999). I again enlisted member checking (Kuzel \& Like, 1991) as needed, via re-contacting participants (as explicated in their consents) to clarify that I was representing their information as they intended.

\section{Human Subjects Protection}

\section{Justification of Special Participant Population \& Minimization of Risks}

In seeking to understand how the Consumer Outcomes are being implemented and used in everyday mental health practice, I would be writing from a "partial 
perspective" of frontline activities if I focused only on CPSTs and excluded the voices of mental health consumers who are also at the frontlines of the efforts to implement to Ohio Consumer Outcomes Initiative. Further, I would be ignoring the voices of those who have the most at stake in the mental health services, along with the most vulnerability. Thus, learning from and giving voice to those with the most to gain or lose by using new practices-mental health consumers-is something I feel ethically compelled to do in this study. Because mental health consumers, who are individuals living with mental illness, comprise a vulnerable population, I minimized risks by taking the following steps:

1) I relied heavily on the CPST worker's clinical knowledge of and relationship with the mental health consumers s/he works with; the CPSTs excluded consumers they felt might have been negatively impacted by participation in this study.

2) The initial mailing (Appendix E) sent by the CPST staff to the consumers specified that this study is voluntary, and in no way was a requirement for receiving or continuing services at the agency.

3) Consumers who responded to the initial mailing (Appendix E) could read and understand written materials, further narrowing my prospective sample to those who have less severe and/or have a transitive cognitive impairment.

4) Prior to any contact I had with the consumers, I asked each CPST staff to reiterate that this study is in no way a requirement or expectation of services at that mental health center. Explicitly and repeatedly indicating 
the voluntary nature of this study, in both verbal and written form, to any interested consumers, hopefully decreased the likelihood that they may have felt any pressure to participate.

5) In addition to a routine research consent form, Health Insurance Portability and Accountability (HIPPA) consent issues were also specifically addressed with the mental health consumers.

6) Risks and benefits were clearly stated in the consent form.

7) The CPST staff routinely worked with their consumers on monitoring psychiatric symptoms and precipitants to symptom changes. Thus, if any consumers had experienced undue anxiety and/or other significant symptom changes that appear related to study participation, their CPST staff would already have been in place to assist with: identifying the symptom change, clinically intervening as needed, and withdrawing from the study and/or reducing participation as needed.

8) All procedures, forms and methodology used in this study were reviewed by: the Institutional Review Board (IRB) of Case Western Reserve University; quality assurance staff at each of the participating agencies; and the Ohio Department of Mental Health Office of Program Evaluation and Research (OPER).

\section{Safeguarding data and Protecting Confidentiality and Privacy}

I assigned all data a numerical code upon being obtained, to mask participant identities. I maintained a master list, with links to individually identifiable data 
(specifically, the names, positions and agencies of those observed/interviewed). I kept the master list in a locked drawer, within my home office which I kept locked when I was not occupying it. Only Dr. Jerry Floersch (my dissertation chair) and I had access to the master list, data and codes. I will destroy the master list, data and codes within three years of completion of this study.

Likewise, I kept all notes of observations, tapes and written transcriptions in a locked desk drawer, within my home office which I kept locked when I was not occupying it. Only Dr. Floersch and I had access to these materials. I did not use any names or means of identifying interviewees in the tapes, transcripts or notes, nor did any such names or means appear in any printed papers on the findings of this project. I used quotes from interviews and field notes in my written reports and presentations, but no identifying information was included or shared. I will destroy all tapes and data within three years of completing this study. I password-protected all software and hardware I used in data analysis for this study, and kept my computer in my locked home office when not in use.

\section{Protecting the Privacy of Participants}

In order to contribute to an understanding of the social processes through which a practice change takes place in a real-world practice setting, this research entailed interviewing in which potentially sensitive information about mental health issues, service provision, and related organization and system issues (such as compliance or lack thereof with mandates) was shared by participants. The eliciting of such information can be construed as a potential invasion of privacy. To both protect the privacy and honor the 
preferences and comfort of all participants, I asked each participant where s/he wanted the interview to take place, and honored all preferences for interview locations. The majority of interviews took place in offices, however, I did complete two interviews at consumer's home per their requests.

\section{Justification for Use of Protected Health Information (PHI)}

The Consumer Outcomes Initiative mandates completing the Consumer Outcomes Surveys at specified interviews (initial and annually), reporting the results to the Ohio Department of Mental Health (ODMH), and using the results of the outcome surveys throughout the various stages of clinical service delivery (assessment, treatment planning, review of treatment progress, termination). Reviewing participating consumers' clinical record and protected health information (PHI) enabled to me to identify documented uses of the outcomes in the various stages of service delivery, and compare documented uses with the actual uses that I observed through participant observation. The data collected through my reviews of PHI enabled me to more fully answer the first research question in this study. I reviewed the following PHI in the clinical record: the diagnostic assessment; the psychiatric evaluation; individualized service plan (ISP); ISP reviews; progress notes (psychiatrist, nurse and CPST notes); the written responses to/ results of the outcomes surveys and any associated reports.

\section{Deductive disclosure}

Perhaps the greatest risk to participants in this study was the risk of deductive disclosure, due to the participant observation component, the relatively small sample size, 
and the sensitivity of the subject. For consumers, the sharing of one's personal mental health information was certainly a potentially sensitive subject. For CPSTs and Administrative Others, reported compliance with the Ohio Consumer Outcomes Initiative could be perceived to impact job performance evaluation and agency funding, respectively. This study was also being externally funded by the Ohio Department of Mental Health (ODMH), which was further worrisome for some participants given the implementation under study is an OMDH mandate. For all of these reasons, I am addressed this risk separately and in-depth.

There is a growing body of literature in which the high risk of deductive disclosure in qualitative research-such as ethnographies-is addressed. I carefully reviewed related articles and discovered two primary harm reduction strategies (with regards to deductive disclosure): 'informed consent' and 'respectful data reporting' (Cassell, 1982; Gallaher, 1964; Glazer, 1982; Johnson, 1982; Kelman, 1968; King, 1996; Wax, 1982). I operationalized these two strategies as follows:

1) Informed consent-the risk of deductive disclosure and the reasons exacerbating this risk (small sample size in each subgroup, fieldwork in which non-participants may see the researcher observing the participant, snowball sampling) will be thoroughly verbally explained to each prospective participant, so that s/he can determine whether s/he wishes to participate under such conditions. This risk is also presented in written format in each of the three versions of the consent forms (see Appendices). 
2) Respectful data reporting-in addition to using de-identified data, the 'ethical proof-reading' guidelines of Johnson (1982) of manuscripts at high risk for deductive disclosure will be used.

a) The first guideline entails operating from the assumption that deductive disclosure will happen while writing and presenting data. Throughout the preparation of study findings, I continually evaluated risks versus benefits to determine which, if any, pieces of high risk data (such as direct quotes, idiosyncratic language, etc.) to include and exclude.

b) The second guideline involves using descriptive rather than judgmental language when presenting information that could be considered negatively. I avoided the use of pejorative language in my data analysis and reporting.

c) The third guideline pertains to including contextual information whenever possible, when presenting information about an individual which could be perceived negatively. For example, when I wrote about a CPST staff who had reviewed outcomes results with a consumer in hasty and cursory fashion, I also included relevant context, such as the CPST being behind in her schedule due to a crisis earlier in the day, and also being overbooked.

d) The fourth guideline recommends avoiding stereotyping. (This seemed obvious to me, but I am including it so as be thorough in my presentation of Johnson's guidelines).

e) The fifth guideline suggests considering whether the research site would be 'reusable', or 'destroyed' after the participants read what has been 
written about them by the researcher. I hope to partner again with participating agencies for future research, and took pains to avoid presenting data in a blunt, inflammatory manner which could destroy the trust the agencies and participants had placed in me.

f) The sixth guideline recommends asking participants and colleagues to proofread manuscripts/presentations and to offer feedback and criticisms, using the above guidelines. I used member checking to employ this guideline.

In addition to the above strategies for reducing harm from deductive disclosure, I for the most part aggregated CPST and consumer experiences, understandings and uses of the Consumer Outcomes Surveys via thematic analysis, rather than sharing this information in my written analysis through describing specific individual experiences at specific agencies. As initially conceived, I wished in this study to specifically explicate the implementation processes within as well as across each of the four agencies, and to explore both unique and cross-individual themes and experience as these related to agency contexts and processes. The drawbacks of an aggregated approach to frontline experiences are thus obvious, with regards to the loss of specific contextual information in my written data chapters. However, in consultation with my dissertation chair and knowledgeable others, I determined this loss of context was necessary in order to further attempt to reduce the risk of deductive disclosure for my participants. 


\section{Plans for Disseminating Study Findings}

I will send a brief of my findings of this study to each participating agency, and will also offer to do additional sharing of findings according to their expressed preferences, in ways (small group discussions, formal presentations, written/e-mailed briefing, etc.) identified as most effective given their informal agency cultures. I presented findings at the Society for Social Work and Research (SSWR) annual meeting in January of 2008, and also expect to present at ODMH's next bi-annual research conference. I will submit a summary of this study to ODMH for publication in its journal New Research in Mental Health. I also plan to submit manuscripts related to this study to Social Service Review, Qualitative Social Work, and the Community Mental Health

Journal; I may identify other journals at a later date. I will credit the Ohio Department of Mental Health for funding in all publications related to this study. 


\section{CHAPTER 4: A BRIEF OVERVIEW OF THE AGENCY CONTEXTS IN WHICH FRONTLINE EXPERIENCES OCCURRED}

\section{Introduction}

There are numerous frontline ethnographic studies which focus on both geographic and/or process contextual information. While in Chapter Two I looked specifically on ethnographies of implementations in peer-reviewed journals, there are also numerous full-length books of such studies drawing from different theoretical and conceptual approaches. DeMontingy (2005), for example, specifically considered social work practice in specific contexts and in relation to service-users through a class-lens, informed by Marxist theory. In his classic work Street-Level Bureaucracy: the Dilemmas of Individuals in Social Services, Lipsky (1980) explored and delineated how frontline discretion is used to negotiate policy implementation issues such as resource scarcity and lack of goal specificity.

Townsend (1998) likewise did an ethnography of frontline experiences, focusing on occupational therapists' experiences with an empowerment model in mental health settings. Townsend identified institutional ethnography as her method. Unlike Lipsky’s (1980) study, which focused on how frontline discretion operates to negotiate system issues within policy implementation, Townsend focused on the constraints experienced by her frontline participants (e.g., how frontline discretion is constrained) through the interplay of larger system forces (Townsend, 1998). While each of these three frontline ethnographies had clear differences, in terms of: differing ethnographic approaches; areas of focus in frontline experiences; and theoretical lens used, a common theme found is the 
relevance of site-specific contextual information in understanding the phenomenon under investigation.

While I cannot compare and contrast agency contexts in-depth as they relate to the Adult Consumer Form (due to deductive disclosure) in my written presentation of my findings, I nonetheless found such agency contexts relevant and in need of some explication. To convey some sense of the diverse contexts in which my participants did their everyday work, I will thus provide some contextual information via detailed physical descriptions of the four urban community mental health center sites, followed by my initial impressions. Because similarities and differences in across these four agencies were especially vivid to me (and hence especially vivid in my field notes) upon my initial entry into each setting, I will be draw from these initial experiences in this chapter.

Specifically, I will first detail my first experience at each agency, followed by my initial impressions, utilizing my field notes. I will not be disclosing any actual locations of the sites, and I will withhold, modify, and/or disguise potentially identifying details to the extent possible. While such modifications further limited my ability to convey the everyday contexts of my frontline participants, I did attempt to make adjustments in ways that did allow salient aspects of the sites to be conveyed, to the best of my abilities.

Drawing from the totality of my field experience at each agency, I will then consider each agency in terms of its culture and climate, two constructs identified by Glisson (2007) as key in understanding organizational contexts as they pertain to implementation endeavors. Glisson (2007) differentiated between organizational culture and organizational climate as follows: 
...culture captures the way things are done in an organization, and climate captures the way people perceive their work environment. That distinction suggests that culture is a property of the organization and climate is a property of the individual. We define culture as the norms, expectations and ways things are done in the organization. We define psychological climates as the individual employees' perceptions of the impact of their work environment on their own well-being. Organizational climate is created when individuals in a work unit, team or organization share perceptions of how their work environment affects them as individuals. (p.739)

Within climate, Glisson (2007) further differentiates between stressful climate and engaged climate. Glisson (2007) explains these as: "Indicators of Stressful Climate were high levels of overload, role conflict and emotional exhaustion. Indicators of Engaged Climate were high levels of personal accomplishment and low levels of depersonalization (p. 740)". In keeping with institutional ethnography tenets that begin an exploration of an institutional field as grounded in particular standpoints and everyday experiences, and to limit and focus my scope, I will consider, in a general fashion, my frontline staffs' experiences at each agency in terms of stressful and engaged climate.

\section{Overview of the Four Agencies}

To recap what I stated in Chapter 3, the four nonprofit agencies at which I did participant observation were similar in a number of ways:

- $\quad$ Each has an annual operating budget of between 10 and 20 million dollars

- $\quad$ Each employs between 60-80 CPST staff 
- $\quad$ Each serves between 3000-5000 mental health consumers

- $\quad$ Each is headquartered in an urban setting in Ohio

- Each has multiple "satellite offices" within urban and suburban settings

- $\quad$ Each serves predominantly low-income individuals

There was significant variation in terms of ethnicity of the staff and clientele, and in the degree of compliance each agency was at in terms of submission of completed outcomes forms (surveys needed to be submitted to the state for $80 \%$ of enrolled mental health consumers in order for the agency to be in compliance with the Ohio Consumer Outcomes Initiative).

Due to the risk of deductive disclosure, specifics of racial and ethnic compositions of people have purposely been omitted from the agency setting descriptions. There were also distinct differences observable in the physical settings of the agencies, which I have attempted to preserve while at the same time disguising the specific agencies. The following sections are derived largely from my field notes from my initial site visits, with occasional clarifications from my participants obtained during my individual interviews with them.

\section{Agency A}

\section{Description of My First Field Experience}

As I drove on a main road to the satellite office, I noticed numerous store fronts containing restaurants, bars, three banks with ATMs and a coffee shop, as well as a couple of chain drug stores. At the main intersection closest to the office was a large shopping plaza, with a chain grocery store, and numerous smaller stores and restaurants. 
The homes in the area were predominantly brick, and the lawns appeared to have been recently cut and edged. No home disrepairs or unkempt lawns were overtly visible as I drove by. Cars of newer models were parked in some of the driveways. A couple of churches were also visible further down the road. The sidewalks appeared to be even, no trash was visible, and bus stops with shelters and benches were on the street corners. I saw a couple of adults walking on the sidewalk, in clothing that appeared in good repair, weather appropriate and of a recent style.

I pulled into the parking lot, and walked up to a large one-story brick building, with a shortly mowed lawn and flowers and trees outside of the numerous large windows that ran the length of the building. I noticed a bus shelter several blocks from the agency building, at which I could see one person waiting. The agency's name was clearly displayed on a sign. I pressed a buzzer and was buzzed in double glass doors, into a carpeted lobby area. Two receptionists (women answering phones and wearing head sets) were seated at a desk, divided from the carpeted waiting area by a glass wall with holes in it where one could talk through. There were about twenty matching chairs along the wall of the waiting area, and some children's toys in the corner in a wooden box. A couple of plastic plants were in other corners of the room. On the walls was some client's rights and privacy information, certification information, some plaques indicating various awards bestowed upon the agency, and a bulletin board with numerous flyers and pamphlets describing various activities and resources in the area. No restroom was immediately visible from this waiting area. I did not see any magazines, and there was no television, but a radio was on in the reception area, playing "light rock" interspersed with commercials. 
I told the closest receptionist to the entrance who I was, and who I was there to see. She smiled, asked me to take a seat, and picked up the phone. I could hear her notifying someone-presumably the CPST staff I was there to see-that I had arrived. I sat in a hard seat framed in metal and covered in black vinyl, facing the reception area, and waited silently. The waiting area had four other adults, all of whom appeared to be racially and ethnically similar, seated silently and apparently also waiting. They were seated so that there were three or four empty seats between each person, and all were silent for a while.

One of the people waiting then spoke to the receptionist, calling her by a first name, and she smiled and responded to him with his first name. He asked her how much longer it would be until the doctor could see him, and she said he had one more person ahead. The man who'd asked this nodded, thanked her, and again fell silent. Another man walked up to the glass doors outside, was buzzed in, and was greeted warmly by name by the same receptionist. He in turn greeted her by name, greeted two of the other people seated in the room by name, and walked over to me. He extended a hand and introduced himself. The receptionist told him his CPST worker was still "out in the field"; he smiled and said "he's a busy man-I'll get some coffee and be back in about an hour", to which the receptionist nodded and smiled silently. He then waved and said goodbye to all of us seated in the waiting area (we all waved back) and left. The room was then quiet, except for the radio playing faintly in the background, and the voices of the receptionists answering the phones and directing calls.

There was a door without a window, just past the glass reception area, which opened after about ten minutes. The CPST staff I was to meet with stepped in from the 
doorway, smiled, greeted me and beckoned me in. She wore a badge with her name and credentials clipped to her shirt. We walked down a carpeted hall, passing several closed doors with name places on them, to her work space. Her workspace was an enclosed office with a one large window, numerous comics posted, inspiring quotes and paintings of scenery hanging up, framed professional degrees and licensing information, a fiveshelf bookshelf full of mental health books, and an L-shaped desk with a computer in the corner of the L. There were also some pencil drawings taped on the wall, which she noticed me looking at and informed me that these were from one of her clients-"he just loves to draw, he gives me these all the time", she said. A round table and two chairs were against the far wall, and another chair was right next to the side of the L desk. There were two tissue boxes-one on the round table (it was the only thing on the table), and the other at the end of the $\mathrm{L}$ desk where the chair was alongside. The large window opened to a view of grass and a large tree in which there was a squirrel, and there was some hanging stained glass art on the window. All furnishings were unstained and looked to be in good repair. I could hear very little when she closed the door, except faint sound of cars and muffled words of people occasionally passing in hall.

We conducted our conversation, interrupted only once by the soft buzz of the phone and a (receptionist's) voice stating on speaker phone "I have a call from X, are you able to take it?" The CPST said to send the call to voice mail and she'd call the person as soon as we were finished. We completed our talk, and she walked me to the door-on the way to the door, I noticed a room filled with file cabinets, a fax machine and a copy machine-she said this was the medical records room, where all charts were kept. A couple of people wearing badges-presumably CPST staff-greeted the CPST staff I was 
with and smiled at me as they walked by. We said goodbye, and I walked back through the waiting area, where two adults were sitting and waiting, neither of whom had been in the room earlier. They were sitting next to each other talking quietly to each other. The receptionist who had greeted me said goodbye to me and waved as I left.

\section{My Impressions}

This satellite office seemed to be a "nicer" part of the city, as evidenced by the multiple community assets (banks, grocery stores, restaurants, etc.) easily accessible to residents in the area. I felt safe as I parked and walked up to the building. I was greeted warmly, and the same receptionist who greeted me seemed to know many of the people who called and walked in, as evidenced by her knowing them on a first-name basis. The waiting room had a suburban doctor's office feel to it-clean, almost sterile, with soft music playing, and quiet. I felt some sense of familiarity in being in this health care setting, and attributed this to my middle class suburban upbringing. The lack of reading materials/magazines was one notable departure from what I referenced to myself as "the suburban doctor's office feel" ("suburban doctor offices" always seemed to have an abundance of magazines, in my experience...).

The CPST's workspace was spacious, welcoming, private and oozed professionalism. Her credentialing was matted and framed on the wall, and the shelves filled to overflowing with all sorts of books and treatment manuals suggested that she read avidly and continually expanded her knowledge base. There were all sorts of personal touches of self-expression, such as the comics and the wall hangings (which looked hand-made), which gave it a warm and "homey" feel. The computer in the corner 
of her desk and the high tech phone both gave the appearance of being "state of the art" in terms of technology.

The nature of this office occupied by a single person, with solid walls and a door, afforded great privacy. I noticed the worker had her desk in the far corner, with the chairs presumably used for guests between her desk chair and the door. This is something I've been told not to do in safety trainings in my own experience as a social worker-"'never put someone between you and the door". I didn't think to ask her about it at the time, and can only assume she's not particularly concerned about needing to make a speedy exit due from her office.

I wondered about the receptionists announcing people's names over a speaker phone, and how this played out in terms of confidentiality-it seemed problematic to me. But overall, this seemed like a safe, private, professional place at which to use mental health services.

\section{Stressful vs. Engaged Climate}

Despite the soothing, quiet physical environment of this agency, individual perceptions of stressful climate were apparent at this agency. CPSTs noted high caseloads, excessive paperwork, and emotional fatigue (pertaining to competing job demands and client worries) as ongoing issues. However, elements of engaged climate were also apparent; CPSTs felt encouraged to individualize and personalize their work spaces, and to have meaningful interactions with each other via eating lunch together in large groups every week or two, and having periodic celebrations of parties and birthdays. 
There also a high sense of personalized professionalism at this agency, which seemed to serve as an engaging climate factor. CPSTs took pride in their clinical expertise, and discussed with me trainings, books, practice models, holistic and alternative health approaches, and other ways through which they could better support their consumers' mental health. While most of the CPSTs had at least a few clinical or reference books of some sort in their offices, I at first wondered if they could be having such conversations with me because I was a researcher and perceived as "academic". After over-hearing such conversations on a daily basis, in passing people as I walked down the hall or through the lunch room, I quickly realized I was in no way a factor.

\section{Agency B}

\section{Description of My First Field Experience}

As I drove to this office, I noticed numerous potholes in the road, more than one of which I had the misfortune of driving into! There were stretches of empty storefronts with windows boarded up, broken, and/or spray painted, and much of the grass along the way seemed overgrow and peppered with different species of weeds. I did not see any single residence homes from the main road I was driving on, but I did pass several apartment complexes, one of which was labeled "public housing". People were outside near each of these complexes-two women with two strollers, four men talking and laughing, a man drinking something out of a brown bag and an older woman using a walker were some of the people I managed to note as I drove. There were also some pager stores, convenience stores, and a chain drug store that I passed along the way that appeared open-cars were parked in front of them, and people were inside presumably 
doing business. I did not notice any banks or ATM signs at convenience stores as I drove along. Twice while stopped at traffic lights, I was unable to hear the music playing in my own car, due to the loud music playing in other vehicles.

I passed the mental health center building the first time, turned around in the parking lot of a church (the first I had seen during my drive), and drove back to the driveway. There was a sign, but it was not easily visible from the road. There was a bus shelter near the driveway, which no one was at. I drove down the driveway into a parking lot that didn't have a single open space. There were two other cars circling in the lot besides mine, and one that was parked along the curb alongside the building. A chain link fence surrounded the parking lot and building. After about ten minutes of circling and becoming increasingly agitated due to being late for my first meeting with the CPST at this site, I found a spot along the fence that could perhaps-given a certain amount of imagination-constitute a parking space, and parallel parked there.

I jumped out of my car, half-running toward the multi-story brick building, when the door opened and a man in a security uniform stepped out, stopped me and with a smile said "I'm sorry ma'am, you can't park there." I asked him where I could park, and he said "parking is a problem", apologized for the lack of space, and suggested I wait for a space to open up or "take your chances with street parking". I got back in my car, not exactly sure what he meant by "taking your chances with street parking", but having enough of an understanding of what he meant to keep me driving in frenzied circles in the fenced lot as I became ever-later for my appointment. After a few laps around the lot, I was overjoyed to see that someone was pulling out of a spot close to the entrance, right as I was approaching the spot. I parked in this spot, got out, and noticed a group of eight or 
ten men smoking and laughing right outside the entrance door, but not blocking it. I noticed a large window next to the door, through which the same man in the security uniform who had stopped me smiled at me and gave me a thumbs up sign. The men smiling and laughing in the group waved at him, and he waved back and smiled at them.

Further along the building, I noticed a man standing in front of a disabled parking sign, seeming to stare at it. He was talking loudly and then began swearing. No one was near him and he appeared to be speaking to himself, or perhaps the sign. He then began to swear even more loudly and started punching the metal disabled parking sign hard enough to make the sign move back and forth on its pole. I cringed, thinking of his hand breaking, and wasn't sure whether to intervene (my roles as "ethnographer" and "social worker with years of crisis intervention work experience" clashed, for the first time but not the last). I was about to chuck my ethnographer role and approach the man hitting the sign, but in next instant the same man in uniform who'd stopped me ran past me to the man hitting the sign, stood beside him, softly said a first name (presumably the name of the man hitting the sign), and continued to say things in a soft voice to the man. The man who had been hitting the sign stopped yelling and hitting the sign immediately, turned toward the man in the uniform, and nodded. I could hear something about "let's see if your worker's in" as they walked past me toward the entrance (I was fumbling with things in my bag, trying not to observe too obviously/intrusively).

Now very late for my appointment with the CPST, I walked into the building. The man in uniform and the man hitting the sign were nowhere to be seen, but there was a reception area enclosed in glass, where one woman alternated between answering the phone and responding to a line of about seven people in front of a small opening in the 
glass wall. I got in line, and one by one the people gave their names, the names of their workers, and were told to have a seat and wait. I told the receptionist my name and who I was there to see when it was my turn to step up to the counter. She typed something in the computer and then looked at me and said "you're not in the system-is she expecting you?" I said I was there for a meeting; the receptionist then told me to sign in on the visitor's sheet which she handed to me on a clip board, and after that I was to go sit in the waiting area.

I signed in and looked for a seat in a room just beyond the glass reception area. There were several rows of chairs all facing toward a television, which was rather loudly playing some Keanu Reeves action movie I did not recognize. Nearly all of the seats were filled, and I made my way to one only to find it wasn't actually empty, but had a small purse on it. The woman sitting next to the chair I'd thought was empty pulled the purse onto her lap without looking at me and nodded, and I thanked her and sat down. I realized I'd sat next to one of the only other women in the room, and that the vast majority of the individuals surrounding me were adult males.

I looked around and noticed client's rights and privacy information and agency certification information prominently posted on the walls, along with a couple of paintings of people I later discovered were community organizers who had positively impacted the surrounding area. The television blared very loudly the action movie I did not recognize, almost precluding conversation. I half-watched the movie and occasionally could hear names called out behind me at the entrance to the room (all the chairs faced toward the television and away from the entrance and glass receptionist area, almost like a movie theatre set up). I noticed a rack of magazines in a far corner, but did 
not see anyone reading any magazines and could not tell what the names of the magazines were. Most of the people were either watching the movie, or sitting silently. A man started swearing somewhere behind me, and I heard what I think was the receptionist's voice telling him if he couldn't talk right he had to leave. No one turned around in the waiting area to see what was happening, or responded in any noticeable way. I heard the man's voice and the receptionist's voice going back and forth about whether the words he used were "talking right" or not, and after a few moments he said "alright" and they stopped talking.

Finally, my name was called, and I stood up, turned around and walked over to the entrance area. The CPST I'd be shadowing smiled and greeted me, and we walked to an elevator and took it up several floors. We stepped out into a hall way with more paintings, and walked to down the hall to an open doorway. We entered an enclosed office. The CPST said she shares the office with a co-worker who was at a training all day today and would not be using his desk space. There were two desks (each facing an adjacent wall), two desk chairs, two phones and two computers in the office and a chair next to each desk, apparently for consumers to sit on. It was a smallish space, not much bigger than an average-sized bedroom. There was no window in the office. There was a bulletin board above my CPST's desk, on which hung numerous colored flyers and resource information. She had framed credentials on the wall behind her. Next to her phone were a couple of stuffed animals and a stack of papers. Her office mate's desk had a computer, a half-full coffee cup, and pile of papers on it which reminded me of the Leaning Tower of Pisa; the walls around that desk were completely bare. 
The phone message light on my CPST's phone flashed " 3 ", which I assume meant she had three new messages. The CPST noticed that I was looking at the phone and said "that's what happened between when I left to get you downstairs, and when we came back up". The words were barely out of her mouth when the phone began ringing; she said "that's the receptionist downstairs", picked up, and said into the phone: "she doesn't have an appointment... I'll see her, but she needs to wait". She then hung the phone up and we began our meeting. The phone rang twice more, with the CPST basically repeating what she'd previously said each time. At the end of our meeting, I noticed she had a blinking " 8 " on her phone, so additional calls must have been sent directly to her voice mail. She looked at the blinking " 8 " and shook her head back and forth, slowly saying "It's hard to stay caught up..."

The CPST said she'd walk me out, and we headed out the door and down the hall toward the elevator. I hadn't heard much with the door closed, once in the hallway, I noticed a man's voice that seemed rather loud; I looked further down the hall toward where the voice seemed to be coming from, and noticed the same man in uniform who'd given me a thumbs up for my successful parking venture earlier. He was leaning against the wall silently, and nodded at us but did not smile this time; his brow appeared furrowed and he turned his gaze back toward where the voice was emanating from. I could not make out what was being said, but the voice did not sound like the voice of the man hitting the sign in the parking lot.

The CPST and I stepped in the elevator and rode down to the waiting area. The CPST stepped off the elevator, to be greeted by a young woman who was seemingly in process of pacing back and forth in front of the elevators. The CPST greeted her, waved 
goodbye to me, and they both stepped into the elevator. I walked outside, passing through what appeared to be the same group of eight or ten men smoking and laughingthey were blocking the entrance a little, but smiled and nodded at me and stepped back so there was a path for me to walk through. I headed toward my car, and noticed a car was driving behind me slowly, basically following me to my parking spot. The driver of that car stopped and waited while I pulled out of my spot and drove away. Behind her car, a second car honked twice loudly while she waited. The car that had honked followed right behind me as I drove across the lot. As I pulled out of the driveway, the car behind me drove pass the driveway and back around toward the building, making what I suspected was going to be one of many laps around that parking lot.

\section{My impressions}

This was an office was in a neighborhood where much poverty was apparent, as well as a substantial sense of community (as evidenced by the paintings of the organizers in the waiting area, and the camaraderie of those standing outside the building). I felt safe enough within the confines of the fenced property, although I must attribute that at least in part to the compassionate security guard who seemed to be everywhere. Because it seemed that no one was willing to do street parking, my concern for my car was raised and hence I joined those driving laps around the parking lot, whereas I normally would have just found a spot somewhere on the street nearby and walked over to the building. (In retrospect, that may have not been a good idea, given I was told I could "take my chances", and considering I was carrying what was obviously a laptop computer.)

I was pleased that the receptionist did not automatically assume I was a nonconsumer; I think because I felt it somehow signified that she did not stereotype "mental 
health consumers" as people who would not wear a dress suit or carry a laptop computer, as I was doing. The set up of the waiting area fascinated me-it was odd to have the activity (incoming people, etc) behind me, as all the seats were facing the same direction, away from the reception area. I wondered if the choice of movie (action film) was due to the overwhelmingly male clientele (then realizing as I was wondering this that I was gender stereotyping...).

The presence of the guard did not surprise me, as there seemed to be regular eruptions of distress at this office that could be intimidating and/or unsafe for the other mental health consumers and staff. The staff and mental health consumers seemed to take such eruptions (yelling, hitting the sign) as matter of fact, and the guard seemed to have fantastic people skills. For example, I strongly suspect that the man hitting the disabled sign calmed through talking with the guard, and that when his worker arrived on the scene, the man was already "de-escalated". (The guard had even "de-escalated" me to some extent, with regards to my frustration with the parking situation.)

The shared office space scenario raised confidentiality concerns for me, for obvious reasons. I would later learn that the CPSTs would take turns using the office space to meet with consumers and never had two consumers together in the office. However, both CPSTs were sometimes in the room while one or the other would meet with a consumer. I'd wonder about phone calls being overhead and so forth, and also about how forthcoming a consumer might be when another CPST was in the room.

I also wondered how the CPST ever found time to return her calls. I discovered upon spending time with her that this was in fact a usual day in terms of phone call volume and people coming in who did not have scheduled appointments. The mental 
health consumers that she worked with who participated in my study later told me that she was very easy to get in touch with, and responsive to their needs, and that they didn't mind waiting for her because "she's always there when I need her".

The non-stop phone calls were just one example of the fast-pace at this urban mental health setting. I think such expressions in more sedate settings that I'm familiar with may have been constituted as necessitating a "pink slip (calling the police and involuntarily hospitalizing)". The staff at this office responded to such expressions/incidents calmly and kindly as they went about the business of their day, and I never saw any police called in my stint there despite seeing numerous incidents such as those described in this section. I wonder if having the "compassionate guard" on site helped reduce such police calls. I recall working at an agency where an administrator was philosophically opposed to hiring security because of a belief that it would make the consumers uncomfortable. This did not seem to be the case at this agency; I often saw the "compassionate guard" bantering with consumers, and at times walking them to their cars and bus stops. I too came to look forward to bantering with him as I entered and exited the building.

\section{Stressful vs. Engaged Climate}

My first experience with a CPST at this agency involved a phone that basically never stopped ringing. As I spent time at this agency, I realized that first day was not an unusual occurrence, but rather, "business as usual". The pace of their work seemed frenetic to me, much more so than at the other agencies I spent time at. Not surprisingly, CPSTs at this agency more strongly noted high caseloads, excessive paperwork, and emotional fatigue (pertaining to competing job demands and client worries) as ongoing 
issues. The office spaces of the CPSTs were shared, and often devoid of any personal decorations or belongings visible. All of these things evidenced a stressful climate for my CPST participants.

CPSTs at this agency also voiced a strong sense of commitment to their consumers, and the community in which their agency was located. There was a clear articulation of being a part of an agency that was felt to be "part of the community". Other than through the agency's history as a grassroots organization, I was not able to get a clear sense of what "part of the community" specifically meant to the CPSTs; it was something I would have liked to have explored in-depth as a phenomenon unto itself. "Part of the community" seemed like a shared identity that the staff took pride in. This perceived agency-community connection seemed to be an engaging climate factor for the CPSTs; it was something they referenced in positive, albeit non-specific ways.

\section{Agency C}

\section{Description of My First Field Experience}

My drive to a satellite office of Agency C, located in a quiet neighborhood of an Ohio city, was uneventful. I got off the highway and passed through a residential area with duplex and residential homes with no visible signs of disrepair, and with yards that had short grass and trimmed shrubs. A couple of the yards had children's toys strewn about, and many of the driveways had multiple cars parked in them, most of which looked to be newer models from a passing glance. I saw a couple of people entering or exiting their cars, but did not notice any people otherwise outside in the residential area. 
I turned onto a main street, which seemed in good repair/had no potholes. I passed a restaurant, gas station, bank, and a store front with numerous businesses (I noted a dry cleaning business and a bakery). I passed by this agency twice the first time I drove there. The one story brick building was set back from the street, between a couple of store front strips, and the sign was barely visible while driving by. I pulled into the driveway and saw several cars in the parking lot, but no one outside the building. I also saw a bus stop across the street. I parked in one of several open spaces, went to the building and opened an unlocked glass door, and walked into a narrow hall with five different-looking/mismatched chairs along one wall. I noticed client's rights and privacy information posted on the same wall above and behind the chairs, as well as agency accreditation information. There was one man seated in the hall. He smiled and nodded at me, and I did the same.

I turned from facing the chairs to the direction the chairs were facing, and noticed a solid brown door with a small window and what looked like a doorbell next to it. I pressed the doorbell and peered into the window and at first saw no one. A woman then walked up, opened the door and said "Can I help you?" I told her my name and that I had an appointment with the CPST I was there to see. The woman told me to come with her. I followed her into and through a room with a desk, chair, copy machine, fax, and numerous inspirational posters from various pharmaceutical companies taped on the walls. We walked through a doorway into a much larger, adjoining room. (There were few halls in this satellite office space; the rooms opened into each other much like most rooms open into each other in a residential home.) In this room there was a large window along one wall, two desks (with desk chairs) facing each other with a space in between 
large enough for the one chair which was placed sideways between the two desks, and two chairs along the far wall. On the wall opposite the doorway through which we'd entered, there was another doorway, which I'd later learn led to another shared office which adjoined this one. (For the most part, one had to walk through at least one CPST office to get to another in this satellite office space.) There were two women seated at the two desks that faced each other, one of whom was the CPST I'd be shadowing.

My CPST smiled at me and told me to have a seat. Because the two chairs along the wall were several feet away from her desk-too far from her to be at a conversational distance that was comfortable for me-I sat at the chair in between her desk and the desk of the other CPST who was typing at the computer on her desk (both desks had computers and phones on them). The other CPST paused for a moment, smiled at me as I sat in the chair between them, and then returned to typing. On top of her computer were a bunch of little rubber figurines wobbling as she typed. On the wall behind the other CPST's desk, I noticed photos of groups in which I recognized both CPSTs. I later learned these were photos of the CPST teams and doctors at various celebrations and social events. There were also various comics and jokes taped on most of the walls. I saw several plants along the ledge of the window, all of which appeared lush and real.

On the wall behind my CPST's desk was a bulletin board with her credentialing information and numerous resource flyers pinned to it. There were pictures of people and pictures of hamsters taped to her computer. I heard music playing from my worker's clock radio, which was on a file cabinet behind her desk, and could hear equally loudly but different music coming from the open doorway which led to the next adjoining office. 
During the time I spent talking with my CPST that day, several people passed through her workspace, coming and going to the other adjoining room I'd entered through, and the adjoining room on the other side of my CPST's desk. Everyone seemed to know each other; both the people with badges and the people who were with them greeted both CPSTs in the room I was in by first name, and the CPSTs in my room reciprocated the greetings, calling each person that walked through by first name. The people (with and without badges) that walked through also smiled and said hello to me as they passed by; several stopped and introduced themselves.

The phone and doorbell that I pressed rang repeatedly through the time I was there. Although there was a secretary-the woman who had let me in and sat at the desk in the room with the copy and fax machines-both CPSTs in my room took turns answering the phone and doorbell. I'd later see that this was standard practice for this office-everyone took responsibility for answering the phone and doorbell. My CPST excused herself several times to answer the phone and transfer calls to other staff, and to get up and let people in the door (as I was first let in) and walk them to the adjoining CPST room.

A male CPST entered my CPST's room and asked us if we wanted to join him for lunch. My CPST asked me if I had time to do this, and I said yes, so we walked through the adjoining CPST room, down a hallway (the first one I'd seen, not counting the one in the entry way with the five mismatched chairs) with several closed doors, to a long rectangular table with chairs around it and newspapers strewn across it. A large paper bag overflowing with sandwiches was in the middle of the table, on top of the newspapers; "it's my treat" said the male CPST who had invited us to lunch. There were 
four other CPST staff seated around the table, and I heard a phone ringing and saw one of them get up and answer a phone on a small table in the corner of a room, which I hadn't noticed. She said to one of the other CPSTs, "it's for you", and that CPST walked over, took the phone, and began talking quietly in the corner of the room. The answering and passing of the phone continued in such a manner throughout the time I spent in the lunch area. The male CPST who'd invited me for lunch handed out sandwiches, and my CPST introduced me to everyone in the room as "the researcher from Case that I'm working with" (so much for deductive disclosure!), and we began to eat. Another CPST came in with cans of pop and handed them out to everyone, including me.

The CPSTs began asking me questions about my research, but stopped abruptly when a teary-eyed younger looking woman (another CPST) walked in and sat down silently. After a moment, she looked up and said "I just got my lay off notice". Then teary CPST noticed me, tried to smile, and introduced herself. My CPST told her I was "a researcher from Case", then shook her index finger at me and said to the teary CPST, "You don't need to worry about her, she's cool". The other CPSTs were silent for a moment; they then all began talking at the same time about how unfair it was and about how uncertain they felt about their own jobs. The teary CPST asked me if Case might be hiring, and I mentioned there were sometimes research assistant positions in mental health-related studies and told her about the web site where she could check this. She thanked me, then took a sandwich proffered to her and began to eat.

The other CPSTs all began telling in tandem about how stressful their precarious job situations were, and how angry they felt about the lay-offs. "We never know when the ax might fall", said the male CPST who'd invited me to join them for lunch. The 
woman who'd let me in (the secretary) walked in, apologized to the teary CPST and said "Bill is here and seems kind of upset, can you see him?" The teary CPST put her sandwich down, wiped her eyes and said, "Yeah, sure, I'll be right out". One of the other CPST staff said "Bill and I go way back, I can see him for you", and the formerly teary CPST staff said "no, I'm fine, I'll see him", and left through the doorway.

After she left, the other CPSTs were silent for a couple of moments, then one of them said "I lost my appetite". Another responded, "Yeah, I'm gonna go back to work". They began standing up, saying goodbye, and leaving the lunch area. I thanked them for including me in their lunch, and my CPST walked me back down the hall, through her workspace and the secretary's workspace, to the entrance area, and we said goodbye. There was no one in the little waiting area/hallway when I left.

Much to my chagrin, I noticed my keys hanging from the ignition in my locked car. I immediately called Triple A on my cell phone, and they told me they were backed up, and that it'd be at least three hours before they could get someone to where I was to assist me. I hesitantly went back to the building, and the secretary buzzed me in again and smilingly asked me if I'd forgotten something. I explained to her what I'd done, and that I'd be around waiting for about three hours. She abruptly and without a word walked out of her office and into my CPST's room. She returned moments later with one of the CPSTs I'd met in the lunch room. She re-introduced him to me and said "He can help you". He smiled at me and we walked outside; he got something out of his car that he used to jimmy my lock open in a matter of seconds, and I thanked him effusively. He said to me "It's not in the job description, but we do what needs to get done around here!", and smiled and waved goodbye to me as I left. 


\section{My impressions}

This is one close-knit group! I felt so incredibly welcomed by them, and noticed that the same personal welcome seemed to be bestowed on anyone who called and/or walked in. It was almost a family-like environment. They seemed to know each other's consumers, and consumers seemed to know all of the staff. Immediately the notion of "continuity of care" came to mind, and I considered how this genuine team approach ensured that each mental health consumer had numerous personal relationships with staff here which could perhaps lessen the negative impact of a primary worker's departure. This team approach seemed an especially good thing given the lay off situation at this agency.

The shared and adjoining office spaces, the phone and in-person conversations within ear shot of each other, and the constant foot traffic to and fro made me wonder about how confidentiality could possibly be maintained. It seemed a HIPPA nightmare to me. Especially peculiar to me was being seated sideways between two CPSTs' desks which faced each other-I felt like the center of attention, and I suppose in terms of the physical set-up, I was. I wondered what it might feel like for a mental health consumer to be in this seat. Without the deep, personal relationships that existed between this team and the mental health consumers they worked with, such a set-up could have been a disaster. Yet in the coming months of observation, I would find only much more of the warmth and camaraderie described in the preceding paragraphs-it was almost like entering someone's living room and sitting and talking while other family members passed by. I could understand why the mental health consumers I spoke with told me they looked forward to coming here; I found myself increasingly looking forward to 
spending time at this office, and was sincerely sad when my time at this office came to a close. I never saw any negative incidents or disruptions at this office related to the mental health consumers' behaviors, despite being told later by administrators that this team worked with some of the "sickest" people at the agency.

Unfortunately, I continued to observe the CPSTs dealing with job stability problems throughout my time at this office. I felt awkward being in the lunch area when the CPST who had been laid off came in-I felt like I was intruding, and wondered if I should leave to give them privacy to process and grieve. Their acceptance of me and willingness to speak so freely in front of me was surprising to me. I would later learn that my years of work experience as a mental health case manager had preceded me, and had given me a certain "you're one of us" status among them. My CPST also later shared with me that she was proud that a former case manager was getting a doctorate, and told me "it's got me thinking that maybe I should get myself back in school".

I was especially impressed that despite the chaotic organizational climate the CPSTs seemed to be experiencing-perhaps best summed up by the statement "we never know when the ax will fall"-the mental health consumers who worked with these CPSTs were still given unwavering personal attention and support. One consumer said to me in passing, "It's like Cheers here". He smiled at me and began loudly humming the refrain to theme song of the television show Cheers. The lyrics of the refrain of this theme song are as follows:

Where everybody knows your name, and they're always glad you came.

You wanna be where you can see, 
our troubles are all the same

You wanna be where everybody knows

Your name.

His comment made complete sense to me, as I'd by that time spent several weeks at this office. Unfortunately, several months after my time at this office had ended, apparently due to agency financial constraints, this team was disbanded and disbursed among several sites, their consumers were likewise redistributed, and this particular location was shut down. I actually became teary-eyed, thinking about, among many things, the man who had hummed the Cheers song to me, and wondering what had become of him after his "Cheers" had been closed down.

\section{Stressed vs. Engaged Climate}

CPSTs at this office seemed to have a drastic juxtaposition of stressed and engaged climate perceptions. Their perceptions of the larger agency of which their unit was a part were extremely negative. I witnessed numerous and lengthy vocalizations of feeling angry, alienated and powerless, regarding the downsizing and restructuring this agency was undergoing. There was an almost palpable sense of mistrust toward the upper-level administration. The word that often came to my mind as I reflected on such observations was "toxic".

In dramatic contrast to the extremely stressful climate CPSTs perceived, regarding the rest of the agency in which their unit was a part, the unit itself seemed to be perceived as an incredibly engaging climate by those who worked there. While Glisson's (2007) constructs of engaging climate pertain to staff at a given agency, the sense of a deeply personal, caring environment within the smaller unit seemed to transcend the staff. 
The overall sense of camaraderie was shared by many of the consumers who worked with CPSTs at this unit. Many of the consumers knew and greeted each other by first name; many consumers also quickly learned who I was and made a point of greeting me and talking with me as they passed through the adjoining office where I often was.

I too felt immediately welcomed and enfolded into this caring little community. The CPSTs quickly learned what my favorite kind of pop was and would set a can out for me during lunch time. Lunch was always a group event for the CPSTs. While spending a great deal of time doing outreach in the community, we'd always reconvene at approximately the same time for a shared lunch. The CPSTs would take turns ordering and picking up food for everyone from various local restaurants. Although I witnessed bickering, it seemed to be in an affectionate manner, and was later described to me as such by the CPSTs involved.

The caring that CPSTs extended toward their consumers was likewise remarkable to me. They often remarked on how much they enjoyed and valued the work they did with their consumers, but even if they had not said as much, it was abundantly obvious to me as I saw them interacting with consumers. In short, this was a group of people who loved their work, but felt extremely alienated from their agency's administration.

\section{Agency D}

\section{Description of My First Field Experience}

I headed to a satellite office of Agency D, located just beyond the outskirts of the downtown area of a large Ohio city. As I drove to this office for the first time, I noticed multiple businesses (banks, insurance companies, and business names I did not 
recognize) and restaurants. There were people in business attire walking quickly on the sidewalk. No residences or green spaces were visible from the road I was driving on. The road was free of potholes and was heavily trafficked; a car behind me honked loudly as I slowed down to check the addresses of the block I was on. I realized I had quite a way to go, and continued to drive. After several minutes, I noticed that the businesses I was passing were primarily pager stores, convenience stores, and one little shoe repair trailer. I also began seeing boarded up storefronts, and passing some residential streets.

I turned down one of the residential streets just to see what it looked like; several of the houses had yards with weeds and tall grass, and broken chain link fences. Most of the houses had chipped paint, and several had boarded up or broken windows. There were what seemed to be later model cars parked in some of the driveways; one of them had a smashed in passenger door and another had doors and hood that were different colors from the rest of the car. Some of the porches had broken stairs, and there were adults seated on several of the porches. I noticed one person drinking what looked like a forty-ounce from the street. I continued around the block, back up a similar street, and turned onto the main road again.

I noticed a large, multi-story brick building with several people standing together outside of it smoking, and one person who was pacing and waving his hands in an animated fashion, several feet away from the others. I saw a bus shelter in front of the building, with eight or ten people standing by or inside of it. There was a sign I could not quite discern, but I decided to pull into the driveway anyway, and realized I'd guessed correctly when I read the name of the mental health center I was looking for on the sign as I got closer to it. 
The parking lot for this building was small, and full; I could barely turn around and drive back out of the lot. I parked on the street in front of the building, and on my way to the front entrance passed the several people waiting at a bus shelter. One approached me and asked me if I could spare a dollar. I shook my head and apologized, and kept walking. I walked past the man who was pacing and waving his hands; now that I was close to him, I could hear him talking seemingly to himself as there was no one else near him. He paid me no attention as I walked past him. I walked through the group of people smoking toward the entrance, and noticed a "For Rent" sign on the building.

I entered the building and a man at a desk asked if he could help me. I saw a sign that listed several businesses in the building, including a medical office on the first floor with a large "Accepts Medicaid" taped to the glass door entrance. I told the man I had an appointment at the mental health center, and he told me to take an elevator on my left to the fourth floor. I hit the elevator button and as I waited, numerous people joined me in waiting. After literally several minutes, the elevator door opened to a car that looked jam packed with people. They all filed out, and those of us waiting crammed ourselves in, and we went up. We were shoulder-to-shoulder, and it was difficult to move in the elevator. (I later learned that there were two elevators, but one of them wasn't working at the time of my first visit to this office.) Most of the people got off at the Social Security Administration office on the second floor, but a handful of us continued up to the fourth floor where the mental health office was.

I saw a sign on a door with the name of the mental health center, and walked through it into room with a glass reception area, a man in uniform seated near the door I had just walked through, and rows of chairs facing each other. There was also a TV 
playing loudly on the far side of the room. Taped below the TV was a sign "Do not touch the dial". Next to the TV was a door, on which was taped another sign which said "Staff Only". I saw client's rights and privacy information posted on the wall, along with agency accreditation information and several award plaques with the agency's name on them. There was a large poster hanging up which said "Recovery is Possible", and a bulletin board next to the poster with various resource and event flyers pinned to it.

Most of the seats in this waiting area were taken by adults who were sitting silently. There was one man talking, and I noticed there was a phone in the corner of the room that he was talking on. There was a sign taped above the phone that said "All calls limited to 5 minutes". As I walked to the glass reception area to tell the receptionist who I was there to see, I repeatedly had to excuse myself as I stepped over the feet of people who were seated on the chairs which faced each other. One of the men I passed yelled out "Tastes like chicken!” as I stepped past him. I thought he was speaking to me, turned, and followed his gaze to the television set, then expecting to see a food program or commercial. I saw nothing on the TV about food, but rather, a soap opera scene. He shouted out this phrase twice more while I was waiting to check in with the receptionist, and the security guard then asked him "What tastes like chicken?" The man looked at the guard and said loudly "Everything!" The guard shook his head, laughed, and said "I bet."

When it was my turn to check in, the receptionist smiled and greeted me, and asked how he could help me. I told the receptionist my name and who I was there to see, and he made a call and said "She'll be right down, have a seat". I went to and sat down in the only open chair at that moment, which happened to be next to the man who 
periodically shouted "Tastes like chicken". He smiled and nodded at me as I sat, and I did the same. There was little leg room, which I had to share with the people sitting across from and facing us. I had to repeatedly move my feet as other people stepped by on their way to checking in with the receptionist. I didn't notice any reading materials.

A man in a suit came in, pulling a black bag on wheels behind him. The guard greeted him by name and asked if he was bringing any lunch today. "Not today, next week", replied the man in the suit. As the man in the suit stepped around our feet, dragging his bag carefully behind him, I noticed he wore a gold pin with the name of a well-known pharmaceutical company. The receptionist told him to "Go ahead", and the man wearing the suit went through the door that said "Staff Only".

Periodically the "Staff Only" door would open, and people wearing badges would step out and loudly call the first name of a person. Usually someone from the waiting room would stand up and walk over, and they'd turn around and together go back through the door. The seats filled up as quickly as they were emptied, by other people who were entering the waiting area. A person wearing a badge opened the "Staff Only" door and called the same name repeatedly, but no one responded. The guard said "I think he's outside", and the man wearing the badge walked outside and returned with the man I'd seen talking and pacing on the street earlier.

After about a half hour, the CPST I had an appointment with opened the "Staff Only" door, called my name and repeatedly apologized, telling me she'd had two emergencies today and was totally off schedule. We walked down a hall, through a doorway, and into a huge room filled with maze-like rows of office cubicles. As we 
walked by them, I noticed some people had pinned up business cards at their cubicle entrances, much like someone might put up a name plate.

The CPST led me past a conference room, then turned back and said "Maybe we should meet in here, there's more room". We walked into a conference room with a large long table, several mismatched chairs, and a dry erase board with what appeared to be a picture of a mouse or rat on it. A man walked in behind us and said "there's going to be a staffing in here in about 15 minutes". The CPST said okay and led me back into the maze of cubicles to her own cubicle.

The CPST's cubicle had a desk with a desk chair, and one chair alongside her desk. There was a phone on her desk, but no computer. I sat at the chair alongside her desk, and noticed several inspirational quotes about mental health recovery that looked like they'd been photocopied from something, and were pinned up on the cubicle wall directly across from the chair I was seated at. On the cubicle wall in front of her desk, I noticed a saw a poster listed numerous "customer care" suggestions. The poster had the mental health center's logo on it.

As we sat and talked, I could clearly hear voices from the other cubicles. It sounded like someone was checking voice mail messages, and I could hear each message clearly, like I was checking messages from the phone next to me on the desk. I heard someone sneeze, and someone else say "God Bless You”. I then heard a man giving reasons why the hospital would be the best place to go (because I heard him talking and then silences, I assumed he was on the phone). We completed our conversation, and the CPST then walked me back through the cubicles, saying hello to several people as we passed them. 
She then stopped abruptly at an office door, saying "Hold on, I want you to meet my supervisor". She knocked on the door, and introduced me to her supervisor, who greeted me and asked me a couple of questions about my research. We then walked to the waiting area, and I asked her if there was a good place to hang out for a little while, as I had some time before my next appointment. She said "You don't want to hang in the waiting room, it gets crazy in there", and suggested I head back toward downtown, where there was a good coffee shop. I thanked her, and walked through the "Staff Only" door back into the waiting area, which was still very crowded. I walked through the waiting area outside to my car, and began driving in the direction of the coffee shop.

\section{My Impressions}

Immediately upon leaving, my first thoughts were about confidentiality limitations given the cubicle situation. I next realized I hadn't reacted nearly so strongly to the shared office scenarios I had observed at the other agencies. I wasn't sure why this was so; perhaps because the cubicles gave some semblance of visual privacy and so the lack of auditory privacy was more startling to me. I looked at my field notes, and saw that I'd noted "cube farm" in the margin of the first page. The cubicles and customer service statements hanging on my CPST's cubicle gave a corporate feel to this office, as did the "Staff Only" sign and the succession of CPST staff calling out names of people in the "Staff Only" doorway. I realized I have a bit of an anti-corporate sentiment, and so strove to set aside these negative judgments and further reflect upon my experiences and observations.

I felt concern that the CPST had disclosed to her supervisor her participation in my study, via introducing him to me. She had acknowledged that she knew her 
participation was confidential and voluntary when we did the consent process. Yet she made a point of seeking him out and introducing him to me, and I could not surmise what her reasons for this might be.

I was excited to see the recovery language that seemed smattered across this office, as well as my CPST's strategic placement of the recovery quotes so that they'd be in direct view of the consumers seated next to her desk. The language of mental health recovery was very visible at this agency, whereas none of the other agencies had any visible artifacts referencing recovery. I wondered whether this embracing of the recovery philosophy would also be apparent in the CPST-consumer interactions I would later observe.

Also, the elevator trip to and from this mental health office would pose significant issues for anyone who was claustrophobic or who otherwise had difficulties in enclosed spaces. I felt a little uncomfortable, and typically am fine in tight spaces. Fortunately, the second elevator was usually working at future visits to this office.

\section{Stressed vs. Engaged Climate}

The CPSTs I interacted with during my field work at this agency echoed the stresses of paperwork voiced by CPSTs at two of the other agencies. Otherwise, they said very little about how they felt about the agency environment, during the time I spent there. One staff person talked about a recent merger, and related differences between the two organizations" "cultures" as being problematic, elaborating that one agency was "more grassroots", whereas the other was "much more corporate-like". But overall, the 
CPSTs I spent time with here were very kind and helpful to me, but seemed guarded in what they said, particularly when they spoke about their administrators. And, they seemed especially concerned about not wanting to "get in trouble" for various things. For instance, when the CPST I met took me to meet her supervisor, I initially thought it was perhaps because she was especially close to her supervisor and wanted to introduce the supervisor to me. As time passed, I realized this instead may have been an effort on the CPST to tacitly ascertain whether participation in my study was permissible.

Certainly the cubicles were depersonalizing to both consumers and staff; I cannot imagine trying to do sensitive clinical work in such an environment, where what is being said can be overhead several cubes out in any direction. The customer service jargon likewise gave me a sense of an impersonal corporate-like environment. However, I am limited to speculating based on my own perceptions with regards to my participating CPSTs' perceived work climate. Because my participants were very task-focused and said very little about how they felt about their work environment, I can only wonder about what that might mean.

\section{Conclusion}

It was readily apparent to me that while the same mandate and outcomes survey were being implemented at each site, there were substantive differences between these urban mental health centers, in terms of physical layouts and organizational climates. The organizational cultures also seemed to differ, from my vantage, and this is something I would have liked to explore further in relation to frontline experiences. 
I made the choice to present the frontline experiences shared by my CPST and consumer participants primarily via aggregated thematic analysis in the next two chapters. Separating these experiences from such unique and rich organizational settings, while methodologically defensible (as I will explain in the next chapter), is nonetheless a major limitation of this study design. However, in the interest of reducing deductive disclosure risks, I feel it is a necessary one. 


\section{CHAPTER 5: THE CPST PERSPECTIVE: "DOING THE OUTCOMES"}

\section{Introduction}

My aim in this chapter is to describe in detail six primary processes (and related understandings and experiences) that all nine participating CPSTs-across all four of the agency sites-referred to in totality as "doing the outcomes". Because all participating consumers referred me only to their respective CPSTs as the person they interact/communicate with regarding the Consumer Outcomes Survey, I am first presenting CPST data to better contextualize the data consumers shared with me. While one of the preferred conventions in institutional ethnographies is to preserve the voices and standpoints of participants as located in specific contexts throughout all written analysis (Campbell \& Gregor, 2002), I have departed from this convention. I made the decision to depart from this convention in analyzing and presenting my findings for two reasons: to reduce the risk of deductive disclosure; and to maintain an analytic focus on institutional processes embedded within the everyday work of the CPSTs and consumers as they "did the outcomes".

Such a departure is not unprecedented in institutional ethnography research. Devault \& McCoy (2006) assert that tagging all quotes with identifying contextual information about each speaker risks individualizing a line of analysis, so that processes become categorized in typologies of individuals or individual organizations/contexts, rather than traced across individuals and settings as institutional relations that socially organize individual experiences across time and space. Smith (2006)-the founder of institutional ethnography methodology-likewise states: 
...some institutional ethnographer writers suppress personal information about informants in order to keep the focus on the institutional processes they are describing; they identify quoted speakers only by their location in the institutional work process of which they speak (e.g. nurse, client, teacher, administrator). (p.41)

Campbell (2006), referencing situations and processes in healthcare settings, similarly maintains that by explicating similar features across differing settings with unique sets of actors and experiences, the social relations that organize such features can be argued to be generalizable to a particular institutional field encompassing the settings and actors.

Given these justifications, I will hence initially present some brief, aggregated demographic information about the nine participating CPSTs to provide some individual level context. For the remainder of this chapter, I will then focus upon explicating in detail the six processes identified by the participating CPSTs "doing the outcomes", suppressing individual participant information other than their role (CPST staff) in the institutional processes of which they are a part. I refer to agency-specific differentials sparingly, referencing them only when necessary to address especially relevant nuances of these six cross-agency processes. The six CPST-identified processes involved in "doing the outcomes"-derived primarily from in vivo language from my field notes (encompassing participant observation and informal conversations) and individual interview transcripts-are as follows: 1) "knowing about the outcomes"; 2) "tracking the survey"; 3) "fitting the survey in"; 4) "filling out the survey"; 5) "getting and understanding the results"; and 6) "documenting". 


\section{Overview of CPST Demographics}

Like the physical settings in which they conducted their everyday work, there were numerous differences and similarities between CPST participants. Education ranged from a bachelor's degree in a non-license eligible field, to a master's degree and additional specialized training in chemical dependency, while experience in social service settings ranged from over 30 years to 3 years. Table 3 details the heterogeneity of participating CPST staff:

Table 3

\section{CPST Demographics}

\begin{tabular}{|c|c|c|c|c|c|c|}
\hline Education & License & $\begin{array}{c}\text { Years } \\
\text { in } \\
\text { field }\end{array}$ & $\begin{array}{l}\text { Years at } \\
\text { agency }\end{array}$ & Gender & Race & Caseload \\
\hline MSW & $\begin{array}{l}\text { LISW/ } \\
\text { CCDC III }\end{array}$ & $\begin{array}{l}\text { over } \\
30 \\
\text { years }\end{array}$ & $\begin{array}{l}\text { over } 20 \\
\text { years }\end{array}$ & $\mathrm{F}$ & $\begin{array}{l}\text { African- } \\
\text { American }\end{array}$ & $\begin{array}{l}\text { approx } \\
50\end{array}$ \\
\hline $\begin{array}{l}\text { BA in } \\
\text { Psychology; MA } \\
\text { in Health }\end{array}$ & none & $\begin{array}{l}6 \\
\text { years }\end{array}$ & 6 years & $\mathrm{F}$ & Caucasian & $\begin{array}{l}\text { approx } \\
40\end{array}$ \\
\hline MSW & LISW & $\begin{array}{l}10 \\
\text { years }\end{array}$ & 5 years & M & Caucasian & $\begin{array}{l}\text { approx } \\
40\end{array}$ \\
\hline BA in Psychology & none & $\begin{array}{l}5 \\
\text { years }\end{array}$ & 5 years & $\mathrm{F}$ & $\begin{array}{l}\text { African- } \\
\text { American }\end{array}$ & $\begin{array}{l}\text { approx } \\
40 \\
\end{array}$ \\
\hline BSW & LSW & $\begin{array}{l}6 \\
\text { years }\end{array}$ & 7 months & $\mathrm{F}$ & $\begin{array}{l}\text { African- } \\
\text { American }\end{array}$ & $\begin{array}{l}\text { approx } \\
40 \\
\end{array}$ \\
\hline BA in Sociology & none & $\begin{array}{l}4 \\
\text { years }\end{array}$ & $21 / 2$ years & $\mathrm{F}$ & Caucasian & $\begin{array}{l}\text { approx } \\
40 \\
\end{array}$ \\
\hline BSW & LSW & $\begin{array}{l}18 \\
\text { years }\end{array}$ & 10 years & $\mathrm{F}$ & $\begin{array}{l}\text { African- } \\
\text { American }\end{array}$ & $\begin{array}{l}\text { approx } \\
18\end{array}$ \\
\hline BA in Psychology & none & $\begin{array}{l}3 \\
\text { years }\end{array}$ & 1 year & $\mathrm{F}$ & Caucasian & $\begin{array}{l}\text { approx } \\
65\end{array}$ \\
\hline BA in Sociology & none & $\begin{array}{l}20 \\
\text { years }\end{array}$ & 5 years & $\mathrm{F}$ & Caucasian & $\begin{array}{l}\text { approx } \\
40 \\
\end{array}$ \\
\hline
\end{tabular}

\section{The Six CPST Work Processes Entailed in "Doing the Outcomes"}

In identifying and describing the everyday understandings, experiences and uses of the Consumer Outcomes Survey articulated and demonstrated by CPST participants, I 
utilized a broad notion of "work" as an orienting concept. Work is explicated by institutional ethnographer McCoy (2006) as simply as the activities people do that are purposive actions, anchored in material conditions and means, and done in 'real time'. McCoy (2006) elaborates:

...work is an empirically empty term; it does not define types of work in contrast with other activities that are found not to be work. Its value lies in directing analytic attention to the practical activities of everyday life in a way that begins to make visible how those activities gear into, are called out by, shape and are shaped by, extended trans-local relations of large-scale coordination. (p.110) Applying McCoy's broad definition of work, I considered CPST understandings, experiences and uses of the Consumer Outcomes Survey as work they did in relation to implementing the survey. To identify this CPST work, I first did line-by-line coding of all field notes and transcripts. I grouped similar codes together, noted processes pertaining to the outcomes described in each grouping of line-by-line codes, created primary work process categories from this groupings, and re-sorted the processes according to how they related to each other temporally and in terms of actual material conditions involved. While I primarily attended to explicating work processes that were referenced across participants and agencies, I did identify and explore idiosyncratic work processes (specific to a single CPST or context) with the individuals who had shared them; I also sparingly reported on such idiosyncratic processes as nuances of cross-site, cross-participant processes when necessary to move the analysis forward (using writing conventions for deductive disclosure harm reduction, as specified in Chapter 3 of this dissertation). 
I clarified cross-participant, cross-site work processes and how they interrelated with each other by member checking (Kuzel \& Like, 1991) with three participating CPSTs. I made revisions according to each CPST's feedback, and individually represented the processes to the three CPSTs. Each of the three CPSTs indicated these six processes seemed to exhaustively encompassed their work of "doing the outcomes". All participating CPSTs typically referred to the Adult Consumer Forms as "outcomes", "outcomes surveys" and "surveys". In an effort to stay close to the perspectives and in vivo language of my CPST participants, in this chapter I utilized their terms whenever possible in referring to the Consumer Outcomes Survey instruments.

\section{Process \#1 - Knowing About the Outcomes}

In my hours of conversation with CPST staff both informally while shadowing them, and during our interviews, "knowing about the outcomes" emerged as the first kind of work CPSTs did in terms of "doing the outcomes". CPSTs referenced "knowing what the outcomes are for", and "knowing what to do with the outcomes", as aspects of "knowing about the outcomes". They described two corresponding processes: receiving initial information about the outcomes; and interpreting that information. CPSTs received such initial information in a variety of fashions:

- $\quad$ Two CPST staff first heard of the outcomes survey in team meetings at which a quality assurance (QA) staff person from their respective agencies attended and spoke about the outcomes. 
- One of the CPST staff first heard of the outcomes from a paper memo "they" sent; the CPST was unable to recollect who specifically sent this memo to her.

- $\quad$ Three CPST staff first heard about the outcomes from their supervisors in a routine staff meeting.

- $\quad$ Two CPST staff first heard about the outcomes from their supervisors in a routine one-on-one supervision meeting.

- $\quad$ One CPST staff first heard about the outcomes from off-site, upper level administration staff who attended one of her routinely scheduled staff meetings.

All of the CPSTs stated it had been a year or longer since they'd first heard of the outcomes survey, and due to the passage of time no one was able to recall specific content or documents they received at these meetings, with the exception of the CPST who reported first learning of the outcomes via a memo received approximately four years ago. This CPST recollected that the memo indicated that the outcomes were both mandated and framed as something positive that would be useful: “ $\ldots$ they sent out a memo saying to look forward to using them, and that there was some type of requirement....”

Each of the CPSTs were, however, able to recollect some of their initial first impressions about the outcomes. Despite the differences ways they received information about the outcomes-and it is likely that there was also substantial variation in the content of what was initially presented to them-their initial impressions were remarkably similar. All of the CPSTs described initial impressions containing the following three ideas: 
outcomes are a requirement; outcomes are related to funding; and outcomes create more paperwork that CPSTs will be responsible for.

With regards to knowing what to do with the outcomes survey, CPSTs stated that formal group trainings were not particularly helpful, and/or had not been done. Of those who attended group trainings, none of the CPSTs were able to recall who specifically performed the formal trainings. Four CPSTs indicated they “...hadn't been trained to do them [the outcomes] in any particular way...", and received instruction packets in their mail boxes; two CPSTs stated they had formal group trainings that they were unable to recall; two CPSTs stated they did not have formal group training, but were given written instructions in individual supervision; and one CPST staff stated she was given written instructions which were reviewed by her supervisor in a routine staff meeting.

All of the CPST staff indicated they'd received some form of written instructions on how to use the outcomes in practice, and all of the CPST staff stated they did not refer to the instructions they received. The following two quotes are representative of the reasons CPSTs gave for not referring to written instructions:

....I remember getting a folder they put together, but I never used it. Stuff like that is generally not helpful for me... usually if someone tells me and shows me [one on one], it is much easier for me to catch on than using one of those guidebooks...

We got references or some information in the training, but it's more in my head, and it's not something I think gets prioritized very much in the course of doing a case management job. I mean a lot of it [case management] is fire fighting, you 
know, so I think that worrying that you're getting the Consumer Outcomes Survey, you know, making sure that you're applying it perfectly isn't something that case managers worry about. It's something that we try to get done and then move on to the agenda that's more pressing...

Although all of the CPST staff indicated they'd received written instructions that they'd read upon initial receipt then no longer looked at, they all also expressed varying degrees of uncertainty about how to use the outcomes with their consumers, for instance: ...I don't know how to use them in treatment planning, and I don't think it was ever really explained. I mean, I know we've had meetings about it and people have, you know, given us guidelines, but the people who are telling us how to use it in treatment planning don't do any treatment planning... they don't work dayto-day with clients and don't have any of the paperwork that we have to do.... A desire for hands-on (simulations, role play) training on outcomes applications with consumers, conducted by experienced clinicians, was referenced by five of the nine CPST staff. One of these CPST staff suggested having a small workshop in which CPST staff would complete outcomes surveys on themselves, and review and discuss their own results, in order to better understand how to meaningfully discuss the survey with consumers.

Participating CPSTs described receiving information about the outcomes in terms of how to use the outcomes with consumers as a fairly circumscribed and finite process. For example: ...we don't talk about how to use the outcomes with our clients in our individual supervisions, we're told how to do them, and that's about it unless they're past due... CPSTs stated the information they received on an ongoing basis about the 
outcomes addressed knowledge of tracking whether and/or when outcomes surveys were due and completed, rather than any knowledge pertaining to uses of the outcomes with consumers. (All of the CPSTs shared at great length with me about the work of "tracking the outcomes", so much so that "tracking" and related communications/information sharing clearly emerged as a separate work process, which will be addressed in detail in a later section of this chapter.) This is expressed at its most extreme by the CPST staff who first heard about the outcomes via a memo: ...they sent out the first memo, and we didn't hear anything until there was a second memo almost a year later, telling us we had to have them all done for our whole caseloads within a month... so we never really heard about the outcomes consistently until there was some sort of pressure on the agency, then it came from the QA [quality assurance department] to our supervisors to us...

Two CPSTs identified two additional sources of ongoing knowledge acquisition about the outcomes. Both of these sources were sought out regarding getting questions answered about the technicalities of completing outcomes surveys electronically on computers. One CPST staff indicated she sought answers to her technical assistance questions by emailing off-site agency information technology (IT) staff, and the other CPST staff said she asked peers when she had questions pertaining to operating the "computerized outcomes survey".

Although ongoing information received about the outcomes pertained primarily to tracking and technical assistance, each of the CPST participants described current understandings of the Consumer Outcomes Survey that had evolved substantially fromwhile continuing to encompass-the unanimous initial impression of "an agency 
requirement related to money". These evolved understandings encompassed the following ideas: seeing outcomes as agency income; seeing outcomes as performance evaluation; and seeing outcomes as a clinical tool.

In addition to understanding the completing the outcomes as "somehow tied to funding with the state", all of the CPST staff indicated completing the survey with consumers was also income in that it was considered "productivity". Each of their definitions of productivity related to the time they spent working face-to-face with consumers (and sometimes "significant others", such as family members and other treatment providers) that could be billed to Medicaid; such time was also referred to as "direct service" and differentiated from "indirect service" which was explained as "not billable”. As stated by one CPST: “...outcomes are a billable CPST activity, it can help our productivity because it is an activity that we can spend with out clients...." A different CPST similarly stated: “...I can do this [the outcomes] and bill for it, and it's all about the billing....

CPSTs also linked the idea of "productivity" with individual CPST income, and as a source of agency revenue. Some of the participating agencies offered a productivity incentive program, through which the CPST staff could earn additional pay if they exceeded a certain number of billable hours. In addition to increasing individual earnings, CPSTs related billable hours to “....making enough money to keep our agency going....” which they then linked back to their own individual job performances: “... there's a set number of billable hours you need to get, and if you don't, you get in trouble.... eventually you'd get fired". The term "productivity" was used interchangeably by all CPSTs as referring to both something that one achieves (as in 
"making productivity"/reporting the required number of billable hours in a given timeframe), and something that one needs to get ("I need to get more productivity").

Performance evaluation, in addition to encompassing productivity, was also linked more vaguely to the completion of the outcomes survey. Three CPSTs (from differing agencies) expressed the idea that the outcomes survey evaluated their own job performances at their respective agencies, as exemplified by: “...the outcomes are to make sure case managers are doing their jobs...." Two CPSTs (from differing agencies) related outcomes to performance evaluation of their respective agencies, for instance: "...the outcomes are done to see if agency clients are treated effectively, meaning are they being respected by the agencies and working on what they need to be working on...."

Each of the CPSTs concurred to varying degrees that measuring outcomes in general offered value and was a good idea. The CPSTs dissented in terms of whether measuring outcomes was generally valuable for clinical practice, program evaluation or both, although all of the CPSTs indicated awareness that “...we're supposed to be using the outcomes in our treatment planning...." In terms of clinical value, CPSTs expressed the following understandings of how outcomes measures might hypothetically be of use: showing change in consumers; helping with coming up with a treatment plan; and seeing if the treatment plan was working on the right things. Overall, in terms of their own work with the Consumer Outcomes Surveys, CPSTs expressed much more clarity about the importance of tracking and completing surveys, than in comparison to their expressed understandings of the clinical utility of the survey. 


\section{Process \#2 - Tracking the Surveys}

Keeping track of when outcomes surveys needed to be completed with consumers was a topic all CPSTs across the four agencies talked about at length, and with varying degrees of frustration. All of the CPSTs stated they received tracking reports computergenerated by the quality assurance (QA) departments at their respective agencies. I reviewed tracking reports from each agency and found them very similar in format; each report format included the consumer's name, the date of the most recently completed survey, and the date the next survey was due. Within "tracking the surveys", CPSTs referenced five interrelated activities tied to the tracking report: getting the tracking reports; using the tracking reports; dealing with inaccuracies on tracking reports; and dealing with "past dues" on tracking reports.

“Getting the tracking report" varied across agencies and per CPSTs occurred in the following ways: received tracking reports via emails sent by quality assurance staff and copied to immediate supervisors; received a hard copy tracking report (generated by quality assurance staff) from their supervisors in supervision; and found a hard copy tracking report in mail box periodically. The CPSTs who received an emailed tracking report both indicated that they received such reports about once per month, whereas CPSTs who received tracking reports via other method stated they did not receive tracking reports with regularity, for example: “...I don't know when I'm going to get the next one exactly, until it is given to me...."

Once receiving the tracking report, eight of the nine CPSTs would review them to see who was "past due" in terms of the most recent survey completion occurring one year ago. The tracking reports seemed to serve as the main way in CPSTs felt reminded (by 
their supervisors and quality assurance staff) to complete the outcomes surveys with their mental health consumers: “...the report kind of keeps the outcomes in my mind as something that needs to get done...." (The ninth CPST used only her own tracking system and did not reference the tracking report generated by the quality assurance department at her agency: “...I keep track of all my own work and the outcomes are no different; I don't rely on someone else to do that-I don't look at the quality assurance report so I don't know if those reports are accurate or not...)."

These eight CPSTs who utilized externally generated tracking reports described "using the tracking report" and "dealing with inaccuracies" as intertwined processes. These CPSTs stated that the tracking reports usually erroneously showed "past due" surveys for one or more consumers who had completed surveys within the past year. Two of the CPSTs who received tracking reports also kept their own lists of when surveys were due consumers and cross-referenced their lists with the received tracking reports. One of these CPSTs pulled out her most recent tracking report and showed me how it compared with her own list: “...look here, all these people they have marked as "past due", they are done... it is scary that with so much riding on the outcomes, that the [tracking] information isn't accurate..." The other CPSTs generally relied on their own recollections of what consumers they had recently completed surveys with as their main way of detecting inaccuracies in the tracking reports: “...I'd see my client's name listed as past due, but could clearly remember us doing the survey say two months ago... this happens a lot...."

When CPSTs identified discrepancies between the QA tracking reports and their own tracking and/or recollections, their usual recourses were to double-check the most 
recent survey completion dates in question via going to consumers' charts (at agencies where surveys were done on paper) or looking the completion date up on their computers (at agencies where surveys were completed electronically). Once the discrepancy was validated, CPSTs typically took this information to their supervisors (some of whom CPSTs stated kept their own tracking lists) verbally or via email. CPSTs indicated this was primarily to “... show that I'd done them, so I didn't hear about it... eventually the tracking report would show it, sometimes there would be some glitch and I'd have to redo the outcomes, but usually it was just the tracking report not keeping up with who was done..."

All but one of the CPSTs indicated that they currently had accurate "past due" listings on their tracking report, and gave similar reasons for why this was occurring and how they addressed it, as exemplified by the following statement:

... I highlight the people where it says "past due"; some of them are past due because they refuse to take it so it always shows up as past due; and then some of them I just forgot to do or the client hasn't been coming in, and I highlight those so I can remember to remind the client, and then when I schedule the appointment, I'll put it in the notes section of my schedule. That's how I usually try to keep up with them...

When I asked what happened in terms of external consequences, if one had "past due" surveys, CPSTs gave responses ranging from “...they'll-my supervisor-ask me what's my plan to get caught out with the outcomes and I'll have to say I'm going to call and schedule so-and-so, so that I have a plan to get the past due ones done..." to "...I don't know, I guess maybe eventually you'd get fired or something if you never did them, but 
maybe not ..." All of the CPSTs stated they received "pressure" to complete past due surveys listing on the tracking report; this pressure was typically communicated from their supervisors via email, memos and/or face-to-face conversations (individual supervision and team meetings) in which CPSTs were told to "do more outcomes". Two CPSTs from two different agencies specifically linked their individual experiences of "pressure to do outcomes" with their beliefs that this occurred mainly when their respective agencies were pressured externally to do more outcomes survey in a more timely fashion: “...when they hear about it [outcomes submissions], then we hear about it - if they don't hear about it, we don't hear about it...”; “...I never hear anything about the outcomes in supervision unless we don't have enough done, that's when I hear about it..."

While being prompted to know when surveys were due was identified as important in "doing the outcomes", CPSTs made it abundantly clear that this in itself was not sufficient in "getting them done". All of the CPSTs indicated that "fitting the survey in" with competing demands-such as a consumer's presented need-was the main reason surveys were past due. Although the number of "past due" surveys varied substantially across CPSTs and agencies, only one CPST voiced awareness of how her agency was faring in outcomes submission rates as compared to other similar agencies. Ironically, the CPST with no "past due" surveys worked at an agency with a low overall survey submission percentage for the number of mental health consumers served there (I obtained this agency level information online via a web site operated by the Ohio Department of Mental Health, on which "Missing Data" reports were posted and publicly available for all agencies required to do the outcomes). Although tracking was 
emphasized to me as the most tedious process entailed in "doing the outcomes"; CPSTs unanimously expressed "fitting the survey in" with competing job demands as the main challenge in getting the surveys completed on time.

\section{Process \#3 - "Fitting the survey in"}

All CPSTs referenced two competing demands with which the outcomes survey had to be "fit in": "fitting the outcomes in with other paperwork" and "fitting the outcomes in with real client needs". As they sought to "fit the outcomes in", CPSTs reported struggling-sometimes unsuccessfully-to avoid transferring "pressure to do outcomes" onto the mental health consumers they worked with. One CPST recounted an incident at length to me, in which he pressured a consumer to do a survey because he had been told he needed to get her outcomes survey completed for an upcoming chart audit: ...she came in very upset, and it was one of those things where I felt like I needed to get this done, had to get it in the chart, it was the time of year that they were really one us about these, you know, chart reviews were coming up from the State or Mental Health Board, and I found myself pushing it and I'm glad she did stop and say 'look, I can't do this' because it sort of grounded me that I needed to, we needed to talk about what she needed to deal with, which was more important, in my eyes. I mean this is also someone I had worked with for about at that time it was roughly about three years. So I mean I was doing this more obligatory sort of perfunctory need and that it was due, and she really had something real to tend to.... 
In shadowing a different CPST who worked for a different agency, I observed a similar albeit more intense scenario first-hand. We made a scheduled home visit to a consumer's home to complete a past due survey with a consumer, only to find the consumer sobbing due to an altercation with a threatening neighbor that had just occurred. While we were waiting inside with the consumer for the police to arrive at the consumer's house (with the threatening neighbor now pacing outside the consumer's home), and after the consumer had stopped crying, the CPST asked the consumer to fill out the outcomes survey because it was "past due". After a moment, the consumer pushed the survey aside, began sobbing again, and ran into another room. The CPST then discarded the survey and focused only on the consumer's current situation and needs for the remaining time we were together.

Each of the nine CPSTs described and/or illustrated as I was shadowing them had variations of the scenarios described above. These situations were far less dramatic then what I recounted in the preceding paragraph, but were nonetheless examples of "balancing real client need with the outcomes". I observed a CPST and a consumer meeting to do the outcomes at the CPST's office. The consumer brought a social security benefits change letter he received in the letter, and stated he was upset and confused by the content of the letter. The CPST and consumer briefly looked over the letter together, spent the bulk of their one hour appointment completing the outcomes survey together, and then revisited the consumer's letter during the final ten minutes of the appointment. (The CPST had a scheduled appointment for the following hour, as well as someone who had come in without an appointment and was waiting, so time was a scarce commodity). 
At the end of that day, the CPST referenced the letter situation and shared feelings of ambivalence with me about beginning or proceeding with the survey rather than spending the bulk of appointment time addressing the consumer's presenting concerns. Emergent consumer concerns were presented by consumers just prior to survey administrations, and/or elicited as consumer responses to survey questions during oral survey administrations. The CPST elaborated more generally on attempting to negotiate the tension between addressing emergent consumer needs and needing to get the survey done:

...you want to be client-centered, start where the client is at, but it's hard sometimes, you know. It's hard sometimes to do the outcomes, even if you know they're due, or worse, past due, and you have an appointment to do the outcomes, or remember them [the outcomes] when the client comes in, ... sometimes it's someone who needs something else, or someone you don't see that often or regularly, their outcomes are due, and then they come in with, 'I don't have any medicine. I'm feeling suicidal. I'm going to be kicked out of my apartment, I need to eat', and the last thing on your mind becomes completing a survey. You know, you're worried about, 'Okay, how do I get this person medicine? Why have they not been here?' I mean, all of these other things will take precedence, a sort of putting out this fire thing...

All of the CPSTs made some sort of reference to the notion of "fire fighting" emergent negative situations within the context of addressing "real client need". However, six of the CPSTs indicated addressing "real client need" was not limited to 
emergent negative situations, but rather encompassed emergent positive situations as well. For instance:

...the other side of the coin is, it [completing the outcomes survey], even when we've scheduled to do it, can feel like an interruption when... I mean, some of them come in and really have a good day and want to share that, need to share that... or they have something wonderful happen to them... when something like that does happen, I think I, should be part of that with that person. I don't want to say 'that's great, but for this appointment I'm going to have you do a survey'... Scheduling appointments specifically to complete outcomes surveys was a strategy each of the CPSTs utilized to varying degrees. However, asking a consumer to meet to complete the outcomes survey posed its own set of challenges in terms of honoring consumer needs and preferences. As one CPST put it:

...many of my clients aren't exactly jumping to do outcomes... sometimes I have to almost not tell them what we have an appointment for because then they won't want to meet, or then when I pull the survey out they're like 'oh no, I don't have time to do that long survey paperwork'...

The completion of the outcomes survey was not the only type of paperwork the CPSTs were attempting to "fit in" their work with consumers. This balancing of "real client need" with "paperwork" was a prevailing theme with various forms the CPSTs stated they were required to complete with their consumers. The required forms were fairly consistent across the four agencies although there was variation (I will discuss salient aspects in an upcoming section on documentation processes). These forms included the following: demographic data sheet; a diagnostic assessment with periodic 
updates; an individualized service plan with specific goals and minimally annual reviews/updates; releases of information; a psychiatric evaluation and psychiatric progress notes (if the consumer was seeing a psychiatrist at the agency); and billing information. CPSTs across agencies referred to these forms in sum as "the chart". Charts across agencies were essentially bound folders stored in "medical records rooms", which contained sections generally according to the type of form each section contained, such as a section entitled "ISPs" (individualized service plans).

CPSTs overwhelming indicated that they (CPSTs) had primary responsibility for "keeping the chart up-to-date", and this "paper work" detracted from their "productivity" (billable hours providing services to consumers). As one CPST explained at length to me:

It's not just filling out a goal sheet with your client... all things to do with the chart seem to fall on the CPST, for example, signatures and dates. Even if a psychiatrist needs to sign something and didn't the first time it passes through his or her mail, it is on us to get it to the psychiatrist again, make sure the psychiatrist signs it and dates it, make sure it ends up back in the chart, in the correct place on the chart... we don't have to file, but we still need to make sure things are filed correctly because if not we're [CPST staff] the ones who get in trouble with audits and such... so that means pulling the chart, checking the goal sheet, if it's not there then looking in the psychiatrist's mail box and the to-be-filed drawers... but then if it is finally there and signed, the date might be late, the psychiatrist's signature date, and there's no fixing that... and this is for every goal sheet, for every client... it's a lot of chasing things down, figuring things out, and none of it 
is billable...we go back and forth from 'get your hours up' to 'get your paperwork in', depending on the time of year, if it's audit time or something... sometimes with so much energy put on making sure the charts are in order and making sure that we are productive in the sense of billable hours productive, I think that sometime people get lost, clients get lost, they become numbers, and that is a very sad thing to me. A very sad thing. I feel passionately about that... In addition to balancing maintaining "the chart" with "real client needs" and "productivity"; all CPSTs referenced maintaining "the chart" as something the outcomes survey completion needed to be "fit in with" to varying degrees. All but two of the CPSTs saw outcomes completion as separate from "the chart paperwork". (The two CPSTs who included the outcomes when describing the chart to me worked at the same agency, and received outcomes results in a packet format related to the ISP due date, which will be discussed in detail in upcoming sections in this chapter on results and documentation.)

“Chart management, that's what I'd call it", said one CPST, further elaborating: “...it's a hierarchy of needs for the chart, and the outcomes are still not as high up compared to chart management at this point because there are other things that come first, within the chart management... the outcomes are becoming more important, though..." When I asked this CPST what things in particular came first and why, she answered without hesitation: "ISPs and goals, you have to have them done within four visits or thirty days or they're late, and then you have to keep them signed and up-to-date..." When I asked how the outcomes were becoming more important, she said “...there's more pressure on the agency to do them now, which means more pressure on us...." All 
CPSTs referenced these ISPs and goal documents as important parts of the chart, and additionally included the diagnostic assessments as priorities:

...diagnostic assessments are the bible of your chart... they are due every three years, and everything is supposed to link with them... I know they and the ISPs have to be done by a certain date, but I can also do them days up to and before that date... I have all kinds of ways I try to keep track of them...

While all but two CPSTs specifically differentiated between "the chart" and "the outcomes", all CPSTs made references to struggling to "fit" the outcomes content with other chart documents. The following CPST statement is fairly representative of such expressed sentiments:

...well see, that's the thing. I mean theoretically I think it is supposed to be part of the chart, but it feels like, it feels like it's its own entity, feels like it's its own separate piece, that must get fit in somehow, but I know it's supposed to be part of the treatment plan or something, but they don't work together so well...

When I explored this with CPSTs further, their responses encompassed the following four interrelated themes: many of the outcomes questions are not "medically necessary"; diagnostic assessment information fits "medical necessity" better than outcomes; the diagnosis must drives goals, more than outcomes; and the survey needs diagnosis-specific categories with specific symptom criteria for it to fit with the rest of the chart. They specifically referenced these themes back to treatment planning as the main way in which outcomes had to be made to fit in, as exemplified by the following two quotes: ...it's not easy or direct as to how to apply that information [outcomes survey results] to the goals that we're writing with the client, you know. Like if the 
client is not happy, for example, with their quality of life... well, it doesn't... I mean, it would be nice if it automatically tied into a symptom with a suggested goal or something...

...I do the best I can, to tie them [the outcomes] into treatment planning, but it's a different language or something...

Another CPST shared with me a "cheat sheet" and explained it was provided to her by quality assurance staff at her agency via email. This CPST described the sheet as follows:

...it lists out the outcomes domains and tries to translate them to possible goals based on symptoms and diagnosis, it still doesn't quite work with my clients, it's just not practical, I'm not sure why... I guess I get goals from talking with my clients, and try to make sure it matches what the diagnostic assessment has down, especially if it is a newer client... otherwise the client might be happy but I get in trouble at audit time [if goals do not match identified diagnostic assessment needs]... the agency might have to pay money back or something if the goal and the assessment don't match, I think...

Because "medical necessity" and "medically necessary" were recurrent themes across all CPSTs' statements in terms of how the outcomes survey did not seem to "fit" with the other chart paperwork, I asked for elaborations of what these phrases meant. (I attempted to suspend my own understandings of what "medical necessity" meant, which I gleaned from fifteen years of work experience in the public mental health system in Ohio, 
so as to better understand the perspectives of the CPSTs I was learning from.) The following statement is fairly representative of how CPSTs responded:

...by 'medical necessity', it is about the symptoms, what mental health symptom does the client have that makes the service or goal or whatever you're doing 'medically necessary'... if it's not 'medically necessary', we're not supposed to be doing it, the agency doesn't get paid for it...

All of the CPSTs indicated the non-symptom content of the outcomes survey was generally important, to varying degrees, irrespective of difficulties encountered when trying to integrate this content with other documents in "the chart", for example:

... feeling empowered, safe in your housing, liking your life, those are important things to know about a person you're working with, no question, in terms of helping that person... I'm just not sure how they fit in [with 'medical necessity']; sometimes the housing fits because the housing can get disrupted by symptoms, but with the other stuff, it's harder to fit it together...

"Fitting the survey in" - in terms scheduling, emergent consumer needs and ongoing existing paperwork demands and related constraints - was a challenge CPSTs across all four agencies identified and emphasized to me at length. This "fitting in" process occurred before, during and after the next work process in "doing the outcomes", commonly referred to by CPSTs as "filling out the surveys".

\section{Process \#4 - Filling out the Surveys}

"Filling out the survey" refers to the physical act of documenting a consumer's answers to the 67 survey questions on an electronic or hard copy form. From my 
conversations about and observations of CPSTs, "filling out the survey" (from CPST perspectives) encompassed: introducing and explaining the survey form to the consumer; deciding how to complete the survey (orally/ "together" or with the consumer reading it silently "by themselves"); and the actual act of filling out the form. I observed sixteen CPST-consumer dyads completing the survey (although 17 consumers participated in my study, one of the consumers had already recently done his outcome survey with his CPST prior to participation in my study). During each of the 16 outcomes administrations I observed, CPSTs began with a brief explanation of the survey purpose. I specifically compared and contrasted within-agency explanations and between-explanations, as they might relate to each agency's compliance status with the $80 \%$ completion threshold mandate. I did not find any particular explanations specific to a particular agency. Below are responses that typify the explanations CPSTs provided to their consumers:

- “...we're very interested in how we're doing with our services, and this is like the survey we did before."

- “... the purpose of the outcomes is to get an overall picture of how you're doing and then to tie that back to treatment goals. There are 67 questions. Tell me if you don't understand anything."

- “...this will be tallied by data entry and put into a report, and then I'll go over it in depth and we'll look at changes for your treatment plan. That's the purpose of this tool."

- “...today we're going to do the outcomes.” No additional explanation was offered to the consumer, who responded "Oh, we're going to do that again". 
- “...this is something from the State, and we'll work with what we have here (gestures at survey), and something good can come of this if you fill it out..."

- “...this is the survey you've done before. We do it when you first come in, then every six months, then yearly..." No additional explanation was offered to the consumer, although she stated she did not recollect doing the survey.

Once a brief explanation was offered to the consumer regarding the survey, the next process entailed deciding how to "do" the outcomes. In the sixteen dyads I observed, all but one CPST offered the consumer two choices regarding how to "do" the outcomes: "together" (CPST orally reads the survey questions to consumer who verbally answers to CPST, CPST then notes or touch screen enters answers) or "by yourself" (consumer silently reads questions to self and silently answers via writing or touch screen). Twelve consumers immediately and explicitly asked their respective CPSTs to complete the survey with them orally when given this option. Of these twelve consumers, two consumers' respective CPSTs read the survey questions to them from a computer screen, and the remaining ten consumers' respective CPSTs read the survey questions to them from a hard copy form.

The four consumers who chose to complete the survey "by themselves" (this was the phrase most typically used when CPSTs referenced to me the consumer reading the survey questions silently and writing the answers on the form or using a computer touch screen to input the answers), three did so via writing answers on a hard copy form and one completed the survey electronically. Of these four consumers, one was not offered 
an option regarding preference of survey administration mode. Each of the four consumers requested that their respective CPST staff remain with them while they completed the survey, in the event that they had any questions, and all of their respective CPSTs did so. Three of the four participating agencies were represented by this group of four consumers who chose to complete the survey "by themselves", and each of the consumers had a different CPST, so this choice did not appear to be a CPST-specific or agency-specific phenomenon.

While literacy would certainly be a determining factor in how the survey was completed with a consumer, as would other communication barriers and impairments, all of the consumers who participated in this study had basic literacy skills, at least some high school education, were English-speaking, and all but one had vision and fine motor capabilities sufficient to complete the form. (One consumer indicated he had difficulty seeing the text, even with his glasses, and said that was part of the reason he wished the CPST to read the questions to him.) Having more education did not coincide with completing the survey "by themselves"; in fact, the converse was true. The group of consumers requesting that the survey be administered orally-"done together"encompassed all of the participating consumers who had some college education or college degrees, as well as consumers with the least amount of education (those who had had completed some high school but not graduated). Mental health diagnoses and symptom-related impairment also varied widely in the group of consumers requesting the survey be "done together". Conversely, the three of the four individuals who requested to do the form "by themselves"-with their CPSTs present-were Caucasian females with high school educations, who were diagnosed with Borderline Personality Disorder. 
The CPST-consumer dyads who completed the survey orally "together" did so in almost identical fashions, regardless of agency, survey administration location, or survey format (electronic vs. paper). The CPST would proceed by reading the directions for each section verbatim, and then would read each question aloud to the consumer, and mark down the consumer's answers. When a paper survey was used, all but one CPST angled it directly toward their respective consumers, seemingly so as to give them the most direct view of the survey. When a computer was used, the CPST asked the consumer to pull up his/her chair next to the CPST, and they would sit together at the CPST's desk; the CPST would then mark the answers given by touching the monitor touch screen.

For these twelve dyads who completed the survey "together", the interactions between the consumers and CPSTs during the reading of the survey also followed a very similar pattern comprised of two processes. CPSTs did work that they referred to as "translating" the abstract survey questions to consumers; in addition, they also "translated" consumers' specific life experience answers into the abstract survey categories. The following exchange illustrates a CPST translating a survey question to a consumer who is struggling to understand the question as written; this CPST (who later told me she'd read somewhere-but couldn't remember where-not to give an explanation of a question when administering the survey) first tries to direct the consumer to use the consumer's own understanding of the question, but quickly gives a direct answer when the consumer becomes frustrated and distressed:

CPST: "Are you in treatment because you want to be?" (Reading survey question aloud) 
Consumer: "Is that mental health treatment? Or drug treatment? I don't have a drug problem. Or is it some other kind of treatment? Or am I just not getting it?"

CPST: “Just go with whatever you think 'treatment' means, and answer by that."

Consumer: But I don't know what it means, I'm confused, I guess I just don't get this stuff." (Voice raises.)

CPST: "No, no, you're right, that could be a confusing question. I think they're referring to mental health treatment there."

Consumer: "Oh, yes, then." (Responding to original survey question as read)

Unlike the exchange above, most CPSTs answered consumers' questions with direct explanations, the first time their respective consumers asked for an explanation of a question. This occurred repeatedly-with one exception-during both oral administrations, and when consumers completed the surveys "by themselves". (The exception occurred with a consumer filling out the survey via reading it silently; she completed the whole survey silently and returned it to the CPST without any questions.) One CPST explained:

Often you have to explain the questions, translate them, because they don't know what they mean... What I find a lot of the time is changing the way it's worded to where it makes sense... like trying to figure out what the question is trying to ask and then rephrasing it in a way that the client gets...but then I'm still not sure we've got it right sometimes....

This CPST's comment is illustrated by the following exchange: 
CPST: "Concerns about my medications (such as side effects, dosage, type of medication) are addressed." (Reading survey question)

Consumer: "What? I don't understand what you mean."

CPST: "When I sit with you and your doctor, and you want to talk about your medicines, when you have questions or problems with them."

Consumer: “It doesn't happen when you're not there, but you usually are, so, put down 'often' as my answer."

The CPST in the exchange above later told me that she wasn't sure what to put, since the consumer reported that medication concerns were not being addressed when the CPST was not present: “...I'm not at that many doctor appointments with her, so I don't know about 'often', but that's what she said so that's what I put." The CPST also noted on a sticky paper to "talk with Dr. X about consumer X's meds". In addition to the CPST doing "translating" work, this exchange illustrates a CPST being given a specific account of a situation, rather than an answer to the abstract survey question; this is also something that occurred repeatedly during oral survey administrations.

The following exchange again illustrates a consumer being asked a general survey question, and responding by sharing a specific scenario in her life that her CPST was unaware of:

CPST: "I am usually confident about the decisions I make." (Reading survey question)

Consumer: "I don't know... I'm thinking about going back to work, my daughter has housekeeping work I could do, but the baker down the street said she needs some part-time cleaning help, too." 
(The CPST and consumer had a brief discussion about the pros and cons of each of these options and what social security reporting would entail.)

Consumer: "I think I'll work with my daughter. I feel sort of confident about that"

CPST: "So that would be.... 'Agree'?" (Looking back at the survey question)

Consumer: "Yes."

Sometimes the specific scenario shared by the consumer in response to an abstract survey question was more urgent in nature:

CPST: "I feel powerless most of the time." (Reading survey question)

Consumer: 'I am bogged down, I'm not helping my daughter... my daughter's school isn't responding to my calls, I've met with her teachers over and over, I don't think they're giving her medicine but they say they are and she just looks worse and worse to me... she sits in her room, doesn't talk with me, let alone tell me if she's getting her medicine at school... and my daughter's counselor here isn't calling me back... I don't know what else to do...." (Consumer begins to cry)

(The CPST ceases reading the survey questions and begins to question consumer further about this situation; she obtains the counselor's name, and asks the consumer if she'd like the CPST to attempt to contact her child's counselor after they finished the survey. The consumer says "yes, please", and the CPST notes the information about the consumer's 
daughter on a piece of notebook paper and clips the notebook paper to a blank release of information which they fill out after the survey is completed.)

CPST: "Back to the question, 'I feel powerless most of the time'."

Consumer: "Every day, because of my daughter's situation."

CPST: "So, 'Agree', or 'Strongly Agree'?”

Consumer: "There are times I feel like I can do something about it, though.” CPST: "So...?"

Consumer: "Agree"

I observed multiple exchanges such as the ones above, in each of the twelve dyads who completed the survey orally "together". The CPST typically briefly explored the concern and made informal notes on notebook paper or "post-its" when consumers shared specific concerns information in response to the abstract survey questions; they would then revisit the scenarios after the survey was completed. When I questioned them about their experiences of such situations, CPSTs repeatedly voiced a tension between "wanting to explore the concern raised" and "needing to get the survey done". However, time constraints often presented a problem with regards to addressing the emergent concern, and an additional appointment or contact was often scheduled to address the concern that had emerged during the oral survey administration.

In contrast, I did not observe any instances such as the ones above when consumers filled out surveys "by themselves". I witnessed numerous exchanges in which the CPSTs were asked by consumers (doing the survey "by themselves") to "translate" the abstract survey question and did so. However, none of the consumers 
shared specific concerns with their CPSTs that were elicited by the process of filling out the survey questions.

With regards to "translating" survey questions to consumers, one African American CPST expressed concern that her African American consumers more often struggled with the survey questions. She shared with me:

...it's not every client, but, we serve a lot of Black clients. Most of them, you know, I can speak how they speak so that they understand, but I still need to rephrase things, constantly repeat and give examples... sometimes they get frustrated and don't want to finish. It's the bias in any kind of standardized test that non-White people face, you know, Blacks often don't do good on those kinds of tests because they don't talk that way. I'm not saying use Ebonics necessarily, but there's certain ways that we phrase things. I can speak both ways, but a lot of my clients can't. That's just reality. They don't need fair treatment, they just need a fair chance to be able to express themselves-they can express themselves just like anybody can-they need a fair chance to express themselves by having [survey] language that doesn't block, confuse, that expression...

The other participating CPSTs in my study did not share this CPST's concerns about racialized bias in the Consumer Outcomes Survey, when I specifically probed regarding this. I did not observe any specific instances in which I was able to detect such a bias as such. I was thus unable to develop a cross-agency thread of analysis regarding these concerns. However, due to the extensive and long-standing institutionalization of racism in the United States, I felt this individual CPST's concerns should not framed as idiosyncratic/specific to one individual, but rather, considered as a potential 
institutionalized aspect of "doing the outcomes" that I am unable to adequately explore due to a short-coming in my study design.

All but one of the CPSTs who completed the survey orally with consumers stated that consumers at times expressed issues that the CPSTs were previously unaware of, via offering situation-specific answers to the abstract survey questions. CPSTs stated this was especially prevalent in working with "new" consumers; consumers could be "new" to the agency, or "new" to that particular CPST. From what the CPSTs shared with me, I ascertained that the agencies varied substantially in terms of when the surveys were completed with new (to the agency) consumers: one of the agencies (with a high survey submission rate) routinely had the outcomes survey completed at the time of intake, which was done by a central intake agency at which the staff had multiple contacts with consumers prior to transferring them to ongoing CPST services; one agency (with a moderate survey submission rate)was working toward having the outcomes survey completed at the time of a typically single session, in-house intake/diagnostic assessment, but this was not routinely occurring due to time constraints; the other two agencies (with moderate or low submission survey submission rates) did not typically have outcomes completed prior to a consumer being transferred to a CPST staff for ongoing services. With regards to initial survey completion, one CPST staff stated: ...I think it'd work better if it was done at intake, from the standpoint of one less form you have to get done like, yesterday, with your new client, but when it's not done, you don't know that person to work with them and see what their needs are... and often when they first meet you, they may not talk about anything deep, 
so the survey could be a way to get them talking, and maybe help in some way with initial goals...

In contrast, another CPST staff (at the same agency) indicated she would prefer to do the survey herself orally with the new consumer, and wished that she could delay the initial administration by a few months to build a rapport with the consumer prior to asking the survey questions:

...it takes some clients a while to warm up, and build a rapport... I don't like doing outcomes with a new client, I'd rather wait a few months and give them a little time to feel safe and comfortable, they've already been asked so much just to get in the door... I know there's the whole baseline thing, but I think the answers would be more accurate later, when the client is feeling more trusting ...

With regards to working with consumers who were "new" to the CPST staff but not the agency, two CPSTs said the felt orally completing the survey was a way to begin to get to know the consumer: “...it helps me, because I'm new [to the consumer] and their treatment plans were written by the previous worker, and the survey can be just another way to begin to understand..." In addition to oral survey administration helping to elicit issues with "new" consumers, CPSTs also indicated that "long-time" consumers (consumers they had worked with for a substantial length of time and felt they knew well) would at times share new issues in response to a survey question, for instance: ...With my one client, we'd worked together for years, and I never knew he was raped, until we were doing the outcomes. I don't even remember what question it was that I asked, that he responded to with the rape. His other symptoms may have been a spin-off 
of this, something that happened long ago and that for whatever reason, he didn't share until now, years later... I mean, he was asked during the diagnostic assessment and psych eval, but sometimes people aren't ready right off the bat to share something like that..." Another CPST stated she felt that orally administering the survey was a way for her "long-time" consumers to consider and verbalize their needs: “...I think most people like to give their opinion, want to know what they need to be working on, and the survey is another way to help them verbalize what they need... it gives them another way to have a voice...

One CPST had a distinctly differing opinion about the value of oral survey administration. She explained that she felt any value of oral survey administration was derived through the process of talking itself, rather than anything to do with the survey content:

You and I are communicating now because I'm talking to you. I talk to my clients. I see them regularly. I don't need a piece of paper to tell me how they're doing, because I already know, I talk to them in real time, I'm already up to speed. But I have to do them [the surveys], so I do, and then we talk some more about things we both know that I already know about them. My clients and I talk, survey or no survey, that's what we do. But they expect my clients to talk to them through a piece of paper [the survey]; the piece of paper is an inanimate object. They'd do better if they did face-to-face interviews, rather than a piece of paper, an inanimate object, as far as the client's feelings go... and that's what agencies are built on now. Once I turn the paper in, the paper is data, the client feelings become data, I took statistics, I know what data is... 


\section{Process \#6 - Getting and Understanding Results}

Once surveys were completed, the processes through which survey answers were converted into "results" were distinctly agency specific, yet the results report formats were nearly identical. A typical results report contained numerical scores for questions in each Consumer Outcomes Survey domain that a consumer had scored high or low on, and indicated such as areas responded to 'most positively' and 'most negatively'. With regards to getting answers processed into such a report, a CPST who completed the survey with consumers electronically explained:

I just hit the button that indicates I'm done, and that's that; it then goes maybe to our QA department who keeps track, and then somehow the State gets it, and I can print out my results right then...problem is, I'm not really sure what to do with them in terms of working with my client...

All CPSTs who completed the surveys electronically similarly stated they had immediate access to survey results reports.

In contrast, CPSTs who completed paper surveys gave the completed surveys to either a designated data entry staff, or their respective supervisor, and then had minimal control over when they would "get the results". CPSTs who completed paper surveys generally described three kinds of experiences with "getting the results": getting the results when the consumer's ISP was next due (which could be months following the date of survey completion); not knowing when one would "get the results" (weeks or months later, without a particular pattern); and "not getting results". 
Upon completing a hard copy survey, CPSTs sent the completed survey via interoffice mail to either a data processing staff or to their supervisor (who then forwarded it to data processing staff). CPSTs who gave their completed surveys to their supervisors indicated that their supervisors kept records of which surveys were completed when and thus wanted to see the completed survey before forwarding it to data entry. Once data processing staff typed the answers into a computer program, the hard copy surveys were then returned to CPST supervisors via inter-office mail, with a results print-out. CPST supervisors then forwarded the hard copy survey and results to the CPST staff.

CPSTs at all three of the agencies that did hard copy survey administration indicated that this process could take months. CPSTs at two of the three agencies who did hard copy data entry (the paper surveys were completed and sent to data processing for entry into a computer) indicated the data processing staff were very busy, and that they did not know when results/hard copy of survey would be returned. As stated by one CPST

...the survey goes to a young lady who does data entry for the whole agency, I think, I know of only her who does it... she compiles the answers up somehow and computerizes them, scores them into a specific ... I know it's a specific program she uses on her computer, then the report goes to my supervisor and then to me. But she [the data processing staff] is really backed up, basically buried, so it can take a long time, weeks, months, I have some people I've never gotten results for...

In contrast, CPSTs at one of the three agencies doing hard copy survey administrations stated they knew for certain that results would be returned shortly before 
the next ISP was due, as part of a packet received in their mailboxes. The packets included the following information: demographics; medications; signs of decompensation; diagnoses; an assessment update; outcomes survey results; and service utilization data. Regarding timing of packet receipt, one CPST noted:

... worst case scenario, it can take as long as eleven months before the packets come, depending on when the outcomes are due and when the ISP is due... if the outcomes are due the month after the ISP is due, I get a packet with outcomes results that are eleven months old... things can change a lot in even a few months...

CPSTs who received the outcomes results as part of packets indicated that the hard copy survey and results were filed in the consumer charts at some point:

... but I have no idea when it [the hard copy survey and respective results report] hits the chart, I'd have to keep pulling the chart and checking and looking for the results, and honestly I don't have that kind of time to be thinking about and doing that...

When I asked about where these packets came from and what they were for, I was told that:

... they come from my supervisor who does the assessment update part, and I think quality assurance does the other stuff... the packet reminds us the ISP is due, and we're supposed to use them for treatment planning...

In contrast to the CPSTs at the other agencies that returned results without linkage to the ISPs, these CPSTs indicated they felt the outcomes were part of "chart management", although they were no more clear on how to "fit" the outcomes results into goal 
formulation with consumers. CPSTs at the agency that dispensed such packets (with outcomes results) also had the highest rate of outcomes completion (as did the agency overall, as compared with the other three agencies in this study).

CPSTs at the other two agencies that administered surveys via hard copies diverged (within and across the agencies) as to what was to be done with the actual hard copy survey and results report, once they received these, despite a specific outcome section existing in their charts (where presumably the outcome surveys and results were to be filed). They were fairly evenly divided (within and across agencies) as to whether the surveys and results were to be filed, or destroyed, once received and reviewed. None of these CPSTs indicated outcomes-related work as part of "chart management".

CPSTs at the agency where surveys were administered electronically did print out hard copies of survey results reports, and indicated that these results were to be destroyed after review rather than filed in the charts. One of the CPSTs printed actual survey questions and answers from the computers for each of her consumers, and kept these documents locked up separately so that she could pull them for comparison purposes from year to year. She stated the computer retained only prior survey results, and that she couldn't print a prior completed survey in its entirety with questions and answers listed, so she kept her own copies in a secured location, explaining: “... I find them more useful that the results format, in terms of reviewing them and comparing them with my clients..."

Of the CPSTs who received results, about half shared them with consumers. In such meetings that I observed, the way in which these CPSTs presented the results reports to consumers were remarkably similar across agency settings. CPSTs typically 
started the results discussions by handing consumers a hard copy of their survey results. The CPST staff would then comment about the content of the report verbatim, using the language and numbers on the report, and attempt to elicit a response from the consumer. Consumers appeared to participate minimally despite CPST attempts to elicit consumer thoughts and feedback. I did not witness any goal formulations based on discussions of results reports. When I explored these observations with CPSTs, they generally stated the format of the report was not conducive to working with the consumer. The following quote exemplifies many of the concerns expressed about the results report format which were cited as impeding clinical usefulness:

...it's all those numbers, and it doesn't explain what the results means, it just regurgitates the questions and scores in a different way... it'd help if it actually talked about findings or described the client or something... and also if it showed how the client's answers changed from the last time... then we'd have something good to talk about...

At the agency that included the results report with an ISP packet, CPSTs informed me that their supervisors use the results when meeting the CPST and consumer regarding the ISP. When I first saw one of these ISP packets, I was impressed by the organization and integration of the information within them and momentarily lost my perspective as a researcher. Memories of my own struggles with voluminous paperwork while working as a case manager/CPST years ago flooded my mind, and I blurted out that I thought the packet was a great idea. The CPST I was speaking with hesitated, looked down at the packet and then back at me, and stated: 
...actually, we get so much paperwork in the packet, it's overwhelming-we don't really look at it-we might look at parts of the packet if we needed something specific, but I don't use it in treatment planning... I already told my agency director that I think the survey results are good for macro measuring service results perhaps, but not so good for helping us in treatment planning...

\section{Process \#7 - Documenting}

All of the participating CPSTs indicated that they "document the outcomes" in the progress notes that are written in the chart after a specific practice encounter (entailing completion and/or review of results of the outcomes survey) with a client; when I asked about how they document the outcomes, this was the only type of outcomes documentation work described to me by each of the CPSTs. However, in addition to this type of documentation, I observed (via participant observation and chart review) the following other kinds of documentation work that CPSTs were involved in regarding the outcomes: handling hard copy survey/results; informal notations of client information elicited through oral administrations of the outcomes; the marking of check boxes and text fields-pertaining to the outcomes-on assessment and treatment planning related documents; and receiving a ISP/outcomes results packet. Each of these kinds of work comprised dimensions of "documenting the outcomes".

As previously stated, CPSTs for the most part did not indicate outcomes-related work as "chart management"; one CPST stated outcomes were perhaps moving in the direction of becoming part of the chart: “... it's [outcomes-related work] starting to head toward becoming sort of chart management, sort of, but really it is still a separate thing in 
my mind and in my work... a separate paperwork thing from the chart paperwork...". The chart paperwork documents-relating to assessment and treatment planning-at all four of the agencies made reference to outcomes-generated information, typically through: text fields in which outcomes-related information was to be noted; and check boxes, that when marked, indicated outcomes-related information had been utilized in completing assessment and/or treatment planning documents. None of the CPSTs made reference to filling these out/using these, and I did not observe them being utilized. I discovered these through reviewing the charts of consumers I had observed, with the exception of the packets with outcome results that were given to CPSTs shortly before ISPs were due (CPSTs at this agency showed me these packets).

I observed clinical utilizations of documented information generated from oral outcomes administration utilized in goal formulation. This information was typically generated through interchanges between CPSTs and consumers in which they moved back and forth from textual abstractions ("being afraid in open spaces") on the survey to specific experiential-based knowledge elicited from the consumer in response to the question ("I had a panic attack on the bus on the way here"). This occurred when the CPST read the abstract survey text question to the consumer, and the consumer responded with a specific instance rather than one of the prescribed answer categories. The CPST would typically acknowledge the instance, and they either briefly discussed it then, or the CPST would make a notation of the specific consumer concern elicited by the survey question and revisit it following survey completion. The notations of specific consumer concerns generated by the oral reading of abstract survey questions were done on a "sticky note" or legal pad or other informal/non-chart document, which was 
shredded after the concern was addressed. While the vast majority of such consumer concerns generated in such a fashion were clinically addressed and noted in the corresponding progress note for that practice encounter, I did not see any progress notes that explicitly linked the consumer sharing of the concern with the oral completion of the Consumer Outcomes Survey. And as stated previously, the vast majority of clinical utilization of outcomes-generated information I observed occurred through such oral administration/informal notation processes. There was thus no chart documentation for the vast majority of consumer-CPST interactions/incidents in which I witnessed clinical use of outcomes-generated information (there was typically documentation of the concern and related intervention, but not of how the concern and intervention related to the outcomes).

Chart documentation written by CPSTs regarding the outcomes most often referenced completing the outcomes survey, and less often referenced discussing the survey results. About half the practice encounters I observed in which surveys were completed had corresponding progress notes indicating survey completion (this was consistent across all agencies); approximately a quarter of the encounters I observed in which results were discussed had corresponding progress notes. At the agency where surveys were completed electronically and results obtained immediately, the progress notes typically noted survey completion rather than discussion of results. One of the agencies had a drop down menu for electronic progress notes; for outcome completion, the drop down auto note read: "Assisted the client in completion of the outcomes survey due to Agency X (name mental health symptom and related barrier)". None of the consumer charts I reviewed at this agency utilized this drop down auto note, rather, 
statements across all agencies typically read: "Completed outcomes survey with client"; or "Completed outcomes survey with client and reviewed results". I found one progress note for an observed practice encounter which did indicate specific consumer concerns and relate them to the outcomes results (at an agency with a low outcomes submission rate).

\section{Conclusion}

In sum, CPSTs across all four agencies shared numerous understandings, experiences and utilizations of the Consumer Outcomes Survey. All CPSTs identified the following dimensions of "doing the outcomes": 1) "knowing about the outcomes"; 2) "tracking the survey"; 3) "fitting the survey in"; 4) "filling out the survey"; 5) "getting and understanding the results"; and 6) "documenting". There was some variation between agencies within each of these processes. The most significant variation seemed to relate to: electronic vs. hard copy administration of the outcomes (and subsequent immediate or delayed availability of results); and in understanding the outcomes as paperwork that was a part of or separate from "chart management".

CPSTs who viewed the outcomes as part of chart paperwork had the highest outcome survey completion rate, as did the agency they worked for. This understanding seemed to be related to how outcomes results were given to them (within a packet to be used for ISP planning). However, these CPSTs were no more likely to clinically utilize the outcomes results. All of the CPSTs voiced a "mismatch" between "medical necessity" documents (the diagnostic assessment and treatment plan) and the outcomes survey, as well as a feeling of "struggling to make them fit together". The vast majority 
of observations of clinical utilization of outcomes elicited information occurred during or immediately following oral administration of the survey; there was no documentation of such clinical utilization of outcomes-generated information noted as such in the progress note or chart. Oral administrations were the method of administration most requested by consumers, when they were offered a choice in how they wished to complete the survey.

There was some overlap between CPST and consumer experiences of "doing the outcomes", which I have provided a partial (CPST) perspective on within this chapter. In the next chapter, I will specifically explore consumers' work (understandings, experiences and uses), with regards to "doing the outcomes". 


\section{CHAPTER 6: THE CONSUMER PERSPECTIVE ON “DOING THE OUTCOMES"}

\section{Introduction}

In this chapter, I will focus upon on explicating in detail the work processes (utilizing the generous definition of work explained in the previous chapter) shared with me by participating consumers in reference to their experiences of "doing the outcomes". The four work processes identified by all consumers, across agency settings, are: 1) making sense of what the outcomes are/are for; 2) filling out the survey; 3) getting/understanding results; and 4) using the outcomes experience to better understand one's self.

As with the previous chapter, I will briefly present initial demographic information on participating consumers to offer some individual-level context. In explicating the work processes identified, I will suppress individual participant information, other than their role (mental health consumer) in the institutional processes of which they are a part. As in the prior chapter, the purpose of this suppression is to maintain an overall analytic focus on the institutional processes as experienced by individuals and to avoid individualizing a line of analysis whereby processes become categorized in typologies of individuals or individual organizations/contexts, rather than traced across individuals and settings as institutional relations that socially organize individual implementation experiences across time and space (DeVault \& McCoy, 2006).

To attempt to remain close to the perspectives of my participating consumers, I will again whenever possible use in vivo language in this chapter. (Not surprisingly, 
consumer terms for referring to the Consumer Outcomes Survey are nearly identical to the terms used by CPSTs, as described in the previous chapter.) I clarified crossparticipant, cross-site work processes and how they interrelated with each other by member checking (Kuzel \& Like, 1991) with four participating consumers. I made revisions according to each consumer's feedback, and shared the revisions with the four consumers, who at that point said the processes were representative of their experiences "doing the outcomes".

\section{Overview of Mental Health Consumer Demographics}

While the seventeen mental health consumers who participated in my study all resided in an urban area (large city municipality neighborhood), they evidenced substantial variation in other demographic characteristics. Ages ranged from 26 years old to 73 years old, with the average age of a consumer participant being 45.76 years of age. Eight males and nine females participated. Racial groups of participants were comprised of African-Americans (seven participants) and Caucasians (ten participants). All participants were English-speaking U.S. citizens.

Education levels varied from no high school to having a bachelor's degree: four participants had less than a high school education (of which one was currently enrolled in a GED program); eight participants had high school diplomas or GEDs; three participants had some college coursework; and two participants had bachelor's degrees. Although reading and writing skill varied widely within this group, all participants demonstrated a basic ability to read and write in my presence. While some of the participants wore 
visual corrective lenses and/or walked with a cane, none evidenced a disability that would preclude independent completion of the outcomes survey.

There was also variation in terms of income. Fourteen of the participants received Supplemental Security Income (SSI), Social Security Disability Income (SSDI), or some combination of the two (all recipients of disability-related income qualified for the income based on a mental health disability). One consumer received SSI and worked part-time; one participant was employed and did not receive SSI/SSDI; and one participant was financially supported by families and friends and did not receive SSI/SSDI. Five participants indicated they were not currently employed, but were actively seeking employment of various kinds. (In filling out the outcomes survey (which will be addressed in-depth in an upcoming section), a demographic question pertaining whether the consumer was disabled or unemployed was problematic for six of the consumers. The five consumers who received disability income and were seeking work, and the one consumer who was employed and receiving disability income, each indicated uncertainty about how to respond.)

There was also substantial diversity in diagnosis: five consumers were living with a primary psychotic disorder; ten consumers were living with a primary mood disorder; and two consumers were living with a primary anxiety disorder. Two consumers were formally dually diagnosed with a substance-related disorder, however, my reviews of consumer charts revealed another four consumers had substance abuse issues documented (but no diagnosis had been made). Five consumers were also diagnosed with personality disorders. Table 4 provides specific diagnostic and demographic details for each of the participating mental health consumers 


\section{Table 4}

\section{Consumer demographics (continued next page)}

\begin{tabular}{llllllll}
\hline Consumer & Age & Gender & Race & Education & Employment & Income & Diagnoses \\
\hline & & & & & & \\
1 & $26 \mathrm{yr}$ & $\mathrm{F}$ & $\begin{array}{l}\text { African- } \\
\text { American }\end{array}$ & some college & none & SSI & $\begin{array}{l}\text { Mood d/o w/out } \\
\text { psychosis }\end{array}$ \\
\hline
\end{tabular}

\begin{tabular}{|c|c|c|c|c|c|c|c|}
\hline & & & & & & & $\begin{array}{l}\text { Mood d/o w/out } \\
\text { psychosis; } \\
\text { Anxiety d/o; }\end{array}$ \\
\hline 2 & $27 \mathrm{yr}$ & $\mathrm{F}$ & Caucasian & h.s. diploma & none/seeking & SSI & Personality d/o \\
\hline
\end{tabular}

\begin{tabular}{|c|c|c|c|c|c|c|c|}
\hline 3 & $33 \mathrm{yr}$ & $\mathrm{F}$ & $\begin{array}{l}\text { African- } \\
\text { American }\end{array}$ & $\begin{array}{l}\text { enrolled in } \\
\text { college }\end{array}$ & none & SSI & $\begin{array}{l}\text { Mood d/o w/out } \\
\text { psychosis; BPD }\end{array}$ \\
\hline 4 & $36 \mathrm{yr}$ & M & Caucasian & h.s. diploma & none & SSI & $\begin{array}{l}\text { Mood d/o w/out } \\
\text { psychosis }\end{array}$ \\
\hline 5 & $38 \mathrm{yr}$ & M & $\begin{array}{l}\text { African- } \\
\text { American }\end{array}$ & $\begin{array}{l}\text { some high } \\
\text { school }\end{array}$ & none/seeking & SSI & $\begin{array}{l}\text { Psychotic d/o; } \\
\text { CD }\end{array}$ \\
\hline 6 & $39 \mathrm{yr}$ & $\mathrm{F}$ & Caucasian & $\begin{array}{l}\text { some high } \\
\text { school }\end{array}$ & none & SSI & $\begin{array}{l}\text { Mood d/o w/out } \\
\text { psychosis; } \\
\text { Personality d/or }\end{array}$ \\
\hline 7 & $41 \mathrm{yr}$ & M & $\begin{array}{l}\text { African- } \\
\text { American }\end{array}$ & $\begin{array}{l}\text { enrolled in } \\
\text { GED }\end{array}$ & part-time & wages & $\begin{array}{l}\text { Mood d/o w/out } \\
\text { psychosis }\end{array}$ \\
\hline 8 & $41 \mathrm{yr}$ & $\mathrm{F}$ & Caucasian & some college & part-time & $\begin{array}{l}\text { SSDI \& } \\
\text { wages }\end{array}$ & $\begin{array}{l}\text { Psychotic/Mood } \\
\text { d/o; Anxiety } \\
\text { d/o; Personality } \\
\text { d/o }\end{array}$ \\
\hline
\end{tabular}

\begin{tabular}{|c|c|c|c|c|c|c|c|}
\hline 9 & $45 \mathrm{yr}$ & M & Caucasian & h.s. diploma & none & SSI & Anxiety d/o \\
\hline 10 & $47 \mathrm{yr}$ & M & Caucasian & h.s. diploma & none/seeking & $\begin{array}{l}\text { friends \& } \\
\text { family }\end{array}$ & $\begin{array}{l}\text { Mood d/o w/out } \\
\text { psychosis; } \\
\text { Anxiety d/o; CD }\end{array}$ \\
\hline 11 & $48 \mathrm{yr}$ & $\mathrm{F}$ & Caucasian & BS degree & none/seeking & SSDI & $\begin{array}{l}\text { Mood d/o w/out } \\
\text { psychosis; } \\
\text { Anxiety d/o; } \\
\text { Personality d/o }\end{array}$ \\
\hline 12 & $53 \mathrm{yr}$ & $\mathrm{F}$ & Caucasian & h.s. diploma & none & SSI & $\begin{array}{l}\text { Anxiety d/o; } \\
\text { personality d/o }\end{array}$ \\
\hline 13 & $55 \mathrm{yr}$ & $\mathrm{F}$ & $\begin{array}{l}\text { African- } \\
\text { American }\end{array}$ & GED & none/ seeking & SSDI & $\begin{array}{l}\text { Mood d/o w/out } \\
\text { psychosis; } \\
\text { Anxiety d/o; } \\
\text { Personality d/o }\end{array}$ \\
\hline 14 & $55 \mathrm{yr}$ & M & $\begin{array}{l}\text { African- } \\
\text { American }\end{array}$ & h.s. diploma & none & $\begin{array}{l}\text { SSI \& } \\
\text { SSDI }\end{array}$ & $\begin{array}{l}\text { Psychotic d/o; } \\
\text { Anxiety d/o }\end{array}$ \\
\hline
\end{tabular}




\section{Table 4}

Consumer demographics (final section)

\begin{tabular}{|c|c|c|c|c|c|c|c|}
\hline Consumer & Age & Gender & Race & Education & Employment & Income & Diagnoses \\
\hline 15 & $57 \mathrm{yr}$ & $\mathrm{F}$ & Caucasian & BA degree & none & SSI & Psychotic d/o \\
\hline 16 & $64 \mathrm{yr}$ & $\mathrm{M}$ & Caucasian & h.s. diploma & none & $\begin{array}{l}\text { SSI \& } \\
\text { SSDI } \\
\end{array}$ & Psychotic d/o \\
\hline 17 & $73 \mathrm{yr}$ & $\mathrm{M}$ & $\begin{array}{l}\text { African- } \\
\text { American }\end{array}$ & $\begin{array}{l}\text { some high } \\
\text { school }\end{array}$ & none & $\begin{array}{l}\text { SSI \& } \\
\text { SSDI }\end{array}$ & $\begin{array}{l}\text { Mood d/o } \\
\text { w/out } \\
\text { psychosis }\end{array}$ \\
\hline
\end{tabular}

\section{The Four Mental Health Consumer Work Processes of "Doing the Outcomes"}

In observing, talking with and learning from this diverse group of participating consumers, four primary work processes pertaining to their experiences of "doing the outcomes" (over half of the consumers used this phrase, likely due to having heard their respective CPSTs using it) emerged. These four processes identified in some fashion by all participating consumers, across agency settings, are as follows: 1) making sense of what the outcomes are/are for; 2) filling out the survey; 3) getting/understanding results; and 4) using outcomes information to better understand one's self.

\section{Process \#1 - Making Sense of What the Outcomes Are/ Are For}

Consumers all articulated a process of making meaning pertaining to the outcomes survey. This process has the following dimensions: first hearing of the outcomes (and related initial understandings); understanding the outcomes survey as a measure of a moment in time ("not me overall"); understanding the outcomes purpose as to help the consumer/self vs. understanding the outcomes purpose as to help the agency; and believing outcomes in general to be helpful. These dimensions identified by 
participating consumers cut across CPST staff and agency differences in their experiences of the outcomes survey.

Fifteen of the seventeen consumers told me they first learned of the outcomes survey from their CPST worker at the time (the majority of consumers indicated they had changed workers since learning of the outcomes). One of the remaining two consumers stated he had first learned of the outcomes survey from a notice in the agency lobby, and the other stated she was unable to recall how she'd first learned of the survey. Participating consumers were unable to recollect specific time frames regarding when they'd first learned about the outcomes, but offered estimates ranging from "sometime last year" to "a few years ago". None of the consumers were able to recall what their initial understandings of the outcomes survey were.

However, all of the consumers were able to articulate to varying degrees their current understandings of the outcomes survey and its purpose. I compared and contrasted these articulated understandings with understandings and explanations voiced by consumers' respective CPSTs, but was unable to find a correlation or pattern. Consumers thus may have been deriving their understandings from their own experiences of completing the outcomes survey and the comprehension of the survey content, and/or from content shared with them by previous CPST staff. The majority of consumers made reference to the survey as measuring "a moment in time" in their lives, rather than making a global statement about them or their entire previous year; the following two quotes are representative of such references:

- “...They [the outcomes survey responses] show more of a moment in time, I answer in the moment rather than the past year, that's how it's 
worded...I had a lot of stress culminating this week, so am bad off compared to maybe last month..."

- “...I feel happy, better, about my housing now, because my sister got a bunch of things fixed for me... if I'd answered that question today instead of a few weeks ago, it'd make a big difference, but that was me, at that moment in time...”

All consumers indicated the survey purpose as "a requirement, something that has to be done", either to assist agencies (and thereby assisting consumers indirectly) or to assist consumers. All of the consumers recognized the survey as something that "...gets done when it is due..." rather than the timing of the survey completion as relating to something intrinsic in their respective life situations. Only one consumer voiced an awareness of a policy necessitating the outcomes, as follows: “...it's kind of like No Consumer Left Behind...." The other consumers expressed an awareness of the survey needing to be done in a more general sense, along with uncertainty as to why. The following statements exemplify this:

- “...it's some kind of rule we have to follow..."

- “...I don't know exactly, my worker says it’s due and so we do it..."

- “...we do it because we're supposed to, I guess..."

Consumers diverged (roughly 50:50) in terms of whether they believed the purpose of the survey completion was primarily to assist them, or primarily to assist the agency staff in their work with consumers. Consumers who understood the survey purpose as assisting them gave two primary understandings of how the survey was to benefit them: “...helping me see changes in me..." and “...helping me better understand 
myself and my current situation". Consumers who indicated the survey was to help them see changes in themselves stated this could occur if they were able to compare current survey responses with past responses; all but one consumer indicated such a comparison had not taken place in their outcomes experiences, and all voiced interest in doing such a comparison. (This will be further discussed in an upcoming chapter in this section regarding getting and understanding survey results.)

The following are expressions of consumer understandings of the outcomes survey purpose as to help them better understand their individual selves and current life situations:

- “...it's [the outcomes survey] for helping me learn more about myself, you know, and how my situation is..."

- “...the questions are to make me look my situation, really look at it, and to see how I am in the situation..."

Such understandings of the survey were present-focused, and related to increasing self awareness, a primary survey use identified by consumers (which is discussed in a later section in this chapter pertaining to using the outcomes experience in addressing one's mental health).

One consumer who indicated the survey was primarily to assist benefit consumers stated it did not actually do so: “... it's a waste of my time, it's not relevant to my situation." This consumer also completed the survey via reading it silently so that the survey would "be over with faster", and reported having refused the survey in the past because "it didn't offer anything to me". This consumer stated the addition of a comments section - where consumers could write concerns and progress in their own 
words and give feedback about the provider agency - would improve her perception of the survey in terms of its usefulness for consumers.

Consumers who understood the purpose of the survey as to assist the agency articulated this in a number of ways, all of which stated or alluded to helping the agency to be of more help to consumers. Hence understanding the survey purpose as to assist agencies also included an understanding that the survey was essentially to "...help them help us...." The following are examples of consumer expressions of this understanding:

- “...the survey is provided to see what services should be provided [to the consumer] or worked on..."

- “...outcomes are done to help staff understand the clients who come in here, to help them [the staff] take care of them [the consumers]..."

- “... it's kind of like 'No Consumer Left Behind'; the outcomes are supposed to make sure the agencies are doing their jobs and helping us..."

- “...the survey helps the agency to see how the clients are doing with things, life and the program..."

- $\quad$ “...the agency people ask the survey questions because they care and want to know how someone like me is doing, so they can help me better..."

Within the group of consumers who understood the outcomes survey purpose as to assist agencies, there was a sub-group of three consumers (spanning three agencies) who, in addition to understanding the survey purpose as assisting staff/the agency, also expressed an understanding of the outcomes survey as "a test", with "right" and "wrong" answers:

- “...I hope I got a good grade on it, do you [the CPST staff] think I will?" 
- “...I tried really hard, I hope I got all the answers right and passed..."

- “...I wasn't sure about some of the answers, but I think I passed pretty good, at least did okay..."

This sub-group of consumers also expressed more anxiety about filling out the outcomes survey (which will be further addressed in an upcoming section in this chapter pertaining to filling out the survey and related consumer identification of feeling states).

All seventeen consumers indicated in some fashion that taking a survey to measure outcomes was in general a good idea and had value. The follow are examples of such understandings:

- “... I think it is a good idea to measure things, to see how people are doing... they should also ask more about our views of the agencies..."

- “Taking polls, asking questions, they're good things, because I think it's good idea to check on, see where someone is from time to time, it's a way to find out, you know, filling out questions helps do that, lets you know people care..."

One consumer (as previously noted) stated she had in the past refused to take the outcomes survey, “...not because I'm against surveys or anything, I just think this one doesn't get information for the consumer, and is not relevant to me...." This consumer similarly concurred that the idea of measuring outcomes in general was a good idea.

\section{Process \#2 - Filling Out the Survey}

The physical act of filling out the survey was a work process engaged in by all consumers across sites, with the following dimensions emerging: deciding how to do (fill 
out) the outcomes survey ("together"-orally via the CPST reading questions aloud vs. "by myself"-reading the survey questions to one's self silently and completing it in this manner); the actual completing of the survey (which encompasses "deciding what the question means" and translating one's specific life experiences into abstracted survey response categories); and awareness of having feeling states pertaining to survey questions and while completing the survey.

As briefly explicated in the prior chapter, the process of "deciding how to do the survey" was one that occurred interactively between CPSTs and consumers, immediately following a brief introduction of the survey given by the CPST. In the sixteen dyads I observed, all but one CPST offered the consumer two choices regarding how to "do" the outcomes: "together" or "by yourself" (which CPSTs referred to when talking with me as "by themselves"). Twelve consumers immediately and explicitly asked their respective CPSTs to complete the survey with them orally when given this option. Of these twelve consumers, two consumers' respective CPSTs read the survey questions to them from a computer screen, and the remaining ten consumers' respective CPSTs read the survey questions to them from a hard copy form.

The twelve consumers who requested doing the survey "together", all but one (who had a visual impairment) did not appear to do so due to literacy or impairmentrelated issues; these consumers' educations ranged from bachelor's degrees to no high school, and their observed and reported symptom impairment on the date of observed survey administrations also varied widely. During our individual interviews, I asked each of these consumers how they decided to do the survey "together". Their responses pertained to: enjoying the interaction with the CPST; feeling that assistance with 
confusing questions was more readily available done "together"; and using survey questions to elicited emergent concerns that they had not yet shared with their workers but meant to. The following are representative of such responses:

- 'It's more fun when we interact; it's boring just reading it, and I like talking together as we do it."

- $\quad$ "I can understand easier when my case manager reads the question; sometimes I get confused when I'm reading by myself..."

- $\quad$ "My worker helps me when I get stuck, I don't have to ask for help because my worker is doing it right with me."

- $\quad$ "I like talking through the questions, it brings up things that I might forget to tell my worker..."

The three consumers who chose to complete the survey "by myself" (this was the phrase most typically used by consumers) all did so via writing answers on a hard copy form. The fourth consumer was not offered an option by his respective CPST regarding his preference of survey administration ("together" vs. "by myself") mode. However, each of the four consumers requested that their respective CPST staff remain with them while they completed the survey, in the event that they had any questions, and all of their respective CPSTs did so. There could be a possible diagnostic correlation, as each of the three consumers who actively chose to do the survey "by myself" were Caucasian females living with/diagnosed diagnosed as having an Axis II personality disorder (Borderline Personality Disorder or Mixed Personality Disorder with Axis II traits). Their educations ranged from having no high school to having some college. 
When I asked these consumers (with the exception of the consumer who had not been offered a choice) how they'd decided to do the survey ("together" or "by myself"), their responses related to: feeling negatively about the survey; wanting to complete the survey quickly, and being familiar with the survey questions. (Consumers who opted to complete the survey orally also seemingly had familiarity with the questions via having completed the survey at least once before I observed them, but did not specifically reference this familiarity.) The following are excerpts from each of their responses:

- $\quad$ 'It's a stupid survey; I just want to get it over with faster so I read it myself..."

- “It's the same questions every time, it doesn't matter, I just need a pen..." - "I've done it before, I know what it asks and I just want to get it done..."

Participating consumers each identified two kinds of work processes they engaged in during in the actual act of completing the survey (irrespective of whether they completed it "together" or "by myself”): “deciding what the question means"; and translating their concrete, specific life experiences into the abstracted survey response categories. "Deciding what the question means" was something each participating consumer spoke about at length during our individual interviews, as well as something I observed during administrations of the survey. Consumers generally talked about struggling with deciphering question content as follows:

- “...some of the questions were, let me see, how do I explain this? They don't make them simply worded, so it's like, I had to ask myself a lot of times 'what does this question mean?', and sometimes I had only vague ideas..." 
- “...I tried to make sense of what it [some survey questions] was saying, but sometimes I really wasn't quite sure what it meant...."

- “...sometimes the questions are tricky, sometimes I understand some of them, and some of them get a little tricky. I think "what do they mean, or what does that answer mean?"

Several consumers who received results reports related misunderstandings of survey question content to whether they agreed or disagreed with the results report summation of their concerns. One consumer stated:

...There were some questions, I tried, but I guess I didn't understand what they, or the answers, meant at that time. So the answer I gave wasn't what I really meant. Meant, yeah. The results then, they don't fit me, yeah....

All consumers indicated they had asked their CPST staff for help in understanding "what the question means". I observed four to ten instances of such assistance (corresponding with the CPST task of translating survey questions to consumers described in the previous chapter) for each of the twelve consumers who completed the survey orally, whereas I observed a total of twelve instances for the four consumers who completed the survey "by myself". Of the seven consumers who completed the survey "together" and received results, five indicated the results were accurate. Of the two consumers who completed the survey "by myself" and received results, both indicated there were aspects of the results that they found inaccurate. (Results will be discussed further in an upcoming section in this chapter.)

The work of translating one's own concrete, specific life experiences into general, abstracted survey response categories was something that I observed only with 
consumers who completed the survey "together" with their CPSTs, and occurred in the context of these consumers sharing actual recent experiences or concerns in response to a survey question read aloud by their respective CPSTs. (Consumers who completed the survey "by myself" may have gone through a similar process as they silently read the questions, but they did not explicitly reference such a process to me.) In the previous chapter, I described the CPST work processes pertaining to this in the section "fitting the survey in", regarding negotiating tensions between addressing emergent consumer needs, other documentation requirements, and needing to get the survey completed. Consumers did not voice such a tension to me in the same fashion when I explored with them their experiences of such times, rather, all participating consumers expressed an awareness of the survey "...being due...". In addition, multiple consumers indicated that the survey questions prompted them to recall specific concerns and share these concerns with their respective CPSTs.

To illustrate this, I revisit below an exchange (shared in the previous chapter in the context of explaining the CPST's work in the situation), this time to explicate the work of the consumer:

CPST: "I feel powerless most of the time." (Reading survey question)

Consumer: “I am bogged down, I'm not helping my daughter... my daughter's school isn't responding to my calls, I've met with her teachers over and over, I don't think they're giving her medicine but they say they are and she just looks worse and worse to me... she sits in her room, doesn't talk with me, let alone tell me if she's getting her medicine at school... and my daughter's counselor here isn't 
calling me back... I don't know what else to do...." (Consumer begins to cry)

(The CPST ceases reading the survey questions and begins to question consumer further about this situation; she obtains the counselor's name, and asks the consumer if she'd like the CPST to attempt to contact her child's counselor after they finished the survey. The consumer says "yes, please", and the CPST notes the information about the consumer's daughter on a piece of notebook paper and clips the notebook paper to a blank release of information which they fill out after the survey is completed.)

CPST: "Back to the question, 'I feel powerless most of the time'."

Consumer: "Every day, because of my daughter's situation."

CPST: “So, 'Agree', or 'Strongly Agree'?”

Consumer: "There are times I feel like I can do something about it, though."

CPST: "So....?"

Consumer: "Agree"

When I talked with this consumer, she explained to me in detail how the question elicited her specific situation:

...it [the survey question] brought it to the surface, I had pushed it down, tried to bury that feeling, what was happening, I wasn't going to tell her [the CPST staff], I don't know why not, but the one question triggered me back to it and I knew I needed to tell my worker, right there and then, and it poured out of me....

When I asked what it was like to continue the survey after having the concern elicited and sharing it, the consumer responded: 
... it was okay, I felt better actually, I knew we were going to take care of it, that I was going to get some kind of help, and we went through the rest of the questions and I was fine, much better than when we'd started...

This consumer made no reference to feeling her needs were disrespected or discounted through the act of resuming and completing the remaining survey questions (after the CPST had stopped the survey completion process, acknowledged, briefly attended to her emergent needs and voiced intention to return to addressing those needs).

Multiple consumers shared similar instances with me (which I also observed), and explained a related scenario to me with regards to sharing their sharing of specific information in response to/elicited by a survey question. This related scenario entailed having intention to share specific information with CPST staff but forgetting to do so until reminded through a survey question. One consumer explained this to me as follows:

...even though the question is more of a general 'Do you feel upset?', you're like 'Oh yeah, this and that happened and I was so upset and I meant to tell my case manager', and then you do it [tell the case manager]...

Awareness of such feeling states was something over half of participating consumers, across all agency sites, voiced to me during our individual interviews. Awareness of feelings, and changes in feelings, occurred prior to, during and after the survey. In the example I gave of the consumer who shared a specific situation relating to her daughter in which she had felt powerless, the consumer expressed awareness of how her feelings changed as follows: 
... it was okay, I felt better actually, I knew we were going to take care of it, that I was going to get some kind of help, and we went through the rest of the questions and I was fine, much better than when we'd started...

When I asked her if she thought she answered the remaining survey questions more positively, she responded: ...yeah, I think so. I mean, I felt powerless, and then I didn't feel powerless so much, I felt like I was doing something by telling my worker, so yeah, I probably had happier answers...

Four consumers also described to me changes in feeling states during the survey, in which they felt more negative, as exemplified by the following statement:

...I was feeling crummy to start with, and starting off with how terrible my money is made me feel more down, so I answered the other questions worse than I might have done otherwise... I mean, come on, it's depressing to think about, you have no friends, no money....it's all terrible... I felt like a loser....

In addition to such verbalizations, I also observed an instance in which a consumer who had begun an oral survey administration in what appeared to be a pleasant state (she smiled and joked with the CPST and I) began crying in response to a survey question mid-way through.

Three consumers (from three different agencies) identified having awareness of feeling states or potential feeling states prior to the survey, all of which related to anxiety. One of these three consumers was diagnosed with a primary anxiety disorder. None of these consumers showed any signs or symptoms of paranoia. All of these consumers completed the survey "together" with their respective CPSTs, and indicated that doing the survey together helped reduce anxiety: 
- “...knowing you have to do a survey can cause someone to stress, so it's better to have your worker do it with you..."

- “...I got kind freaked out after my worker said there's a survey to do, but we did it together and it wasn't so bad that way..."

- “...just the idea of a survey makes me nervous, I don't know why...” Multiple consumers, across agency sites, suggested that a question be added to address “. ...you're feeling while you're taking the survey", and/or "...how it feels to take the survey".

\section{Process \#3 - Getting and Understanding Results}

The consumers' work of getting and understanding survey results fell under three dimensions: receiving results; reviewing results; and understanding results. All of the consumers indicated they did not actively ask their CPST staff for results, but expected the CPST to share the results at some point. Of the consumers who didn't get results the day they completed the survey, none indicated they had given thought to getting results after the day they completed the survey. As put by one consumer: “...I assumed I'd get results of some sort whenever they were ready, I didn't really think about it after I did the survey, but when I was doing the survey I figured I'd get results some kind of way...it's not something I really thought about again...."

While all but one of the participating consumers voiced to me an interest in seeing their respective survey results, several consumers at two of the four agencies (both agencies did hard copy administrations; one had high survey completion rate and one had a low survey completion rate) stated they had never seen/received results. At the agency 
where the survey was completed electronically (moderate survey completion rate), all consumers stated they had received results from their CPST staff immediately after they did the survey. At the fourth agency (hard copy survey administration, low survey completion rate), consumers stated they usually received results from their CPST staff, but typically weeks or months after they had completed the survey.

All consumers who received results stated the format was confusing-both during my observations and during our individual interviews-and indicated they would have difficulty understanding results without CPST assistance. I observed three consumers reading the results silently when they first were given them, and one consumer told me he'd tried to look at his results report at home. These consumers all stated they have difficulty interpreting what the results meant and relied upon their respective CPST staff to "interpret them".

Difficulties shared related primarily to the numerical format and lack of inclusion of prior survey results, and were conveyed to me primarily via suggestions for changing the survey format. Suggestions for improving the survey related directly to these two identified difficulties, and pertained to using narration and pictures instead of numbers. The following two quotes exemplify such suggestions:

- “...they should use words to tell you instead of numbers, like a personality profile or something that you can read easily that says you're this or that at the present time...."

- “...it would help to have last year and this year's results pulled together so I could look at both of them and think on it better, maybe like a graph or 
something that you can look at and understand easy, whether you've improved or changed...."

Of the consumers who received the results, all received the results from their CPST staff in a face-to-face meeting. In such meetings that I observed, the ways of presenting results were remarkably similar across agency settings. Consumers were provided with a copy of the survey results report by their CPST staff; CPST staff would talk about the content of the report verbatim, using the language and numbers on the report, and consumers appeared to participate minimally even when CPST staff made attempts to elicit consumer feedback.

Although from my observations, reviewing results appeared to be a very rote process in which consumers did not verbally participate much, most consumers who received and reviewed results indicated that they found the review process in at least one of several ways. Although none of the consumers recalled using the results in treatment planning, one consumer linked reviewing the outcomes results as being helpful in eliciting specific concerns that could potentially be addressed in treatment planning:

In some points, as far as me and the Case Manager went through, it helped me to point out some of the issues that I need help on to help me develop a plan and a goal. So it helped a little bit with identifying some areas that I needed more help in, and it expressed the needs that I needed more, especially when my mind is like boggled with so much stuff...

Other consumers (across all four agencies) found discussing results with their CPST generally helpful with regards to raising self-awareness in two ways: agreeing with the results and "learning more about myself"; and disagreeing with the results and 
"making me think more about why I disagreed with them [the results]". Consumers who agreed with the results referenced positive aspects of the results-most often from the empowerment section of the survey-when telling me about how their self-awareness was raised, for example: “...I learned I'm more confident, more comfortable with myself, and I like myself too...." Consumers who disagreed with the survey results as showing an accurate depiction of them related this inaccuracy to difficulties with survey wording and responses:

- “...I didn’t understand some of the questions as worded, I guess, so the answer I gave wasn't really what I meant and the results don't fit me.....”

- “...when the questions didn't have a middle response I was forced to choose when my real answer was neutral.....so the scoring didn't reflect what I was really thinking when I took the test and I don't like my responses...."

- “...I kind of felt like some of the question wording was off, so that my answer didn't show how I was thinking and feeling..."

- “...I don't think it [the results] reflected me very well, so 'cause like some of the questions I answered, didn't have the right response, a neutral response...."

In the process of determining that the results didn't accurately reflect "what I was thinking and feeling", these consumers indicated that self-reflection was prompted and awareness was raised: “...figuring out why I disagreed helped me to think more about what was going on with me...." Since self-awareness uses of reviewing results were primarily introspective/internal, it makes sense that I learned about this from consumers 
primarily though their self-report during our interviews, rather than through participant observation.

\section{Process \#4 - Using the Outcomes Experience to Better Understand One's Self}

The process of using the outcomes experience to address one's own mental health was referenced in some capacity by all but one consumer, irrespective of whether they had received survey results or not. Consumers did not identify this as a discrete process, but rather, as one that occurred in the contexts of the other processes previously explicated: understanding the survey, completing the survey, discussing survey questions, and understanding survey results (when received). Aspects of consumer uses of the outcomes to better understand themselves have already been described into in sections on the other processes. However, to ensure that the process of using the outcomes experience to better understand one's self is not obfuscated by the other processes in which it occurs, I have chosen to add an additional section highlighting it.

Consumers identified two sub-dimensions of using the outcomes experience to better understand one's self: using survey questions and results to elicit specific concerns to be shared with CPST staff; and introspectively increasing self-awareness through completing/discussing the survey questions (and results, when received). (Although I observed numerous instances of survey questions eliciting specific concerns from consumers, I did not observe this occurring during discussions of results. However, one consumer did reference results as eliciting specific concerns during our interview.)

While the eliciting of specific consumer concerns via answering abstract survey questions-a process that I could observe as well as be informed about by consumers-was 
discussed in detail in the section in this chapter on filling out the survey. However, the eliciting of introspection and raising of self-awareness were processes I could not observe, but rather, were conveyed to me through my conversations with consumers. Most of the consumers told me that the process of answering the questions and/or reviewing results (including disagreeing with results) made them think about things they normally didn't.

Most of consumers also indicated that the outcomes process could, or should help them to see changes in themselves over time/potential progress (consumers indicated this in the context of wanting to see previous results or survey answers compared with current results or survey answers). Several consumers emphasized to me that their answers (and survey results, if received) did not heighten their awareness about their year in its entirety, but rather awareness about "how things had been going for me recently". One consumer elaborated: “...it shows a moment in my past year.... A moment in time does not equal me, I am many moments... but it does get me thinking more about those moments..."

\section{Conclusion}

In sum, all consumers across agency settings identified four primary work processes pertaining to their experiences of "doing the outcomes": 1) making sense of what the outcomes are/are for; 2) filling out the survey; 3) getting/understanding results (or not getting results); and 4) using the outcomes experience to better understand one's self. The process of using the outcomes experience to better understand one's self was not a discreet or homogenous process, but rather, was conveyed to me the context of the other three processes. 


\section{CHAPTER 7: EXPLICIT IMPLEMENTATION PROCESSES}

\section{Introduction}

In the previous two chapters, I presented the work processes of "doing the outcomes" from the perspectives of CPSTs and consumers in explicit detail, using their language and concrete examples whenever possible. Their experiences of implementing the Consumer Outcome Surveys are localized activities occurring in concrete material conditions; however, their experiences are linked implicitly and explicitly with other people doing related work in other settings, at other times. Drawing from participant observation, interviews, and document review, I will begin to explicate in this chapter how consumer and CPST outcomes-related experiences constitute and are constituted by the work of these others. To do this, I created a highly detailed map of interrelated processes occurring across the system (Appendix K), from which I will narratively explain the interrelated activities connected to consumer and clinician experiences of "doing the outcomes".

\section{Processing Interchanges: Explicit Implementation Processes}

\section{A Note on Methodology}

Guided by the tenets of institutional ethnography, rather than dividing the work and settings into discrete "micro", "meso" and "macro" categories in this analysis, I will employ the IE construct of "processing interchanges" (Pence, 2001) to trace how the work experiences of CPSTs and consumers tie into the work of "absent others" outside of their localities, and across time and space. Pence (2001) explains processing 
interchanges as sequences of occasions in which a given text enters a locality, is processed in some fashion (which may entail modifying, checking or creating a new related text) by a person who may then in turn forward the text to its next destination. McCoy (1995) describes this as texts being "activated" (read or otherwise used) by people and thus occurring as a social process in actual local settings at particular times. My identification of "processing interchanges" thus allows for an explorationanchored in the everyday material conditions/ practice experiences of CPSTs and consumers-of the textually-mediated and other social processes that coordinate the implementation of the Consumer Outcomes Initiative across time and space. Smith (2005) elaborates on this as follows:

...the text and its transformations coordinate people's action; each move initiates a new action on its arrival at someone's work site; the product is passed on, transformed or not, to the next site, where it again initiates an action... Thus, not only do texts mediate the process of coordinating each stage of work with the next, but they also coordinate the whole work process... (p. 173).

\section{Administrative/Others as Intermediary Perspectives}

In order to begin to identify the processing interchanges extending from the work of CPSTs and consumers, I asked CPSTs and consumers to identify individuals they interacted with about the Consumer Outcomes Surveys in any fashion; I also asked for permission to contact these individuals so that I could continue in a snow ball sampling fashion (as detailed in Chapter 3). In this chapter I refer to Administrative/Others (supervisors, quality assurance staff, etc.) other than frontline groups (consumers and 
CPSTs) as intermediary due to underscore how the activities of those in these various places in institutional processes mediate between the Ohio Consumer Outcomes Initiative as conceptualized (in Ohio Administrative Codes and the manual it mandated), and frontline attempts to implement this mandate "where the rubber meets the road". Following the tenets of IE, I noted CPST and consumer references to "documents-inuse"-any form related to the outcomes that they indicated they actually used/referred toand followed the trajectories of these documents. I continued these two strategiesinterviewing people I was referred to and noting and tracking any "documents-in-use"until no new names or documents were being generated by any participants and both document and participant sampling were thus saturated.

All of the consumers indicated their CPSTs (current and previous) were the only people they'd interacted with regarding the outcomes and referenced the outcomes survey (and in some instances a results report) presented to them by CPSTs. Each CPST identified and referred me to at least one individual as someone who was communicated with regarding the outcomes. Interestingly, none of the CPSTs referred me back to their consumers. I contacted the people CPSTs referred me to, questioned them about their work with the outcomes, and asked them who their work connected with. I continued in until I was being continually referred to the same people. Figure 5 depicts who I was directed to, and by what sub-group of participants. Because individual participants within each sub-group often referred me to more than one person, numbers listed on the arrows do not necessarily total the number of individuals in a sub-group category. The arrows do not depict directionality of actual communications I observed, but rather, directionality of referring and perceived communications reported to me. 
Figure 5. Flow of snowball sampling

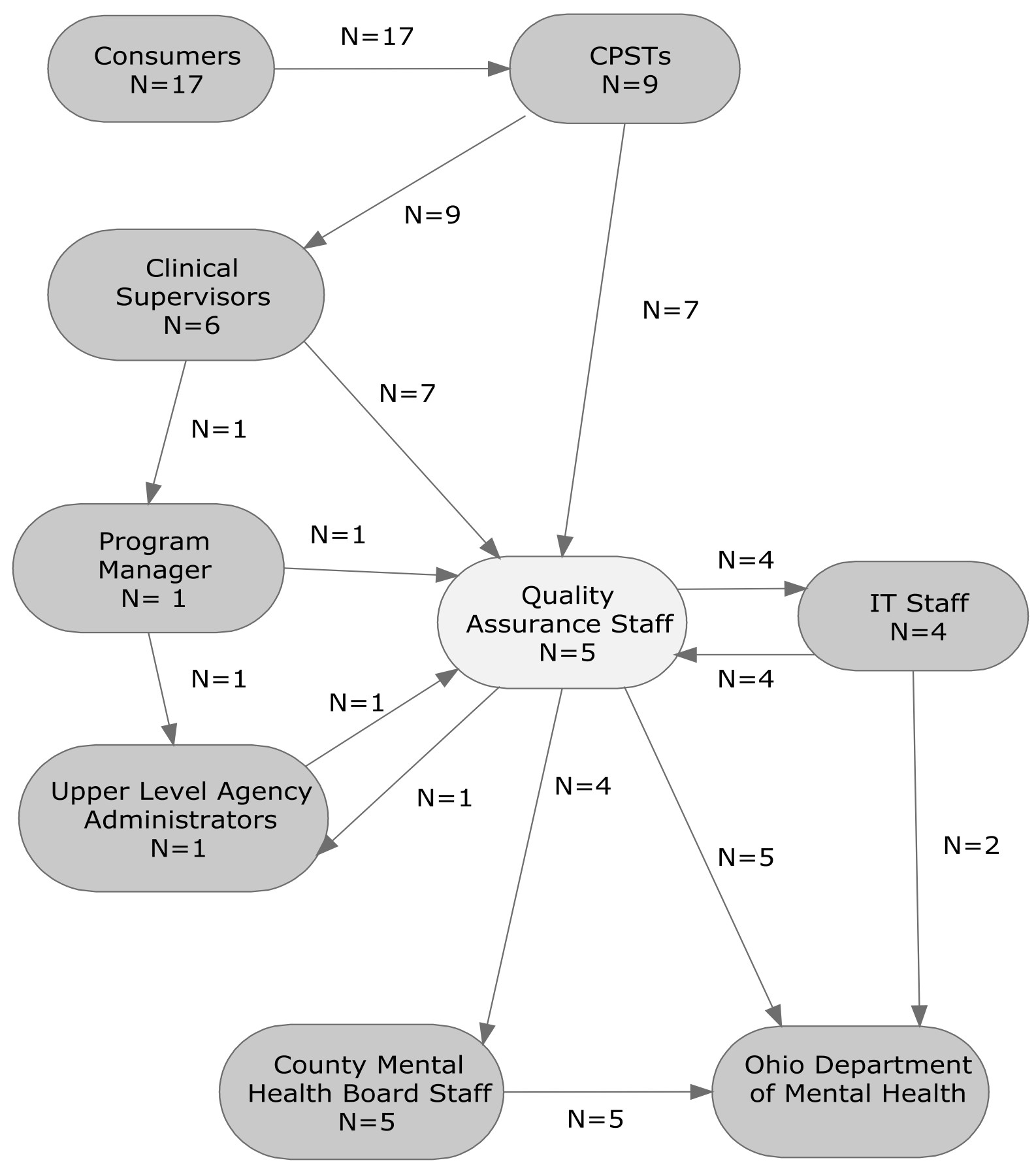


In viewing Figure 5, it is clear that agency-level Quality Assurance (QA)

comprises the perceived hub of communication, with regards to communications about the outcomes. This is consistent with at least one of the stated intentions of the Consumer Outcomes Initiative as per $\mathrm{ODMH}^{1}$ (2002):

1. Assist consumers and clinicians in developing treatment plan goals and measuring progress using consumer's individual outcome scores

2. Promote quality improvement at the agency, board and state level using aggregate consumer outcomes scores

3. Demonstrate accountability of the public mental health system for tax dollars. (p. 1)

\section{Tracing the Processing Interchanges}

Through speaking with participants in various sub-groups and following their referrals, in terms of who to speak with and how their work connected with the work of others, I was able to piece together processing interchanges within and beyond each agency. To narrow the scope and focus, and because all participating consumers had been attending their respective agencies and completed at least one survey prior to participation, I focused on interchanges pertaining to survey completion for these current consumers and their CPSTs. CPSTs across agencies indicated that survey completion with consumers new to the agency entailed substantively differing processing interchanges.

Appendix K depicts a detailed map of the processing interchanges described to me and/or that I observed, within and across agencies. A major limitation of this 
mapping is that I was unable to adequately convey the complexities of temporality in this map; many of this interchanges occurred simultaneously and/or cyclically. I obtained descriptive and explanatory information for the processing interchanges directly from participants whose work directly related to respective processes. An exception to this is with regards to the work of data entry staff; I attempted without success to recruit data entry staff to participate in this study. In viewing Appendix $\mathrm{K}$ it may appear that there is no particular starting point to the mapped processes; I thus re-emphasize that despite the limitations of such a pictorial depiction, my tracing and mapping of processing interchanges is grounded in and departed from the perspectives and actual experiences of participating CPSTs and consumers.

When a given process in Appendix K varied across agencies, I mapped each process separately. Typically, such divergent processes converged further along the processing interchanges depicted in Appendix K. For the remainder of this chapter, I will narratively explain the processes pictorially illustrated in Appendix K, so as to make explicit how identified work processes (relating to the Consumer Outcomes Survey) of the CPSTs and consumers are connected across time and space to the work of others.

\section{Processes Related to Tracking the Consumer Outcomes Surveys}

The vast majority of processing interchanges across the system (Appendix K) pertained to tracking rates and timeliness of survey completion. Consumers indicated to me that they either receive a phone contact from their CPST to schedule an appointment to do the Consumer Outcomes Survey "when it is due", or are asked by their CPST to do the Consumer Outcomes Survey when they come in for a routine appointment. "My 
worker tells me when it'd due, and that's when I come in and we do it." According to CPSTs, the first impetus for them to do a Consumer Outcomes Survey with a current client arrives as a hard copy or electronic (between agency differential) tracking report indicating outcomes survey due dates. "We get the reports, and I try to read mine and start to figure out who I need to see, and when..." This varied between agencies in whether CPSTs received a hard copy or electronic tracking report, and in whether the tracking report (hard copy or electronic) is given to them by their supervisor or quality assurance staff.

Supervisors elaborated that tracking reports (hard copy or electronic) are generated by quality compliance staff, and that they cross-reference it with their own tracking list they keep for each of their respective CPSTs. One supervisor explained: “...the report we get from QA isn't always accurate, so I keep one too and crossreference them". Both QA and supervisory staff indicated program support staff assisted in dispensing the hard copy tracking reports to appropriate supervisors; however, I was unable to recruit a program support staff participant to further explore this.

Dates of when the most recent Consumer Outcomes Survey had been completed and when the next Consumer Outcomes Survey was due for each consumer on a given caseload comprised the content of the tracking reports across agencies. Quality assurance (QA) staff informed me that they referenced the ODMH Consumer Outcomes Manual (which they downloaded online periodically as revised versions became available) and the Ohio Administrative Code (Appendix A) in ascertaining appropriate time frames for the tracking reports. (The Ohio Administrative Code specifically referenced the Consumer Outcomes Manual as the text to comply with in implementing the Ohio 
Consumer Outcomes Initiative. While the manual is too large to be contained in an appendix, it can be accessed online at:

http://www.mh.state.oh.us/oper/outcomes/instruments/procedural.manual.pdf )

Time frames complying with specifications in the manual were programmed into a database used for tracking survey completion, created by agency information technology staff. I was able to recruit information technology staff at two of the four participating agencies. These information technology staff stated they utilize specifications from the ODMH Consumer Outcomes Manual (which they obtained from QA staff or online) to create and maintain this agency database program. At the two agencies where I was unable to speak with IT staff responsible for such tasks, QA staff referenced similar processes.

Once survey information was entered (through electronic completion of the survey or data entry of hard copy survey responses), information technology staff and quality assurance staff (varied across agencies) periodically uploaded the agency data from the agency database to the county mental health board via a server. County mental health board staff stated they retrieve this uploaded agency data into their own database and review it for errors (incomplete fields, unacceptable characters in text fields, etc.). "It [the data] can't have any errors when it goes to the state [ODMH]." If errors were discovered, board staff stated they notify (via email or phone) designated quality assurance staff of needed corrections. The agency data is not forwarded until ODMH until corrections are received by the board staff.

Quality assurance staff stated they reviewed the errors reported by the board, and first attempt to make corrections themselves by removing unacceptable characters, filling 
in the blank fields when they had the information (such as consumer's date of birth) available via other agency databases, and by contacting (via phone or email) the CPST to request the needed information/answer for the field that had been left blank. Because none of my participating CPSTs indicated they had been contacted regarding such corrections, I am thus unable to construe how such interchanges would continue, presumably between a CPST and consumer, if additional information was needed. Quality assurance staff stated once they made corrections and added any needed information from the CPST; they resubmit the data to the county mental health board via again uploading it.

County mental health board stated they review agency data to ensure that surveys are completed and at the rate required ( $80 \%$ of consumers at each agency) by the Ohio Consumer Outcome Manual (which they indicated they obtained online). One of the two boards also instituted a county-mandated rate of completion (negotiated between board staff and agency quality assurance staff); when this rate was not met, agency contracts with the board as mental health providers could be terminated. Agencies in this county that do not meet the county mandate receive written notification and are given a 6 month provider contingency contract during which they must meet the county mandate rate. If this rate is not met (via electronic data submission monitoring), the board that instituted the county-mandate may revoke the agency's contract with the county mental health board as a mental health provider. However, staff from this board reported revoking of a contract with the county mental health board as a mental health provider can pertain only to local county-levied/non-Medicaid billings. Board staff reported they do not have legal authority to deny Medicaid payments based on outcomes data completion/submission. 
Similarly, board staff stated that while per the Ohio Consumer Outcomes Initiative/Ohio Administrative Code (Appendix A), an agency's certification status (agencies must obtain certification from ODMH and renew it every three years in order to contract with a local board to be a mental health service provider) is now contingent upon the $80 \%$ threshold of outcomes survey completion, there is currently no legislation in place that would enable ODMH to revoke certification should that threshold not be met.

Agencies might not have their certifications renewed based on poor outcomes completion, but I was told that this does not function in the same way that having certification status revoked would. Board staff informed that many agencies provide services with expired certifications, and that is a long precedent of doing so, in part due to the back log processing the certifications. One board staff remarked ...right now there are no teeth in the rules, and the agencies know it, but my guess is that is going to change, there's nothing specifying revocation in how the Ohio Administrative Code for the outcomes is written....

In terms of how state certification and board contracts fit together, one board staff explicated these connections as follows:

.... Say someone calls and says, hey, we want to contract with you [the county board] and provide counseling and CPST. We'll ask, well are you certified by ODMH? If they say no, we'll give them information about who to contact in the state's certification and licensing department, and give them technical assistance if needed. Once they have everything in order and have the certification in hand, they can come back and be considered for a board contract. Once they have a board contract, they can bill Medicaid, if those kinds of services are what they're 
certified and contracting for. Some agencies contract only for Medicaid billing, or only for non-Medicaid billing-county levy and related dollars. Some agencies are contracted for both. And some services aren't Medicaid-billable, such as employment or Club House, because they're not medically necessary..."

A further caveat explicated by agency and board staff to me is the change in new certification and certification renewal requirements. In addition to needing to meet the outcomes threshold, a currently certified agency will now need to be accredited by a private national accreditation agency (such as "CARF"-the Commission on Accreditation of Rehabilitation Facilities; "JCAHO"-the Joint Commission on the Accreditation of Healthcare Organizations; or "COA"-the Council on Agency Accreditation) approved by ODMH for the type of agency (hospital, community mental health center, etc.) and services (CPST, residential, inpatient, etc.) provided. This new private accreditation rule is referred to as "deemed status". According to board staff, ODMH has its own "accreditation standards" (a.k.a. - certification standards), which in the past had sufficed; agencies that obtained private accreditation were considered to have gone "above and beyond" in terms of quality assurance of services. This "deemed status" rule is mandated in the Ohio Administrative Code (Appendix J), and stipulates that all agencies applying for new and renewal certifications must obtain private accreditation with one of the national, private accreditation agencies. A board staff elaborated on this: ...every two years you have to get reaccredited and pay the big bucks... it'd be like $\$ 10,000$ with JCHAO, every two years. It's a pretty pricey process, it's really going to be only the larger entities that can afford contracts, because they're the only ones who'll be able to afford the deemed status in the certification process. 
Part of it is because of the shrinking Medicaid dollars, and not wanting the dollars to go everywhere. The real premise was to ensure the quality of services. But by the same token, it's going to eliminate a lot of the smaller agencies... With the Deemed Status Rule, they set a deadline by which the private accreditation had to be accomplished, and the consequence being your certification could be revoked... It is a legal process to revoke a certification, it is not an easy thing to do, you can put their certification on probation, but to revoke it is a legal process and they can appeal. Here's the Catch 22 with the Outcomes rule because there's wording to that effect [specifying revoking], all ODMH can do is hold up the certification until they're satisfied the outcomes threshold is being met.... And your certification would stay in good standing, expiration date doesn't mean a thing, you're in good standing unless you're revoked... at this point, nobody has been revoked by the state because of the Outcomes-there's no legal way they can be. But at some point, the standards [Ohio Administrative Codes] come up for review and revision, and I bet that's going to change.... Deemed Status, that's another story..."

While the private accreditation standards vary according to type of facility and service, commonalities include being costly and requiring an outcome measure of some sort to be completed and used in service planning. This outcome measure is not required to be the Consumer Outcomes Survey; however, the use of the Consumer Outcomes Survey does fulfill this measurement requirement. Agency QA staff explained to me that compliance with private accreditation standards is monitored through periodic chart audits and site visits from private accreditation staff; they described these as similar to 
board audits but much more intensive: “...it's much more than chart audits, they'll come and spend a week or two here, talk to clients, talk to staff, walk around and watch how things are done, it's a big deal...".

While board staff informed me that the use of outcomes information is not looked for in Medicaid audits: “...really they [the outcomes] have nothing to do with the Medicaid audit at this point...”. Frontline staff indicated they thought their outcomes work was part of what was being audited by the board, and agency staff at other levels indicated some confusion regarding whether or not outcomes use in treatment would be part of the Medicaid audit in the future. However, agency administrators and quality assurance staff were very clear on the need for chart evidence of both completion and use of an outcomes measure in treatment in order to obtain and/or and maintain private accreditation via passing the private accreditation audits. When I asked QA staff about how they obtained information about what was needed to meet respective private accreditation standards, I was told the main information sources were the private accreditation agency web sites. (No names of individuals from these private accreditation agencies were generated during my snowball sampling, so I thus have no participants who worked at these private accreditation entities.) As explained to me by QA staff, the county board audits focused on medical necessity, and the private accreditation audits focused on “...just about everything, outcomes, clinical care, what our service philosophy is, you name it...".

From board staff explication as previously stated, the completion and/or use of the Consumer Outcomes survey did not have any bearing on Medicaid audit results. 
In speaking with board staff, I thus discovered that while the completion of outcomes surveys is easily monitored electronically, there is no particular compliance function at the board level to monitor whether or how agencies are clinically using outcomes in treatment. There is a particular state process through which ODMH staff audit for use of outcomes data in treatment planning via a "Desk audit process" via certification form information (http:www.mh.state.oh.us.licensurecert/forms.reports/accred-update.revisedcross.ltr.05262006.pdf), however, no participant in this study referenced this process to me. QA staff informed me that the agency's initial focus on completion rather than use related specifically to the specified time frames for activities within the Ohio Administrative Code Consumer Outcomes Mandate (Appendix A):

...within twelve months of the effective date [9-4-03] of this rule, or within twelve months of an agency's initial application for certification, the agency shall be flowing data through the mental health board to the department... as specified in the Consumer Outcomes Procedural Manual... within twenty four months of the effective date of this rule, or within twenty-four months of an agency's initial application for certification, the agency shall be able to provide evidence that outcomes data is being used in both treatment planning and performance improvement activities.

Each of the CPSTs discussed "tracking" the outcomes completions for their respective caseloads at great length. Two participating CPSTs related the pressure they felt to complete Consumer Outcomes Surveys with external pressure upon their respective agencies: “...when there was pressure on the agency, the agency pressed us to get them [the Consumer Outcomes Survey] in...." I was able to determine (through 
publicly available online information) that both of these two agencies were well below the $80 \%$ survey submission rate and had certification concerns. In relating these CPST experiences to the Ohio Administrative Code and Consumer Outcomes Manual, it is apparent that tracking relates to getting the surveys completed within the externally/textually prescribed time frames, so that the data can be flowed to the Ohio Department of Mental Health (ODMH) in a timely manner as per mandate requirements. Because data flow precedes outcomes use in the mandate, I speculate that agency emphasis (at three of the four agencies) on clinical use is not yet emphasized due to the temporal differential in the mandate. However, both completion of the survey and use of the survey are both required per Ohio Administrative Code timeframes. (Appendix A).

However, both completion and use of the Consumer Outcomes survey do relate to state certification to provide mental health services, which in turn related to whether or not an agency could obtain or maintain certification status which was required to get a Medicaid contract with a local board. While board and agency administrators indicated there was no particular process to revoke certification, a process is indicated on an ODMH web page (http:www.mh.state.oh.us/licensurecert/forms.reports/accredupdate.revised-cross.1tr.05262006.pdf). Medicaid rules and the Consumer Outcomes Initiative intersect more obviously in the progress notes written by CPST staff following the completion of the outcomes survey with a consumer.

\section{Processes Related to "Chart Management", "Productivity" and "Medical Necessity" \\ Progress notes, a key area of a Medicaid audit, had text fields for a billing code and notation of the duration of the appointment. CPSTs who did hard copy progress}


notes indicated they put the actual progress notes in a bin; program support staff then filed the progress note in the consumer's respective chart. CPSTs explained that they noted the billing code and appointment duration on a time report, which was sent to billing staff, and in this way the "service" was "billed for". CPSTs doing electronic progress notes stated the notes automatically went into the consumer's electronic record, and were also billed for from the electronic record. Along with progress notes, the content of and time frames for ISPs and other clinical chart documents (excluding the Ohio Consumer Outcomes Survey) originate primarily in "Medicaid rules", per the quality assurance staff, who stated they receive information about the Medicaid rules from the ODMH web site, and from county board staff. Medicaid rules were described to me as both federal and state in origin. No one specifically identified texts that contained federal Medicaid rules, even when I specifically asked for such textual references; I was directed to the Ohio Administrative Codes for state Medicaid information, but no particular codes were identified to me.

Per quality assurance and administrative staff, billing staff at each respective agency amass CPST time reports into an agency billing report, which is sent to the county mental health board for compensation from typically one of two funding streams, Medicaid (for consumers who had Medicaid insurance) and non-Medicaid (local/county dollars levied to provide care for consumers who don't have Medicaid insurance). Per county mental health board staff, payment is then dispensed by board staff to the agency fiscal staff, for billable services provided in accordance with the county contract (the contract the agency has with the board to provide specific services to specific populations, such as community support and psychiatric services for adults with severe 
mental illness) and Medicaid rules (see Appendix M, referred to and understood by CPSTs as "medical necessity") if the agency has contracted with the board as a Medicaid provider.

County board staff indicated they monitor for compliance with Medicaid rules via reviewing selected consumer charts periodically, and will give a written report to agency staff of aspects of the chart that are out of compliance with the Medicaid rules. County board staff then forwards a written report to designated agency staff, who forwards it to the CPST's supervisor, who forwards it to the CPST and instructs the CPST to make needed corrections in the chart. The CPST pulls the chart, attempts to make the needed corrections via scheduling with the consumer, obtaining signatures, and so forth. The CPST reports these corrections to the supervisor. No further auditing action is typically undertaken by the board, and the next audit occurs as typically scheduled.

A related function of board staff reviews of agency charts, including the progress notes on outcomes administration, is to determine whether a service billed for via the billing report is indeed reimbursable according to Medicaid rules. If the auditor determines that the billed service reviewed (via reading the progress note, individualized service plan/service plan updates and diagnostic assessment/assessment updates) was not billable according to Medicaid rules, the auditor issues a findings report to designated agency administrators requiring that the money paid for that service be paid back to the board. Regarding service billings meeting Medicaid rules, a board staff explained to me: ...it's got to meet medical necessity. The true definition of medical necessity is basically the medical model, like a doctor making a clinical judgment to order medically necessary services based on your symptom or diagnosis, then you come 
up with a plan or intervention and you're going to document it in your progress note...

In reviewing the Ohio Administrative Code (Appendix L), I found "medical necessity" to be defined as:

Services ordered are necessary for diagnosis treatment of disease, illness, or injury and without which the patient can be expected to suffer prolonged, increased or new morbidity, impairment of function, dysfunction of a body organ or part, or significant pain and discomfort.

The notion of "medical necessity" originated in health insurance circles as a rationing response to "twin pressures of escalating costs and demands from consumers and providers" (Bergthold, 1995, p.182), as well as a quality assurance safeguard to create parameters on what constitutes an appropriate billing and help reduce billing abuses. Medical necessity is a federal guideline, but not explicitly defined in federal policy (National Center on Disability Research, 2005). Rather, it is a guideline that each state government defines to administer the federal Medicaid program set forth through the Social Security Act. While there is thus some variation in state definitions of "medical necessity", by and large the Ohio Administrative Code definition is very similar to other state definitions (Bergthold, 1995); diagnosis and symptoms are paramount in ascertaining whether a given service is "medically necessary" or not.

According to QA and agency administrative participants, an outcomes administration documented in a progress note without reference to a specific mental health symptom necessitating CPST assistance-such as all of the oral administrations requested by consumers participating in this study-is considered non-billable according 
to current interpretations of Medicaid rules, and would require any money received by the agency for this time to be paid back. However, board staff indicated that even billing for oral survey administrations necessitated by a mental health symptom impairment was not automatically an eligible billing: “...it's a gray area, case-by-case, there's no hard and fast rule, other than that if you intervene it needs to be documented..."

Participating CPSTs generally did not express an understanding of such nuances in documenting the outcomes survey administration; most indicated a belief that routine oral outcomes administration provided "billable time" and "productivity" (they used these terms interchangeably). In reviewing progress notes of the oral survey administrations I observed, roughly half made reference to completing and/or discussing the outcomes survey (and roughly half made no reference to the outcomes whatsoever). These casual distinctions between notations of completing versus discussing the outcomes literally translate into agency income versus the agency paying back reimbursed billings for services rendered. According to board staff:

If the only thing in the progress note is that they sat with the client while they filled out the outcomes form, that'd be payback. They would half to pay back for that half hour, or hour, or however long they spent. But more commonly we see a mixture. For Medicaid compliance there's billable, problematic or ineligible. [I was recently updated by a participant that the problematic billing category has been eliminated]. So a mixture would be problematic billing, they did the form, and based on that they discussed the results and did the ISP. Then you have documentation for a session where you did something that are Medicaid billabledoing the ISPs is Medicaid billable, discussing the results is Medicaid billable, but 
actually filling out the survey is not. But if the whole note was only just doing the outcomes, it is not a billable intervention, it'd be a payback. It's not a billable intervention, you're just watching someone do something or reciting a form to them, you're not providing a mental health intervention... Observations are not billable. When you're saying "based on this form, this means you have needs for this or that, and we could do something about it, what do you think?" That is a mental health intervention... Because doing the ISP, discussing survey results, you're discussing and talking.

While the CPSTs and consumers who participated in my study completed the survey orally were doing much more than merely reciting a form together, this was clearly not evident in the progress notes. The progress notes done my CPSTs basically pointed to rote compliance with a mandate: “... completed the outcomes survey with client". To make sense of the differences between what I observed through participant observation and how it was documented in the charts, I drew from Floersh's (2000) ideas on comparing oral with written narratives:

The written narratives of case managers told the story of disciplinary knowledge/power... Scholars who have relied only on social workers' texts (mostly case records) have written a history or sociology of the conditions (e.g., the disciplinary) for social work... to understand practitioner activity, we must research written and oral narratives. (p.185-186)

It was through participant observation that I could access consumer-CPST interactions in naturalistic situations with the Consumer Outcome Survey, and witnessed knowledge that was “...personal, strategic, specific contextual...” 
Such differences between written and oral narratives (Floersch, 2000) were also apparent in considering differences between textual representations of outcomes use in treatment planning, as compared with how this was described to me by CPST and consumer participants. One of the four agencies integrated ISPs with the outcomes survey results in a systematic way that was verbally identified to me by all participants at this agency. This process began for CPSTs with a discovery of a packet in their respective mail boxes: “... it comes about five weeks before the ISP is due, and I know I need to start calling and scheduling for the client to meet with my supervisor who helps the client and I come up with goals." An administrator described this packet and its use to me as follows:

...quality compliance generates reports of when ISPs [individualized service plans/treatment plans] are due, then program support staff put the packets together based on the reports that show when ISPs are due... the packets include the most recent outcomes results report... and the case managers get their part of the packet in their mailbox about five weeks ahead of the treatment plan due date...I use the outcomes report to fill out part of the packet, and I meet with the CPST and client and we talk about what's been going on, and come up with recommendations for goals.

The three agencies who did not have such integrative packets did include text fields for outcomes-related information on other required documents, such as the ISP, diagnostic assessment and annual review forms, presumably to evidence use of the outcomes results in treatment planning. Both the text field and packet methods appeared effective in evidencing outcomes use in treatment planning in written narratives. However, my 
participants (CPSTs and consumers) did not self-report such routine use of Consumer Outcomes information during treatment planning. While the Consumer Outcomes Survey information was thus included on treatment plan documents via marked check boxes, text fields, and/or integrated packets, when juxtaposed with the oral narratives of participants (Floersch, 2000), it seemed the inclusion of the outcomes information was perhaps more about evidencing compliance and less about actual clinical utility in everyday practice.

\section{Conclusion}

At first glance, the completion of Consumer Outcomes Survey would appear to be an action that occurs in a circumscribed event, involving a consumer and a CPST. However, I have in this chapter traced and made explicit a myriad of social processes involving the work of many other individuals; the work of these other individuals is connected to CPST and consumer understandings, experiences and uses of the Consumer Outcomes Surveys, in both explicit and implicit ways. As evidenced by Appendix K, three bodies of regulations appear to factor into consumer and CPST work with the outcomes survey: "Medicaid rules"; Ohio Administrative Codes (containing the “Outcomes Rule”, “Deemed Status Rule”, and "Medical Necessity” ); and private accreditation standards.

The confluences of these regulations in everyday practice appeared to institutionally structure numerous aspects of CPST and consumer experiences across agencies by "requiring, directing, resourcing and organizing" (Pence, 2003, p.7) how CPSTs and consumers interacted with regards to each other and the Consumer Outcomes 
Surveys. In the next chapter, I specifically explore the character of these confluences of system processes, and how they are negotiated by consumers and CPSTs. 


\section{CHAPTER 8: EMBEDDED SYSTEM PROCESSES \& FRONTLINE IMPLEMENTATION EFFORTS}

\section{Introduction}

Appendix $\mathrm{K}$ in the previous chapter denotes-through the mapping and narrative explication of concrete, empirically observable processing interchanges-how CPST and consumer experiences of "doing the outcomes" are connected through the work of others not only to the Ohio Consumer Outcomes Initiative, but also to federal and state Medicaid laws, state certification standards, and accreditation standards from private national accreditation organizations. For ease of reference, I will refer to these readily traceable processes (that are connected to CPST and consumer experiences) as explicit implementation processes. In this chapter, I will explicate what institutional ethnographer Townsend (1998) refers to as the narrowing, undermining or otherwise distorting system processes that are routinely organized, not readily visible, and create tensions regarding what can and cannot be done with the Consumer Outcomes Survey at the frontlines. According to Townsend (1998):

...these tensions are not experienced as such; rather, professionals.... tend to feel overwhelmed, inadequate, or not fitting into the system... herein lies the disjuncture: a fundamental contradiction between divergent ways of routinely organizing power... this contradictory organization of power is so embedded and invisible that it is experienced as taken for granted routines that seem natural and unquestionable... (p. 153-4) 
Kerr (2006), an institutional ethnographer who works within the education system, similarly asserts:

...comparing the experiences of teachers with related documentary texts (policies, procedures, legislation, stats, reports, classifications, and so on ) draws attention to contradictions and disjunctures...by tracking the social relations that connect the work of participant teachers with the work of others, the 'invisible' process of the educational system were located, revealing how routinized organizational procedures regulate the everyday work... the social reorganization of knowledge within public education, orchestrated through organizational policies and procedures, is coordinated across multiple sites through the texts of an institution... these texts carry ideological beliefs, norms and values that are introduced into local sites where they are reproduced through the activities of participants within the institution... (p.41)

For ease of reference, I will refer to such processes as embedded processes. According to Pence (2003), these processes function as partial determinants of CPST and consumer experiences by creating a web of routines that require, resource and organize how CPSTs and consumers interact with regards to each other and the outcomes.

Put another way, even if CPSTs and consumers fully embraced the outcomes and wanted to use them to their fullest potential and as intended by the Ohio Consumer Outcome Initiative, they would face limitations created by converging system constraints. Three CPSTs articulated an awareness of such primarily textually-mediated, converging system constraints as follows: 
- $\quad$...there's this sort of shifting invisible fence of rules that I can't see, I don't know where it came from, but I keep getting zapped by it ...

- $\quad$...it's like we're not even writing these things for ourselves or our clients, we're writing treatment plans and notes or whatever for all these requirements that are somewhere out there and don't talk to each other much...

- $\quad$...we have to keep things in the money language; I can write up the goal in a way that works for my client and I, but then I have to rewrite it in other certain ways, with symptoms, so it is good and we get paid... empowerment and quality of life [two of the four domains in the outcomes survey] aren't money language...

In doing thematic analysis of the processing interchanges and relating this analysis to the experiences of consumers and CPSTs "doing the outcomes" (as articulated in earlier chapters), two organizing, embedded processes (tensions) emerged across sites and work processes. These two organizing embedded processes served as barriers to implementing the outcomes meaningfully (as per consumers and CPSTs) and as intended by ODMH. The first of these embedded processes is compliance-driven organization of time, and the second relates to the dominance of the medical model in public mental health funding-related documentation. The focus of this chapter is to explain how these two underlying, institutionalized processes specifically undermine the "good intentions" (Townsend, 1998) of the CPST, consumer and ODMH in the implementation of the outcomes survey in everyday practice. 


\section{Compliance-driven Organization of Time}

Compliance-driven organization of time is a theme that is consistent across agencies and throughout consumer and CPST experiences. In viewing the processes tied into consumer and CPST activities involving the Consumer Outcomes Survey (Appendix $\mathrm{K})$, it is apparent that nearly all of the mapped processes relate to compliance to one or more regulatory bodies. Figure 5, which shows the flow of snowball sampling, also reveals that quality assurance (QA) are the perceived hub of communications relating to the outcomes survey. As stated earlier, none of the CPSTs directed me to their consumers when I asked them who they communicated with about the Consumer Outcomes Survey and related work. Yet I observed each of the participating CPSTs to be very consumer-centered in their everyday work with consumers, and consumers conveyed as much to me when they talked about their relationships with their respective CPSTs. The absence of consumers referenced in CPSTs' answers does not seem to relate to how these CPSTs regarded their consumers, rather, it points to an outwarddirected compliance focus in this aspect of their work.

Compliance with governing entities is a fact of life in any human service providing entity; however, the purpose of compliance activities is generally to ensure that quality services are provided, rather than to be the driving force in service delivery organization. From my observations, the self-reporting of my participants, and the nature of the interrelated processes connecting to frontline experiences, the everyday experiences of participating consumers and CPSTs, with regards to documents (including the Consumer Outcomes Survey), were organized around compliance rather than consumer need. That is, documentation seemed to be conducted primarily for the sake of 
compliance, and secondarily for clinical purposes. This compliance-focus was perhaps most apparent and poignant to me in the cross-agency language of consumers, with regards to how they experienced the completion of clinical documents in their mental health service use:

- $\quad$....my CPST said my treatment plan is due, so I came in to do it...

- $\quad$...it's time to do the outcomes survey again.....

- $\quad$....she [the consumer's CPST] said it was due again, so I'm doing it [the outcomes survey] again...

- $\quad$...it's something we have to do, so we do it [surveys]....

Across all four agencies, I observed numerous instances in which consumer needs and clinical care were "fit in" with completion of various clinical documents, rather than the purpose of completing the documents. To state this another way, I observed two incidents of actual consumer situations driving completion of new goal sheets in ISPs; typically the "due date" was the reason given for doing an ISP or outcomes survey, rather than because these documents were viewed as relevant to a change in the consumer's situation or needs.

As explicated in the chapter on CPST experiences of "doing the outcomes", "fitting them in" was a prominent work activity. "Fitting them in" was something viewed in terms of juggling the survey due dates with other document due dates, and with "real consumer needs". "Real consumer needs" were repeatedly differentiated from "chart management" and "doing the outcomes" at three of the four agencies. CPST at the fourth agency considered the outcomes part of the chart; this is also the agency at which outcomes were included in an ISP packet issued five weeks before the ISP was due for a 
given consumer. While this approach integrated the outcomes survey results and ISPs on paper (meeting compliance requirements for the outcomes mandate and private accreditation with regards to evidence of us, and perhaps being a factor in high survey completion rates at this agency), uses of these packets as described to me in everyday practice were driven by primarily by compliance.

For example, a hypothetical worst case scenario for clinical utility in this approach (the only approach I observed that consistently evidenced use of outcomes in treatment) would be one in which the ISP was due a month before the outcomes survey. The ISP packet would then be issued five weeks before the ISP was due, but contain outcome survey results that were eleven months old. Staff at all levels at this agency acknowledged that this was highly problematic and something that was being worked on: “... it's a rock and hard place thing, once the timing is off [for a document], it's so labor intensive to get things lined up in the tracking system, but we're fixing it, we don't want old results going out in ISP [individualized service plan] packets...”.

According to staff across all four agencies, the Consumer Outcomes Survey would ideally be completed before the ISP (the Consumer Outcomes Survey is thus being perceived as an assessment as well as an outcomes tool), and the results would be one of the things considered in updating the ISP. However, consumers at the agencies who had been using services for over a month already had time frames in existence for their ISPs, diagnostic assessment updates, etc. Across all four agencies, CPSTs reported difficulty integrating the Consumer Outcomes Survey completion with "due dates" for other required clinical documents (such as the ISP) that the outcomes information is to inform.

The difficulty with integrating due dates from various documents was not 
something that was merely mentioned in passing to me. CPSTs were very vocal about timing and tracking issues, with regards to "things not fitting together". About a third of participating CPSTs-across all four agencies-remarked that when the survey was done for new consumers at intake, things made the most sense and flowed the smoothest in terms of document due dates (notably, these CPSTs did not make reference to increased clinical utility in such situations, which is related to a paradigm conflict that I will address in the following section of this chapter).

However, CPSTs reported that while the surveys were "supposed to be completed at intake for new consumers", this was not always the case. CPSTs indicated that they are then responsible for completing both the Consumer Outcome Survey and an ISP, and unanimously stated that at this point they'd prioritize completing the ISP over completing the survey. One CPST expressed these tensions in a way that is fairly representative of the experiences CPSTs shared with me, regarding getting Consumer Outcomes Surveys and ISPs completed for new consumers:

...ideally a new client consumer does the outcomes survey before I meet him or her... (laughs)... but that's not always the case... the client may not be able to tolerate doing the survey at that point [intake] for all kinds of reasons, symptoms, trust issues, having such a long first appointment, whatever, so, then it's something we're [CPSTs] expected to do, but that makes it crunch time because the ISP is due within four appointments or thirty days, whatever comes first... that's the first priority... I'll do the outcomes survey, but it's probably not going to get done before the ISP because there's only so much time and without the ISP done by a certain time I get dinged in my audit; it's not like it [the outcomes 
survey] is all that helpful with the ISP, and I think we have to pay back money if the ISP isn't done on time... and of course, new clients usually come in with all kinds of needs, so I'm dealing with those too....

The disjuncture, or "fault line" between different regulatory entities (Medicaid rules and Ohio Administrative Codes pertaining to the outcomes survey) creating tensions in everyday experience, is fairly clear in the above CPST statement.

CPSTs indicated they also experienced-perhaps even more so-such tensions in the routine everyday work of "keeping all the documents up to date for clients on my caseload". "Tracking the outcomes", along with managing the due dates for the other documents in the chart that needed to be re-done or updated periodically, were tasks that CPSTs expressed a great deal of frustration with and anxiety about. One CPST stated: “...it's pretty much the only time we [CPST and clinical supervisor] talk about them, it's when they're past due, we never talk about them clinically in supervision, they just have to be done..." As previously stated, consumers similarly typically experienced this compliance-driven organization of time as "being due" and "having to be done", with regards to documents relating to their service use.

As one CPST put it: "it's not like everything is equally important, there's a hierarchy of chart needs...." CPSTs at the agency with the highest rate of outcomes survey completion also viewed the outcomes as part of "the chart"; only the CPSTs at this agency viewed the outcomes survey as part of "the chart". All CPSTs viewed "keeping up the chart" as "very important", and it seems that the one agency's use of the ISP packets which included outcomes survey results did serve to integrate the outcomes survey as part of "the chart" for participating CPSTs, which in turn may have resulted in 
higher rates of completion. However, this did not translate into perceived clinical utility for frontline participants at this agency.

Clinical utility is both a purpose of survey as per the Ohio Consumer Outcomes Initiative, and an expressed desire from frontline participants. While nearly all CPSTs and consumers participating in this study expressed a belief that outcomes measures in general were a good idea, and an explicit purpose of the outcomes survey stated by ODMH relates to the survey being used in treatment planning, it is clear that these good intentions are undermined a great deal under everyday practice conditions due to embedded, seemingly impregnable, and at times divergent processes relating to compliance with regulations from various entities (Townsend, 1998).

\section{Compliance, Oral Survey Administrations, and Buried Clinical Dialogues}

The vast majority of incidents that I observed in which there was clinical use of the outcomes survey occurred during oral survey administrations. This was not something explicitly identified by either the consumer or CPST as clinical use; consumers tended to describe it to me as “...being reminded of something I needed to tell my worker..." and CPSTs tended to describe it to me as "...the client telling me something that's going on that we'll get to after the survey..". While addressed in previous chapters, I feel it is worth repeating that all but one of the oral administrations I observed occurred in response to consumers' explicit requests; likewise, the majority of consumers expressed a preference for oral survey administrations. All of the CPSTs generally indicated that they strove to be consumer-centered in their practice approach: “...I always try to be client-centered..."; “...you have to start where the client is at...”; 
"... it really comes down to where is the client at right now and you go from there...." It could thus be argued that oral survey administration in and of itself is a consumercentered practice (when the oral administration is requested by a consumer).

Within all but one of the oral administrations I observed, consumer-initiated dialogues occurred in the midst of reading the survey questions together. I examined the following exchange between a consumer and CPST from the perspective of the CPST in the CPST experience chapter, and from the consumer in the consumer experience chapter. I am revisiting this exchange a third time, this time to consider it as an example of both clinical utility occurring during oral survey administrations, and as an example of the tension between compliance-organized time and clinical utility:

CPST: "I feel powerless most of the time." (Reading survey question)

Consumer: “I am bogged down, I'm not helping my daughter... my daughter's school isn't responding to my calls, I've met with her teachers over and over, I don't think they're giving her medicine but they say they are and she just looks worse and worse to me... she sits in her room, doesn't talk with me, let alone tell me if she's getting her medicine at school... and my daughter's counselor here isn't calling me back... I don't know what else to do....” (Consumer begins to cry)

(The CPST ceases reading the survey questions and begins to question consumer further about this situation; she obtains the counselor's name, and asks the consumer if she'd like the CPST to attempt to contact her child's counselor after they finished the survey. The consumer says "yes, please", and the CPST notes 
the information about the consumer's daughter on a piece of notebook paper and clips the notebook paper to a blank release of information which they fill out after the survey is completed.)

CPST: "Back to the question, 'I feel powerless most of the time'."

Consumer: "Every day, because of my daughter's situation."

CPST: “So, 'Agree', or 'Strongly Agree'?”

Consumer: "There are times I feel like I can do something about it, though." CPST: "So.....?"

Consumer: "Agree"

The above exchange exemplifies what I observed in all but one oral administration of the outcomes survey. The consumer responded to an abstract question with a concrete, specific life situation that was causing concern or distress. The CPST noted the concern on a notebook or sticky paper or other non-chart documentation, and then redirected the consumer back to completing the survey to "get it done". The CPST thus attended to the consumer's concern (a.k.a.-"real client need") in the middle of a compliance-focused activity, and after attending to the consumer's concern returned to the business of compliance. Similarly, the consumer's specific concern was recollected by an outcomes survey question and the consumer took the opportunity to initiate a consumer-driven exchange in the middle of the oral survey administration; once the consumer-driven consumer was addressed to the consumer's satisfaction, the compliance-focused survey completion then resumed. There were thus such pockets of consumer-centered, clinical dialogue-which I will henceforth refer to as "buried dialogue"-prompted by the outcomes questions in the midst of all but one oral survey administration. Smith used the 
term "buried dialogue" to explain how professional jargon and objectification of client experiences is used to subsume a consumer's experience (i.e.-“denial", "noncompliance", etc.). In my observations of the oral survey administrations, I am similarly using the phrase the "buried dialogue" to describe the complications of the dialogic ground between the consumers and CPSTs, given the presence of a standardized survey that in effect serves as a distinctive third party whose compliance-driven completion subsumes the emergent dialogue pertaining to consumers' actual experiences and concerns (Smith, 2005).

Such buried dialogues prompted by oral outcomes completions exemplify the beginnings of problem-solving interventions, which would seem to meet the following board staff interpretation of federal Medicaid billing eligibility: ...discussing and talking about the consumer's issues in a mind-to-mind way; a mind-to-mind intervention is the standard... where is the mind-to-mind, where is the mental health intervention, that is what is looked for... However, the buried dialogues were documented informally (notebook or sticky notes) and I viewed evidence of only one in a progress note. These buried dialogues were thus invisible in the textually-mediated (chart) processes through which compliance is determined, with regards to using outcomes in treatment planning. All but one of the progress notes for the oral administrations I observed referenced completing the outcomes, rather than using them, although I observed such uses in all but one oral administration. As mentioned in the prior chapter, the act of completing the outcomes is not considered in and of itself billable, and such notations of completion without information about the dialogue that occurred in between questions could actually result in agency paybacks of Medicaid revenue for that billing. 
While all agency administrators and QA staff voiced a clear understanding that oral administrations of outcomes were not routinely billable, none of the CPSTs indicated awareness of this. Administrators and QA staff at two of the agencies stated if the CPST noted in the progress note that a mental health symptom necessitated the oral administration, that time was eligible for Medicaid billing. Administrators and QA staff across the board stated they were working with CPST so that oral administrations were only done when "medically necessary", to avoid a Medicaid payback situation. All agency participants voiced awareness that the discussion of survey results was billable.

While I observed numerous instances the results reports being reviewed and read, I did not observe any exchanges between the CPST and consumer that indicated that the course of treatment would be altered by the results. Both consumers and CPSTs expressed both confusion and dissatisfaction with the results report format, and difficulties in accessing the results report (with the exception of those who did the survey electronically), as detailed in previous chapters. The clinical utility of the oral survey administrations could thus be an adaptation due to CPST and consumer difficulties accessing and understanding the results format. And certainly the buried dialogue interspersed between outcomes survey questions could be problematic in terms of impacting consumer response bias.

Even so, the outcomes-generated buried dialogue seemed to hold value for both consumers and clinicians, and comprised the vast majority of outcome uses in treatment that I observed. Ironically, such clinical, outcomes-generated dialogues were: textually invisible to regulatory agencies; not Medicaid billable as oral administrations; and generally not recognized as clinical work by CPSTs. The convergence of the disjunctures 
between Medicaid billing eligibility and consumer-centered practice within the oral administration process were not yet experienced as tensions by CPSTs at the time of my data collection, however, I speculate that this likely may no longer be the case, given the voiced intentions of agency administrators to address the non-billable nature of oral survey administration. And certainly the embedded process of compliance-driven time clearly created points of tension within CPST experiences during oral administrations in which consumers initiated dialogue during the survey administration.

One CPST expressed this tension as: “...balancing the need to get it [the survey] done versus being where the client is at during the appointment...." Consumers similarly expressed this as: “... getting it [the survey] done so we can talk about what's really

going on with me...." Whereas a diagnostic assessment (a service and document that is linked with Medicaid rules, Ohio Administrative Codes and private accreditation requirements) is considered "medically necessary" and allotted up to three sessions to complete, the oral administration of the outcomes survey is not recognized as clinical, despite serving an assessment-like function under everyday practice conditions for my participants.

\section{Medical Model Dominance in Funding-Related Documentation}

Compliance-driven organization of time is one of the embedded, institutionalized process within in frontline experiences that is undermining the clinical utility of the Consumer Outcomes Survey across participating agencies. A paradigm conflict between the non-symptom aspects of mental health recovery, and the symptom-driven medical model, is the second institutionalized is a second, related embedded process that featured 
prominently across CPST experiences. This paradigm conflict was repeatedly conveyed to me by CPST statements of confusion and frustration regarding "how to make the outcomes fit with the treatment plan".

The notion of a 'paradigm conflict' is a nebulous one, and not readily amenable to being explained as a social process! To better articulate the social processes through which CPSTs experienced the disjuncture between the mental health recovery and the medical model, I am going to introduce the interrelated ideas of "inter-textual hierarchies" and "inter-textual circles" (Smith, 2005).

According to Smith (2005):

....incorporating texts into ethnographic practice is essential to institutional ethnography. It is what enables it to reach beyond the locally observable and discoverable into the translocal social relations and organization that permeate and control the local... they [texts] are read, seen, heard, watched and so on in particular local and observable settings while at the same time hooking up an individual's consciousness into relations that are translocal...discovering then, how texts articulate our local doings to the translocally organized forms that coordinate our consciousnesses with those of others elsewhere and at other times is the objective... to describe and explicate in the text a local coordinating... within which institutions form functional complexes... (p. 65-66) Smith (2005), in addition to emphasizing the importance of texts in understanding institutional complexes, differentiates in a hierarchical sense between regulatory texts (rules, policies, procedures, etc.) and subordinate texts (those texts produced as a result of specific regulatory texts, which are capable of being interpreted as compliance with the 
specific regulatory texts). Smith (2005) articulates inter-textual circles related to the inter-textual hierarchies between regulatory and subordinate texts as follows:

...from activating/reading the regulatory text, the question arises of what to do that can be fitted to the framework of that text; the work that is done to produce the appropriate [subordinate] text... must be readable as a text that fulfills the function ascribed to it in the regulatory text... (p. 85)

And, Smith further asserts that most formal texts are "... bearers of the paradigm that formulated them..." (p. 84).

In the everyday work of the CPSTs, all of the documents CPSTs referenced or worked with would be considered subordinate texts according to Smith (2005). Using the constructs of Smith, the disjuncture experienced by the CPST, relating to "fitting the outcomes with the treatment plan", can be construed as a conflict between regulatory texts and their paradigms (Figure 6). The Medicaid rules (Appendix L), e.g., the regulatory text, which CPSTs understand in their everyday work as "medical necessity", require that mental health interventions be tied to diagnosis and symptoms. Subordinate texts related to this regulatory text are thus construed as needing to relate to diagnosis and symptoms. The documents (diagnostic assessment, individualized service plan (ISP), annual ISP review, progress notes) collectively referred to by CPSTs as "the chart" and explained to me by CPSTs (and administrative participant) as needing to "show medical necessity" are those that would be considered subordinate texts to medical necessityrelated Medicaid rules. (These documents also meet Ohio Administrative Code and private accreditation requirements, and are thus articulated to multiple regulatory texts; however, CPSTs explicitly expressed a lack of fit between "medical necessity" and the 

documents.

Figure 6. Inter-textual circle (Smith, 2005) - medical model

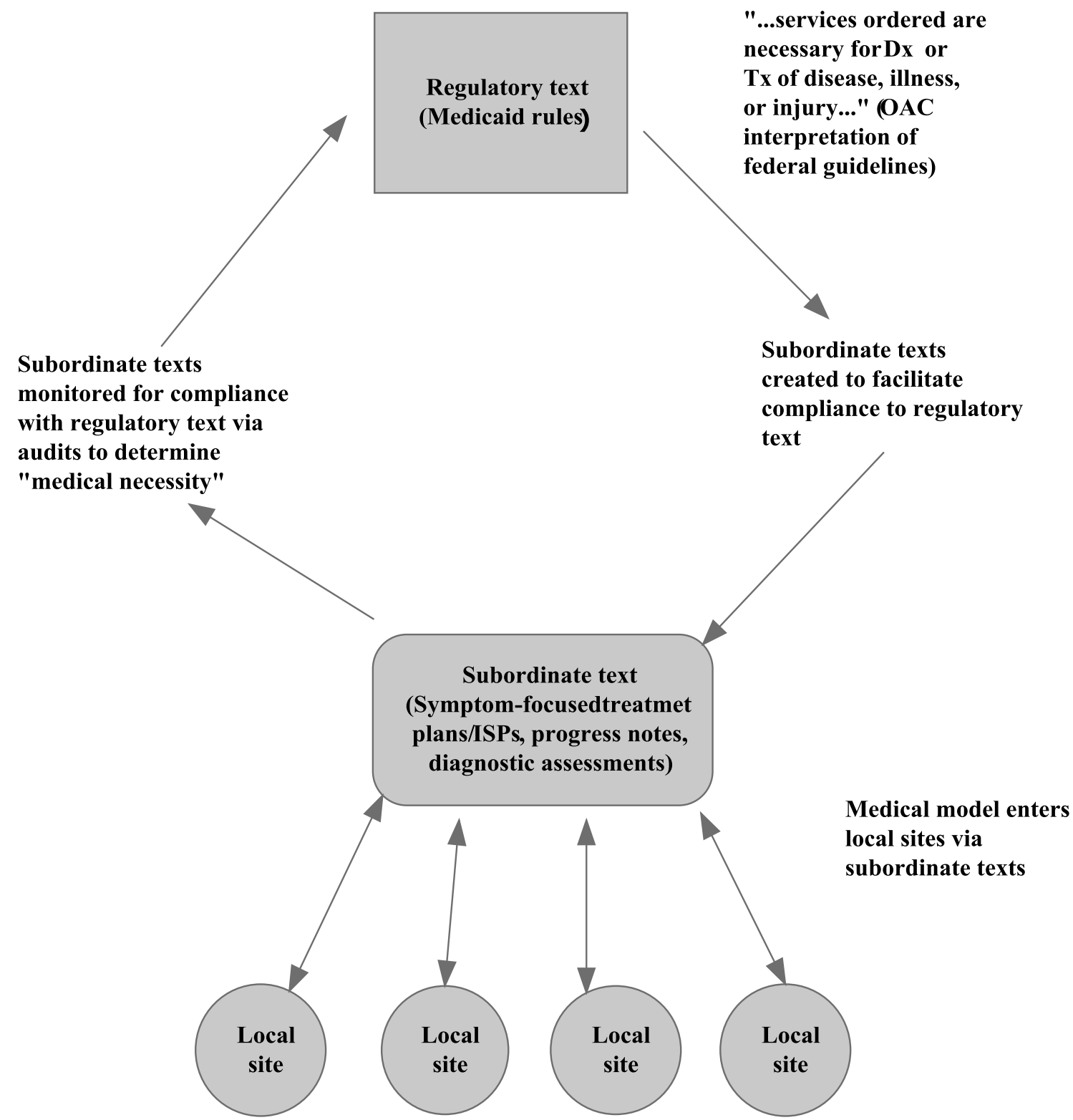


As articulated to me by board staff, the "true definition of medical necessity is the medical model"; interpretations of subordinate text compliance with Medicaid rules would thus need to reflect interventions necessitated by specific mental health symptoms. In contrast, the Ohio Consumer Outcomes Initiative (Appendix A), and its subordinate documents, introduce a mental health recovery-focused paradigm into everyday practice conditions, via subordinate documents (the Consumer Outcomes Survey) that are created in relation to it (Figure 6). While the outcomes survey encompasses mental health symptoms via one of its four domains (the symptom distress category), it entails the broader view of mental health recovery through inclusion of empowerment, quality of life and community activism constructs.

CPSTs specifically and repeatedly, across agencies, referenced these nonsymptom domains as those that "don't fit with medical necessity". In a previous chapter addressing CPST experiences of "doing the outcomes" I presented interview and participant observation data relating to CPST experiences of the lack of fit between the outcomes and ISP documents. I now revisit this presentation of data to underscore the conflicting regulatory texts and related paradigms embedded in these frontline experiences. Although the CPSTs did not specifically articulate to me an awareness of competing paradigms as such, they did articulate a sense of the outcomes survey being "its own entity", "separate" from the chart documents (subordinate to the medical model Medicaid regulations). Because all but two CPSTs specifically differentiated between "the chart" and "the outcomes", I asked the CPSTs specifically whether and how "doing the outcomes" fit with "the chart". 
Figure 7. Inter-textual circle (Smith, 2005) - mental health recovery

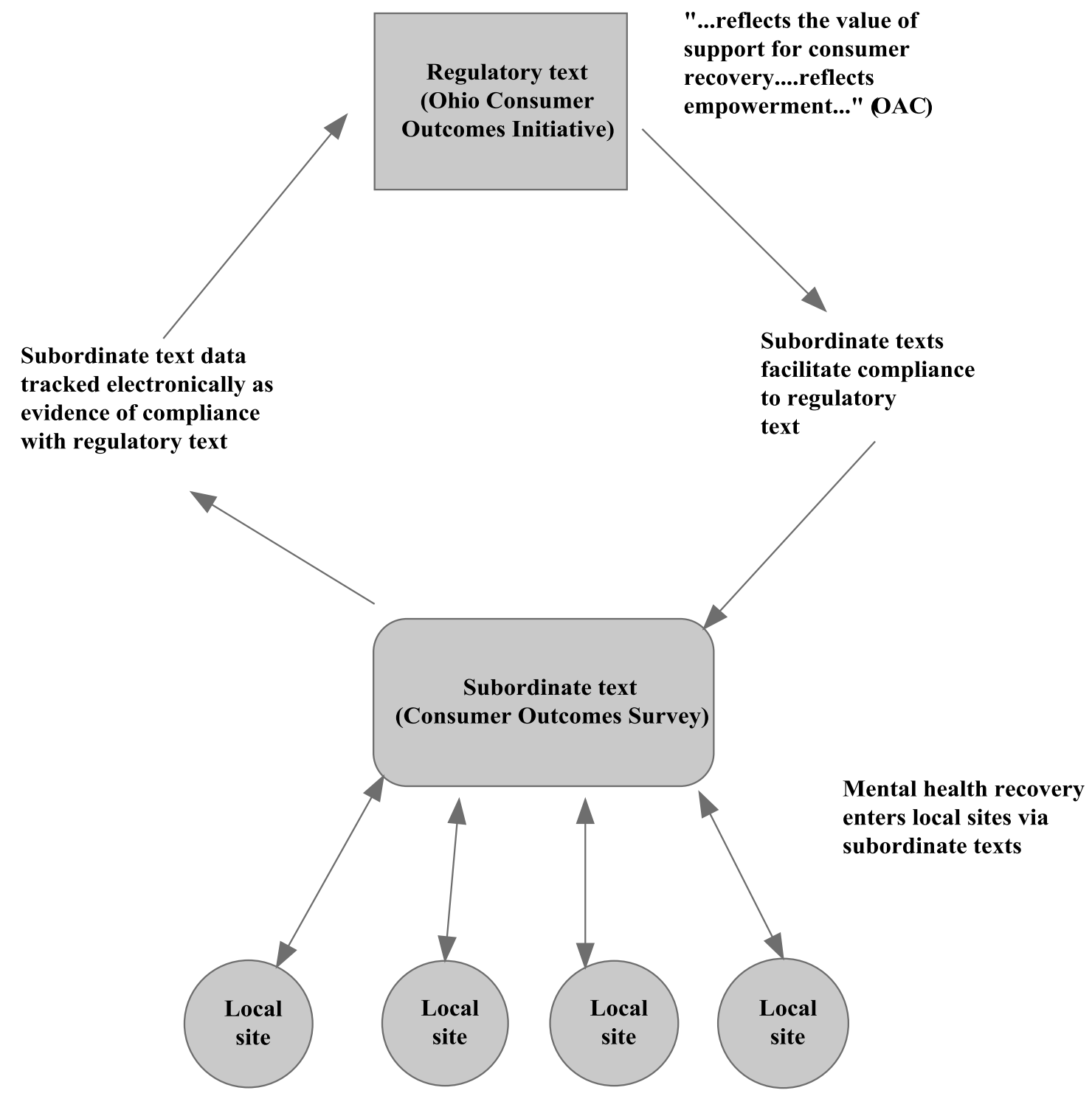

The following CPST statement is fairly representative of responses to this question (including responses from CPSTs who received outcomes results as part of packet sent to them shortly before the ISP was due): “...well see, that's the thing. I mean theoretically I think it is supposed to be part of the chart, but it feels like, it feels like it's 
its own entity, feels like it's its own separate piece, that must get fit in somehow, but I know it's supposed to be part of the treatment plan or something...”.

Here, the CPSTs clearly articulated how the Medicaid subordinate documents needed to be articulated to "medical necessity", and their difficulty in doing such an articulation between the outcome survey and the federal Medicaid subordinate documents:

When I explored this [sense of outcomes and chart not fitting] with CPST further, their responses encompassed the following themes: many of the outcomes questions are not "medically necessary"; diagnostic assessment information fits "medical necessity" better than outcomes; the diagnosis must drives goals, more than outcomes; and the survey needs diagnosis-specific categories with specific symptom criteria for it to fit with the rest of the chart. They specifically related these themes to the forms they considered as parts of "the chart", and then referenced these themes back to treatment planning as the main way in which outcomes had to be made to fit in: “...it's not easy or direct as to how to apply that information [outcomes survey results] to the goals that we're writing with the client, you know. Like if the client is not happy, for example, with their quality of life... well, it doesn't... I mean, it would be nice if it automatically tied into a symptom with a suggested goal or something...”; “...I do the best I can, to tie them [the outcomes] into treatment planning, but it's a different language or something...."

Another CPST shared with me a "cheat sheet" and explained it was provided to her by QA staff at her agency in an email. This CPST described the sheet as follows: 
...it lists out the outcomes domains and tries to translate them to possible goals based on symptoms and diagnosis, it still doesn't quite work with my clients, it's just not practical, I'm not sure why... I guess I get goals from talking with my clients, and try to make sure it matches what the diagnostic assessment has down, especially if it is a newer client... otherwise the client might be happy but I get in trouble at audit time [if goals do not match identified diagnostic assessment needs]... the agency might have to pay money back or something if the goal and the assessment don't match, I think...”.

Each of the participating CPSTs were quick to acknowledge the value of domains other than symptoms in the Consumer Outcomes Survey, irrespective of difficulties encountered when trying to integrate this content with other documents in "the chart", thus implicitly endorsing a paradigm of understanding their respective consumers that was much broader than a strictly symptom-focused medical model. The following CPST statement is fairly representative of expressions relating to fitting the non-symptom domains of the Consumer Outcomes Survey with treatment planning:

... feeling empowered, safe in your housing, liking your life, those are important things to know about a person you're working with, no question, in terms of helping that person... I'm just not sure how they fit in [with 'medical necessity']; sometimes the housing fits because the housing can get disrupted by symptoms, but with the other stuff, it's harder to fit it together...."

It is in such frontline experiences of disjuncture that the paradigm conflict-between the medical model and the more broad mental health recovery approach-within regulatory texts is readily apparent (Figure 8). Through tracing the textually-mediated processes 
relating to differing regulatory texts, and employing Smith's (1995) idea of inter-textual circles, I was able to see at least in part how these paradigms entered in to local sites.

Figure 8. Lived experience of paradigm juncture via textually-mediated processes

Regulatory text

(medical model)

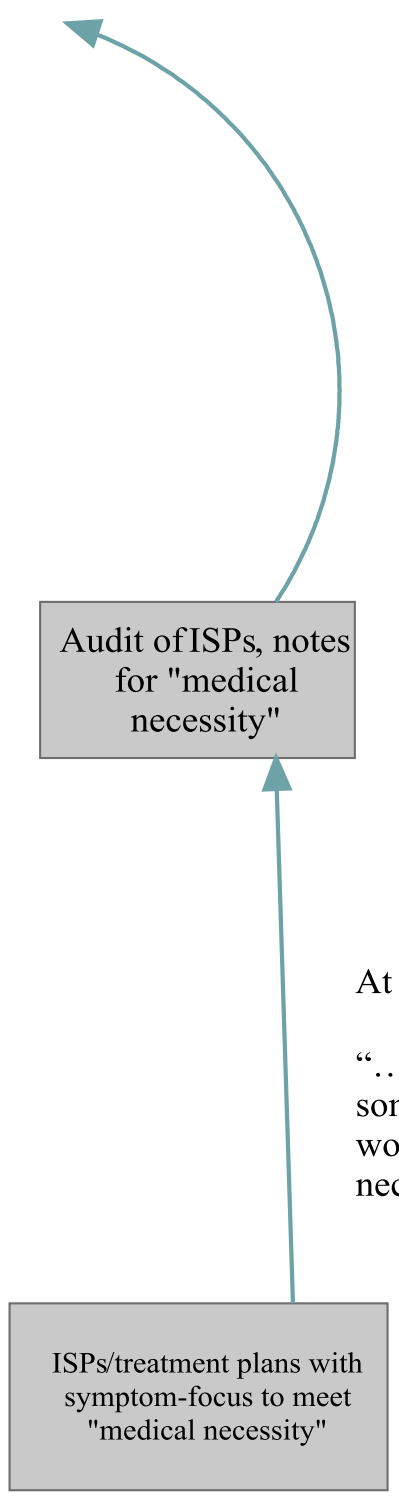

Regulatory text (recovery)

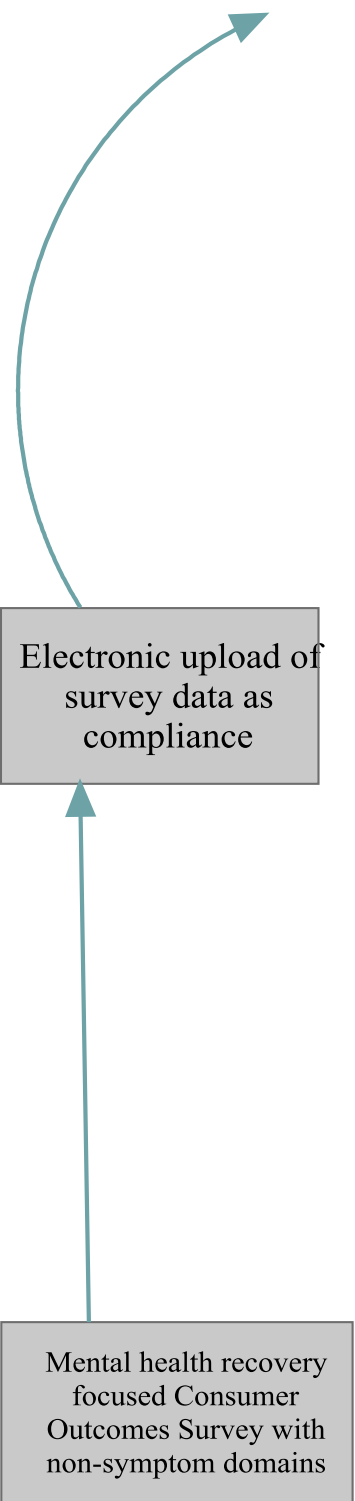




\section{Conclusion}

At first glance, the completion and use of a Consumer Outcomes Survey might be construed as a micro-level activity that occurred or not occurred solely due to CPST and consumer factors. However, based on the cross-agency processes identified (pertaining to compliance-driven organization of time and to a paradigm conflict between mental health recovery and the medical model), a strictly micro-level conceptualization (or even a strictly meso-level conceptualization, for that matter) would be oversimplified. Edward Demming (1994), in his system of profound knowledge framework, indicated that when a problem is being experienced by multiple employees within a given system, the system should be considered as containing the cause of the problem, rather than the employees experiencing the problem. Shaw (2005) similarly referred to oversimplified microconceptualizing of issues with practitioners as "practitioner blame"; specifically, Shaw described "practitioner blame" as the framing of practice occurrences embedded in “complex service development and delivery agendas" as solely "practitioner-level decisions" (p. 1238). While not readily visible, confluences of system processes are embedded within and influencing CPST and consumer practice occurrences, with regards to the Consumer Outcomes Survey. In particular, compliance-organized time and the dominance of the medical model in funding-related documentation are serving to undermine meaningful uses of the Consumer Outcomes Survey in everyday practice conditions. In addition, there are also organization-specific climate and culture factors, not addressed in this written analysis due to deductive disclosure risks, which influenced the completion and uses of the Consumer Outcomes Survey. 


\section{CHAPTER 9: DISCUSSION, IMPLICATIONS \& CONCLUDING THOUGHTS}

\section{Introduction}

In this study, I used the method of institutional ethnography (IE) to understand how institutionalized social relations (embedded system processes) are manifested in frontline (consumer and CPST) efforts to implement the Ohio Consumer Outcome Initiative (which they refer to as "doing the outcomes"). My hopes in employing this method were to: generate specific information that would be helpful to stakeholders attempting to implement the Ohio Consumer Outcomes Initiative; and generate general information that would contribute to the field of implementation science. In this chapter, I will begin discussing and summarizing my major research findings. I will next delineate the strengths and limitations of this study, as they relate to each other and to my findings. I will continue by considering the significance of this study and findings in terms of both suggested applications to practice and general contributions to the field of implementation science. Then, I will reflect on future directions for research, and make concluding statements for this dissertation.

\section{Recapping Frontline Experiences and System Processes in "Doing the Outcomes"}

In answering the research questions of this study, and in keeping with the conventions of IE, I set out to first generate a richly detailed, data-grounded description of frontline (CPST and consumer) understandings, uses and experiences (which I referred to in totality as "work") related to the survey. To provide context for these understandings, as well as to provide a rationale for my claim in later chapters to have identified system processes (due to the existence of these processes across diverse agency 
settings), I first described each of the four settings, drawing from my initial observations when the differences and unique aspects of each setting were most salient. Following these descriptions, because of a high deductive disclosure risk and expressed concerns of participants, I then for the most part divorced specific individual understandings, experiences and uses (which I refer to as "work processes", using the broad definition of "work" in IE methodology) from specific agency contexts via aggregating through thematic coding. (As the researcher I of course had access to organization context information. I created four primary documents in Atlas.ti-each containing all notes, transcripts and other documents relating to each of the four agencies-and thus moved through each agency as a separate entity in my line-by-line coding, and through my continued analysis. While my overall analysis was thus informed by consideration of individual-agency contextual information, I am unable to specifically explicate such analysis in my written presentation of findings.) Despite this limitation, through spending time immersed in and talking with consumers and CPSTs in their everyday practice contexts, distinct, detailed processes emerged pertaining to their understandings and experiences of "doing the outcomes".

CPSTs identified six processes involved in "doing the outcomes": "knowing about the outcomes"; "fitting the survey in"; "filling out the survey"; "getting and understanding the results"; and "documenting". I first mapped how these processes connected with the work of others at different times and place, and then excavated the institutional processes embedded within these CPST-identified processes and considered how these institutionalized processes related to the frontline implementation experiences. 
Similarly, consumers identified four processes involved in "doing the outcomes": making sense of what the outcomes are/are for; "filling out the survey"; getting/understanding results; and "understanding myself better". Three of these four processes overlapped with CPST processes and contained much of the same institutionalized processes, not surprisingly given the CPST was the identified gate keeper into the complex of institutional processes, per consumers (that is, consumers identified only CPSTs and their interactions with CPSTs as the ways in which they interfaced with the outcomes). However, the process of "understanding myself better" in "doing the outcomes" was unique to consumers, likely for obvious reasons (the survey pertaining to the consumer's life experience, not the CPST's).

The process of "understanding myself better", with regards to "doing the outcomes", was explained to me by consumers as introspective as well as dialogical (with their CPST staff). The introspective aspect of "understanding myself better" was perhaps the most exciting thing I discovered, as within such introspections were: 1) clear expressions of hope and expectations of improvement in mental health and 2) a sense of empowerment conveyed through being willing to dispute the results report and reflect on why the results report was felt to be inaccurate. CPSTs explored and supported such contestations of the results report, which seemed to further encourage a sense of empowerment on the parts of the disputing consumers.

Such interactions suggest to me that mental health recovery and/or consumerrights discourses are entering practice settings, perhaps in part conveyed through the content of the outcomes survey, perhaps in other ways-via the consumers themselvesthat have yet to be discovered! Only one of the four agencies espoused "mental health 
recovery" as a practice philosophy; a simple word count across the primary documents (containing all field notes and transcripts) for each of the four agencies showed the document for the recovery-espousing agency contained the word "recovery" over fifty times, compared to the other agency primary documents which each contained the word recovery less than five times. Yet, an empowered and hopeful consumer view of "understanding myself better" was espoused by participating consumers across all four agencies. Such an empowered, hopeful perspective could be related to client-centered professional discourse, and/or, it could be brought into the CPST-consumer relationship by the consumers themselves (that is, the consumers could be gate-keepers into a differing complex of social relations not tapped into by my study).

\section{Content and Structural Issues Relating to the Survey and Results Report}

In attempting to understand and use the outcome survey, both CPSTs and consumers identified concerns related to the survey instrument itself. Most concerns centered generally around awkward wording and unclear constructs. (CPST concerns specifically regarding the "lack of fit" between survey content and other documents are specifically addressed in previous sections.) Consumers (without a documented history of paranoia and no signs of paranoia during my study) also voiced wariness about the repetitiveness of questions as "someone trying to trip me up". CPSTs noted that psychosis was not at all addressed in symptom distress, despite many of their consumers experience substantial impairment and distress due to psychosis. One CPST expressed concerns about the outcomes survey not being written in a way that is relevant to her 
urban, African American consumers, and named several particular questions that she felt were problematic.

CPSTs and consumers also gave feedback about the results report format, and specific suggestions for improvement. All CPSTs and consumer participants (who received results reports) expressed some sense of dissatisfaction with the numerical format of the results report, and indicated it was not particularly easy to interpret. The two main themes about the results report were: a desire for more narrative and less numerical information; and a report that compared in a graphical way a consumer's prior answers with current answers so that change over time could be pictorially viewed by both consumers and CPSTs. Both CPSTs and consumers expressed a belief that the inclusion of more narrative and graphical information on the results report would render the results report more accessible and usable, particularly for consumers. As one consumer put it: “...I want to understand what my results say about me, but I just don't get all this number stuff...it needs to be put in plain English...."

\section{Explicating Embedded System Processes in Frontline Experiences}

Unlike the introspective consumer process of "understanding myself better"; the other processes identified by consumers and CPSTs relating to "doing the outcomes" can be clearly seen to tie into the trans-local, trans-temporal work of others in a textually mediated way (Appendix K). These textually-mediated institutional processes created an institutional context spanning all frontline experiences, and reflected: 1) a compliancedriven organization of time which typically displaced client-centered practice, with regards to when and how documentation (including outcomes administration) is 
conducted; and 2) a textually mediated paradigm conflict between the medical model (understood by CPSTs as "medical necessity") and mental health recovery (which encompassed the medical model but also other non-medical model constructs such as empowerment).

Tensions between Paradigms (Medical Model, Mental Health Recovery and ClientCentered Practice) Embedded in Frontline Experiences

Both the medical model and mental health recovery were easily traced (through the mapping of explicit implementation processes pertaining to the outcomes) to specific "regulatory texts". The narrower medical model ("medical necessity") paradigm is contained in Medicaid rules (Appendix L). The specific Ohio Administrative Codes (Appendices A) pertaining to the outcomes survey did not contain explicit mental health recovery language, however, the manual on its implementation contains a mental health recovery paradigm (which encompasses but is not limited to the medical model). These paradigms are at least in part introduced into the everyday experiences and understandings of CPSTs and consumers via "subordinate texts" which relate back to and are interpreted as compliance with the "regulatory texts", via "inter-textual circles". Subordinate texts in everyday CPST and consumer work relating to Medicaid rules (as well as other regulatory texts such as private accreditation and state certification standards) include documents identified as part of "the chart" across all four agencies, most notably: the diagnostic assessment; individualized service plan (ISP); annual review; and progress notes. Subordinate texts in everyday CPST and consumer work 
relating to the Ohio Consumer Outcomes Initiative would primarily be the outcomes survey, and to a lesser extent results reports.

The divergent paradigms between the regulatory texts manifested primarily in CPST experiences, as disjunctures/points of tension in trying to make the respective subordinate texts "fit". Specifically, CPSTs across all settings voiced a sense of the outcomes survey "not fitting" with "medical necessity", particularly the domain of empowerment which is arguably one of the pivotal constructs in the mental health recovery paradigm. CPSTs at one agency who received outcomes results as part of a packet containing ISP information viewed the outcomes as part of "the chart", differing from CPSTs at the other three agencies who viewed the outcomes as distinct from and less important than "the chart". Because CPSTs across agencies ascribed high importance to "chart management" (keeping the chart documents up-to-date); there may be a relationship between how CPSTs view the outcomes in relation to the chart, and rates of survey completion. CPSTs who viewed the outcomes as part of the chart were at the agency with the highest rate of survey completion. However, despite the difference in ascribed importance to survey completion, CPSTs across all agencies voiced a sense of the survey "not fitting" with the ISP and diagnostic assessment in particular. The use of the outcomes survey in treatment planning under everyday practice conditions was thus substantially undermined by these confluences of textually-mediated, divergent system processes pertaining to differing paradigms (medical model vs. mental health recovery) of mental health.

Another instance of a similar paradigm conflict occurred during consumerrequested oral survey administrations. During oral survey administrations, "medical 
necessity" (clearly linked with Medicaid law) collided with client-centered practice (which was clearly present in the practice encounters I observed and in how CPSTs talked with me about their work, although not connected to a particular regulatory text). Oral survey administration was the expressed preference of all but four consumers participating in my study. For these consumers, I was unable to determine any clinical or other barrier that would preclude them from filling out the survey "on their own". In this instance, progress notes were typically where the disjuncture would be located. A progress note indicating completion of the survey (without an explanation of why CPST assistance was medically necessary for the completion) would be interpreted as a nonbillable service according to Medicaid rules. The tension between these paradigms at the time of my research was expressed predominantly by administrative staff who indicated they were worried about having to pay back Medicaid billings of oral outcomes administrations that weren't "medically necessary". However, it seemed highly likely to me that this tension was rapidly making its way to manifesting at the frontline lines, as a CPST-experienced tension between doing what was "medically necessary" and thus billable with regards to the survey, and a consumer's expressed preference for an oral survey administration.

Theoretical and Empirical Considerations on the Clinical Utility of Oral Survey Administrations

I cannot conclusively offer an explanation for why the most observed instances of clinical utility of the survey content occurred during oral survey administrations. The difficulties cited by CPSTs and consumers regarding the results format, the inconsistency 
in receiving results, and the duration of time passing before receiving results are all likely to be contributing factor, with regards to why I did not observe clinical uses outside of oral administrations. In addition, three of the four consumers who wished to do the survey "by themselves" were Caucasian females diagnosed with Borderline Personality Disorder. There could thus be a clinical diagnosis-related or other individual-level reason for why outcomes information was not utilized during my observations with these consumers and their CPSTs. Because my sample size is so small, I cannot make any generalizations about how non-oral survey administrations occur with regards to whether or not clinical utility, rather, I can only report on the four of such instances I observed.

However, drawing upon explanatory constructs in institutional ethnography scholarship, I can speculate on how clinical utility might occur more readily in oral administrations rather than when consumers doing the survey "by themselves". Specifically, Smith's (2005) explication of “inter-textual territory", offers potential explanatory power with regards to the clinical utility of the survey during oral administrations.

Smith (2005) suggests a given text (such as the outcomes survey) coordinates subjectivities between the reader and the text author. When a CPST and consumer are reading the text together, they're thus sharing an inter-textual territory (comprised of two readers and the text author) in which the abstract survey questions generalize and suppress particularities of what they focus on. (That is, the outcomes questions identify aspects of symptoms but suppress the differentiating particulars of each consumer's experiences of those symptoms). Smith (2005) refers to this generalizing of particularities of experience as "perceptual standardization" (p.85). An oral survey 
administration allows a CPST to enter into inter-textual territory in real time along with the consumer, and thus gives the CPST more immediate access to the consumer's work of translating the particularities of his/her unique experience of a given symptom into a perceptual standardization.

With regards to inter-textual territory, Smith (2005) further differentiates between experience-based and text-based communication. Experience-based communication is communication grounded in actual experience, with references to time and place: “...I had a panic attack on the bus on the way here this morning". Text-based communication does not reference a time or place, but rather, refers back to a text: “...my score is high on the panic questions...." CPSTs and consumers doing an oral administration typically discussed at least one experience-based consumer-initiated communication pertaining to a survey question. Such experientially-based consumer articulations of symptoms created a shared experience-based point of reference for the consumer and the CPST, from which they collaboratively generated individualized problem-solving/courses of action. Such dialogue was in stark contrast to the dialogue of consumers in my study who completed surveys "by themselves"; little consumer-generated discussion of the survey occurred and was limited to brief textually-based references typically initiated by CPSTs (i.e.-“you scored high in symptom distress") that did not easily translate into individualized interventions. Smith's notion of inter-textual territory thus offers one potential theoretical explanation of how oral administrations of the outcomes surveys generated the most clinically useful dialogue. (Interestingly, several consumers emphasized to me both their feeling states immediately before and during the survey completion, and the majority of consumers stated they understood their survey answers as 
"me in a moment in time" rather than as an aggregate of how they'd been functioning over the past year. These consumers thus assigned a time and place to their feeling states as they completed to the survey, viewed their survey answers as related to this, and interpreted answering the questions experientially as well as in a text-based communication fashion.)

With regards to the importance of dialogue, the empirical findings of Howe (1993) may also shed light on the clinical utility occurring during observed oral survey administrations. Howe (1993) reviewed a cross-section of studies covering a sixty-year period; the studies included empirical intervention studies, program evaluation studies, studies on the experiences of consumers, and writings by consumers about their experiences. Howe (1993) reports that service users identify the experience of actively talking about themselves as what helps them to understand their experiences and creates opportunities for change; he also more broadly asserts that opportunities to engage in a meaningful conversation about oneself can elicit change as much or more than specific procedures and techniques. The very nature of orally asking consumers questions about themselves via the survey questions may thus be perceived as an opportunity to talk about and reflect on one's self with one's CPST. When I asked consumers why they preferred oral survey administrations, all responses related to interaction with the CPST in one way or another. One CPST (who incidentally had the most negative opinions about the outcomes) specifically stated that if the surveys were at all useful in treatment planning, it was because of the talking that was prompted through doing them.

The reasons pertaining to why observed clinical dialogue occurred typically occurred during oral administrations remain unclear. However, I can with confidence 
state that such clinical dialogues, along with consumer introspections about the survey, were textually absent in the chart, and thus invisible in the inter-textual circles between regulatory and subordinate documents (textually-mediated social processes). They subsequently were thus neither visible as a mental health intervention that could meet the definition of medical necessity and be eligible for Medicaid billing, nor visible as evidence of clinical use of the outcomes. Further, such consumer-initiated, outcomesrelated dialogues were typically cut short to complete the outcomes survey.

\section{Compliance-driven Organization of Time and Client-Centered Practice}

Such compliance-driven organization of time superseding consumer/clientcentered practices (CPSTs across sites defined this simply as "starting where the client is as") with regards to documentation was pervasive across all for agencies. All participating consumers indicated they viewed the outcomes survey as something that is "due", and that is "done when it is due" (the survey administration revolved around an externally imposed deadline, rather than at a time relevant to the consumer's unique life circumstances). All CPSTs voiced "fitting the surveys in" with competing job demandsboth "real client needs" and other paperwork deadlines-as the main challenge to getting surveys done "on time". The only agency that was in compliance with the outcomes completion threshold, and that showed consistent written evidence of the use of the outcomes in treatment planning, was nonetheless partially undermined through a need to comply with multiple timeframes. Integrating outcomes survey completion with preexisting ISP due dates posed an ongoing challenge. Consumers who were active with the agency when the outcomes survey completions began already had existing ISPs and ISP 
timeframes, and some initial survey completions occurred out of sync with ISPs. Once this cycle started and was entered into computer tracking systems, it became more labor intensive to track and interrupt. In an effort to maintain compliance with both outcomes and ISP due dates, there were thus some instances during which survey results used in treatment planning were several months old. While consumers did not voice awareness of specific timeframes relating to regulatory texts, as with the outcomes surveys, consumers clearly identified ISPs as something that "is due" rather than something that is timed according to their unique life circumstances.

I witnessed multiple times a consumer's presenting concern being sandwiched at the beginning and end of an appointment, with completion of a required document occurring during the majority of appointment time. For example, as noted in a previous chapter, one consumer came in with a social security letter he was confused about. The CPST and consumer briefly talked about the letter, completed the outcomes survey orally (during which the consumer's concern about the social security letter again surfaced in response to financial satisfaction questions but was redirected), and then discussed the letter further at the end of the appointment. (This CPST had two other consumers-one who had walked in without an appointment, and another who was two hours late for an appointment-waiting in the waiting room, so time was a scarce commodity during this observed clinical encounter. I also observed the blinking phone message count increasing from three to ten during the appointment I observed.) CPSTs referred to such encounters as "balancing real client needs with the outcomes"; I observed similar balancing acts during completions of other required documents such as diagnostic 
assessment updates and ISPs. As previously quoted, this CPST clearly felt the tension between compliance-driven time and client-centered practice:

...you want to be client-centered, start where the client is at, but it is hard sometimes, you know. It's hard sometimes to do the outcomes, even when you know they're due, or worse, past due, and you have an appointment to do the outcomes, or remember them [the outcomes] when the client comes in... sometimes it's someone who needs something else, or someone you don't see that often or regularly, their outcomes are due, and then they come in with, 'I don't have any medicine. I'm feeling suicidal. I'm going to be kicked out of my apartment, I need to eat', and the last thing on your mind becomes completing a survey.... the other side of the coin is, some of them come in and have a really wonderful day and want to share that, need to share that... I don't want to say 'that's great, but for this appointment I'm going to have you do a survey'... Progress notes documenting oral outcomes administrations similarly contained information relating to doing the survey (i.e.-“completed the outcomes survey”) rather using it (clinically-oriented notations about how the survey or results were used) with consumers. Documented evidence of use of the outcomes in treatment was typically done through text fields on ISP documents. These text fields ranged from a text box indicating outcomes use, to a field for each of the four domains of the outcomes. At three of the four agencies, I saw these text fields only through chart reviews. At the agency with the ISP packet containing outcomes results, completing the outcomes-related text fields were referenced to me as part of the ISP process. The insertion of outcomesrelated text fields on ISPs served as documentation of the use of outcomes in treatment, 
thus demonstrating compliance with the state mandate to use the outcomes in treatment. However, I did not observe clinical use of such text fields, and at three of the four agencies, such text fields were not referenced to me as a way in which the outcomes were used clinically.

As previously stated, the vast majority of my observed clinical uses of the outcomes survey occurred in the context of oral survey administration via "buried dialogues" (specific consumer concerns generated by and briefly discussed in between the standardized outcomes questions), and there was no textual evidence of such uses in any chart document. In addition to not being present in written records, these clinically rich, consumer-initiated "buried dialogues" were not even recognized by any of the CPSTs as a clinical use of the outcomes. Although I had observed at least one such "buried encounter" in each oral survey administration I observed, none of the CPSTs referenced these "buried encounters" in our interviews. It was through observing the oral interactions occurring between CPSTs and consumers in natural practice settings that these "buried dialogue" clinical uses became evident to me.

Such discrepancies between documented practices and actual lived experiences are not unusual, which is why it is useful to juxtapose self-reports, written narratives and observations of actual practice interactions in order to fully understand what has occurred (Floersch, 2004). In a study of case managers' uses of a strengths-based approach, Floersch (2004) asserted:

I think it is possible to approximate a copy of actual practice by utilizing methods that juxtapose the written with the oral practice events. Furthermore, in doing so, we can methodologically represent what part of practice (KIA [knowledge-in-use] 
or TR [technical rational knowledge]) the written actually represents. And until the oral and written narratives are consistently compared, we cannot know what the written reliably and validly represents. (p.169)

In the notes written by the CPST participants, a general evidencing of compliance (e.g., "completed the outcomes") was represented; the notes did not in any fashion represent the consumer-driven clinical interactions generated through oral survey completions. Both the subversion of the consumer-initiated concerns to survey completion, and the absence of these "buried dialogues" in both compliance-oriented documents and CPSTs" own awareness, demonstrate the disjuncture between client-centered practice and compliance-driven time as manifested in frontline experiences and understandings.

\section{Strengths and Limitations of Study}

The institutional ethnographic design was appropriate for the descriptive, processfocused aims of this study, and also enabled me to incorporate stakeholder perspectives (something pointed to as very important in the implementation literature as explicated in Chapter Two) in an explicit way. Through generating detailed descriptions of frontline (CPST and consumer) understandings, experiences and uses of the Consumer Outcomes Survey in Chapter Five and Chapter Six, I answered my first research question, pertaining to how the CPSTs and consumers were understanding, experiencing and using the survey, in an aggregated fashion.

Thematic analysis is a defensible analytic strategy within institutional ethnographic approaches (as explained in Chapter Five). However, thematic analysis is also a hotly contested approach among those who do institutional ethnographies due the 
loss of concrete, material conditions in which actual experiences occurred. Likewise, my aggregated analysis spliced the specific accounts of CPST and consumer experiences from the specific contexts in which they occurred. Further, how specific organization cultures and climates (Glisson, 2007) as they related to specific frontline experiences is something I purposefully did not address in Chapter Four.

Both of these choices (e.g., aggregated analysis and describing the agencies without referencing the Consumer Outcomes Survey) were limiting measures I took purposefully, to reduce the risk of deductive disclosure concerns. The resulting loss of context reduced the sharing of potentially valuable information on how processes interfaced both within and across agencies during this implementation effort. Stakeholders from one agency who may be seeking specific, detailed information on how other stakeholders from other agencies are implementing the Consumer Outcomes Initiative will likewise find the aggregated analysis to be of less use.

Related to my aggregated analysis and cross-agency focus strategy, was a frustration I had (and certainly a limitation of this study) with not being able to develop an analytic thread on the concerns shared with me by one CPST pertaining to racial bias. This CPST talked at length with me about her experiences with African American consumers, who she indicated often struggled with some of the content of the Consumer Outcomes Survey due to the survey having a racial bias. While the Consumer Outcomes Survey was collaboratively developed, and tested with multi-racial, multi-ethnic groups, that unfortunately doesn't eliminate the possibility of racial bias. Such collaborative and developmental activities did not occur in a vacuum, but rather, occurred as embedded 
within a larger society within which institutional racism and white privilege remain pervasive and insidious (Bonilla-Silva, 2006).

Because all of the other CPSTs stated they noticed no racial or ethnic differences in how consumers experienced the Consumer Outcomes Survey (I specifically probed for this in interviews, and watched for it in my observations of survey administrations), I was unable to develop a cross-agency analytic thread through which I could explore the racial bias concerns identified to me. Deductive disclosure risk also further hindered my ability to explore the CPST's racial bias concerns. One might say I had "disconfirmed" the initial CPST's concern regarding racial bias, due to my other CPSTs indications of not having the same concerns/experiences with the Consumer Outcomes Survey. However, given the often subtle nature of institutional racism (Bonilla-Silva, 2006), I am explicitly rejecting such a "disconfirmation" interpretation. Rather, I fully acknowledge the weaknesses in my methodological approach, which precluded me from exploring the identified racial bias concern.

While my chosen analytic strategy had numerous limitations as described above, a great strength of the overall institutional ethnography (IE) approach was in the treatment of texts as social processes. Approaching texts as such enabled me to make connections between activities that were not self-reported to me, and that I did not observe, but were nonetheless salient aspects in frontline CPST and consumer experiences with the Consumer Outcomes Survey. And, IE emphasizes grounding such processes in actual experiences of individuals in particular standpoints in an institutional complex; thus, my explication of system processes relating the implementation of the Consumer Outcomes Initiative (and the uses of the Consumer Outcomes Survey) are empirically grounded. 
Through mapping the social processes connected to (Chapter Seven) and embedded in (Chapter Eight) frontline experiences of the Consumer Outcomes Survey, I was able to fully answer my second research question regarding the system processes related to frontline experiences.

In particular, the construct of inter-textual circles (Smith, 2005) was particularly useful in elucidating how abstract philosophies entered into specific local sites and lived experiences. (That is not to say that there aren't numerous other ways in which medical model and mental health recovery discourses have made their way into mental health settings and lived experiences!). While I hope my descriptive study findings will be of use to a wide variety of stakeholders in the Ohio public mental health system, I ultimately hope that this information will be relevant in particular to CPSTs and consumers seeking to better understand and negotiate in the context in which they practice and use mental health services.

While I fully addressed both research questions as such, the Ohio public mental health system is itself embedded in a larger context, which was left largely unexplicated in this analysis. If I had another year to continue this research, I would delve into the numerous sociopolitical and economic facets in which the institutional field (the Ohio public mental health system) I studied is situated. The national state of healthcare funding in general, and mental health care and parity in particular, are undoubtedly relevant. Corporate rationalism in the delivery of mental health services, the spread of consumer culture as it relates to mental health services, the legacy of Reaganomics on the organization and funding of public mental health services, and the increasing importance of outcomes measures each warrant additional investigation with regards to how they 
relate to the Ohio Consumer Outcomes Initiative. The evolving ideology of evaluation and incentivization within mental health care settings, in terms of how it impacts relationships and interactions between consumers and direct service providers, and between direct service providers and agency administrators, also bears further exploration in light of the findings of this study.

I speculate that continued snowball sampling would have provided an entry into such broader contextual dimensions. To delimit my study to a manageable scope, I chose to end my snow ball sampling recruitment activities when I was being repeatedly referred only to two staff from the state agency (e.g., the Ohio Department of Mental Health and Office of Program Evaluation and Research) from which the Ohio Consumer Outcomes Initiative originated. Had I contacted these state administrators and continued on from them with my snowball sampling, I may have empirically encountered (via narratives of work and related texts-in-use) broader sociopolitical process linkages with CPST and consumer experiences.

\section{Considering Implications for Practice Suggested by These Frontline Implementation Experiences and Embedded System Processes}

One of the two aims of this study was to generate specific information that could be useful to stakeholders in Ohio's public mental health system, with regards to the implementation of the Ohio Consumer Outcomes Initiative. In considering the information shared by participants in this study, several immediate practice implications emerged: a need to alter the format of the results (and possibly the survey as well); a need to bring client-centered practices to the forefront in documentation (currently driven 
primarily by compliance) in a way that is compatible with an agency's financial solvency and compliance with required regulations; and a need to document and understand oral survey administrations in a way that allows encourages and financially compensates for consumer-initiated clinical dialogues that may occur. A longer term implication, regarding the need for advocacy for the expansion and/or reinterpretation of Medicaid law to include mental health recovery constructs, is also apparent.

Both consumers and CPSTs expressed a desire to alter the current results format to one that is narrative and graphical, rather than numerical (without pictorial graphics). Reasons cited related to clinical utility and to increasing accessibility of the results report for consumers. Further, the inclusion of graphics that showed change over time was also repeatedly identified as a need. Some agencies, other than those that participated in this study, do have such graphical outcomes reports. The Benjamin Rose Institute, for example, has a graphics report that shows both a consumer's previous and current answers on the same graph, so as to easily compare and see change over time. There is also a consumer training program in place at a peer support center in Lorain County, which is taught by consumers and specifically explains the outcomes survey and results report in an empowering, utility-focused way. Such consumer-driven trainings would seem to hold promise for increasing consumer knowledge on the outcomes survey and results report, rendering both potentially more understandable/accessible and useful. Perhaps such consumer-conducted outcomes trainings could be routinely done at agency sites where surveys are administered.

With regards to finding ways to privilege client-centered practice over compliance-driven organization of time in documentation, a fascinating idea was shared 
by a QA staff at one of the participating agencies. This staff explained to me that at least one agency in Ohio (she wasn't sure which one) was doing "annual life reviews" during the month of consumers' birthdays. These annual life reviews served as ISPs/subordinate documents to regulatory texts such as Medicaid laws, but were done at times that were specifically relevant to each consumer's unique life circumstances. Orienting both the outcome survey completion and ISP completion to a consumer's birthday month would anchor the timing of these documents in a way that could be personally relevant to consumers, as well as meet the textually-mediated regulations. (The timing of the survey would likely remain problematic in terms of doing it so that results were available on the consumer's birthday; this would clearly need to be tweaked out via a pilot of some kind for agencies that don't do electronic survey completions whereby results are immediately available.)

Two of the four agencies were also experimenting with what one agency referred to as "concurrent documentation". While none of my participants were involved in any of the concurrent documentation pilots occurring at these agencies, these pilots were mentioned in passing to me by administrative participants. As it was explained to me, concurrent documentation refers to the consumer and CPST co-writing progress notes during actual appointment times. The documentation of the appointment thus occurs concurrently with the actual appointment. The benefits of concurrent documentation of outcomes-related activities would seem to be three-fold: the consumer would be afforded increased access to and ownership of his/her service documentation; the time for the codocumentation could be considered Medicaid billable (according to the agency staff I spoke with); and such co-documentation might elicit consumer introspections pertaining 
to the outcomes (the primary consumer use of the outcomes for the consumers in this study, which was invisible in textually mediated social relations). The challenges to concurrent documentation are also numerous; for example, CPST may need to document information that could be distressing to the consumer due to the nature of the consumer's mental illness or particular life circumstance. However, like the consumer-taught outcomes trainings and annual life reviews, I believe concurrent documentation holds promise as a way to shift from the institutionalized compliance-driven organization of time around documentation to more client-centered documentation practices.

It may be that the clinical utility of oral survey administrations would decrease once narrative, graphical survey results report was readily accessible. However, for the time being, the buried dialogues occurring during oral administrations need to be identified, optimized, and documented as billable mental health interventions. There are precedents for compensation of survey administrations in the field of psychology. The documentation of oral administrations could also be done in a way that is mindful of the actual consumer-elicited concerns during the outcomes and makes the intervention that occurred explicit and textually visible (i.e.-“'facilitated collaborative assessment of consumer needs via interactive completion and discussion of the Consumer Outcomes Survey questions and answers"), rather than compliance-focused (i.e.-“completed the outcomes survey"). From my conversations with board staff, it seems that such a documentation of an oral survey administration would meet the "mind to mind connection" litmus test for determining whether a mental health intervention occurred; that is, the consumer and CPST were clearly and actively connecting around and dialoging about the consumer's mental health concerns. Further, ongoing assessment of 
needs and monitoring of symptoms are both listed as billable interventions within CPST practice in the Ohio Administrative Codes.

However, in the larger context of "medical necessity", when non-symptom related consumer concerns are generated in response to non-symptom outcomes domains during oral survey administrations, even an explicit notation of a "mind to mind connection" might not suffice as "medically necessary". This relates back to the divergent paradigms of the narrower medical model and the broader mental health recovery paradigms contained within regulatory texts and experienced at the frontlines as disjunctures between subordinate texts. To reconcile this disjuncture, a mobilization and advocacy effort within the public mental health system is needed that would either alter or allow for reinterpretation of Medicaid law (pertaining to "medical necessity") so that aspects of mental health recovery (other than the medical model) can be offered and compensated for in routine CPST service delivery.

Such a reformation effort is daunting, but not impossible. Ohio has one of the most progressive and highly ranked state mental health systems in the United States (NAMI, 2006); the Ohio Department of Mental Health has championed a mental health recovery-driven service system for over a decade. While modification of the medicalmodel oriented financial infrastructure (Medicaid laws) to support funding mental health recovery-oriented CPST services would be a formidable task, such a Medicaid reform effort would not be occurring in isolation. Rather, such a Medicaid reform effort would build upon over a decade of ODMH's work to transform Ohio's public mental health system into one that is truly recovery-driven. 


\section{Situating this Study of Frontline Implementation Experiences and Embedded System Processes in Existing Implementation Science Literature}

While the first aim of this study pertains to generating specific information that would be of use to stakeholders in the Ohio public mental health system, my second aim pertains to generating information that contributes to the existing body of scholarship in implementation science. In qualitative research, empirical generalizations are typically difficult to make with any accuracy due to convenience sampling, sample size, and other methodological constraints that don't lend themselves to conventions for empirical generalizability. However, in qualitative research, theoretical generalizations are possible, with regards to how findings may fit with existing theoretical understandings of a given phenomenon. In considering the existing body of literature on implementation I reviewed in Chapter Two, my study can be situated in terms of the existing work that it confirms, and in terms of what it contributes. In my initial thematic analysis in Chapter Two, I identified one particularly cross-referenced barrier to implementation efforts: difficulty in and lack of knowledge about developing system policies and infrastructures that are integrated with and support practitioners' everyday attempts to implement a given intervention (Haynes and Haines, 2002; Fadden, 1997; Farhall \& Cotton, 2002; Bower, 2002). My study was consistent with claims regarding infrastructures as implementation barriers, through explicating in detail how confluences of system processes (compliance-organized time, medical model dominated documentation/funding) undermined frontline attempts to implement the Consumer Outcomes Survey in a clinically relevant way. 
My findings were also consistent with claims of implementation as a multi-level phenomenon (Panzano et al, 2002-2003; Proctor, 2004; Fixsen et al, 2005). Although my primary focus was on system-wide, cross-agency (macro) processes, I also identified agency-specific (meso) processes on a limited basis, and explicated in detail how two system processes in particular impacted frontline (micro) attempts to implement the Ohio Consumer Outcomes Initiative. However, because my explication of meso processes was extremely limited to attempt to reduce deductive disclosure risk, my study thus is very limited in explicating how such three levels specifically interfaced.

With regards to the existing state of knowledge on implementations, Fixsen et al (2005) asserted: “...there is little evidence related to organizational and systems influences on implementation, their specific influences, or the mechanisms for their impact (but there is little doubt as to their having an impact (p. 70)". My study findings thus offer a contribution in terms of explicating systems influences (explicit and implicit processes) on a given implementation effort, as well as the specific influences (compliance-driven time, medical model dominated documentation/funding) and mechanisms for impact (primarily textually-mediated social processes, driven by compliance and funding). Methodologically, I also confirmed that institutional ethnography can enable one to "see" such systems influences, by using textuallymediated social relations to trace implementation processes as well as to illuminate the divergent system processes/barriers manifesting in frontline implementation experiences.

Finally, in considering my four suggested continuums of implementation from the perspectives of CPST and consumer participants, it would seem that these continuums, combined with stakeholder standpoint theory and chaos, could offer some explanatory 
power if further developed. In my study, "the nature of the problem" in its best sensemeasuring treatment outcomes-seemed relatively clear and well-structured to participating CPSTs and consumers, all of whom agreed that measuring outcomes in general was a worthwhile idea. Their understandings of the "innovation" through which to "address the problem"-the Consumer Outcomes Survey-was both fixed and dynamic. While the Consumer Outcomes Survey questions and results report formats were treated as fixed and portable, how these "innovations" were utilized was clearly dynamic and context-dependent (undermined by contextual factors such as compliance-driven time and funding paradigms). The nature of appropriate activities relating to implementing the innovation - in this case the completion and uses of the Consumer Outcomes Survey-was treated as both fixed and dynamic. While the completion of the survey by the consumer was treated as a fixed aspect, how the completion was fit into everyday work, actually occurred ("together" or "by themselves"), and documented was dynamic and contextdependent.

The Consumer Outcomes Survey (the innovation) was developed through a highly collaborative, multi-year approach involving a diverse group of stakeholders, and, an ongoing workgroup of diverse stakeholders remains in place to continually address implementation issues. Such collaborative processes are highly suggestive of multidirectional knowledge-exchanges. However, from self-reports of my frontline (CPST and consumer) participants, the Consumer Outcomes Initiative was perceived primarily as a knowledge-transfer, top-down implementation. My frontline participants' negative perceptions of top-down communication, despite such extensive and ongoing stakeholder collaborations, did not seem to fit with the most cross-referenced facilitating factor I 
located in my thematic analysis of literature (collaboration between representatives of stakeholder groups impacted by an innovation implementation).

In reflecting on this seeming discrepancy between my participants' top-down perceptions, and statements in the literature pertaining to stakeholder collaboration facilitating multi-directional knowledge exchange, chaos theory came to mind, along with fragments of the following statement from Litaker et al (2006):

Complex nonlinear systems, in contrast, are difficult to fully characterize because of the potential for multiple interactions and recursive feedback loops between components within and outside the system. Furthermore, many of these systems exhibit actions that follow nonlinear, unpredictable trajectories, but possess underlying patterns that are detectable and based in probabilities related to constraints placed on each system [emphasis added]. (p.S31)

I speculate that in a system as large as a state public mental health system, the potential for feedback loops of all sorts seems almost infinite. And certainly there are numerous constraints placed on the system that I have not delved into; for example, changes in state and federal funding availability for public mental health services in Ohio. The collaborative design of the Consumer Outcomes Survey, and the ongoing stakeholder collaborations, are only two of many factors that may be impacting how my participants are experiencing the implementation of the Ohio Consumer Outcomes Initiative.

\section{Future Directions}

As I reflected on my findings, as related to the implementation literature, and as related to current circumstances in the Ohio public mental health system, several specific 
thoughts related to studies came to mind. These specific thoughts, in no particular order, are as follows:

- Following up with and integrating the findings of a top-down policy implementation study of the Ohio Consumer Outcomes Initiative (Polly, 2004), so as to further explore the complexities of the social processes within this implementation effort;

- $\quad$ using IE to address concerns recently shared with me by stakeholders in the Ohio public mental health system regarding certification issues as they relate to frontline CPST and dually diagnosed (addiction and mental illness) consumer experiences;

- the need to explore potential racial bias in the Consumer Outcomes Survey in natural practice settings;

- exploring how consumers' introspections regarding the Consumer Outcomes Survey might be better supported and facilitated in CPST service delivery (as embedded in larger structures, of course!);

- a curiousness as to how mental health recovery culture becomes present in a given organization, and the differences between such an organization and "service as usual" organizations;

- a follow-up study focusing specifically on system-related facilitators in the implementation of the Ohio Consumer Outcomes Initiative, perhaps using an appreciative inquiry (AI) approach, which focuses on collaboratively identifying and developing what a given entity does best (Cooperrider, D., 2007) 
In addition to the specific thoughts above, the potential for IE to augment research on the implementation of evidence-based practices also seems substantial. Through using IE to delineate and flesh out the system-related infrastructure processes that are both problematic in terms of practitioners' attempts to implement the desired practice change (Haynes \& Haines, 2002), and not readily visible from non-frontline perspectives, such contextual issues could be explicated and addressed. Further, the IE approach, because of its roots in standpoint theory, would also specifically explore the implementations of particular evidence-based practices beginning from the perspectives of frontline clinicians and consumers. While there are many studies detailing the roles that consumers and frontline clinicians should play in implementing an evidence-based practice, there are few in-depth studies on how those on the frontlines are actually experiencing such evidencebased practices (Lockwood, 2005).

\section{Concluding Thoughts: Illuminating the "Invisible Fences"}

In concluding this dissertation, it is apparent to me that I have merely scratched the surface, in terms of the complexities of the interconnected, micro-to-macro social processes through which a given implementation occurs. Much more work is needed in implementation science, particularly work that explicitly avoids "practitioner blame" (Shaw, 2005) through incorporating how confluences of larger system processes serve to partially structure everyday practice experiences during implementation endeavors. Illuminating and making explicit such regulatory "invisible fences" (as one CPST put it) could render them more amenable to being transformed via advocacy efforts (when needed). And, where "the rubber meets the road", such work may help empower 
frontline practitioners and users of services, by generating information that could help them better understand and negotiate the contexts in which they practice and use services. 


\section{APPENDICES}

Appendix

A - Consumer Outcomes Rule.............................. 284

B - Adult Consumer Form.............................. 288

C - CPST recruitment flyers........................... 294

D - CPST consent forms................................... 295

E - Consumer mailing letter............................. 298

F - Consumer consent form................................. 299

G - CPST interview form............................. 304

H - Administrative/other consent form................... 305

I - Administrative/other interview form.................. 308

J - Consumer Interview............................... 309

K - Interconnected Social Processes....................... 310

L - Deemed Status Rule................................ 312

M - Medical Necessity .................................. $\quad 314$ 


\section{APPENDIX A - Consumer Outcomes}

\section{2-28-04 Ohio Administrative Code: Consumer Outcomes}

(A)

The purpose of this rule is to ensure that consumer outcomes are appropriately and adequately measured in order to facilitate management of consumer care, to improve the quality of the services being delivered, and to provide accountability for public resources. Outcomes data submitted by agencies will be used by ODMH to prepare reports that will provide statewide comparative information to agencies, boards and consumer and family advocates.

(B) The following definitions apply to this rule:

(1)

"Consumer outcomes" means indicators of health or well-being for an individual or family as measured by statements or observed characteristics of the consumer/family, not characteristics of the system. These measures provide an overall status measure with which to better understand the life situation of a consumer or family.

(2)

"Vital Signs" means the document in the following citation: "Ohio Mental Health Outcomes Task Force (1998). Vital Signs: A Statewide Approach to Measuring Consumer Outcomes in Ohio's Publicly Supported Community Mental Health System, (final report). Columbus, Ohio: Ohio Department of Mental Health".

(3)

"Consumer Outcomes Procedural Manual" means the most recent version of the document in the following citation: "The Ohio Mental Health Consumer Outcomes System: Procedureal Manual (third edition, revised), (2000). Columbus, Ohio: Ohio Department of Mental Health. It is available on-line at: http://www.mh.state.oh.us/initiatives/outcomes/outcomes.html. (C)

Each agency shall use a system to measure consumer outcomes for children and youth and for adults who receive publicly funded mental health services, as specified in the "Consumer Outcomes Procedural Manual".

(1)

Agencies shall use the standardized statewide consumer outcomes system as specified in the "Consumer Outcomes Procedural Manual" with the following exceptions:

(a)

Agencies that provide mental health services that are intended to be brief one-time-only services, such as crisis intervention service and forensic evaluation service, are not required to measure consumer outcomes for those services as specified in the "Consumer Outcomes Procedural Manual"; and (b)

Agencies covered by a written agreement between their local mental health 
board and the department prior to the effective date of this rule, to modify the requirements of the "Consumer Outcomes Incentive Grant", will be acknowledged by the department to continue to implement the "Ohio Mental Health Consumer Outcomes System" as described in the prior written agreement. (2)

Upon application to the department, agencies may be exempted from the requirements of paragraph $(\mathrm{C})(1)$ of this rule if they meet the following conditions:

(a)

The agency must have a twelve month history as of the effective date of this rule of implementing an alternate consumer outcomes measurement system that was required by its local county mental health board.

(b)

The agency must be geographically located in a county mental health board area that has not accepted the "Consumer Outcomes Incentive Grant".

(c)

For adult consumers, the alternate consumer outcomes measurement system must be psychometrically sound, and shall meet eight of the following ten requirements:

(i)

Reflects the value of support for consumer recovery;

(ii)

Measures outcomes from the perspective of the consumer;

(iii) Measures outcomes from the perspective of the direct care staff most knowledgeable about the consumer;

(iv)

Demonstrates cultural sensitivity;

(v)

Has reasonable levels of cost and burden for provider agencies, consumers and families;

(vi)

Measures the domain of symptom distress;

(vii) Measures the domain of functioning;

(viii) Measures the domain of quality of life;

(ix)

Measures the domain of health and safety, e.g., harming self or others, getting in trouble with the law, etc.;

(x)

Reflects empowerment.

(d)

For child/youth consumers, the alternate consumer outcomes measurement system must be psychometrically sound, and shall meet nine of the following eleven requirements:

(i)

Reflects the value of support for resiliency;

(ii) 
Measures outcomes from the perspective of the child/youth consumer; (iii) Measures outcomes from the perspective of the child/youth's parent or guardian;

http://onlinedocs.andersonpublishing.com/oh/lpExt.dll/OAC/12a13/12b49/12b59?f=temp

12/28/2005 Anderson's OnLine Documentation Page 2 of 2

(iv)

Measures outcomes from the perspective of the direct care staff most knowledgeable about the child/youth;

(v)

Demonstrates cultural sensitivity;

(vi)

Has reasonable levels of cost and burden for provider agencies, consumers and families;

(vii) Measures the domain of symptoms or problems;

(viii) Measures the domain of functioning;

(ix)

Measures the domain of quality of life;

(x)

Measures the domain of health and safety, e.g., harming self or others, getting in trouble with the law, etc., and

(xi)

Is consistent with "NIMH Child and Adolescent Service System Program (CASSP)" requirements.

(D)

Within six months of the effective date of this rule, or within six months of an agency's initial application for certification, the agency shall have completed an internal planning process and be prepared to collect consumer outcomes data.

(E)

Within twelve months of the effective date of this rule, or within twelve months of an agency's initial application for certification, the agency shall:

(1)

Be flowing data through the mental health board to the department, if it is using the standardized statewide "Ohio Mental Health Consumer Outcomes System" as specified in the "Consumer Outcomes Procedural Manual". The mental health board shall handle the data in a manner that complies with the "Health Insurance Portability and Accountability Act" [42U.S.C. sections 1320-1320d-8] and the privacy regulations promulgated thereunder [45C.F.R. Part 164], and applicable provisions of state law; or

(2)

Agencies that have been acknowledged or exempted by the department pursuant to paragraph $(\mathrm{C})(1)(\mathrm{b})$ or $(\mathrm{C})(2)$ of this rule for a different consumer outcomes system than that specified in the "Consumer Outcomes Procedural Manual", shall send to the department a detailed report of outcomes data collected on an 
annual basis.

(F)

Within twenty four months of the effective date of this rule, or within twenty

four months of an agency's initial application for certification, the agency shall be able to provide evidence that outcomes data are being used in both treatment planning and performance improvement activities.

HISTORY: Eff 9-4-03

Rule promulgated under: RC 119.03 Rule authorized by: RC 5119.01(H), 5119.06(A), 5119.61(A), 5119.611(C) Rule amplifies: RC 5119.01(H), 5119.06(A), 5119.61(A), 5119.611(C)

R.C. 119.032 review dates: 03/12/2003 and 09/04/2008

http://onlinedocs.andersonpublishing.com/oh/lpExt.dll/OAC/12a13/12b49/12b59?f=temp

$12 / 28 / 2005$ 
APPENDIX B

\section{Ontal Health Consumer Outcomes System Adult Consumer Form}

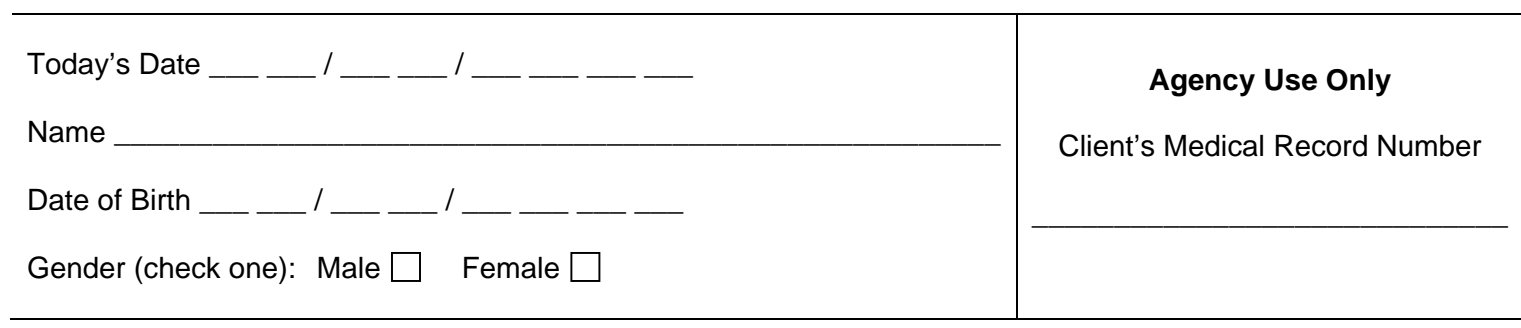

We are very interested in how you are doing, and how our services may or may not be helping you. Please answer all of the questions below, then give the questionnaire to your case manager or another staff person at the mental health agency.

\begin{tabular}{|l|}
\hline \multicolumn{1}{|c|}{ Part 1} \\
\hline Below are some questions about how satisfied you are \\
with various aspects of your life in the past 6 months. \\
For each question, checkmark $\square$ the answer that best \\
describes how you feel.
\end{tabular}

How do you feel about:

\section{The amount of friendship in your life?}

$\square$ Terrible
$\square$ Mostly dissatisfied
$\square$ Equally satisfied/dissatisfied
$\square$ Mostly satisfied
$\square$ Very pleased

2. The amount of money you get?

$\square$ Terrible
$\square$ Mostly dissatisfied
$\square$ Equally satisfied/dissatisfied
$\square$ Mostly satisfied
$\square$ Very pleased

3. How comfortable and well-off you are financially?

$\square$ Terrible
$\square$ Mostly dissatisfied
$\square$ Equally satisfied/dissatisfied
$\square$ Mostly satisfied
$\square$ Very pleased

\section{How much money you have to spend for fun?}

$\square$ Terrible
$\square$ Mostly dissatisfied
$\square$ Equally satisfied/dissatisfied
$\square$ Mostly satisfied
$\square$ Very pleased

5. The amount of meaningful activity in your life (such as work, school, volunteer activity, leisure activity)?

$\square$ Terrible
$\square$ Mostly dissatisfied
$\square$ Equally satisfied/dissatisfied
$\square$ Mostly satisfied
$\square$ Very pleased

6. The amount of freedom you have?

$\square$ Terrible
$\square$ Mostly dissatisfied
$\square$ Equally satisfied/dissatisfied
$\square$ Mostly satisfied
$\square$ Very pleased

7. The way you and your family act toward each other?

$\square$ Terrible
$\square$ Mostly dissatisfied
$\square$ Equally satisfied/dissatisfied
$\square$ Mostly satisfied
$\square$ Very pleased
$\square$ Does not apply


8. Your personal safety?

$\square$ Terrible
$\square$ Mostly dissatisfied
$\square$ Equally satisfied/dissatisfied
$\square$ Mostly satisfied
$\square$ Very pleased

9. The neighborhood in which you live?

$\square$ Terrible
$\square$ Mostly dissatisfied
$\square$ Equally satisfied/dissatisfied
$\square$ Mostly satisfied
$\square$ Very pleased

10. Your housing/living arrangements?

$\square$ Terrible
$\square$ Mostly dissatisfied
$\square$ Equally satisfied/dissatisfied
$\square$ Mostly satisfied
$\square$ Very pleased

11. Your health in general?

$\square$ Terrible
$\square$ Mostly dissatisfied
$\square$ Equally satisfied/dissatisfied
$\square$ Mostly satisfied
$\square$ Very pleased

12. How often do you have the opportunity to spend time with people you really like?

$\square$ Never
$\square$ Seldom/rarely
$\square$ Sometimes
$\square$ Often
$\square$ Always

\begin{tabular}{|l|}
\hline Part 2 \\
\hline The next few items ask you about your health and \\
medications within the past 6 months.
\end{tabular}

13. How often does your physical condition interfere with your day-to-day functioning?

$\square$ Never
$\square$ Seldom/rarely
$\square$ Sometimes
$\square$ Often
$\square$ Always

14. Concerns about my medications (such as side effects, dosage, type of medication) are addressed:

$\square$ Never
$\square$ Seldom/rarely
$\square$ Sometimes
$\square$ Often
$\square$ Always
$\square$ Not applicable/no medications

The next two items deal with how you have been treated by other people.

15. I have been treated with dignity and respect at this agency.

$\square$ Never
$\square$ Seldom/rarely
$\square$ Sometimes
$\square$ Often
$\square$ Always

16. How often do you feel threatened by people's reactions to your mental health problems?

$\square$ Never
$\square$ Seldom/rarely
$\square$ Sometimes
$\square$ Often
$\square$ Always

\begin{tabular}{|l|}
\hline \multicolumn{1}{|c|}{ Part 3} \\
\hline The following questions ask you about how much \\
you were distressed or bothered by some things \\
during the last seven days. Please mark the \\
answer that best describes how you feel.
\end{tabular}

During the past 7 days, about how much were you distressed or bothered by:

\section{Nervousness or shakiness inside}

$\square$ Not at all
$\square$ A little bit
$\square$ Some
$\square$ Quite a bit
$\square$ Extremely

Please turn to the next page $\rightarrow$ 
APPENDIX B

18. Being suddenly scared for no reason

$\square$ Not at all
$\square$ A little bit
$\square$ Some
$\square$ Quite a bit
$\square$ Extremely

19. Feeling fearful

$\square$ Not at all
$\square$ A little bit
$\square$ Some
$\square$ Quite a bit
$\square$ Extremely

20. Feeling tense or keyed up

$\square$ Not at all
$\square$ A little bit
$\square$ Some
$\square$ Quite a bit
$\square$ Extremely

21. Spells of terror or panic

$\square$ Not at all
$\square$ A little bit
$\square$ Some
$\square$ Quite a bit
$\square$ Extremely

22. Feeling so restless you couldn't sit still

$\square$ Not at all
$\square$ A little bit
$\square$ Some
$\square$ Quite a bit
$\square$ Extremely

23. Heavy feelings in arms or legs

$\square$ Not at all
$\square$ A little bit
$\square$ Some
$\square$ Quite a bit
$\square$ Extremely

24. Feeling afraid to go out of your home alone

$\square$ Not at all
$\square$ A little bit
$\square$ Some
$\square$ Quite a bit
$\square$ Extremely

\section{Feeling of worthlessness}

$$
\begin{aligned}
& \square \text { Not at all } \\
& \square \text { A little bit } \\
& \square \text { Some } \\
& \square \text { Quite a bit } \\
& \square \text { Extremely }
\end{aligned}
$$

26. Feeling lonely even when you are with people

$$
\begin{aligned}
& \square \text { Not at all } \\
& \square \text { A little bit } \\
& \square \text { Some } \\
& \square \text { Quite a bit } \\
& \square \text { Extremely }
\end{aligned}
$$

27. Feeling weak in parts of your body

$$
\begin{aligned}
& \square \text { Not at all } \\
& \square \text { A little bit } \\
& \square \text { Some } \\
& \square \text { Quite a bit } \\
& \square \text { Extremely }
\end{aligned}
$$

28. Feeling blue

$$
\begin{aligned}
& \square \text { Not at all } \\
& \square \text { A little bit } \\
& \square \text { Some } \\
& \square \text { Quite a bit } \\
& \square \text { Extremely }
\end{aligned}
$$

29. Feeling lonely

$$
\begin{aligned}
& \square \text { Not at all } \\
& \square \text { A little bit } \\
& \square \text { Some } \\
& \square \text { Quite a bit } \\
& \square \text { Extremely }
\end{aligned}
$$

30. Feeling no interest in things

$$
\begin{aligned}
& \square \text { Not at all } \\
& \square \text { A little bit } \\
& \square \text { Some } \\
& \square \text { Quite a bit } \\
& \square \text { Extremely }
\end{aligned}
$$

31. Feeling afraid in open spaces or on the streets

$$
\begin{aligned}
& \square \text { Not at all } \\
& \square \text { A little bit } \\
& \square \text { Some } \\
& \square \text { Quite a bit } \\
& \square \text { Extremely }
\end{aligned}
$$

Please turn to the next page $\rightarrow$ 
32. How often can you tell when mental or emotional problems are about to occur?

$\square$ Never
$\square$ Seldom/rarely
$\square$ Sometimes
$\square$ Often
$\square$ Always

33. When you can tell, how often can you take care of the problems before they become worse?

$\square$ Never
$\square$ Seldom/rarely
$\square$ Sometimes
$\square$ Often
$\square$ Always

\begin{tabular}{|l|}
\hline \multicolumn{1}{|c|}{ Part 4} \\
\hline Below are several statements relating to one's \\
view about life and having to make decisions. \\
Please check the response that is closest to how \\
you feel about the statement. Check the word or \\
words that best describes how you feel now.
\end{tabular}

34. I can pretty much determine what will happen in my life.

$\square$ Strongly agree
$\square$ Agree
$\square$ Disagree
$\square$ Strongly Disagree

35. People are limited only by what they think is possible.
$\square$ Strongly agree
$\square$ Agree
$\square$ Disagree
$\square$ Strongly Disagree

36. People have more power if they join together as a group.

$\square$ Strongly agree
$\square$ Agree
$\square$ Disagree
$\square$ Strongly Disagree

37. Getting angry about something never helps.

$\square$ Strongly agree
$\square$ Agree
$\square$ Disagree
$\square$ Strongly Disagree

38. I have a positive attitude toward myself.

$\square$ Strongly agree
$\square$ Agree
$\square$ Disagree
$\square$ Strongly Disagree

39. I am usually confident about the decisions I make.

$\square$ Strongly agree
$\square$ Agree
$\square$ Disagree
$\square$ Strongly Disagree

40. People have no right to get angry just because they don't like something.

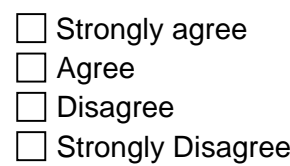

41. Most of the misfortunes in my life were due to bad luck.

$\square$ Strongly agree
$\square$ Agree
$\square$ Disagree
$\square$ Strongly Disagree

42. I see myself as a capable person.

$\square$ Strongly agree
$\square$ Agree
$\square$ Disagree
$\square$ Strongly Disagree

43. Making waves never gets you anywhere.

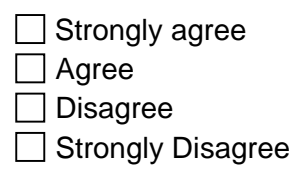

Please turn to the next page $\rightarrow$ 
44. People working together can have an effect on their community.

$\square$ Strongly agree
$\square$ Agree
$\square$ Disagree
$\square$ Strongly Disagree

45. I am often able to overcome barriers.

$\square$ Strongly agree
$\square$ Agree
$\square$ Disagree
$\square$ Strongly Disagree

46. I am generally optimistic about the future.

$\square$ Strongly agree
$\square$ Agree
$\square$ Disagree
$\square$ Strongly Disagree

47. When I make plans, I am almost certain to make them work.

$\square$ Strongly agree
$\square$ Agree
$\square$ Disagree
$\square$ Strongly Disagree

48. Getting angry about something is often the first step toward changing it.

$\square$ Strongly agree
$\square$ Agree
$\square$ Disagree
$\square$ Strongly Disagree

49. Usually I feel alone.

$\square$ Strongly agree
$\square$ Agree
$\square$ Disagree
$\square$ Strongly Disagree

50. Experts are in the best position to decide what people should do or learn.

$\square$ Strongly agree
$\square$ Agree
$\square$ Disagree
$\square$ Strongly Disagree

51. I am able to do things as well as most other people.

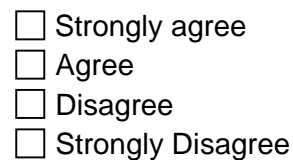

52. I generally accomplish what I set out to do.

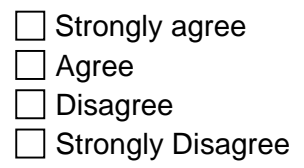

53. People should try to live their lives the way they want to.

$\square$ Strongly agree
$\square$ Agree
$\square$ Disagree
$\square$ Strongly Disagree

54. You can't fight city hall (authority).

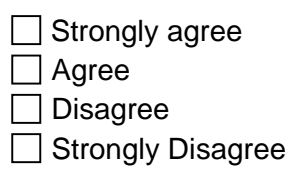

55. I feel powerless most of the time.

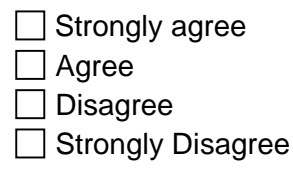

56. When I am unsure about something, I usually go along with the rest of the group.

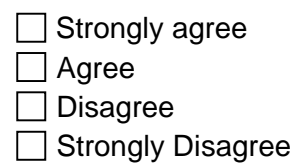

57. I feel I am a person of worth, at least on an equal basis with others.

$\square$ Strongly agree
$\square$ Agree
$\square$ Disagree
$\square$ Strongly Disagree

Please turn to the next page $\rightarrow$ 
58. People have a right to make their own decisions, even if they are bad ones.

$\square$ Strongly agree
$\square$ Agree
$\square$ Disagree
$\square$ Strongly Disagree

59. I feel I have a number of good qualities.

$\square$ Strongly agree
$\square$ Agree
$\square$ Disagree
$\square$ Strongly Disagree

60. Very often a problem can be solved by taking action.

$\square$ Strongly agree
$\square$ Agree
$\square$ Disagree
$\square$ Strongly Disagree

61. Working with others in my community can help to change things for the better.

$\square$ Strongly agree

$\square$ Agree

Disagree

Strongly Disagree

\section{Part 5}

Please tell us some things about yourself.

62. What was the last school grade you completed?

$\square$ Less than $1^{\text {st }}$ grade
$\square 1^{\text {st }}$ grade
$\square 2^{\text {nd }}$ grade
$\square 3^{\text {rd }}$ grade
$\square 4^{\text {th }}$ grade
$\square 5^{\text {th }}$ grade
$\square 6^{\text {th }}$ grade
$\square 7^{\text {th }}$ grade
$\square 8^{\text {th }}$ grade
$\square 9^{\text {th }}$ grade

$\square 10^{\text {th }}$ grade
$\square 11^{\text {th }}$ grade
$\square$ High school diploma/GED
$\square$ Trade/Tech school
$\square$ Some college
$\square 2$ yr college/Associate degree
$\square 4$ yr college/Undergraduate degree
$\square$ Graduate school courses
$\square$ Graduate degree
$\square$ Post-graduate studies
$\square$ Further special studies

\section{Race (check all that apply):}

$\begin{array}{ll}\square \text { White } & \square \text { Hispanic/Latino } \\ \square \text { Native American/Pacific Islander } & \square \text { Asian } \\ \square \text { Black/African American } & \square \text { Other }\end{array}$

\section{What is your marital status?}

$\square$ Never married
$\square$ Married
$\square$ Separated
$\square$ Divorced
$\square$ Widowed
$\square$ Living together

65. What is your current living situation?

$\square$ Your own house/apartment
$\square$ Friend's home
$\square$ Relative's home
$\square$ Supervised group living
$\square$ Supervised apartment
$\square$ Boarding home
$\square$ Crisis residential
$\square$ Child foster care
$\square$ Adult foster care
$\square$ Intermediate care facility
$\square$ Skilled nursing facility
$\square$ Respite care
$\square$ MR intermediate care facility
$\square$ Licensed MR facility
$\square$ State MR institution
$\square$ State MH institution
$\square$ Hospital
$\square$ Correctional facility
$\square$ Homeless
$\square$ Rest home
$\square$ Other

66. What is your employment status?

$\square$ Employed full time
$\square$ Employed part time
$\square$ Sheltered employment
$\square$ Unemployed
$\square$ Student
$\square$ Homemaker
$\square$ Retired
$\square$ Disabled
$\square$ Inmate of institution

67. Are you in treatment because you want to be?

Yes

Please stop here. Thanks! 
APPENDIX C - CPST recruitment flyer

\section{ATTENTION CPST STAFF:}

\section{DO YOU CARE ABOUT IMPROVING MENTAL HEALTH SERVICE DELIVERY?}

\section{ARE YOU WILLING TO SHARE YOUR THOUGHTS ABOUT AND EXPERIENCES WITH THE CONSUMER OUTCOMES SURVEYS?}

\section{CONSIDER PARTICIPATING IN A NEW RESEARCH STUDY!}

This study is being done at Agency $X$ by researchers (Janet Hoy and Dr. Jerry Floersch) from Case Western Reserve University. You would be paid $\$ 50$ in a Visa gift card (you would be paid immediately after completing an interview with the researcher, which would happen approximately 2 months after your participation begins) as compensation for participating in this study. And, if you volunteer to participate, you may be contributing valuable and critically needed information about how mental health practice changes are implemented. Your participation would include:

- Having a researcher (Janet Hoy) observe outcomes-related sessions with participating clients

- Doing one tape-recorded interview with a researcher (Janet Hoy) about the Consumer Outcomes Surveys.

- Having charts of your participating clients reviewed by a researcher (Janet Hoy) to see how the Consumer Outcomes Surveys are written about

- Suggesting other possible research participants (people who've been relevant to your work with the Consumer Outcomes Surveys) for the researcher (Janet Hoy) to contact

To protect confidentiality, all notes and tapes kept in a safe and locked office, and no names or means of identifying you (or others) will be used. Contact Janet Hoy at 216-410-1660 or jmh7@sbcglobal.net for more information! 
APPENDIX D - CPST Consent Form

INFORMED CONSENT DOCUMENT - CPST

Implementing the Consumer Outcomes Surveys

Thank you for your interest in participating in this study. Janet Hoy (co-investigator) and Dr. Jerry Floersch (principal investigator) are conducting this study; both are affiliated with the Mandel School of Applied Social Sciences at Case Western Reserve University. Please read this form and ask any questions that you may have before agreeing to participate in this research.

\section{Background Information}

Community Psychiatric Supportive Treatment Staff (CPSTs) are frequently asked to change how they do their work to incorporate new practice tools. Yet putting a new practice to use - a.k.a. 'implementing' - in the midst of the everyday demands of CPST work is often much easier said than done! There are many things, some obvious and some less so, that may impact one's ability to make a practice change. Understanding how everyday CPST work is interrelated with less obvious policy and regulatory work of others may increase our abilities to make desired changes, and ultimately to better help our consumers in their mental health recovery. To begin to build such an understanding, this study examines how the Consumer Outcomes Surveys (a newer practice tool) are being implemented in the pressures of real world practice. The two purposes of the research are to see: 1) how CPSTs and mental health consumers are actually doing/using the Consumer Outcomes Surveys in everyday work, and 2) how these everyday uses of the Consumer Outcomes Surveys are connected with the work of others at the county, state and federal levels through mental health policies, procedures, and regulations.

\section{Procedures}

Please be aware that your participation in this study is strictly voluntary. If you choose not to participate, it will in no way adversely impact your relationship with your employer, Case Western Reserve, or other cooperating agencies. If you decide to participate in this research, your involvement would entail:

- Using your clinical judgment to identify clients on your caseload who are clinically stable/appropriate for study participation. Janet would arrange a study recruitment letter mailing to these clients. Clients responding to the recruitment letter would then contact you and request that you initiate a meeting with them and Janet to further explore their interest in participation.

- Being intensively observed in your CPST work, with or without participating clients, $1 / 2$ to one day a week, for approximately two months, while Janet takes notes about how you are learning about/doing/using the Consumer Outcomes Surveys and/or related tasks.

- Providing access to other documents (memos, policies, etc.) that have informed your uses and understandings of the Consumer Outcomes Surveys.

- Doing a tape-recorded interview, lasting approximately one hour, with Janet about your experiences and understandings of the Consumer Outcomes 
Surveys. Janet will transcribe the interview(s) from the tape-recording after your meeting. The tape recording of interviews is required for this study.

- Having your charts reviewed by Janet to see how uses of the Consumer Outcomes Surveys are being documented.

- Recommending key people for Janet to interview - such as supervisors, quality assurance staff, information technology staff, or others - who impact your experiences with the Consumer Outcomes Surveys. Before Janet contacts these people, she will ask your permission to identify you as the person who recommended that she interview them. When she contacts them, she will state 'Hi - I'm Janet Hoy; I'm affiliated with Case Western Reserve University, and I'm doing a study on how the Consumer Outcomes Surveys are being implemented. X (name of person who suggested I contact the potential interviewee) told me you were important in their work with the Consumer Outcomes Surveys, and suggested I interview you". No information other than your identity would be disclosed to the people you suggest for interviews. If you do not give permission to be identified and/or do not recommend any key people, you can continue to participate in the study; anyone you do suggest can be contacted without your identity being disclosed if you request this.

- Janet or Jerry may contact you up to six months after the interview, observation and chart reviews, if they have questions and/or need more information to better understand what you have shared.

\section{Confidentiality}

To ensure confidentiality, all notes of observations, tapes and written transcriptions will be kept in a safe and locked office. No names or means of identifying you or others will be used in the transcripts or notes, or appear in the printed paper of the findings of this project. Quotes from your interview may be used, but no identifying information associated with you will be included or shared. Research records, including tapes, will be kept in a locked file, and access will be limited to the researchers, the University review board responsible for protecting human participants, regulatory agencies, and funding agencies. All tapes and other data will be destroyed within three years of completing this study.

\section{Risks and Benefits to Being in the Study}

Your participation is strictly voluntary. If you choose not to participate or to discontinue participation, it will not affect your current or future relations with your current employer, the Ohio Department of Mental Health, Case Western Reserve University, or with any other cooperating agencies. There is no penalty for not participating or for discontinuing your participation. Research questions and observations have been planned so as to minimize any psychological discomfort on your part. You are free to discontinue your participation in this project at any time, without penalty or prejudice, no questions asked. If you find yourself experiencing intense or prolonged anxiety or discomfort after participation, please contact Janet or Jerry (contact information is below). All information you share during this project will be strictly confidential (with the exception of identifying you as the referent to potential interviewees, as previously explained). When study findings are written up, quotes from 
you may be used, but no identifying information pertaining to you will be included. However, because the study involves a relatively small number of CPST staff, it may be possible for individuals familiar with you and/or your work to identify what you specifically have shared in the written analysis of this study. Your participation will give you an opportunity to provide valuable information, which can contribute to understandings about how we can get desired practice changes into place in the mental health system, ultimately to better help those recovering from mental illness.

\section{Compensation:}

You will receive the following payment/reimbursement: \$50 in form of a Visa gift card. The $\$ 50$ gift card will be given to you immediately after Janet has completed a taped recorded interview with you. The interview will be scheduled and conducted after you and your participating clients have been observed by Janet for approximately two months. Unfortunately, compensation for participating cannot be pro-rated; you must complete the approximately two months of observation and the interview in order to receive the $\$ 50$ reimbursement.

\section{Contacts and Questions}

You may ask Janet any questions you have now. If you have any questions later, you may contact Janet at 216-410-1660, or Dr. Floersch at (216) 368-5598. If Janet and Jerry cannot be reached, or if you would like to talk to someone other than Jerry or Janet about; (1) concerns regarding this study, (2) research participant rights, (3) research-related injuries, or (4) other human subjects issues, please contact Case Western Reserve University's Institutional Review Board at (216) 368-6925 or write: Case Western Reserve University; Institutional Review Board; 10900 Euclid Ave.; Cleveland, OH 44106-7230. You will be given a copy of this form for your records.

\section{Statement of Consent}

I have read the above information. I have received answers to the questions I have asked. I consent to participate in this research. I am at least 18 years of age.

Print Name of Participant:

Signature of Participant:

Date:

Signature of Person Obtaining Consent:

Date: 


\section{APPENDIX E - Consumer mailing letter}

Date:

Dear

As your CPST (Community Psychiatric Treatment Support) worker, I am writing to let you know that a research study is being planned at our agency that may be of interest to you. As a client of our agency, you may be eligible to participate. Final eligibility is determined by the researchers from Case Western Reserve University doing the study.

Even if you are eligible, your participation in this or any research study is completely voluntary. There will be no consequences to you whatever if you choose not to participate, and your regular mental health care will not be affected in any way by your choice.

Compensation for your time in the amount of $\mathbf{\$ 3 0}$ in Visa gift cards would be paid (a \$15 card after the researcher observes us for the first time, and a second $\$ 15$ card after you complete an interview with the researcher which would happen about 2 months after we're observed for the first time). And, if you do choose to participate, you will be sharing important information which could ultimately help others dealing with mental illness.

If you are eligible and choose to participate, the study will involve:

- Having a researcher observe and take notes during our routine meetings for about two months, to see how we use the Consumer Outcomes Surveys (a mental health survey we ask people to fill out at this agency).

- Doing a tape-recorded interview with a researcher about the Consumer Outcomes Surveys

- Allowing your chart to be reviewed by the researcher, so she can see how those involved in your mental health care are writing about the Consumer Outcomes Surveys.

- To ensure confidentiality, all notes and tapes kept in a safe and locked office, and no names or means of identifying you (or others) will be used

If you are interested in participating, please contact me within the next two weeks at and I will arrange a meeting with you, me, and

a researcher, so that you can further explore whether you would like to participate. Sincerely 
APPENDIX F - Consumer consent form

\section{$\underline{\text { Consumer Version }}$}

INFORMED CONSENT DOCUMENT - Implementing the Consumer Outcomes Surveys

Thank you for your interest in this study! Your community psychiatric supportive treatment (CPST) worker indicated that you have some interest volunteering to participate in this research on how the Consumer Outcomes Surveys are being used. Please read this form and ask any questions that you may have before agreeing to be in the research.

Janet Hoy (co-investigator) and Dr. Jerry Floersch (principal investigator) are doing the study, and are both affiliated with the Mandel School of Applied Social Sciences at Case Western Reserve University.

\section{Background Information}

Using something new is often easier said than done. In this study, the researchers seek to understand how people are using a new mental health questionnaire in the public mental system in Ohio. The name of the questionnaire is the Consumer Outcomes Survey. The Consumer Outcomes Survey was created by mental health consumers, mental health center staff and others who care about mental health recovery. The Ohio Department of Mental Health is now asking staff and consumers in mental health centers across Ohio to use these questionnaires to better understand the mental health recovery process.

\section{The purposes of this research are to see:}

1) How real people are using the Consumer Outcomes Surveys in everyday situations and,

2) How these everyday uses are tied into mental health policies, procedures, regulations and other mental health system issues.

\section{Voluntary Nature of the Study}

Your participation is strictly voluntary. If you choose not to participate, it will not affect your current or future relations with your current mental health service provider, the Ohio public mental health 
system, Case Western Reserve University, or with any other cooperating agencies. There is no penalty or loss of benefits for not participating or for discontinuing your participation.

If you agree to participate in this research, it would involve the following:

- Janet would observe your usual meetings between you and your community psychiatric support treatment (CPST) worker, and take notes about uses of and references to the Consumer Outcomes Surveys, over a period of about two months.

- You would do a tape-recorded interview, lasting about one hour, with Janet about your experiences and understandings of the Consumer Outcomes Surveys. The interview would take place in a private place. If you want your CPST staff to be present during the interview, please notify Janet prior to scheduling the interview. To make sure that the thoughts and information you share with Janet will be understood as accurately as possible, the tape recording of your interview is required for this study. Janet would then transcribe your interview from the tape-recording after the meeting.

- To ensure confidentiality, all notes from observations, tapes and written transcriptions will be kept in a safe and locked office. No names or means of identifying you (or others) will be used in the transcripts or notes, or appear in the printed paper of the findings of this project. Quotes from your interview may be used, but no identifying information associated with you will be included or shared (not even with your worker, the agency, or the Ohio Department of Mental Health).

- Janet or Jerry may contact you up to six months after our interview and request a follow-up interview, either face-to-face or by phone, if they have questions and/or need more information to help me understand what you have shared.

\section{**Procedures Involving the Protected Healthcare Information in Your} Chart**

Janet and Jerry would also review your chart to see how your CPST worker and others involved in your mental health care are writing about your uses of the Consumer Outcomes Surveys. To ensure confidentiality, all notes from reviews of your chart would be kept in a safe and locked office. No names or means of identifying you (or others) will be used in the notes, or appear in 
the printed paper of the findings of this project. Quotes from your chart may be used, but no identifying information associated with you or your worker will be included or shared.

Please read the information below carefully. It explains in detail how your chart information, referred to as 'protected health information' or 'PHI', may be used by the investigators or shared (disclosed) with other people or groups for this research study. Your decision to allow the use of your PHI is voluntary. However, if you do not give your permission (authorization) for the use of your PHI, you will not be able to participate in this research study.

\section{What PHI will be collected?}

If you give permission, Janet and Jerry, and research staff members under their guidance would use the following PHI for this study: progress notes written by your CPST worker; individualized service plans developed by you and your CPST staff; your Consumer Outcomes surveys and reports; your diagnostic assessment; your psychiatric evaluation and progress notes. This information will be provided by Agency X, and/or created during the study as you receive care at Agency X.

\section{Why is this information needed?}

This information is needed for this study because it will help the researchers better understand how the Outcomes surveys are being used and documented in your mental health care.

\section{Who will have access to my PHI, and for how long?}

In addition to the investigators and staff listed above, your PHI may be looked at by other groups involved with the study such as the Institutional Review Board, and the Ohio Department of Mental Health. Please understand that, in general, once you give your permission to release the information needed for this study, federal and state laws that protect your privacy might no longer protect this information. The investigators for this study would like to have access to your PHI until the end of the study. You will also have access to the PHI contained in your medical record that is related to this study.

If I give permission now, can I withdraw my permission in the future? You can withdraw from this study at any time. You also have a right to withdraw your permission/authorization to use your PHI. To withdraw permission to use your PHI, you must submit a written statement indicating 
this (per federal regulations). You can send your statement to Dr. Jerry Floersch at Case Western Reserve University; Mandel School of Applied Social Sciences; 10900 Euclid Ave.; Cleveland, OH 44106-7230. Unless you submit a written statement indicating you withdraw your permission to use your PHI, the PHI that has already been collected about you for the study may continue to be used. However, the investigators will not be able to collect any additional information about you.

\section{Questions about PHI and HIPAA (the agency that oversees PHI} protection)? For questions about Case's HIPAA education program and requirements, please contact Dr. Donald Feke, University Privacy Officer, at: 216-368-4389 or donald.feke@case.edu

\section{Risks and Benefits to Being in the Study}

The interview, observations and chart review involved in studying uses of the Outcomes have been carefully planned so as to minimize any psychological discomfort on your part. Nonetheless, being observed and questioned may cause some people a degree of anxiety and/or discomfort. You are free to discontinue your participation in this project at any time, without penalty or prejudice, no questions asked. If you choose to discontinue, it will in no way jeopardize your eligibility for continued mental health services in the Ohio public mental health system. If you find yourself experiencing intense or prolonged anxiety or discomfort after participation, please contact your community support worker immediately.

Participation in this project is completely voluntary. You will be paid \$30 in Visa Gift Cards as compensation for your participation. You will be paid with a $\$ 15$ gift card immediately after the first time the researcher observes a session with your worker, and another \$15 gift card immediately after you've completed your individual taped interview with the researcher (approximately 2 months after your first session). If you do not complete the two months of observation and the interview, you will not receive the second \$15 gift card, but you will have the first \$15 gift card (which you will receive immediately after the first session that Janet observes with you and your worker).

Your participation will also give you an opportunity to provide valuable information, which could ultimately contribute to understandings about living with and recovering from mental illness. 


\section{Confidentiality}

As I explained in the procedures section of this form, all records of this research will be kept private. In any sort of report we might publish, we will not include any information that will make it possible to identify you. Research records, including tapes, will be kept in a locked file, and access will be limited to the researchers, the University review board responsible for protecting human participants, regulatory agencies, and funding agencies. All tapes and other data will be destroyed within three years of completing this study.

\section{Contacts and Questions}

The researchers conducting this study are Janet Hoy (co-investigator) and Dr. Jerry Floersch (principal investigator). You may ask Janet any questions you have now. If you have any questions later, contact Janet Hoy at 216410-1660, or Dr. Floersch at (216) 368-5598.

If Janet and Jerry cannot be reached, or if you would like to talk to someone other than Jerry or I about; (1) concerns regarding this study, (2) research participant rights, (3) research-related injuries, or (4) other human subjects issues, please contact Case Western Reserve University's Institutional Review Board at (216) 368-6925 or write: Case Western Reserve University; Institutional Review Board; 10900 Euclid Ave.; Cleveland, OH 44106-7230. You will be given a copy of this form for your records.

\section{Statement of Consent}

I have read the above information. I have received answers to the questions I have asked. I consent to participate in this research. I am at least 18 years of age.

Print Name of Participant:

Signature of Participant:

Date:

Signature of Parent or Guardian:

Date:

Signature of Person Obtaining Consent:

Date: 


\section{APPENDIX G - CPST interview form \\ Semi-structured CPST Interview: Understanding and Using the Consumer Outcomes}

1. How you did you hear about and learn to use the Consumer Outcomes? Who was involved? What did they say and/or do? What did you think about the Outcomes at that time?

2. Tell me about your current understanding of the Consumer Outcomes surveys. What do you think they are about? Why do you think they are being used?

3. How do you do and use the Outcomes surveys? How do you get the consumer and provider surveys completed? What do you do with them after they're filled out? What, if anything, do you document about the Outcomes in the chart? How do you obtain survey results for individual clients, and what do you do with the results?

4. What people and resources are helpful and/or important in your work with the Outcomes? How are they helpful and/or important? How did you/do you come into contact with the particular resource(s) and/or contact person(s)?

5. Tell me a story about a positive experience you had using the Outcomes with a consumer. How did it happen? What did you do? Who else was involved? What did they do?

6. Any other thoughts about using the Outcomes survey that you'd like to share? 


\title{
APPENDIX H - Administrative/other consent form
}

\author{
INFORMED CONSENT DOCUMENT - Administrative/Other Version \\ Implementing the Consumer Outcomes Surveys
}

Thank you for your interest in participating in this study! (Name) identified you as someone important to his/her work with the Consumer Outcomes Surveys, and suggested you be contacted. Janet Hoy (co-investigator) and Dr. Jerry Floersch (principal investigator) are conducting this study; they are both affiliated with the Mandel School of Applied Social Sciences at Case Western Reserve University. Please read this form and ask any questions that you may have before agreeing to participate in this research.

\section{Background Information}

As we gain more knowledge about mental health recovery and related practices, we often need to change mental health service delivery to incorporate new information. Yet getting a new mental health practice or practice tool implemented in the complex administrative layers of the public mental health service arena is often easier said than done. Fleshing out how everyday practice changes are explicitly and implicitly connected with administrative, policy and regulatory work may increase our ability to understand how implementing a new practice occurs, and ultimately our ability to better help consumers in their mental health recovery.

To begin to build such an understanding, this study focuses on how the Consumer Outcomes Surveys are being implemented in Ohio's public mental health system. The two specific purposes of this research are to see: 1) how Community Psychiatric Support Treatment staff (CPSTs) and mental health consumers are actually doing/using the Consumer Outcomes Surveys in everyday work, and 2) how these everyday uses of the Consumer Outcomes Surveys are connected with the work of others at the county, state and federal levels through mental health policies, procedures, regulations and other mental health system issues.

\section{Procedures}

If you agree to be a participant in this research, your involvement would entail the following:

- Doing a tape-recorded interview with Janet, lasting approximately one hour, about your experiences and understandings of the Consumer Outcomes Surveys. The interview(s) would then be transcribed and kept in a locked, private office. The tape recording of interviews is required for this study.

- Providing access to documents (memos, policies, etc.) that have informed your uses and understandings of the Consumer Outcomes Surveys.

- Recommending other key people for Janet to interview who impact your experiences with the Consumer Outcomes Surveys. Before Janet contacted these people, she would ask your permission to identify you as 
the person who recommended she interview them. When she contacts those you've recommended, she will state " $X$ (your name) told me you were important in their work with the Consumer Outcomes Surveys, and suggested I interview you". No information other than your identity pertaining would be disclosed to the people you suggest for interviews. If you do not give permission to be identified, you can continue to participate in the study, and anyone you suggest will be contacted without your identity being disclosed.

- Janet and/or Jerry may contact you up to six months after your interview, if they have questions and/or need clarification of what you have shared.

\section{Confidentiality}

To ensure confidentiality, all notes of my observations, tapes and written transcriptions of your interview will be kept in a safe and locked office. No names or means of identifying you or others will be used in the transcripts or notes, or appear in the printed paper of the findings of this project. Quotes from your interview may be used, but no identifying information associated with you will be included or shared. Research records, including tapes, will be kept in a locked file, and access will be limited to the researchers, the University review board responsible for protecting human participants, regulatory agencies, and funding agencies. All tapes and other data will be destroyed within three years of completing this study.

\section{Risks and Benefits to Being in the Study}

Your participation is strictly voluntary. If you choose not to participate or to discontinue participation, it will not affect your current or future relations with your current employer, the Ohio Department of Mental Health, Case Western Reserve University, or with any other cooperating agencies. There is no penalty for not participating or for discontinuing your participation.

Interview questions have been planned so as to minimize any psychological discomfort on your part. However, being questioned may cause some people a degree of anxiety and/or discomfort. You are free to discontinue your participation in this project at any time, without penalty or prejudice, no questions asked. If you find yourself experiencing intense or prolonged anxiety or discomfort after participation, please contact Janet or Jerry to assist you in getting help with this (our contact information is below).

All information you share during this project will be kept strictly confidential, with the exception of identifying you as the referent when contacting potential interviewees you suggest, as explained above. When the findings of this study are written up, quotes from you may be used, but no identifying information pertaining to you will be included. However, there will be a relatively small number of people in this study; it may be possible for individuals familiar with you and/or your work to identify what you specifically have shared in the written analysis of this study. 
It is understood that your agreement to participate will not result in any financial payment/reimbursement. However, your participation will give you an opportunity to provide valuable information, which can contribute to understandings about how we can get desired practice changes into place in the mental health system, ultimately to better help those recovering from mental illness.

\section{Contacts and Questions}

You may ask Janet any questions you have now. If you have any questions later, you may contact Janet at 216-410-1660, or Dr. Floersch at (216) 368-5598.

If Janet and Jerry cannot be reached, or if you would like to talk to someone other than Jerry or Janet about; (1) concerns regarding this study, (2) research participant rights, (3) research-related injuries, or (4) other human subjects issues, please contact Case Western Reserve University's Institutional Review Board at (216) 368-6925 or write: Case Western Reserve University; Institutional Review Board; 10900 Euclid Ave.; Cleveland, $\mathrm{OH}$ 44106-7230. You will be given a copy of this form for your records.

\section{Statement of Consent}

I have read the above information. I have received answers to the questions I have asked. I consent to participate in this research. I am at least 18 years of age.

Print Name of Participant:

Signature of Participant:

Date:

Signature of Person Obtaining Consent:

Date: 
APPENDIX I - Administrative/other interview form

Semi-structured Key Other/Administrator Interview: Understanding and Using the Consumer Outcomes

1. How did you first learn about the Consumer Outcomes? Who was involved? What did they say and/or do? What did you think about the Outcomes at that time?

2. Tell me about your current understanding of the Consumer Outcomes. What do you think they are about? Why do you think they are being used?

3. Tell me about your involvement with the Outcomes. What do you do pertaining to the Outcomes? How has this changed over time?

4. What people and resources are helpful and/or important in your work with the Outcomes? How are they helpful and/or important? How did you/do you come into contact with the particular resource(s) and/or contact person(s)?

5. Tell me a story about a positive experience you had involving your work with the Outcomes. How did it happen? What did you do? Who else was involved? What did they do?

6. Any other thoughts about the Consumer Outcomes that you'd like to share? 


\section{APPENDIX J - Consumer Interview \\ Semi-structured Consumer Interview: Understanding and Using the Consumer Outcomes}

1. How did you first you hear about the Outcomes. Who was involved? What did they say and/or do? What did you think about the Outcomes at that time?

2. Tell me about your current understanding of the Consumer Outcomes survey. What do you think it is about? Why do you think it is being used?

3. How did you complete the survey? (Hard-copy or on a computer? At home or at the mental health center? By yourself or with your worker or someone else?) What was it like for you to complete the survey? How did you think and feel as you answered the questions?

4. Who and/or what was helpful to you in doing the survey? How were they helpful and/or important?

5. Have you gotten a summary of your survey results? If yes, tell me about how they were shared with you, and what you thought about them. What did you do with the results at that time? Have you thought about or done anything with them since? If yes, tell me about that.

6. Any other thoughts about using the Outcomes survey that you'd like to share? 


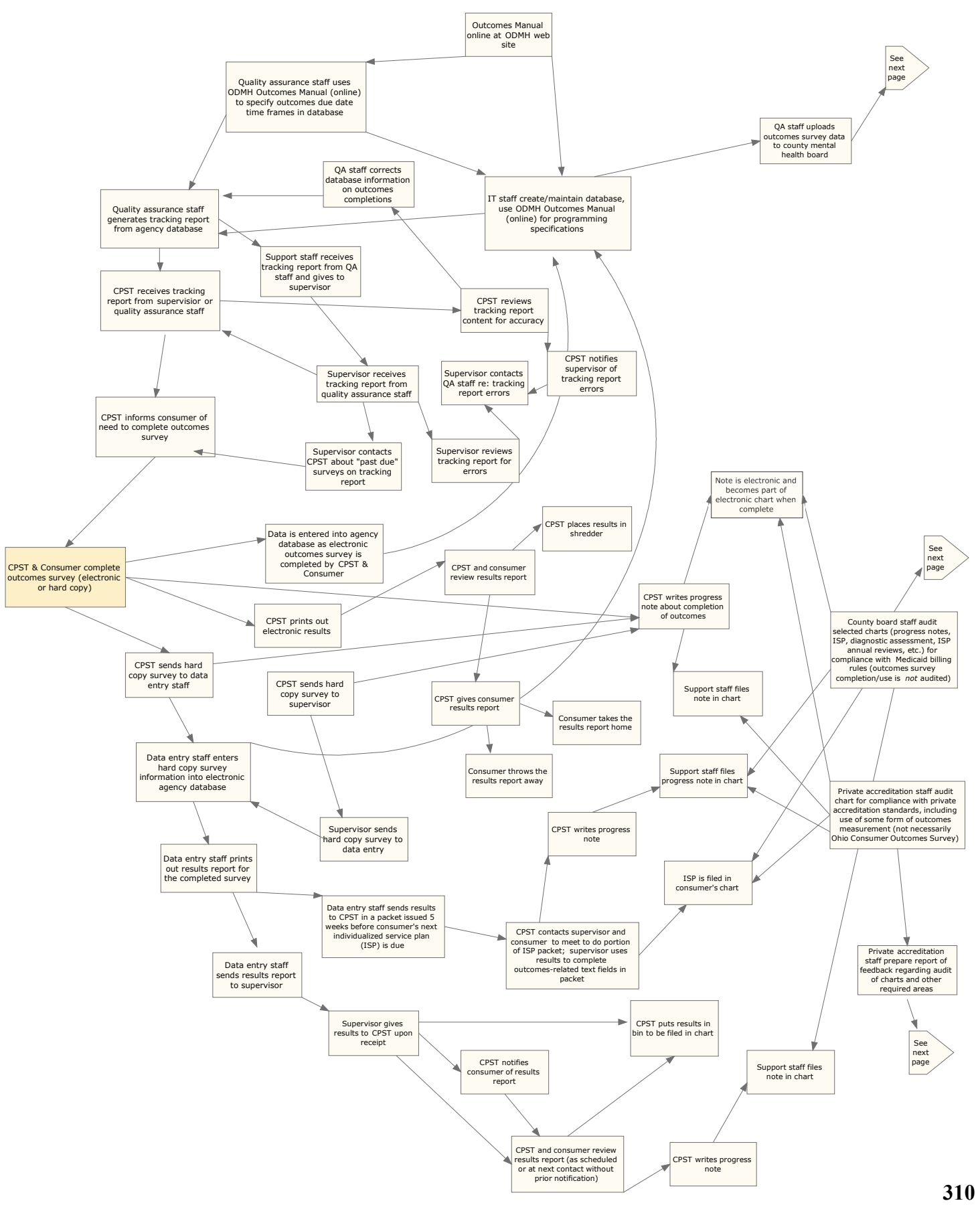


Processing Interchanges in Routinely "Doing the Outcomes" (continued)

APPENDIX K

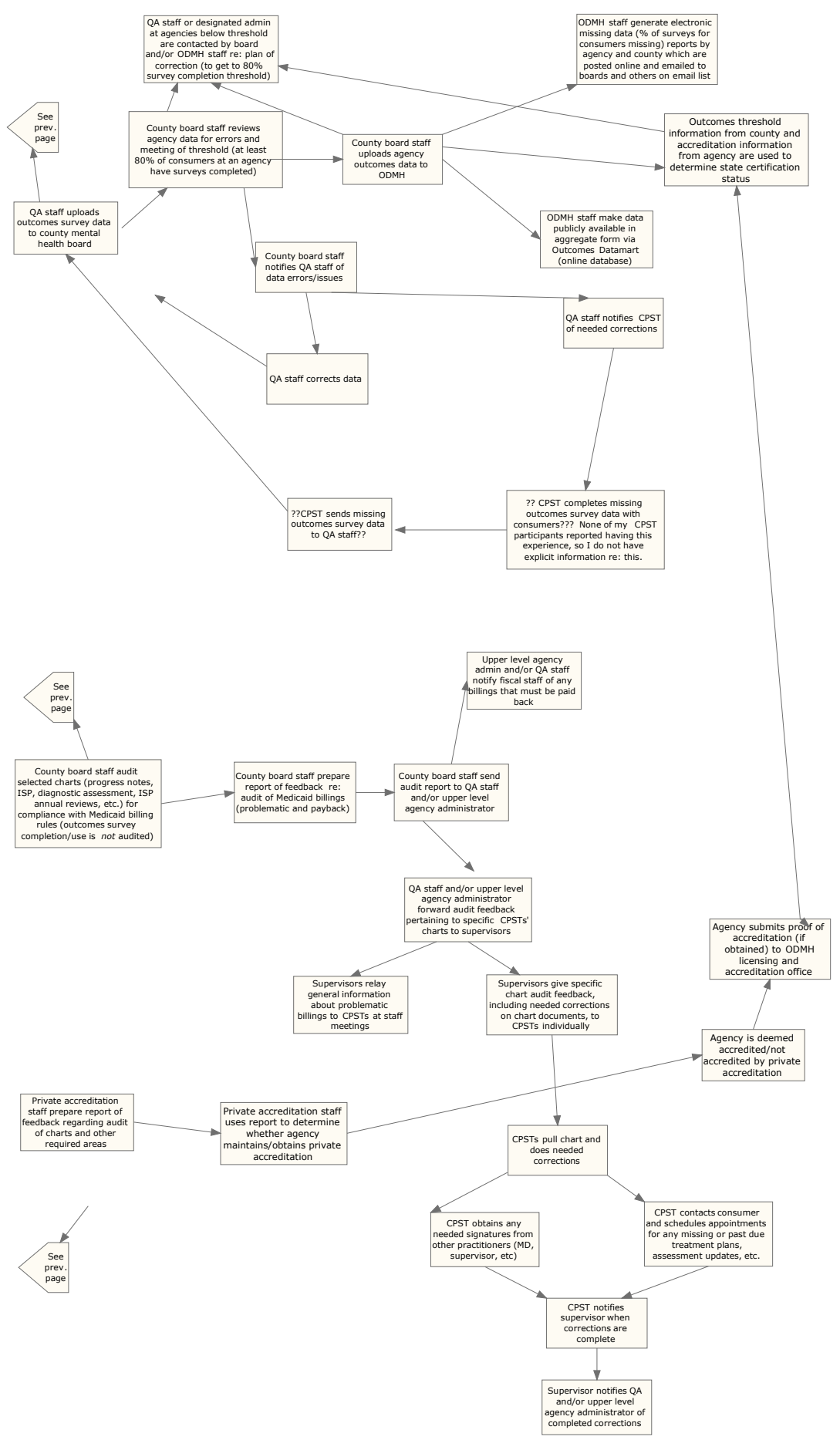




\section{APPENDIX L - Deemed Status Rule}

Ohio Administrative Code 5122-25-02: Accreditation Requirements.

["Deemed Status Rule"]

(A) Agencies seeking certification for one or more of the following services shall attain appropriate behavioral health accreditation by September 30, 2006:

(1) Behavioral health counseling and therapy service as defined in rule 5122-29-03 of the Administrative Code;

(2) Mental health assessment service as defined in rule 5122-29-04 of the Administrative Code;

(3) Pharmacologic management service as defined in rule 5122-29-05 of the Administrative Code;

(4) Partial hospitalization service as defined in rule 5122-29-06 of the Administrative Code;

(5) Crisis intervention mental health service as defined in rule 5122-29-10 of the Administrative Code;

(6) Community psychiatric supportive treatment (CPST) service as defined in rule 512229-17 of the Administrative Code;

(7) Intensive home based treatment (IHBT) service as defined in rule 5122-29-28 of the Administrative Code; and/or

(8) Assertive community treatment (ACT) service as defined in rule 5122-29-29 of the Administrative Code.

(B) Behavioral health accreditation referenced in paragraph (A) of this rule shall be obtained from one or more of the following accrediting bodies:

(1) "The Joint Commission on Accreditation of Health Care Organizations;"

(2) “The Commission on Accreditation of Rehabilitation Facilities;” and/or

(3) "The Council on Accreditation for Children and Family Services."

(C) The department may:

(1) Add the names of other accrediting bodies to those listed in paragraph (B) of this rule if it determines that such bodies meet its accreditation requirements. 
(2) Likewise, the department may delete the names of accrediting bodies from those listed in paragraph (B) of this rule if it determines that such bodies no longer meet its accreditation requirements.

(a) An agency accredited by a body the department chooses to delete from those listed in paragraph (B) of this rule shall remain certified until its current accreditation expires. If an agency wishes to retain certification after that time, it must attain accreditation from a body recognized by the department.

(D) Agencies seeking certification subsequent to the time frames referenced in paragraph (A) of this rule shall have achieved accreditation from one or more of the aforementioned accrediting bodies prior to making application for certification.

(E) The agency shall inform the department, appropriate community mental health boards, and local client advocacy groups in writing of its accreditation survey date(s) at least thirty days prior to the beginning of a scheduled accreditation survey, or when the agency is given less than thirty days notice of a scheduled survey, within seven days of receiving notice from the accrediting body. An agency undergoing an unannounced or unscheduled accreditation survey shall inform the department within seven days after the conclusion of the unannounced or unscheduled accreditation survey.

Effective: 08/23/2007

R.C. 119.032 review dates: 06/08/2007 and 08/23/2012

Promulgated Under: 119.03

Statutory Authority: 5119.61(A), 5119.611(C)

Rule Amplifies: 5119.61(A), 5119.611(C)

Prior Effective Dates: 10/1/2003; 3/25/04; 11/15/04; 7/1/05; 1/09/06 


\section{APPENDIX M - Medical Necessity}

1) Ohio Admin. Code section 5101: 3-1-01(A)"Medical necessity" is a fundamental concept

underlying the medicaid program. Physicians, dentists, and limited practitioners render, authorize, or prescribe medical services within the scope of their licensure and based on their

professional judgment judgment regarding medical services needed by an individual. Unless a

more specific definition regarding medical necessity for a particular category of service is included within division-level designation 5101:3 of the Administrative Code, "medically necessary services" are defined as services which that are necessary for the diagnosis or treatment of disease, illness, or injury and without which the patient can be expected to suffer prolonged, increased or new morbidity, impairment of function, dysfunction of a body organ or part, or significant pain and discomfort. A medically necessary service must:

(1)

Meet generally accepted standards of medical practice;

(2)

Be appropriate to the illness or injury for which it is performed as to type of service and expected outcome;

(3)

Be appropriate to the intensity of service and level of setting;

(4)

Provide unique, essential, and appropriate information when used for diagnostic purposes;

(5)

Be the lowest cost alternative that effectively addresses and treats the medical problem; and

(6)

Meet general principles regarding reimbursement for medicaid covered services found in rule 5101:3-1-02 of the Administrative Code.

http://codes.ohio.gov/oac/5101\%3A3-1-01 retrieved 1/4/2008 


\section{REFERENCES}

Aarons, G. \& Palinkas, L. (2007). Implementation of Evidence-based Practice in Child Welfare: Service Provider Perspectives. Administration and Policy in Mental Health and Mental Health Services Research. 34, 411-419.

Abbott, A. (1995). Sequence Analysis: New Methods for Old Ideas. Annual Review of Sociology, 21:93-113.

Allen, D., Gilchrist, L., Brown, L., \& Cox, G. (1994). One System, Many Perspectives: Stakeholders and Mental Health System Evaluation. Evaluation and Program Planning, 17(1), 47-51.

Angus, J., Hodnett, E. \& O’Brien-Pallas, L. (2003). Implementing evidence-based nursing practice: A tale of two nursing units. Nursing Inquiry, 10(4), 218-228.

Aram, J. \& Salipante, P. (2003). Bridging Scholarship in Management: Epistemological Reflections. British Journal of Management, 14, 189-205.

Aram, J. \& Salipante, P. (2003). Managers as Knowledge Generators: The Nature of the Practitioner-Scholar Research in the Nonprofit Sector. Non-profit Management \& Leadership, 14(2), 129-150.

Atwal, A. (2002). Getting the Evidence into Practice: the Challenges and Successes of Action Research. British Journal of Occupational Therapy, 65(7), p. 335-341.

Baer, D. (2004). Program Evaluation: Arduous, Impossible and Political. In H. Briggs, \& T. Rzepnicki (Eds.), Using Evidence In Social Work Perspectives (pp. 310322). Chicago: Lyceum. 
Bailey, D. (1992). Organizational Change in a Public School System: the Synergism of Two Approaches. Social Work in Education, 14(2), 71-82.

Bailey, D. \& McNally Koney, K. (2000). Strategic Alliances Among Health and Human Service Organizations. Thousand Oaks: Sage Publications.

Bain, R. (1932). The Concept of Social Process. Publications of the American Sociological Society, 25, p.10-18.

Bammer, G. (2005). Integration and Implementation Sciences: Building a New Specialization. Ecology and Society, 10(2), [online] URL: http://www.ecologyandsociety.org/vol10/iss2/art6/

Barker, S. B., \& Barker, R. T. (1994). Managing Change in an Interdisciplinary Inpatient Unit: an Action Research Approach. Journal of Mental Health Administration, 21(1), 80-91.

Barratt, M. (2003). Organizational Support for Evidence-based Practice Within Child and Family Social Work: a Collaborative Study. Child and Family Social Work, 8, 143-150.

Bartels, S., Haley, W., \& Dums, A. (2002). Implementing Evidence-Based Practices. Geriatric Mental Health. 90-98.

Bedregal, P., \& Ferlie, E. (2001). Evidence-based Primary Care? A Multi-tier, Multiple Stakeholder Perspective from Chile. International Journal of Health Planning and Management, 16, 47-60.

Behavioral Health Generations (n.d.). The Ohio Behavioral Healthcare System. http://www.bhg.org/system.htm 
Bellman, L. M. (1996). Changing Nursing Practice through Reflection on the Roper, Logan and Tierney Model: the Enhancement Approach to Action Research. Journal of Advanced Nursing, 24(1), 129-138.

Bergthold, L. (1995). Medical Necessity: Do We Need It? Health Affairs, 14(4), 180190.

Biegel, D., Kola, L., Ronis, R., Boyle, P., Delos Reyes, C., Wieder, B., Kubek, P. (2003). The Ohio Substance Abuse and Mental Illness Coordinating Center of Excellence: Implementation Support for Evidence-based Practice. Research on Social Work Practice, 13(4), 531-545.

Blum, A., Biegel, D. E., Tracy, E. M., \& Cole, M. J. (1995). Agency-University Collaboration: Partnerships for Implementing and Studying Practice Innovations. In P. M. Hess \& E. Mullen (Eds.), Practitioner-Researcher Partnerships: Building Knowledge From, In, and For Practice. Washington DC: NASW Press. Boland, R.J., \& Tenaski, R. V. (1995). Perspective making and perspective taking in communities of knowing. Organizational Science, 6, 350-372.

Bond, G., Becker, D., Drake, R., Rapp, C., Meisler, N., Lehman, A., Bell, M., \& Blyler, C. (2001). Implementing Supported Employment as an Evidence-Based Practice. Psychiatric Services, 52(3), 313-322.

Bonilla-Silva, E. (2006). Racism without Racists: Color-Blind Racism and the Persistence of Racial Inequality in the United States. Lanham: Rowman and Littlefield.

Bottrup, P. (2005). Learning in a network: a "third way" between school learning and workplace learning. Journal of Workplace Learning, 17(8), 508-520. 
Bower, P., \& Gask, L. (2002). The changing nature of consultation-liaison in primary care: bridging the gap between research and practice. General Hospital Psychiatry, 24(2), 63-70.

Boyle, P. \& Kroon, H. (2006). Integrated Dual Diagnosis Treatment: Comparing Facilitators and Challenges of Implementation for Ohio and the Netherlands. International Journal of Mental Health, 35(2), 70-88.

Bradbury, H. \& Reason, P. (2001). Conclusion: Broadening the Bandwith of Validity: Issues and Choice-points for Improving the Quality of Action Research. In P. Reason \& H. Bradbury (Eds.), The Handbook of Action Research. London/Thousand Oaks: Sage Publications.

Bradbury, H. \& Reason, P. (2003). Action Research: An Opportunity for Revitalizing Research Purposes and Practices. Qualitative Social Work, 2(2), 155-175.

Brekke, J.; Ell, K; \& Palinkas, L. (2007). Translational Science at the National Institute of Mental Health: Can Social Work Take Its Rightful Place? Research on Social Work Practice, 17(10), p.123-133.

Brodkin, E. (2003). Street-Level Research at the Frontlines. In M. Lennon \& T. Corbett (Eds.), Policy into Action: Implementation Research and Welfare Reform (pp.145164). District of Columbia: Urban Institute Press.

Broner, N., Franczak, M., Dye, C., \& McAllister, W. (2001). Knowledge Transfer, Policymaking and Community Empowerment: A Consensus Model Approach for Providing Public Mental Health and Substance Abuse Services. Psychiatric Quarterly, 72(2001), 79-102. 
Caburnay, C., Kreuter, M., \& Donlin, M. (2001). Disseminating Effective Health Promotion Programs From Prevention Research to Community Organizations. Public Health Management Practice, 7(2), 81-89.

Cameron, C., \& Naylor, C. D. (1999). No Impact from Active Dissemination of the Ottawa Ankle Rules: Further Evidence of the Need for Local Implementation of Practice Guidelines. Canadian Medical Association, 160(8), 1165-1173.

Campbell, M. (2006). Institutional Ethnography and Experience as Data. In D. Smith (Ed.), Institutional Ethnography as Practice (pp. 91-108). Toronto: Altimira Press.

Campbell, M. \& Gregor, F. (2002). Mapping Social Relations: A Primer in Doing Institutional Ethnography. Garamond Press: Aurora.

Caplan, N. (1976). Social Research and National Policy: What Gets Used, by Whom, for What Purposes, and with What Effects? Social Science Journal, 28(1), 187-194.

Cassell, J. (1982). Harms, benefits, wrongs, and rights in fieldwork. In J. Sieber (Ed.), The ethics of social research: Fieldwork, regulation and publication (pp. 7-31). New York: Springer Verlag.

Charlesworth, L. \& Born, C. (2003). Approaches to Data Collection for Implementation Analysis. In M. Lennon \& T. Corbett (Eds.), Policy Into Action (pp.239-280). Washington D.C.: Urban Institute Press.

Chieh, L. J. \& Myers, M. (2004). Dominant actors, political agendas, and strategic shifts over time: a critical ethnography of an enterprise systems implementation. Journal of Strategic Information Systems, 13(4), 355-374 
Chilvers, R., Harrison, G., Sipos, A., \& Barley, M. (2002). Evidence into Practice: Application of Psychological Models of Change in Evidence-based implementation. British Journal of Psychiatry, 181(2), 99-101.

Coffield, C. (2002). Welfare Reform in Indiana: The Political Economy of Restricting Access to Education and Training. Journal of Family and Economic Issues, 23(3), 261-284.

Collins, P.H. (1990). Black feminist thought: Knowledge, consciousness, and the politics of empowerment. New York: Routledge.

Cooperrider, D., Whitney, D. Stavros, J. (2007). Appreciate Inquiry Handbook (2nd ed.). San Francisco: Berrett-Koehler

Coulton, C. (2004). The Place of Community in Social Work Practice Research: Conceptual and Methodological Developments. Presented for the Aaron Rosen Lecture, Society for Social Work and Research Conference, New Orleans, Louisiana.

Cowley, S., \& Billings, J. R. (1999). Implementing New Health Visiting Services through Action Research: an Analysis of Process. Journal of Advanced Nursing, 30(4), 965-974.

David, M. (2003). The politics of communication, information technology, local knowledge, and social exclusion. Telematics and Informatics 20, 235-253.

Deci, P., Santos, A., Hiott, W., Schoenwald, S., \& Dias, J. (1995). Dissemination of Assertive Community Treatment Programs. Psychiatric Services, 46(7), 676-678. Demming, W.E. (1994). The New Economics for Industry, Education and Government. Cambridge: MIT Press. 
DeMontigny, G. (2005). Social Working: An Ethnography of Front-line Practice. Toronto: University of Toronto Press.

Depoy, E., Hartman, A., \& Haslett, D. (1999). A Critical Action Research: a Model for Social Work Knowing. Social Work, 44(6), 560-569.

DeVault, M.L. (1999). "Institutional ethnography: A strategy for feminist inquiry." pp.46-54, in Liberating method: Feminism and social research. Philadelphia: Temple University Press.

DeVault, M. \& McCoy, L. (2006). Institutional Ethnography: Using Interviews to Investigate Ruling Relations. In D. Smith (Ed.), Institutional Ethnography as Practice (pp. 15-44). Toronto: Rowman \& Littlefield Publishers, Inc.

Dixon, L., McFarlane, W., Lefley, H., Lucksted, A., Cohen, M., Falloon, I., Mueser, K., Miklowitz, D., Solomon, P., \& Sondheimer, D. (2001). Evidence-Based Practice for Services to Families of People with Psychiatric Disabilities. Psychiatric Services, 52(7), 903-910.

Drake, R., Goldman, H., Leff, H. S., Lehman, A., Dixon, L., Mueser, K., \& Torrey, W. (2001). Implementing Evidence-Based Practices in Routine Mental Health Service Settings. Psychiatric Services, 52(2), 179-182.

Essock, S., \& Kontos, N. (1995). Implementing Assertive Community Treatment Teams. Psychiatric Services, 46(7), 679-683.

Fadden, G. (1997). Implementation of Family Interventions in Routine Clinical Practice Following Staff Training Programs: a Major Cause for Concern. Journal of Mental Health, 6(6), 599-613. 
Farhall, J., \& Cotton, S. (2002). Implementing Psychological Treatment for Symptoms of Psychosis in an Area Mental Health Service: the Response of Patients, Therapists and Managers. Journal of Mental Health, 11(5), 511-623.

Fisher, K., \& Urich, P. (1999). Information Dissemination and Communication in Stakeholder Participation: the Bohol-Cebu Water Supply Project. Asia Pacific Viewpoint, 40(3), 251-269.

Fitzsimons, S., \& Fuller, R. (2002). Empowerment and its Implications for Clinical Practice in Mental Health: a Review. Journal of Mental Health, 11(5), 481-499.

Fixen, D., Blasé, K., Friedman, R. \& Hernandez, M. (2003). Fundamentals of Program Implementation. Unpublished manuscript-obtained from The Louis de la Parte Florida Mental Health Institute, University of South Florida.

Fixen, D., Naoom, S., Blasé, K., Friedman, R. \& Wallace, F. (2005). Implementation Research: A Synthesis of the Research. Tampa: University of South Florida Fliegel, F. (1993). Diffusion Research in Rural Sociology: the Record and Prospects for the Future. Westport: Greenwood Press.

Floersch, J. (2004). A Method for Investigating Practitioner Use of Theory in Practice. Qualitative Social Work, 3(2), 161-177.

Floersch, J. (2000). Reading the Case Record: The Oral and Written Narratives of Social Work. Social Services Review, 169-192

Foxon, M. (1997). The Influence of Motivation to Transfer, Action Planning, and Manager Support on the Transfer Process. Performance Improvement Quarterly, 10(2), 42-63. 
Frese, F., Stanley, J., Kress, K., \& Vogel-Scibilia, S. (2001). Integrating Evidence-Based Practices and the Recovery Model. Psychiatric Services, 52(11), 1462-1468.

Gallagher, A. (1964). Plainville: The twice-studied town. In A. Vidich, J. Bensman, \& N. Stein (Eds.), Reflections on community studies. New York: Wiley, 1964.

Gambrill, E. (1997). Social Work Practice: A Critical Thinker's Guide. New York: Oxford University Press.

Gambrill, E. (2006). Evidence-based Practice and Policy: Choices Ahead. Research on Social Work Practice, 16(3), p. 338-357.

Gerrish, K., Clayton, J., Nolan, M., Parker, K., \& Morgan, L. (1999). Promoting Evidence-based Practice: Managing Change in the Assessment of Pressure Damage Risk. Journal of Nursing Management, 7, 355-362.

Gibbons, M., Limoges, C., Nowotny, H., Schwartzman, S., Scott, P., \& Trow, M. (1994). The New Production of Knowledge: the Dynamics of Science and Research in Contemporary Societies. London: Sage Publications.

Gilliam, A., Davis, D., Barrington, T., Lacson, R., Uhl, G., \& Phoenix, U. (2002). The Value of Engaging Stakeholders in Planning and Implementing Evaluations. AIDS Education and Prevention, 14(A), 5-17.

Glazer, M. (1982). The threat of the stranger: Vulnerability, reciprocity and fieldwork. In J. Sieber (Ed.). The ethics of social research: Fieldwork, regulation and publication (pp. 49-70). New York: Springer Verlag.

Glisson, C. \& Schoenwald, S. (2005). The ARC Organizational and Community Intervention Strategy for Implementing Evidence-based Children's Mental Health Treatments. Mental Health Services Research, 7(4), 243-259 
Glisson, C. (2007). Assessing and Changing Organizational Culture and Climate for Effective Services. Research on Social Work Practice, 17(6), 736-747.

Grammig, T. (2003). Sociotechnical Relations and Development Assistance. Technological Forecasting \& Social Change, 70, 501-523.

Gray, J.A.M. (2001). Evidence-based Healthcare: How to Make Health Policy and Management Decisions (2 ${ }^{\text {nd }}$ Ed.). New York: Churchill Livingstone. Washington DC: NASW Press.

Grimshaw, J., Shirran, L., Thomas, R., Mowatt, G., Fraser, C., Bero, L., Grilli, R., Harvey, E., Oxman, A., \& O'Brian, M. A. (2002). Changing Provider Behavior: an Overview of Systematic Reviews of Interventions to Promote Implementation of Research Findings by Healthcare Professionals. In A. Haines \& A. Donald (Eds.), Getting Research Findings into Practice (Vol. 2). London: BMJ Books.

Haines, A., \& Donald, A. (2002). Introduction. In A. Haines \& A. Donald (Eds.), Getting Research Findings into Practice (Vol. 2). London: BMJ Books.

Hamman, E.T., \& Lane, B. (2004). The roles of state departments of education as policy intermediaries: Two cases. Educational Policy, 18, 426-455

Haraway, D. (1988). Situated knowledges: The science question in feminism and the privilege of partial perspective. Feminist Studies 14 (Fall): 575-599.

Harding, S. (1991). Whose science Whose knowledge? Thinking from women's lives. Ithaca, NY: Cornell University Press.

Harper, I. (2006). Anthropology, Dots and Understanding Tuberculosis Control in Nepal. Journal of Biosocial Science, 38(1), 57-67. 
Harris, L., Sachs, S., \& Brome, B. (2001). Wisdom of the People: Potential and Pitfalls in Efforts by the Commanches to Recreate Traditional Ways of Building Consensus. American Indian Quarterly, 25(1), 114-134.

Hartsock, N. (1983): 'The Feminist Standpoint: Developing the Ground for a Specifically Feminist Historical Materialism', In S. Harding \& M.B. Hintikka (Eds.), Discovering Reality. Feminist Perspectives on Epistemology, Metaphysics, Methodology, and Philosophy of Science. Dordrecht: Reidel, pp. 283-310.

Harvey, G., Loftus-Hills, A., Rycroft-Malone, J., Titchen, A., Kitson, A., McCormack, B., \& Seers, K. (2002). Getting evidence into practice: the role and function of facilitation. Nursing Theory and Concept Development or Analysis, 37(6), 577588.

Hasenfield, Y. \& Brock, T. (1991). Implementation of Social Policy Revisited. Administration and Society, 22(4), 451-479.

Hasenfeld, Y. (1992). Human Services as Complex Organizations. Thousand Oaks: Sage Publications.

Haynes, B., \& Haines, A. (2002). Barriers and Bridges to Evidenced-based Clinical Practice. In A. Haines \& A. Donald (Eds.), Getting Research Findings Into Practice (Vol. 2, pp. 115-122). London: BMJ Books.

Henggeler, S., \& Schoenwald, S. (1994). The contribution of treatment outcome research to the reform of children's mental health services: multisystemic therapy as an example. Journal of Mental Health Administration, 21(3), 229-330.

Herie, M., \& Martin, G. (2002). Knowledge Diffusion in Social Work: A New Approach to Bridging the Gap. Social Work, 47(1). 
Ho, B. (2002). Application of Participatory Action Research to Family-School Intervention. School Psychology Review, 31(1), 106-121.

Holcomb, P. \& Nightingale, D. (2003). Conceptual Underpinnings of Implementation Analysis. In M. Clare-Lennon \& T. Corbett (Eds.), Policy Into Action (pp. 3956). Washington D.C.: Urban Institute Press.

Holland, T. P. (1995). Organizations: Context for social service delivery. In R.L. Edwards (Ed.), Encyclopedia of Social Work. Washington DC: NASW Press. hooks, b. (1994). Teaching to Transgress. New York: Routledge.

Howe D (1993). On Being a Client: Understanding the Process of Counseling and Psychotherapy. London, Sage.

Huff A. (2000). Changes in Organizational Knowledge Production. Academy of Management Review, 25(2), 288-293.

Hugentobler, M. K., Israel, B. A., \& Schurman, S. J. (1992). An Action Research Approach to Workplace Health: Integrating Methods. Health Education Quarterly, 19(1), 55-76.

Implementation and Integration Science. (n.d.). Retrieved February 7, 2006 from http://www.anu.edu.au/iisn/

Implementation Science. (n.d.). Retrieved February 7, 2006 from http://www.implementationscience.com,

Innes, J., \& Booher, D. (1999). Consensus Building as Role Playing and Bricolage: Toward a Theory of Collaborative Planning. Journal of the American Planning Association, 65(1), 9-26. 
Johnson, C. (1982). Risks in the publication of fieldwork. In J. Sieber (Ed.), The ethics of social research: Fieldwork, regulation and publication (pp. 71-92). New York: Springer Verlag.

Jones, A. (2000). Implementation of Hospital Care Pathways for Patients with Schizophrenia. Journal of Nursing Management, 8(4), 215-225.

Kaplan, T. \& Corbett, T. (2003). Three Generations of Implementation Research: Looking for the Keys to Implementation Success. In M. Clare-Lennon \& T. Corbett (Eds.), Policy Into Action. Washington D.C.: Urban Institute Press.

Kelly, J. A., Somlai, A. M., DiFranceisco, W. J., Otto-Salaj, L. L., McAuliffe, T. L., Hackl, K. L., et al. (2000). Bridging the gap between the science and service of HIV prevention: Transferring effective research-based HIV prevention interventions to community AIDS service providers. American Journal of Public Health, 90(7), 1082-1088.

Kelman, H. (1968). A time to speak: On human values and social research. San Francisco: Jossey-Bass.

Kerr, D. (1996). The Use of Action Research as an Appropriate Method of Introducing and Evaluating Change in Nursing Care in an Accident and Emergency Unit in Durban. Curationis, 19(3), 12-16.

Kerr, K. (2006). Between Caring and Counting. Toronto: University of Toronto Press. King, S. (1996). Researching internet communities: Proposed ethical guidelines for the reporting of results. The Information Society, 12:119-127.

Kirk, S. \& Reid, W. (2002). Science and Social Work: a Critical Appraisal. New York: Columbia University Press. 
Koh, S., Gunasekaran, A., Thomas, A., \& Arunachalam, S. (2005). The application of knowledge management in call centers. Journal of Knowledge Management, 9(4), 56-69.

Kuzel, A.J., \& Like, R.C. (1991). Standards of trustworthiness for qualitative studies in primary care. In P.G. Norton, M. Stewart, F. Tudiver, M.J. Bass, \& E.V. Dunn (Eds.), Primary Care Research: Traditional and Innovative Approaches. Newbury Park: Sage, p. 138-158.

Lauri, S. (1982). Development of the Nursing Process Through Action Research. Journal of Advanced Nursing, 7(4), 301-307.

Lee, F.-K., Chang, A., \& Mackenzie, A. (2002). A Pilot Project to Evaluate Implementation of Clinical Guidelines. Journal of Nursing Care, 16(2), 50-59.

Lee, R. G., \& Garvin, T. (2003). Moving from Information Transfer to Information Exchange in Health Care. Social Science and Medicine, 56, 449-464.

Leighton, A. (2000). Community Mental Health and Information Underload. Community Mental Health Journal, 36(1), 77-95.

Lennon, M.C. \& Corbett, T. (Eds.). (2003). Policy Into Action. Washington D.C.: The Urban Institute Press.

Lewin, K. (1946). Action Research and Minority Problems. Journal of Social Issues, 2, 34-36.

Linton, J. (2002). Implementation Research: state of the art and future directions. Technovation, 22, 65-79.

Lipsky, M. (1980) Street Level Bureaucracy: the Dilemmas of Individuals in Social Services. Cambridge: MIT Press. 
Litaker, D., Tomolo, A., Liberatore, V., Stange, K., Aron, D. (2006). Using Complexity Theory to Build Interventions that Improve Heath Care Delivery in Primary Care. Journal of General Internal Medicine, 21, S30-34.

Lockwood, S. (2004). "Evidence of me" in evidence based medicine? British Medical Journal, 329, p. 1033-1035.

Lundy, C. (2004). Social Work and Social Justice: A Structural Approach. Toronto: Broadview Press.

Lyons, S.; Tripp-Reimer, T.; Sorofman, B.; DeWitt, J.; Bootsmiller, B.; Vaughn, T.; and Doebbling, B. (2005). Information Technology for Clinical Guideline Implementation: Perceptions of Multidisciplinary Stakeholders. Journal of the American Medical Informatics Society. 12(1), p.64-71.

Mander, A., Gomes, A., \& Castle, D. (2002). The Management of Change in a Community Mental Health Team. Australian Health Review, 25(2), 115-121.

Marcri, D., Tagliaventi, M., \& Bertolotti, F. (2001). Sociometric location and innovation: how social network intervenes between the structural position of early adopters and changes in the power map. Technovation, 21, 1-13.

Marshall, T., Solomon, P., \& Steber, S.A. (2001). Implementing Best Practice Models by Using a Consensus-Building Process. Administration and Policy in Mental Health, 29(2), 105-116.

Mattessich, P. \& Monsey, B. (1992). Collaboration: What Makes it Work. Amherst H. Wilder Foundation: St. Paul. 
McAdam, R. (2005). A Multi-level Theory of Innovation Implementation: Normative Evaluation, Legitimisation and Conflict. European Journal of Innovation Management. 8(3), 373-388.

McCormack, B., Kitson, A., Harvey, G., Rycroft-Malone, J., Titchen, A., \& Seers, K. (2001). Getting Evidence into Practice: the Meaning of 'Context'. Journal of Advanced Nursing, 38(1), 94-104.

McCoy, L. (1995). Activating the photographic text. In M. Campbell \& A. Manicom. (Eds.), Knowledge, Experience, and Ruling Relations: Studies in the Social Organization of Knowledge. University of Toronto Press Incorporated: Toronto.

McCoy L. (2006). Keeping the Institution in View: Working With Interview Accounts of Everyday Experiences. In D. Smith (Ed.), Institutional Ethnography as Practice (pp. 109-128). Toronto: Altimira Press.

McDevitt, D. (1998). How Effective is the Cascade as a Method for Disseminating Ideas? A Case Study in Botswana. Journal of Educational Development, 18(5), 425-428.

McKenna, H., Parahoo, K. A., \& Boore, J. R. P. (1995). The Evaluation of a Nursing Model for Long-Stay Psychiatric Patient Care. Part 1-Literature Review and Methodology \& Part 2-Presentation and Findings. Journal of Nursing Studies, 32(1), 79-95.

Mechanic, D. (1999). A Balanced Framework for Change. Journal of Health Politics, Policy and Law, 24(5), 1107-1114 
Mechanic, D. (1999). Mental Health Service and Policy: the Emergence of Managed Care. Boston: Allyn and Bacon.

Meiland, F., Droes, R., De Lange, J., \& M. Vernooij-Dassen. (2004). Development of a Theoretical Model for Tracing Facilitators and Barriers in Adaptive Implementation of Innovation Practices in Dementia Care. Archives of Gerontology, 9, 279-290.

Miller, C. (1991). Feminist Research Methods : An Annotated Bibliography. New York: Greenwood Press.

Milligan, S., Coulton, C., York, P., \& Register, R. (1996). Implementing a Theories of Change Evaluation in the Cleveland Community Building Initiative. Cleveland: Center on Urban Poverty and Social Change.

Mittman, B., Tonesk, X., \& Jacobson, P. (1992). Implementing Clinical Practice Guidelines: Social Influence Strategies and Practitioner Behavior Change. Quality Review Bulletin, 18(12), 413- 422.

Moody, G., Choong, Y. Y., \& Greenwood, J. (2001). An Action Research Approach to the Development of a Clinical Pathway for Women Requiring Caesarean Sections. Contemporary Nurse, 11(2), 195-205.

Mosse, D. (2003). Good Policy is Unimplementable? Reflections on the Ethnography of Aid Policy and Practice. Paper presented at the EIDOS Workshop on 'Order and Disjuncture: the Organization of Aid and Development', London 26-28.

Mueser, K., Corrigan, P., Hilton, D., Tanzman, B., Schaub, A., Gingerich, S., Essock, S., Tarrier, N., Morey, B., Vogel-Scibilia, S., \& Herz, M. (2002). Illness 
Management and Recovery: A Review of the Research. Psychiatric Services, 53(10), 1272-1284.

Mullen, E. \& Steiner, D. (2004). The Evidence For and Against Evidence-Based Practice. Brief Treatment and Crisis Interventions, 4(2), p.111-121.

NAMI. (2003). Evidence Based Interventions. Retrieved February 27, 2003 from http://il.nami.org/evidence.htm

Natasi, B., Varjas, K., Schensul, S., Tudor, K., Schensul, J., \& Ratnayake, P. (2000). The Participatory Intervention Model: A Framework for Conceptualizing and Promoting Intervention Acceptability. School Psychology Quarterly, 15(2), 207232.

National Alliance for Mental Illness (2006). http://www.nami.org/gtstemplate.cfm?section=grading_the_states National Center for the Dissemination of Disability Research (NCDDR). (1996). A Review of the Literature on Dissemination and Implementation. (1996). National Institute of Mental Health. (2002). Dissemination and Implementation Research in Mental Health-Program Announcement. Retrieved at http://grants.nih.gov/grants/guide/pa-files/PA-02-131.html

National Institute of Mental Health. (2005). Dissemination and Implementation Research in Mental Health-Program Announcement. Retrieved at http://grants.nih.gov/grants/guide/pa-files/PA-02-131.html

Ochocka, J., Janzen, R., \& Nelson, G. (2002). Sharing Power and Knowledge: Professional and Mental Health Consumer/Survivor Researchers Working 
Together in a Participatory Action Research Project. Psychiatric Rehabilitation Journal, 25(4), 379-387.

Ohio Administrative Code. (2005, December 28). 122-28-04.

http://onlinedocs.andersonpublishing.com/oh/lpExt.dll/OAC/12a13/12b49/12b59? $\underline{\mathrm{f}=\text { temp }}$

Ohio Department of Mental Health ${ }^{1}$. (2002). Consumer Outcomes Incentive Grant Report. Retrieved at http://www.mh.state.oh.us/initiatives/ outcomes/outcomes.html

Ohio Department of Mental Health ${ }^{2}$. (2002). History of the Outcomes Initiative. Retrieved at http://www.mh.state.oh.us/iniatives/outcomes/hist.html Ohio Department of Mental Health ${ }^{3}$. (2002). Highlights of the Initial Statewide Report of the Consumer Outcomes System. Retrieved at http://www.mh.state.oh.us/ iniatives /outcomes/duseinitrpsm.html

Ohio Department of Mental Health ${ }^{4}$. (2002). Outcomes Pilot Evaluation. Retrieved at http://www.mh.state.oh.us/initiatives/outcomes/histoipeval.html

Ohio Department of Mental Health" (n.d.). Retrieved online March 8, 2006. http://www.mh.state.oh.us/oper/outcomes /outcomes.index.html

Ohio Department of Mental Health (2005). Retrieved at http://www.mh.state.oh.us/oper/outcomes/reports/rpt.norms.adult.race.gender.pdf

Oliver, S., Entwistle, V., \& Hodnett, E. (2002). Roles for Lay People in the Implementation of Healthcare Research. In A. Haines \& A. Donald (Eds.), Getting Research Findings Into Practice (Vol. 2, 86-94). London: BMJ Books. Oxford Dictionary. (n.d.). Retrieved from http://www.dictionary.oed.com 
Oxman, A., Thompson, M. A., Davis, D., \& Haynes, B. (1995). No Magic Bullets: A Systematic Review of 102 Trials of Interventions to Improve Professional Practice. Canadian Medical Association, 153(10), 1423-1431.

Palley, E. (2004). Balancing Student Mental Health and Discipline: A Case Study of the IDEA. Social Service Review.78 (2), 243-266.

Panzano, P., Seffrin, B., Chaney-Jones, S., Roth, D., Crane-Ross, D., Massatti, R., \& Carstens, C. (2002-2003). The Innovation Diffusion and Adoption Research Project (IDARP): Moving from the Diffusion of Research Results to Promoting the Adoption of Evidence-based Practice Innovations in Ohio. In D. Roth \& W. Lutz (Eds.), New Research in Mental Health (Vol. 16, pp. 1 -13). Columbus: Ohio Department of Mental Health.

Parsons, R.; Hernandez, S.; \& Rothman, J. (1995). Integrated Practice: A Framework for Problem-Solving. In Rothman, J., Erlich, J., \& Tropman, J. (Eds.), Strategies of Community Intervention (5th ed.), p.195-203. Ithasca: F.E. Peacock Publishers, Inc.

Pearcey, P., \& Draper, P. (1996). Using the Diffusion of Innovation Model to Influence Practice: a Case Study. Journal of Advanced Nursing, 23(4), 714-721.

Pease, B. (2003). Rethinking the Relationship Between the Self and Society. In Allan, J., Pease, B., \& Briskman, L. (Eds.), Critical Social Work: an Introduction to Theories and Practices. Crows Nest: Allen \& Unwin Pettigrew, A. (1997). What is a Processual Analysis? Scandinavian Journal of Management, 13, 337-348. 
Pettigrew, A. (1995). Longitudinal Field Analysis on Change: Theory and Practice. In G. Huber \& A. Van de Ven (Eds), Longitudinal Field Research Methods: Studying Processes of Organizational Change. Sage Publications: Thousand Oaks.

Pence, E. (2001). Safety for Battered Women in a Textually Mediated Legal System. Studies in Cultures, Organizations and Societies, 7(2), 199-229.

Pence, E. \& Taylor, T. (2003). Building Safety. Duluth: Praxis International

Penn-Kekana, L., Blauuw, D. \& Schneider, H. (2004). 'It makes me want to run away to Saudi Arabia': management and implementation challenges for public financing reforms from a maternity ward perspective. Health Policy and Planning, 19(1), 71-77.

Pfeil, M. (2001). Re-introducing Skills Teaching to Nurse Education: an Action Research Project. Nurse Education Today, 21(8), 616-623.

Pilgrim, D., \& Waldron, L. (1998). User Involvement in Mental Health Service Development: How Far Can It Go? Journal of Mental Health, 7(1).

Polanyi, M. (1966). The Tacit Dimension. Gloucester: Peter Smith.

Porras, J. I. \& Robertson, P. J. (1992). Organizational Development: Theory, Practice and Research. In M.D. Dunnette \& L.M. Hough (Eds.), Handbook of Industrial and Organizational Psychology (2 ${ }^{\text {nd }}$ Ed., Vol. 3). pp.719-822. Palo Alton: Consulting Psychologists Press.

Proctor, E. (2004). Leverage Points for the Implementation of Evidence-based Practice. Brief Treatment and Crisis Intervention, 4(3), 227-242. 
Proctor, E., Knudsen, K., Fedoravicius, N., Hovmand, P., Rosen, A. \& Perron, B. (2007). Implementation of Evidence-based Practice in Community Behavioral Health: Agency Director Perspectives. Administration and Policy in Mental Health and Mental Health Services Research. 34, 479-488.

Puddifoot, J. (2000). Some Problems and Possibilities in the Study of Dynamical Social Processes. Journal for the Theory of Social Behavior, 30(1), p.79-97.

Rappaport, J. (1990). Research Methods and the Empowerment Agenda. In P. Tolan, C. Keys, F. Chertok, \& L. Jason (Eds.), Researching Community Psychology: Issues of Theory and Methods (pp. 51-63). Washington DC: American Psychological Association.

Reason, P., \& Bradbury, H. (Eds.). (2001). Handbook of Action Research: Participative Inquiry and Practice. London: Sage Publications.

Reinhold, S. (1994). Local conflict and Ideological Struggle. Unpublished manuscript. Ring, C. (2001). Quality Assurance in Mental-health Care: a Case Study From Social Work. Health Care Community, 9(6), 383-390.

Rogers, E. (1995). Diffusion of Innovations (4 ${ }^{\text {th }}$ Ed.). New York: Free Press.

Rogers, E. (2001). Diffusion of Preventive Innovations. Addictive Behaviors, 27(6), 989-993.

Roshenheck, R. (2001). Stages in the Implementation of Innovative Clinical Programs in Complex Organizations. Journal of Nervous and Mental Disease, 189(12), 812821.

Rousseau, D. M. (1977). Technical Differences in Job Characteristics, Employee Satisfaction and Motivation: a Synthesis of Job Design Research and 
Sociotechnical Systems Theory. Organizational Behavior and Human Performance, 19, pp. 18-42.

Roth, D. (2005). The Ohio Mental Health Consumer Outcomes System. In T. CampbellOrde, J. Chamberlin, J. Carpenter, \& H. Leff (Eds.), Measuring the Promise: a Compendium of Recovery Measures (Volume II), pp. 42-49. Cambridge: Evaluation Center @ HSRI.

Rousseau, D. M. (1977). Technical Differences in Job Characteristics, Employee Satisfaction and Motivation: a Synthesis of Job Design Research and Sociotechnical Systems Theory. Organizational Behavior and Human Performance, 19, 18-42.

Ruhe, M., Weyer, S., Zronek, S., Wilkinson, A., Wilkinson, P., Stange, K. (2005). Facilitating Practice Change: Lessons Learned from the STEP-UP Clinical Trial. Preventative Medicine, 40, 729-734.

Ryan, B. \& Gross, N. (1943). The Diffusion of Hybrid Seed Corn in Two Iowa Communities. Rural Sociology, 8, 15-24.

Sarker, S. (2000). Toward a Methodology for Managing Information Systems Implementation: A Social Constructivist Perspective. Informing Science 3(4), 195-205.

Saunders, M., \& Thornhill, A. (1988). Assessing the Effectiveness of Relocation Support: Some Evidence from the UK. Personnel Review, 27(2), 124-142. Schoenwald, S., \& Hoagwood, K. (2001). Effectiveness, Transportability, and Dissemination of Interventions: What Matters When? Psychiatric Services, 52(9), 1190-1197. 
Schultze, U. \& Boland, R.J. (2000). Knowledge Management Technology and the Reproduction of Knowledge Work Practices. Journal of Strategic Information Systems, 9, 193-212.

Scott, F. G. (1959). Action Theory and Research in Social Organization. American Journal of Sociology, 64(4), 386-395.

Senge, P., \& Scharmer, O. (2001). Community Action Research: Learning as a Community of Practitioners, Consultants and Researchers. In P. Reason \& H. Bradbury (Eds.), Handbook of Action Research. London: Sage Publications.

Shaw, I. (2005). Practitioner Research: Evidence or Critique? British Journal of Social Work, 35, 1231-1248.

Sheldon, T., Guyatt, G., \& Haines, A. (2002). Criteria for the Implementation of Research Evidence in Policy and Practice. In A. Haines \& A. Donald (Eds.), Getting Research Findings Into Practice (Vol. 2, pp.11-18). London: BMJ.

Shore, C. \& Wright, S. (1997). Anthropology of Public Policy: Critical Perspectives on Governance and Power. London: Routledge.

Siegel, C. (2005). Implementing a research-based model of cooperative learning. The Journal of Educational Research, 98(6), 339-348

Simpson, D. D. (2002). A Conceptual Framework for Transferring Research to Practice. Journal of Substance Abuse Treatment, 22(4).

Sindelar, P., \& Brownell, M. (2001). Research to Practice Dissemination, Scale and Context: We Can Do It, But Can We Afford It? Teacher Education and Special Education, 24(4), 348-355. 
Sindelar, T. (2002). The "Medical Necessity Requirement" in Medicaid. Boston: Disability Law Center

Slade, M., Kuipers, E., \& Priebe, S. (2000). Mental Health Services Research Methodology. International Review of Psychiatry, 14, 12-18.

Sloboda, Z., \& Schildhaus, S. (2002). A Discussion of the Concept of Technology Transfer of Research-Based Drug "Abuse" Prevention and Treatment Interventions. Substance Abuse and Misuse, 37(8-10), 1079-1987.

Small, S. (1995). Action-Oriented Research: Models and Methods. Journal of Marriage and the Family, 57, 941-955.

Smith, D. (2005). Institutional Ethnography: A Sociology for People. AltaMira Press: Toronto.

Smith, D. (2006). Institutional Ethnography as Practice. Toronto: AltaMira Press.

Smith, Dorothy E. (1987). The everyday world as problematic: A feminist sociology. Boston: Northeastern University Press

Smith, Dorothy E. (1999). Writing the social: Critique, theory, and investigations. Toronto: University of Toronto Press.

Smith, P., Masterson, A., Basford, L., Boddy, G., Costello, S., Marvell, G., Redding, M., \& Wallis, B. (2000). Action Research: a Suitable Method for Promoting Change in Nursing. Nurse Education Today, 20(7), 563-570.

Somekh, B. (1995). The Contribution of Action Research to Development in Social Endeavors: A Position Paper on Action Research Methodology. British Educational Research Journal, 21(3), 339-355. 
Sosin, M. (2001). Service Intensity and Organizational Attributes: A Preliminary Inquiry. Administration and Policy in Mental Health and Mental Health Services Research, 28(5), 371-392.

Stake, R. (1998). Case Studies. In Y. Lincoln (Ed.), Strategies of Qualitative Inquiry (86-109). Thousand Oaks: Sage Publications.

Tanenbaum, S. (1999). Evidence and Expertise: The Challenge of the Outcomes Movement to Medical Professionalism. Academic Medicine, 74(7), 757-763.

Thorslund, M. (1988). The De-institutionalization of the Elderly: Some Notes About Implementation and Outcome of a Swedish Case Study. Health Policy, 10(1), 4156.

Tobin, M., Dakos, T., \& Urbanc, A. (1997). Using Action Research to Facilitate Organisational Change in Mental Health Service Delivery. Australian and New Zealand Journal of Psychiatry, 31(5), 739-743.

Torrey, W., Drake, R., Dixon, L., Burns, B., Flynn, L., Rush, A. J., Clark, R., \& Klazker, D. (2001). Implementing Evidence-Based Practices for Persons with Severe Mental Illness. Psychiatric Services, 52(1), 45-49.

Townsend, E. (1998). Good Intentions Overruled: A Critique of Empowerment in the Routine Organization of Mental Health Services. Toronto: University of Toronto Press.

Waterman, H., Webb, C., \& Williams, A. (1995). Parallels and Contradictions in the Theory and Practice of Action Research and Nursing. Journal of Advanced Nursing, 22, 779-784.

Wax, M. (1982). Research reciprocity rather than informed consent in fieldwork. In J. 
Sieber (Ed.), The ethics of social research: Fieldwork, regulation and publication (pp.33-48).

Webster, J. (1999). Practitioner-centered Research: an Evaluation of the Implementation of the Bedside Hand-over. Journal of Advanced Nursing, 30(6), 1375-1362.

Wedel, J., Shore, C., Feldman, G., Lathrop, S. (2005). Toward an Anthropology of Public Policy. Annals of the American Academy of Political and Social Science, 600(1), 30-51

Wells, K., Feldman, R., \& Kelman, S. (1988). Toward Institution of Research Capacity in Mental Health Service Organizations. Professional Psychology: Research and Practice, 19(1), 63-67.

Werner, A. (2004). A Guide to Implementation Research. Washington D.C.: Urban Institute Press.

Wiebe, G. (1952). Merchandising Commodities and Citizenship on Television. Public Opinion Quarterly, 15, 679-691.

Wood, M., Ferlie, E., \& Fitzgerald, L. (1998). Achieving Clinical Behavior Change: A Case of Becoming Indeterminate. Social Science and Medicine, 47(11), 17291738.

Woogara, J. (2005). Patients' Privacy of the Person and Human Rights. Nursing Ethics, 12(3), 273-287. 